\title{
Ascent of ultrahigh-pressure rocks in southeastern Papua New Guinea, as revealed by Ti-in-quartz thermometry and $\mathrm{Rb}-\mathrm{Sr}$ dating
}

\author{
Megan S. Korchinski \\ A thesis submitted to Victoria University of Wellington in partial \\ fulfillment of the requirements for the degree of \\ Masters of Science in Geology
}

School of Geography, Environment, and Earth Sciences

Victoria University of Wellington

2011 


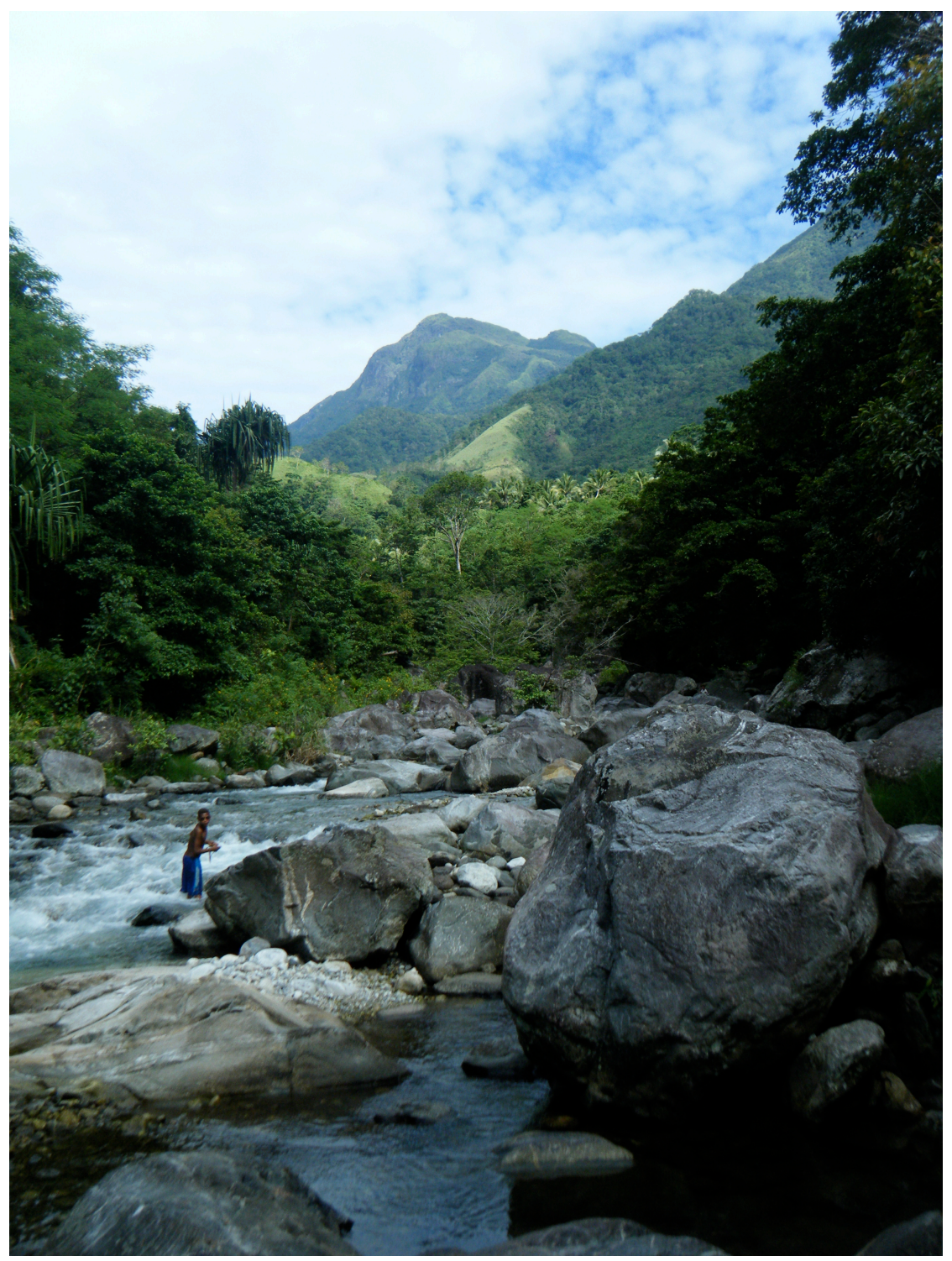

Frontispiece: Jumbled gneiss boulders in the Gulawata gorge, looking northwest towards the highest peak of Goodenough Island with a fisherman from Maligalima Village in the foreground. This trek was to be the most difficult of our 2010 field season, as the boulders in this river were rumored to be extremely slippery. Two weeks of clear skies made the walking easy. 


\section{Thesis abstract}

Debate concerns the timing of ultra-high pressure (UHP) metamorphism and the kinematics of exhumation of the world's youngest known eclogite-facies rocks (U-Pb ages of $4-8 \mathrm{Ma}$ ) in the Woodlark Rift of southeastern Papua New Guinea. End-member kinematic models that have been proposed for the crustal exhumation of metamorphic gneiss domes that host these young eclogites include detachment-related (asymmetric) gneiss doming (metamorphic core complexes), and pure shear-dominated (symmetric or diapiric) gneiss doming. The former is predicted to exhume the deepest structural levels of the domes adjacent to a major normal fault. The latter is predicted to yield a concentric pattern of exhumation levels with the deepest rocks located near the center of the domes. As far as can be determined, there are no mappable field gradients with respect to either the high-pressure metamorphism or the later pervasive amphibolite-facies overprint in the lower crust. This apparent uniformity contributes to uncertainty regarding the distribution of vertical strain in the body, and thus to the mode of dome emplacement.

To delineate spatial differences in exhumation and cooling rates, I measured Ti content in quartz for 90 samples of quartzofeldspathic gneiss and eclogite distributed across four migmatitic gneiss domes using laser ablation inductively coupled plasma mass spectrometry. I calculated paleo-temperatures from these data using the Ti-in-quartz geothermometer (Thomas et al., 2010; Wark and Watson, 2006). The Ti concentration in quartz in these samples ranges from 10 to $20 \mathrm{ppm}$, corresponding to an apparent temperature range of $500^{\circ} \mathrm{C}$ to $600^{\circ} \mathrm{C}$ (calculated using the Wark and Watson, 2006 calibration). As the apparent temperatures do not have a clear correlation with lithology and the quartz grains exhibit amoeboid grain boundaries, I infer that the Ti content in the quartz grains is capturing information related to quartz recrystallization and grain growth during the final stages of dynamic recrystallization by high-temperature grain-boundary migration (GBM). The presence of pervasive partial melt in the rocks and of chessboard microstructures in the quartz grains implies that the rocks in the D'Entrecasteaux Islands once attained temperatures of $>630^{\circ} \mathrm{C}$; however the $93 \%$ of the apparent temperatures calculated here are $<630^{\circ} \mathrm{C}$. Based on the pervasive GBM and the Ti-in-quartz apparent temperatures, I infer that the mean Ti content in these quartz grains was chiefly dependent on the relative rates of cooling and recrystallization as the body ascended through the crust. If the recrystallization rate was less spatially variable relative to the cooling rates across the gneiss domes, more quickly exhumed rocks would retain a larger relict fraction of unrecrystallized, hightemperature quartz grains. Ti content in quartz can therefore be used to map spatial changes 
in mean exhumation rate. As a rule, Ti concentrations in quartz in the D'Entrecasteaux Islands increase concentrically inward from $2.5-25 \mathrm{ppm}$ at the dome margins to $20->100$ ppm in the core of the domes. Based on this apparent increase in Ti content in quartz, I interpret the most rapidly cooled and exhumed rocks to occur today near the center of the gneiss domes. Thus, the Ti content in quartz data presented here indicate that the gneiss domes were emplaced in the crust by predominantly pure-shear symmetric doming.

The timing of rock fabric development at the (U)HP conditions and during the main amphibolite-facies retrogression at lower crustal depths in the D'Entrecasteaux Islands has not been dated. To that end, I present nine Rb-Sr internal mineral isochrons for samples of eclogite, quartzofeldspathic gneiss, and granitic rock from four gneiss domes. Rb-Sr internal mineral isochrons for two samples of eclogites from the core zone of the Mailolo gneiss dome (Fergusson Island) date the timing of the (U)HP eclogite-facies metamorphism at mantle depths to $5.7 \pm 2.0 \mathrm{Ma}$ and $5.6 \pm 1.6 \mathrm{Ma}(2 \sigma)$, respectively. One sample preserves coesite and the other contains radial fractures around quartz inclusions in garnet, implying that coesite was once been present in this rock. From this data, I infer that the eclogites in the Mailolo dome were metamorphosed at UHP depths of $>90 \mathrm{~km}$ at $5.6 \pm 1.2 \mathrm{Ma}$ (approximate 95\% confidence interval for the weighted mean of the two samples). The $\mathrm{Rb}-\mathrm{Sr}$ isochron ages of amphibolite-facies rock fabric development in a granodioritic orthogneiss and quartzofeldspathic gneiss from the Mailolo and Goodenough dome are $2.4 \pm 1.4 \mathrm{Ma}(2 \sigma)$ and $2.38 \pm 0.3 \mathrm{Ma}(2 \sigma)$ respectively. This similarity in these $\mathrm{Rb}-\mathrm{Sr}$ ages implies that deformation at amphibolite-facies conditions took place nearly simultaneously in these gneiss domes. A granodiorite $>40 \mathrm{~km}$ to the south of the Mailolo granodioritic orthogneiss yielded a $\mathrm{Rb}-\mathrm{Sr}$ age of $3.90 \pm 0.44 \mathrm{Ma}$. This latter age is $1.5 \pm 1.1 \mathrm{Ma}$ (approximate $95 \%$ confidence interval) older then the Mailolo and Goodenough samples, indicating an apparent westward younging in the age of the amphibolite-facies metamorphism in the northwestern D'Entrecasteaux Islands.

Five samples of quartzofeldspathic gneiss and quartzose rock were analyzed for pressure and temperature estimates using the garnet-plagioclase-muscovite-quartz barometer, the garnet$\mathrm{Al}_{2} \mathrm{SiO}_{5}$-plagioclase-quartz barometer, and the garnet-phengite exchange thermometer. These data indicate a temperature range of $640-720^{\circ} \mathrm{C}$ and a corresponding pressure range of $10-17 \mathrm{kbar}$ for the amphibolite-facies metamorphic overprint in the D'Entrecasteaux Islands. This pressure estimate is higher then previous estimates $(7-11 \mathrm{kbar})$ by $\sim 3-6$ kbar, which implies the HP body was thicker then previously inferred when it ponded at the lower crust. 
Combining these new $\mathrm{Rb}-\mathrm{Sr}$ ages with $\mathrm{U}-\mathrm{Pb}$ zircon ages by Gordon et al. (in review), I calculate a time lag of $2.2 \pm 1.2 \mathrm{Ma}$ (approximate $95 \%$ confidence interval) between eclogite-facies deformation in the mantle and amphibolite-facies foliation development in the lower crust for rocks in the Mailolo dome. This time lag, when combined with the amphibolite-facies pressure estimates presented here and pressure estimates consistent with the preservation of coesite in one sample, implies a minimum unroofing rate of $19 \pm 11 \mathrm{~mm}$ $\mathrm{yr}^{-1}$ (approximate 95\% confidence interval) for the (U)HP body from the mantle to the lower crust. This minimum unroofing rate strongly supports previous inferences that the exhumation from the mantle to the surface of the gneiss domes in the D'Entrecasteaux Islands took place at plate tectonic rates. 


\section{Acknowledgments}

I would like to first acknowledge my supervisor Tim Little, whose knowledge and patience has made this thesis possible. Tim has undertaken editing of this manuscript, and has unstintingly provided guidance on geological fieldwork, scientific writing, and structural geology methods and concepts. In addition, he survived two field seasons that included a serious bout of food poisoning and too much crying in high places.

Thanks also go to Marc-Alban Millet and Julie Vry for dragging a structural geologist through the intricacies of the $\mathrm{Rb}-\mathrm{Sr}$ analytical method and the probe. Marc is a phenomenal geochemist and a font of knowledge, and has provided lab assistance and theoretical background for both chapters of this thesis. Julie actually IS better than the probe when presented with a microscope, and was always available for questions about everything petrological. In addition, she helped me to navigate the GTB program.

This research was funded by a Marsden grant awarded to Tim Little and Laura Wallace. Euan Smith deserves mention here as he found me about to embark on three weeks of data processing, and then wrote a MATLAB ${ }^{\mathrm{TM}}$ script that condensed that time down to three hours. Euan has answered many questions about statistics, most delivered twice. Joel Baker was very helpful on several occasions when Marc and I were lost in the dissolution of my mineral separates. John Creech was a fantastic probe technician and an amazingly patient individual all around. Aidan Allan and George Cooper were also a huge help on the probe. Monica Handler is a beacon of calm in the clean lab, and Holly Winton was an awesome beaker-cleaning buddy. Special thanks to my "minion" Gemma Wihare, who helped pick mineral separates and sort out early probe work for this thesis. Stuart Bush prepared all the thin sections used here. Susanne Baldwin was a great help over email, and has sent samples and mineral splits to me from her collection in Syracuse. Gemma Wihare, Katy Chamberlain, Dee Ninnis and Dan Logan all helped with proofreading the last drafts of this manuscript, and were there to help me get it all together in the final days. Thanks also to Colin Wilson for providing advice on Ti-in-quartz and an eagle eye for references formatting.

I could not have completed this thesis without help from my university mates. First and foremost, Ben Gillam has born the brunt of my university stress over the last five years with admirable aplomb. He has forgotten more about Adobe Illustrator than I will even know, and has provided hours of office bickering to take my mind off broken machines. Katy 
Chamberlain provided no-nonsense support and slices. Thanks to my first university officemates Suzanne, Rachel, and Dee for dinners and daiquiris. Everyone who stuck with me all this time, regardless of how stressed out I was: Gemma, Chris, Mona, Emily, Andrea, Ollie, Kim, Rookie, Sam, Holly, Zara, Melissa, and Simon. Thanks guys, it's been a blast!

Thanks to my Mum for really understanding what I was up against, and to Dad and Adrienne for always believing I was doing better then I said I was.

Finally thanks to Dan for unending support over five years of university. Phantom acid burns, PPS, migraines, OCD, three months of $7 \mathrm{am}$ to $1 \mathrm{am}$ at the end of $4^{\text {th }}$ year, exams, pizza, support for two expeditions into PNG, around 50 colds, mice, moving house three times; he's had to deal with it all and has done it with grace. Thank you Boy. 


\section{Contents}

Frontispiece II

Thesis abstract III

$\begin{array}{lll}\text { Acknowledgments } & \text { VI }\end{array}$

Contents VIII

List of figures XIII

1. Introduction 1

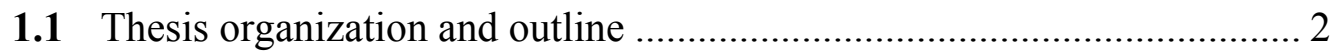


2. Evaluation of gneiss dome emplacement mechanisms in southeastern Papua New Guinea using Ti content in quartz

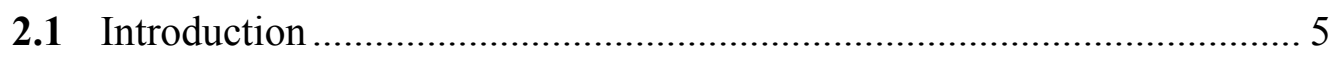

2.2 Geologic and tectonic setting .......................................................... 9

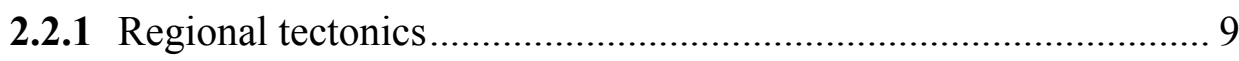

2.2.2 Structural geology of the D'Entrecasteaux Islands........................ 10

2.3 Models for gneiss dome emplacement .................................................... 18

2.4 Theory of the Ti-in-quartz geothermometer and analytical

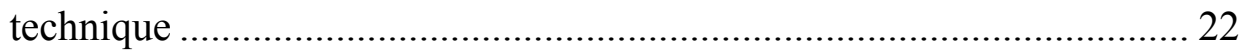

2.4.1 The Ti-in-quartz geothermometer (TitaniQ) _................................. 22

2.4.2 Analytical procedure and apparent temperature

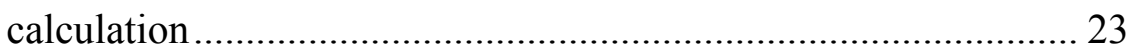

2.5 Results of cathodoluminescence imaging and LA-ICP-MS Ti-

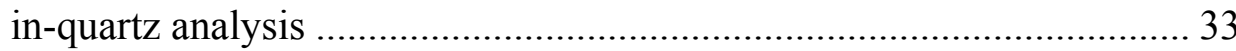

2.5.1 Cathodoluminescence images ....................................................... 33

2.5.2 Ti content in the quartz grains and TitaniQ apparent

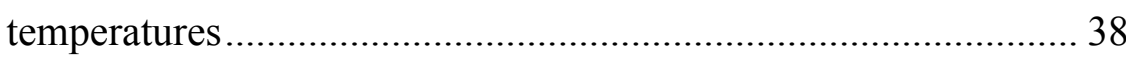

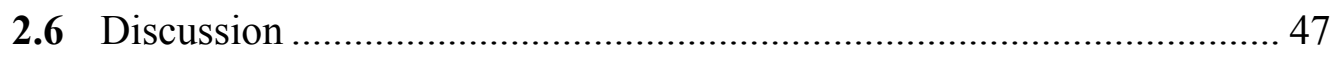

2.6.1 Fluid control on the uptake of Ti within quartz grains ................. 47

2.6.2 Testing the activity model of the calculated TitaniQ apparent temperatures for rutile-bearing and non-rutile

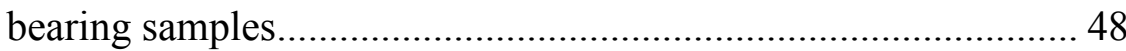

2.6.3 Application of the TitaniQ to metamorphic rocks .......................... 50

2.6.4 Interpretation of the spatial pattern of TitaniQ apparent

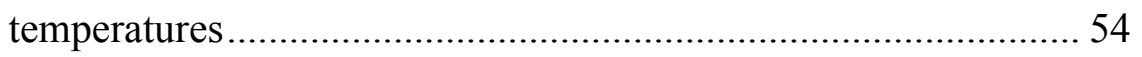

2.6.5 Comparison of TitaniQ apparent temperatures to

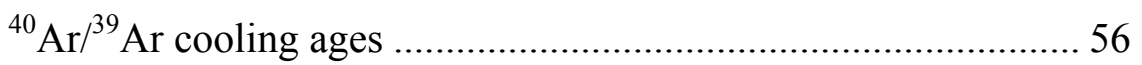

2.6.6 Kinematics of gneiss dome emplacement in the D’Entrecasteaux Islands .............................................................. 58

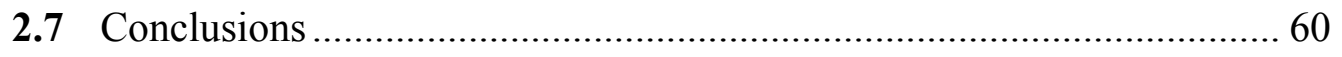


3. Rb-Sr dating of eclogite- and amphibolite-facies metamorphic events in the D'Entrecasteaux Islands, southeastern Papua New Guinea

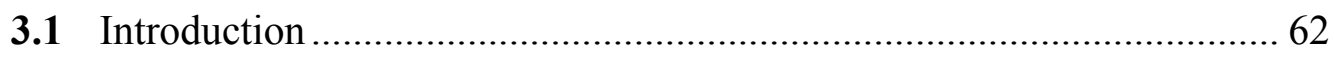

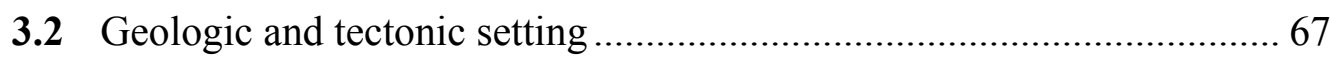

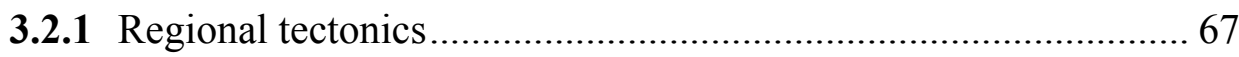

3.2.2 Structural geology of the D'Entrecasteaux Islands....................... 68

3.2.3 Previous thermobarometric studies in the D'Entrecasteaux Islands ............................................................. 72

3.2.4 Previous dating studies in the D'Entrecasteaux Islands .............. 75

3.3 $\mathrm{Rb}$-Sr dating of rocks by internal mineral isochrons ............................ 77

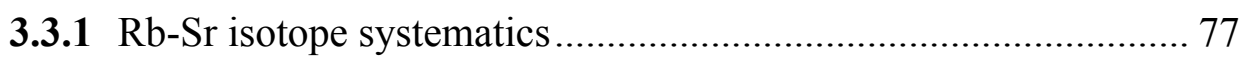

3.3.2 Requirements for isotopic dating via $\mathrm{Rb}-\mathrm{Sr}$ internal

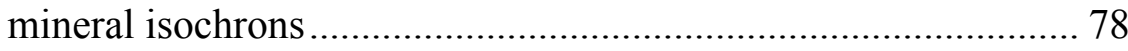

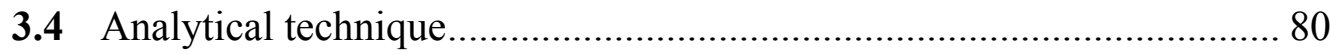

3.4.1 Thermobarometric and major element analytical technique ........................................................................... 80

3.4.2 $\mathrm{Rb}$-Sr dating analytical technique ........................................... 83

3.5 Results of thermobarometry and white mica major element

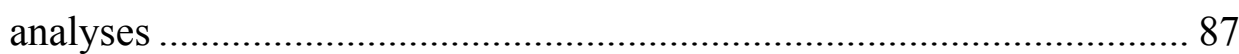

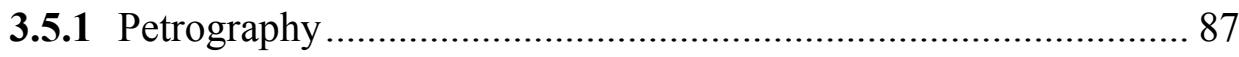

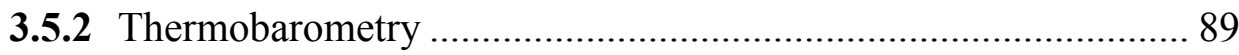

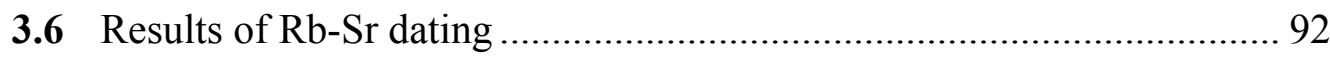

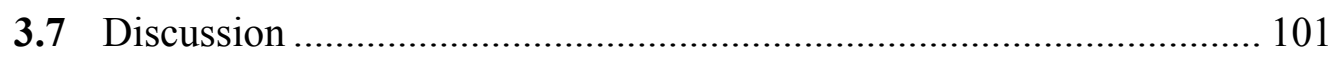

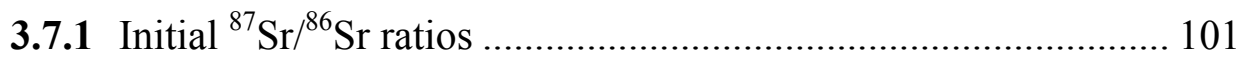

3.7.2 $\mathrm{Rb}-\mathrm{Sr}$ constraints on the timing of the eclogite-facies metamorphic crystallization

3.7.3 $\mathrm{Rb}-\mathrm{Sr}$ constraints on the timing of the amphibolitefacies metamorphic crystallization

3.7.4 Time scale for decompression of the (U)HP terrane from the mantle to the crust

3.7.5 Ages and pressure-temperature estimates for fabric formation in the core and carapace zones 
3.7.6 Post-metamorphic ductile strain estimate

108

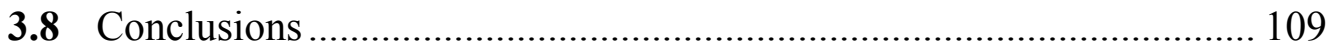




\section{Appendix B. Ti-in-quartz methods}

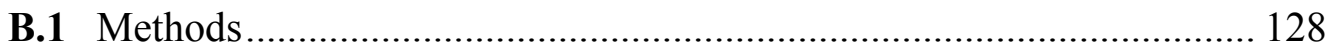

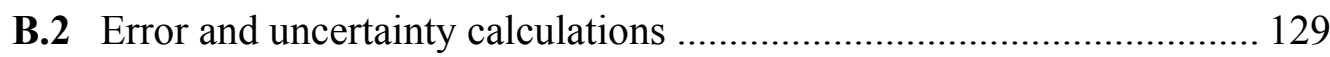

B.2.1 Wark and Watson (2006) uncertainty ........................................ 130

B.2.2 Thomas et al. (2010) uncertainty ............................................. 131

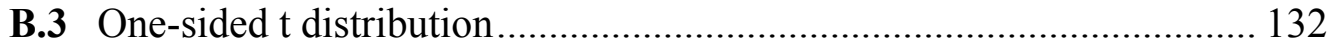

\section{Appendix C. MATLAB ${ }^{T M}$ script}

C.1 MATLAB ${ }^{\mathrm{TM}}$ input file formatting................................................... 134

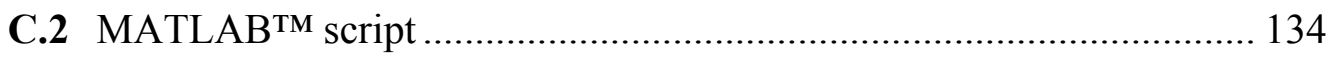

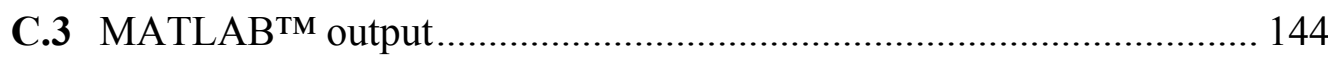

\section{Appendix $\mathrm{D}$. Rb-Sr and thermobarometry sample petrology}

D.1 Mailolo dome, Fergusson Island ..................................................... 146

D.2 Morima dome, Fergusson Island ...................................................... 148

D.3 Goodenough dome, Goodenough Island ............................................ 149

D.4 Northwest Normanby dome, Normanby Island ................................. 150

Table D.1 Representative white mica major element compositions............ 151

Table D.2 Representative mineral compositions for plagioclase in samples analyzed for thermobarometry.

Table D.3 Representative mineral compositions for garnet in samples analyzed for thermobarometry

\section{Appendix $\mathrm{E}: \mathrm{Rb}-\mathrm{Sr}$ dating and thermobarometry methods}

E.1 Sample selection and preparation.

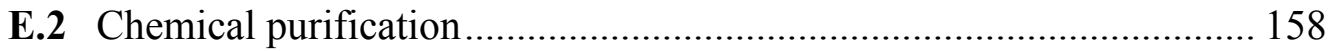

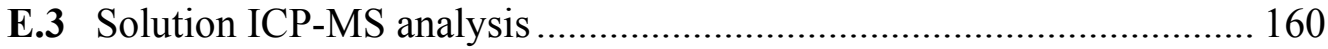




\section{LIST OF FIGURES}

2. Evaluation of gneiss dome emplacement mechanisms in southeastern Papua New Guinea using Ti content in quartz

2.1 a-b Tectonic setting of southeastern Papua New Guinea .......................... 6

2.2 a-b Kinematic models for crustal exhumation of gneiss domes................. 8

2.3 Tectonic and geologic map of the D'Entrecasteaux Islands

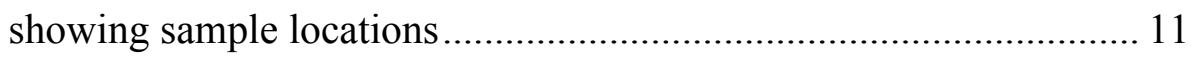

2.4 DEM of the northwest D'Entrecasteaux Islands ............................. 12

2.5 a-d Rock types in the D'Entrecasteaux Islands ..................................... 14

2.6 P-T path of the ultra-high pressure gneisses from the

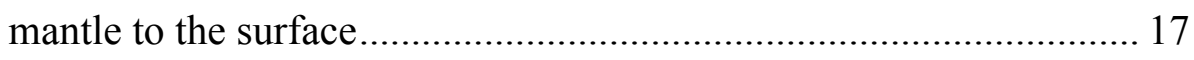

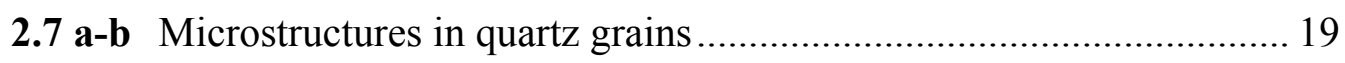

2.8 Reproducibility of the NIST 612 standard for all analytical

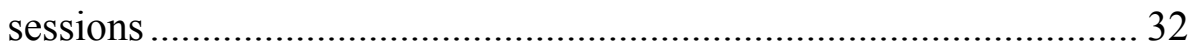

2.9 a-h Intra-granular Ti content and concentration variation....................... 34

2.10 a-d Inter-granular Ti content and concentration variation....................... 37

2.11 Mean Ti concentration as a function of $95 \%$ confidence interval

2.12 a-e Ti concentration and TitaniQ apparent temperatures compared by rock type and structural zone.

2.13 Spatial pattern of mean $\mathrm{Ti}$ concentrations in the

D’Entrecasteaux Islands

2.14 a-d Cross-sections across four gneiss domes in the

D’Entrecasteaux Islands

2.15 a-e Ti concentration as a function of distance from the active dome-bounding faults

2.16 a-c TitaniQ activities and calibrations for the Wakonai Fault,

Goodenough dome 46

2.17 Al concentration as a function of $\mathrm{Ti}$ concentration 49

2.18 TitaniQ apparent temperatures for rutile and non rutilebearing samples 
2.19 ${ }^{40} \mathrm{Ar} /{ }^{39} \mathrm{Ar}$ cooling ages as a function of TitaniQ apparent temperatures

3. Rb-Sr dating of eclogite- and amphibolite-facies metamorphic events in the D'Entrecasteaux Islands, southeastern Papua New Guinea

3.1 a-b Tectonic setting of southeastern Papua New Guinea ....................... 63

3.2 DEM of the northwest D'Entrecasteaux Islands ............................. 64

2.3 P-T path of the UHP gneisses from the mantle to the surface. 66

3.4 Tectonic and geologic map of the D'Entrecasteaux Islands showing sample locations

3.5 a-d Rock types in the D'Entrecasteaux Islands ..................................... 71

3.6 a-k Photomicrographs of $\mathrm{Rb}$-Sr and thermobarometry samples ............ 84

3.7 Ternary composition plot for phengite and white mica.................... 88

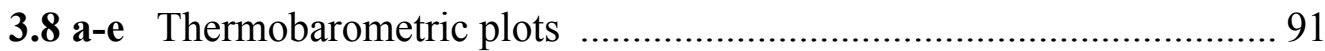

3.9 a-b Eclogite-facies $\mathrm{Rb}-\mathrm{Sr}$ internal mineral isochrons............................. 95

3.10 a-g Amphibolite-facies Rb-Sr internal mineral isochrons ..................... 97

\section{Appendix B}

B.1 A Normal or Gaussian distribution 133

\section{Appendix B}

C.1 MATLAB ${ }^{\mathrm{TM}}$ input formatting 135

C.1 MATLAB ${ }^{\mathrm{TM}}$ output files 145 


\section{Introduction}

The recognition of coesite-bearing rocks in eclogite-facies metamorphic terranes has been an exciting discovery in the field of continental dynamics (Chopin, 1984; Smith, 1984). Coesite-bearing rocks may have once been generated in the majority of global exhumed collisional orogen, even if they are no longer preserved or are not currently exposed at the surface (Beltrando et al., 2010; Chopin, 1984; Chopin, 2003; Ernst, 2001; Liou et al. 2004; Liou et al., 2009). The exposure of these ultrahighpressure (UHP) rocks at the Earth's surface implies subduction of low-density crustal material through dense mantle rocks to depths of $>90 \mathrm{~km}$ at subduction zones (Chopin, 1984; Chopin, 2003; Lapen et al., 2003; Leech, 2001; Liou et al. 2009; Little et al., 2007; Little et al., 2011; Smith, 1984). In some cases this subduction has been followed by exhumation at plate tectonic rates $\left(\mathrm{cm} \mathrm{yr}^{-1}\right)$, resulting in the rapid translation of UHP rocks into the crust or even to the Earth's surface (Baldwin et al., 2004; Baldwin et al., 2008; Glodny et al., 2005b; Parrish et al., 2006; Rubatto and Hermann, 2001). The exhumation of UHP rocks may be the result of buoyancydriven transport of material, when buoyancy of the crustal material overrides the subduction or slab-pull forces and results in detachment of material from the subducting slab (Ernst, 2001; Hacker, 2007; Jolivet et al., 2005; Kurz, 2005). This exhumation can occur in two stages: (1) rapid and nearly isothermal decompression from the mantle to the lower crust, and (2) cooling and emplacement in the crust (Baldwin et al., 2004; Baldwin et al., 2008; Ernst, 2001; Gordon et al., in review). For example, the UHP slab of the Western Gneiss Region, Norway, underwent isothermal decompression as a coherent body $(>20-30 \mathrm{~km}$ thick $)$ from UHP conditions at $410-400 \mathrm{Ma}$ to the lower crust in $\sim 5 \mathrm{Ma}$, and was exhumed through the crust between 400 - 390 Ma (Glodny et al., 2008b; Hacker, 2007; Hacker and Gans, 2005; Terry et al., 2000; Young et al., 2007). The subduction of crustal material to depths in excess of $>90 \mathrm{~km}$ does not fit with the conventional plate tectonic theory, which includes classic metamorphic recycling of continental crust to 30 - 40 km (Beaumont et al., 2009; Chopin, 2003; Lapen et al., 2003; Smith, 1984).

The D'Entrecasteaux Islands of southeastern Papua New Guinea (PNG) are domal culminations of quartzofeldspathic gneiss, which host the youngest known (U)HP 
eclogite-facies rocks on Earth (U-Pb zircon ages of 8 - 4 Ma; Baldwin et al., 2004; Gordon et al., in review; Monteleone et al., 2007). Previous geochronological studies in the D'Entrecasteaux Islands have focused on dating the timing of zircon crystallization during (U)HP and amphibolite-facies metamorphism, and magmatic crystallization of zircons in granitic dikes that intrude the migmatitic gneiss domes (Baldwin and Ireland, 1995; Baldwin et al., 2004; Gordon et al., in review; Monteleone et al., 2007). A recent study by Zirakparvar et al. (2011) carried out LuHf dating on garnets in a sample of coesite-bearing eclogite, determined an age of $7.1 \pm 0.7 \mathrm{Ma}(2 \sigma)$ for the timing of garnet crystallization at UHP conditions. In addition, the timing of final cooling in the upper crust $\left(<400^{\circ} \mathrm{C}\right)$ has been constrained by ${ }^{40} \mathrm{Ar} /{ }^{39} \mathrm{Ar}$ techniques on white mica and biotite $(3.0-1.4 \mathrm{Ma})$ and apatite fission track analysis (0.4 - 0.1 Ma; Baldwin et al., 1993; Fitzgerald et al., 2008). As of yet, the timing of deformation during the (U)HP and subsequent amphibolite-facies metamorphism has not been well constrained. In addition, the exhumation of these gneiss domes through the crust is controversial, as a lack of metamorphic isograds makes tectonic reconstruction of post-metamorphic ductile strain patterns difficult. Two possible models that have been proposed for the mode of crustal emplacement of the gneiss in the D'Entrecasteaux Islands include detachment-bounded metamorphic core complexes, and symmetrical (diapiric) gneiss domes (Davies and Warren, 1988; Hill, 1994; Hill and Baldwin, 1993; Hill et al., 1995; Little et al., 2011; Martinez et al., 2001; Webb et al., 2008).

\subsection{Thesis organization and outline}

This thesis contains two chapters designed and organized as self-contained papers intended for publication in a scientific journal, and as such each chapter necessarily contains repetition of some introductory material, context setting, and certain figures. Chapter 2, entitled "Evaluation of gneiss dome emplacement mechanisms in southeastern Papua New Guinea using Ti content in quartz", examines the significance of variations of $\mathrm{Ti}$ content in quartz in high-grade metamorphic rock, particularly in rapidly exhuming and high-temperature bodies. I present Ti content in quartz data and Ti-in-quartz apparent temperatures for 90 samples of 
quartzofeldspathic gneiss, granitic rock, and eclogites from the northwestern D'Entrecasteaux Islands. The physical processes of Ti mobility and homogenization in ductilely deforming metamorphic rock are constrained here by optical microscopy and cathodoluminescence analysis. Spatial gradients in Ti content in quartz across the gneiss domes are used as a proxy for relative cooling and exhumation rates within the dome, which refines the current understanding of kinematics of gneiss dome exhumation in the D'Entrecasteaux Islands.

Contributions to Chapter 2 include supervision, guidance, and editing of the manuscript by Timothy Little. He also offered guidance during two field seasons (2009, 2011), and provided thin-sections and hand samples for my analysis from previous field seasons in the D'Entrecasteaux Islands. Marc-Alban Millet provided technical assistance with analysis of samples on the LA-ICP-MS, and proofread Chapter 2 and the associated appendices. Euan Smith wrote a MATLAB ${ }^{\text {TM }}$ script that calculated background-corrected counts per second or signal for ICP-MS analysis. He also advised on data processing and error calculations, and proofread a copy of this Chapter.

In Chapter 3, entitled " $\mathrm{Rb}-\mathrm{Sr}$ dating of eclogite- and amphibolite-facies metamorphism in the D'Entrecasteaux Islands, southeastern Papua New Guinea", I present $\mathrm{Rb}-\mathrm{Sr}$ internal mineral isochrons for nine samples of mafic and quartzofeldspathic composition collected from four gneiss domes in the D'Entrecasteaux Islands. These ages are inferred to date rock fabric development during: (1) the peak eclogite-facies metamorphism, and (2) the later amphibolitefacies retrogression. Moreover, these ages constrain the duration of time between the peak UHP metamorphism in the mantle and the later retrogressive amphibolite-facies metamorphism in the lower crust, and thus the exhumation rate of the (U)HP body. I also contribute to a revision in the estimate of the age of the UHP metamorphic event from 8 - 7 Ma down to 5 Ma (Baldwin et al., 2004; Baldwin et al., 2008; Gordon et al., in review; Monteleone et al., 2007; Zirakparvar et al., 2011). Pressure and temperature estimates for five samples of quartzofeldspathic gneiss and quartzose rocks retrogressed during the amphibolite-facies metamorphic event are presented here, along with an estimate of the unroofing rate for the (U)HP body from the mantle to the surface. 
Contributions to Chapter 3 include scientific guidance and editing from Timothy Little. Marc-Alban Millet provided technical assistance with chemical purification of samples and analysis of sample aliquots on the multi-collector ICP-MS and ICP-MS. In addition, Marc-Alban Millet advised on data processing and interpretation of $\mathrm{Rb}$ $\mathrm{Sr}$ ages, and proofread Section 2.4.2 (Sampling and Analytical Method for Rb-Sr dating and thermobarometry) and Appendix E (Rb-Sr dating and thermobarometry methods). Julie Vry assisted with preparation of mineral separates and electron probe microanalyzer lab work for Chapter 3, and wrote the Microsoft Excel (Microsoft. Redmond, WA, USA) spread sheets used in major element data processing.

Appendix A contains all cathodoluminescence images of quartz grains collected during this study on a compact disk. Images are organized first by rock type and then by sample number. Images are labeled according to the wavelength that was isolated during data processing: "blue" is the $415 \mathrm{~nm}$ wavelength inferred by Spear and Wark (2009) to be associated with the Ti concentration within quartz, "green" is the $650 \mathrm{~nm}$ wavelength which may be related to the oxygen vacancy in quartz, "bluegreen" is a combination of both the $450 \mathrm{~nm}$ and $650 \mathrm{~nm}$ wavelengths, and "onlySi" is a specific wavelength dispersive spectrometry map showing the location of quartz grains. Appendix B presents Ti-in-quartz analytical and statistical methods not included in Chapter 2, along with machine settings and conditions used during LA-ICP-MS analysis. Appendix C presents the MATLAB ${ }^{\mathrm{TM}}$ script written by Euan Smith and instructions for its use. Appendix D contains a complete petrologic description of each sample analyzed for $\mathrm{Rb}-\mathrm{Sr}$ isotopic composition and thermobarometry in Chapter 3, along with representative major element analysis for white mica, garnet, and plagioclase. Appendix E details the analytical technique used for chemical purification of mineral separates and standards, and the machine settings and conditions used during LA-ICP-MS analysis and quantitative major element analysis on the electron probe microanalyzer. 


\section{Evaluation of gneiss dome emplacement mechanisms in southeastern Papua New Guinea using Ti content in quartz}

\subsection{Introduction}

Previous petrological and geochronological work on four young metamorphic gneiss domes that host the world's youngest eclogite-facies rocks in the Woodlark Rift of southeastern Papua New Guinea (PNG; Fig. 2.1) has focused on the timing of highpressure (HP) and the ultrahigh-pressure (UHP) metamorphism, and the pressure/temperature conditions of this crystallization (Baldwin et al., 1993; Baldwin et al., 2004; Baldwin et al., 2008; Davies and Warren, 1988; Hill et al., 1992; Hill et al., 1995; Gordon et al., in review; Monteleone et al., 2007; Zirakparvar et al., 2011). The D'Entrecasteaux Islands do not exhibit mappable metamorphic isograds or preserved metamorphic field gradients, for example between (U)HP eclogite-facies rocks and lower grade rocks (Little et al., 2011). The homogeneity between the UHP and HP rocks within the D'Entrecasteaux Islands makes determining spatial differences in exhumation level within the gneiss domes difficult. The kinematics of the metamorphic terrane's deformation and crustal exhumation and emplacement is thus relatively uncertain; for example, it is controversial to what degree the gneiss domes are detachment-bounded metamorphic core complexes or symmetrical gneiss domes (Baldwin et al., 2004; Davies and Warren, 1988; Hill et al., 1995; Little et al., 2011; Martinez et al., 2001; Webb et al., 2008).

Application of the Ti-in-quartz geothermometer (TitaniQ) as a potential tool to constrain the deformational and temperature history of ductilely deformed metamorphic rocks is an exciting prospect, but is currently in its infancy (Grujic et al., 2011; Kohn and Northrup, 2009; Pennacchioni et al., 2010; Spear and Wark, 2009). Aspects of the TitaniQ under scrutiny include uncertainties in the Ti activity coefficient in quartz (Grujic et al., 2011). More generally, the validity of the thermodynamics on which the original calibrations were based has been questioned (Wilson et al., in review). Another major uncertainty related to the application of the TitaniQ to deformed metamorphic rocks is identifying which grain-scale process or 


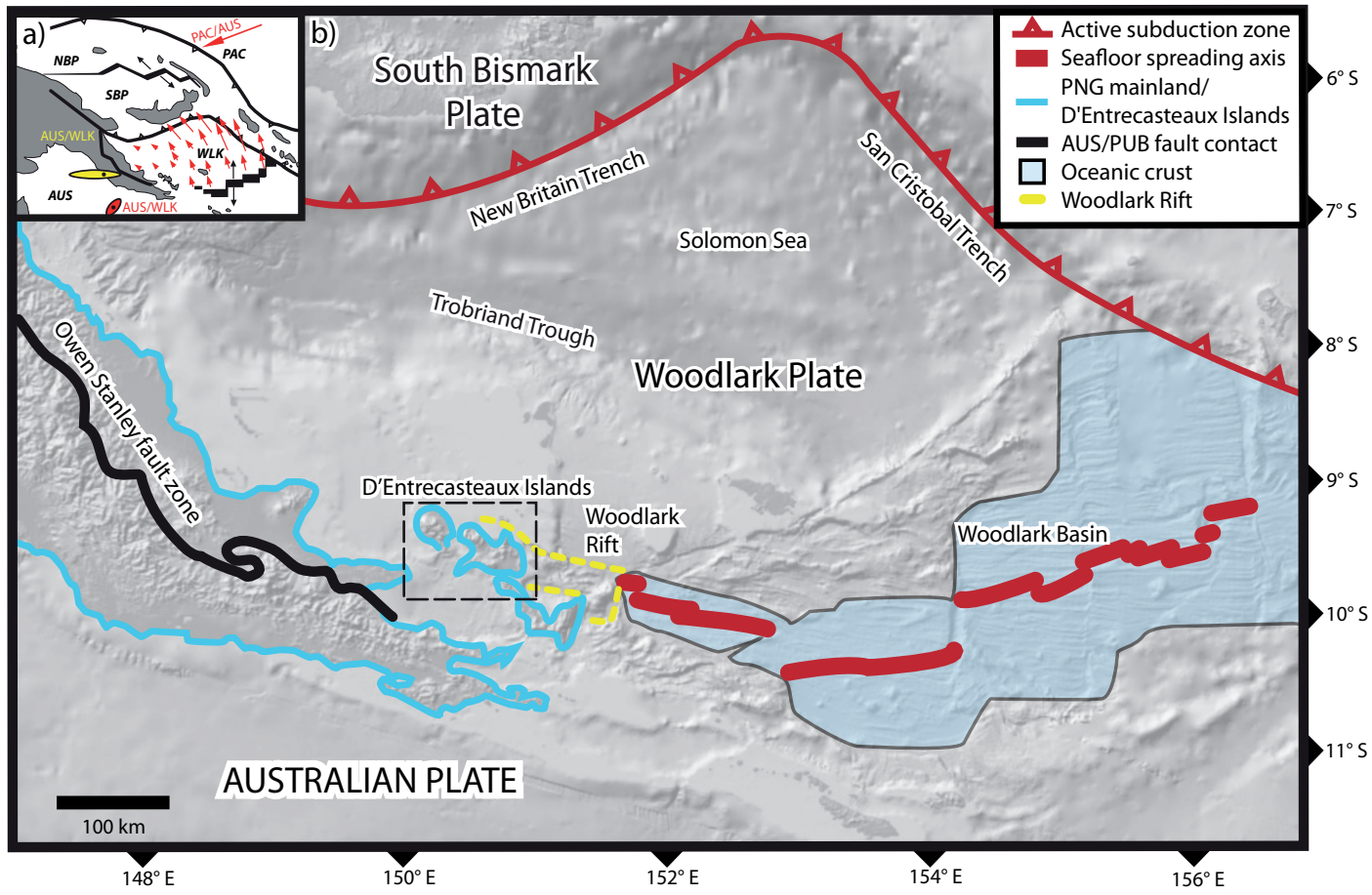

Figure 2.1 (a) Plate tectonic map of eastern Papua New Guinea. Adapted from Wallace et al. (2004), Webb et al. (2008), and Little et al. (2011): PAC, Pacific Plate; AUS, Australian Plate; WLK, Woodlark Plate, NBP; North Bismark Plate, SBP; South Bismark Plate. Direction of movement of the Pacific Plate relative to the Australian Plate shown by the bold red arrow. Pole of WLK-AUS relative rotation (with error ellipse) for the present-day (after Wallace et al., 2004). Pole of WLK-AUS relative rotation (with error ellipse) for 3.6-0.5 Ma (after Taylor et al., 1999). The small red arrows depict the current velocities of the Woodlark Plate relative to the Australian Plate (after Wallace et al., 2004). (b) Simplified tectonic map of southeastern Papua New Guinea. Background is a Digital Elevation Model from GeoMapApp (http://www.GeoMapApp.org). Location for figures 2.3, 2.4, and 2.13 shown in the dashed box. Location of Woodlark Rift zone after Baldwin and Ireland (1995). 
processes may be responsible for $\mathrm{Ti}$ transport and equilibration within plastically deforming and dynamically recrystallizing grains of metamorphic quartz (Spear and Wark, 2009). For these reasons it is now timely to test the TitaniQ in sequences of metamorphic tectonites that span a wide crustal range of exposure levels and metamorphic grades (paleo-temperatures), in order to better clarify the technique's potential applicability to tectonic studies of ductilely deformed quartzose rocks. Potential problems in the application of the TitaniQ to metamorphic quartz include: incomplete $\mathrm{Ti}$ homogenization within quartz grains (zoning), heterogeneous $\mathrm{Ti}$ concentrations between quartz grains, and the possibility of post-recrystallization volume diffusion of Ti in quartz grains (Spear and Wark, 2004).

The D'Entrecasteaux Islands are domal culminations of quartzofeldspathic gneiss with minor mafic units ( $5-10 \%$ volume), the latter of which has been exposed to eclogite-facies metamorphic conditions at $8-4 \mathrm{Ma}$ (Baldwin et al., 2004; Gordon et al., in review; Monteleone et al., 2007; Zirakparvar et al., 2011). Rocks that comprise

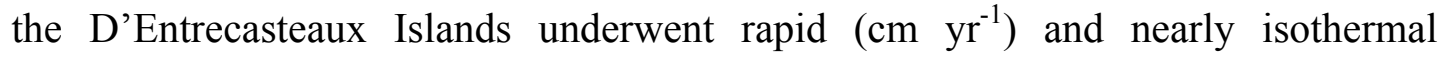
decompression from the mantle to the lower crust at $4-2 \mathrm{Ma}$, followed by extremely rapid cooling at $<2 \mathrm{Ma}\left(>100{ }^{\circ} \mathrm{C} \mathrm{Ma}^{-1}\right.$; Baldwin et al., 1993; Baldwin et al., 2004; Baldwin et al., 2008). The young, almost neotectonic, age of the exhumation in the D'Entrecasteaux Island region provides several advantages towards the study of (U)HP exhumation processes, including the active and well-constrained geodynamic context that surrounds the terrane and the lack of tectonic overprinting unrelated to the exhumation from the mantle to the surface.

This study is an attempt to map spatial differences in exhumation rates within the gneiss domes of the D'Entrecasteaux Islands. In particular, I will test which of the following end-member kinematic models is more applicable for crustal exhumation of (U)HP-bearing gneiss domes in the Woodlark Rift: a) pure-shear dominated symmetric domes, or b) detachment-style asymmetric metamorphic core complexes (Fig. 2.2; Yin, 2004). Each model predicts a unique spatial pattern of exhumation rates, and $\mathrm{I}$ will argue that gradients in $\mathrm{Ti}$ content and apparent TitaniQ deformational temperatures help to distinguish between these models. In particular, these spatial patterns may be used to better understand processes that have led to the exhumation of gneiss domes that host the world's youngest (U)HP rocks in 
a) pure-shear dominated symmetric doming

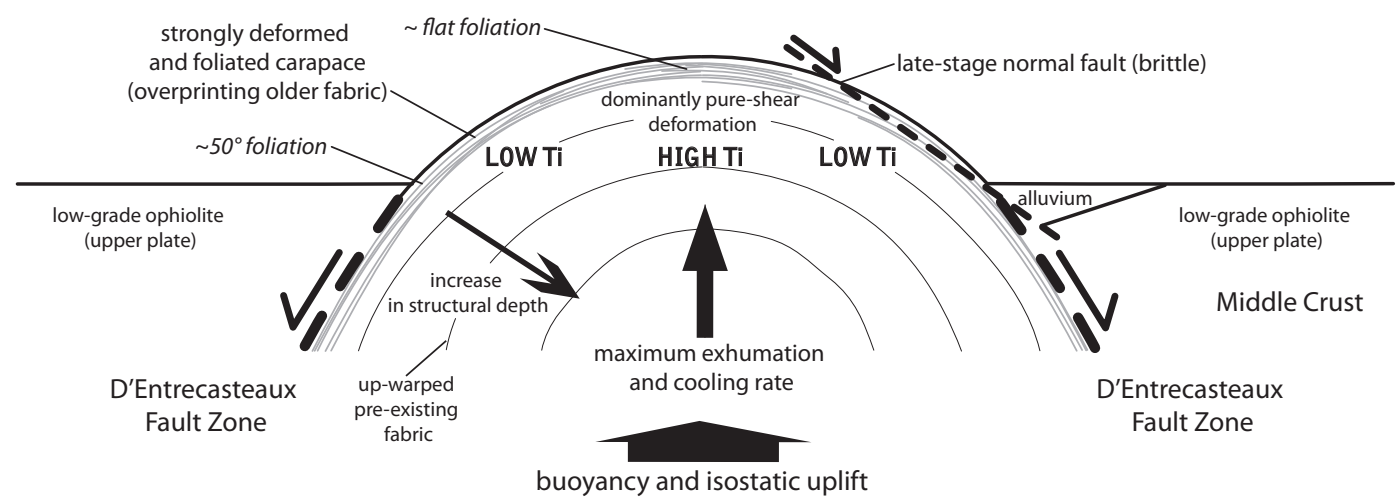

b) detachment-style asymmetric metamorphic core complex development

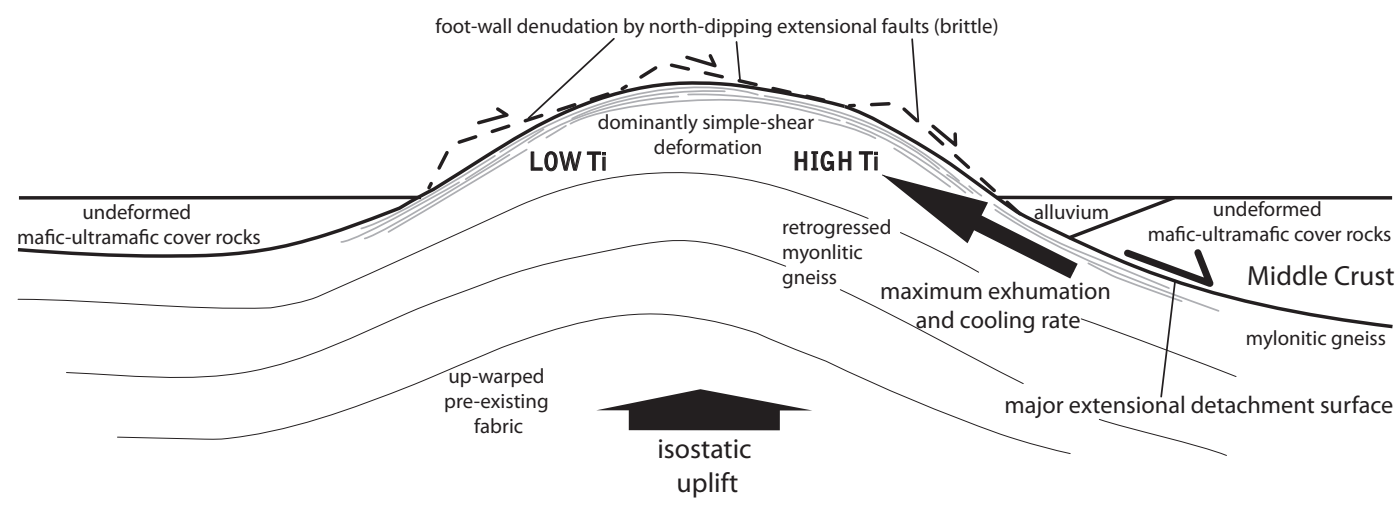

Figure 2.2 Schematic cartoons of end-member kinematic models for crustal exhumation of gneiss domes in the D'Entrecasteaux Islands. Bold text shows predicted spatial pattern of Ti concentration. (a) Pure-shear dominated symmetric doming after Little et al. (2011). (b) Detachment-style asymmetric metamorphic core complex development after Davis et al. (1986). 
southeastern PNG. In this study, I report on new data set of Ti content in quartz determined by laser ablation inductively coupled plasma mass spectrometry (LAICP-MS) for 90 quartz-bearing samples from the D'Entrecasteaux Islands, including both quartzofeldspathic and mafic protoliths. I calculate TitaniQ apparent paleotemperatures, and address the effects of pressure, uncertainties in Ti activities, and alternate calibrations for the TitaniQ geothermometer. This paper is particularly focused on the application of Ti-in-quartz data to a body of high-grade metamorphic rocks that was rapidly exhumed into the upper crust, and continued to deform ductilely until it cooled rapidly at shallow crustal levels.

\subsection{Geologic and tectonic setting}

\subsubsection{Regional tectonics}

Eastern PNG is situated in a mosaic of microplates between the Pacific and Australian plates, which includes the Woodlark microplate (Fig. 2.1; Wallace et al., 2004). This boundary accommodates $\sim 110 \mathrm{~mm} \mathrm{yr}^{-1}$ of north-northwest to southsoutheast horizontal motion (Wallace et al., 2004). The continental Woodlark Rift separates the Woodlark microplate to the north from the Australian plate to the south, and transitions along strike to the east into the Woodlark Basin oceanic spreading center (Fig. 2.1; Taylor et al., 1999; Wallace et al., 2004). Since $\sim 6$ Ma, the Woodlark Basin spreading center has been actively spreading and has propagated westward through orogenic continental crust of the Papuan Orogen at a rate of $\sim 150$ $\mathrm{km} \mathrm{Ma}^{-1}$ (Taylor et al., 1999). This orogen developed in the early to middle Eocene as the result of an arc-continent collision that emplaced the Cenozoic Papuan Ultramafic Body over Australian crustal material along the Owen Stanley fault zone (Davies and Jaques, 1984; Lus et al., 2004). The D'Entrecasteaux Islands are situated $\sim 100 \mathrm{~km}$ to the west of the tip of the Woodlark Basin spreading center (Fig. 2.1). The shedding of metamorphic debris as conglomerate in the offshore region to the north of the D'Entrecasteaux Islands indicates that the gneiss domes became emergent in the Pliocene (Baldwin et al., 1993; Davies and Warren, 1988). Elevated coral platforms of probable Holocene age on the southeast coast of Goodenough 
Island, and incised flights of river terraces on the northeastern coastal plains of Goodenough Island, indicate that uplift of the D'Entrecasteaux Islands has persisted, if only slowly, into the Late Quaternary (Little et al., 2011). In addition, apatite fission track ages of $\sim 0.8 \pm 0.1 \mathrm{Ma}$ indicates unroofing of the domes in the Late Quaternary (Baldwin et al., 1993).

\subsubsection{Structural geology of the D'Entrecasteaux Islands}

The Goodenough, Mailolo, and Oiatabu gneiss domes are bounded by active north or northeast-dipping normal faults on their northeast margins (Fig. 2.3, 2.4). The Morima dome is bounded to the southwest by an active southwest-dipping normal fault (Fig. 2.3, 2.4). Where exposed on Goodenough Island, the Wakonai normal fault dips $35-40^{\circ}$ (Fig. 2.3; Little et al., 2011). These faults separate unmetamorphosed late Quaternary alluvium sediments and volcanic rock in their hangingwall, from erosional remnants of the Cenozoic Papuan Ultramafic Body and underlying amphibolite-facies gneisses in their footwall (Fig. 2.3; Hill, 1994; Little et al., 2011). Structural data suggest that Goodenough and Mailolo Domes have been back-tilted $\sim 20^{\circ}$ to the southwest as a result of slip on the dome-bounding faults, implying an original dip for the faults of $\sim 55-60^{\circ}$ (Little et al., 2011).

The footwalls of these normal faults consist of a high-grade gneissic terrane with an outwardly dipping domal foliation. The dome-defining foliation post-dates the (U)HP metamorphic event, and developed during a widespread syn-exhumational upper amphibolite-facies overprint that affected the gneiss terrane after it had risen from the mantle to the lower crust (Little et al., 2011). At the crest of the domes the foliation is generally sub-horizontal but elsewhere it dips outward at $30-70^{\circ}$, with the steepest dips typically being found on the southwest flanks of the domes as a result of their back-tilting (Little et al., 2011). These gneiss domes are $2-2.5 \mathrm{~km}$ high at their crests, and are rounded or elongate in map view. They have been eroded sufficiently so that a once continuous sheet of overlying ultramafic rock of the Cenozoic Papuan Ultramafic Body has largely been stripped away from their uplifted centers, leaving only a scatter of small erosional remnants that are exposed in structural lows (Fig. 2.3; Little et al., 2011). Each dome is separated from its neighboring domes by tight synforms (Fig. 2.3). The gneiss domes can be divided 


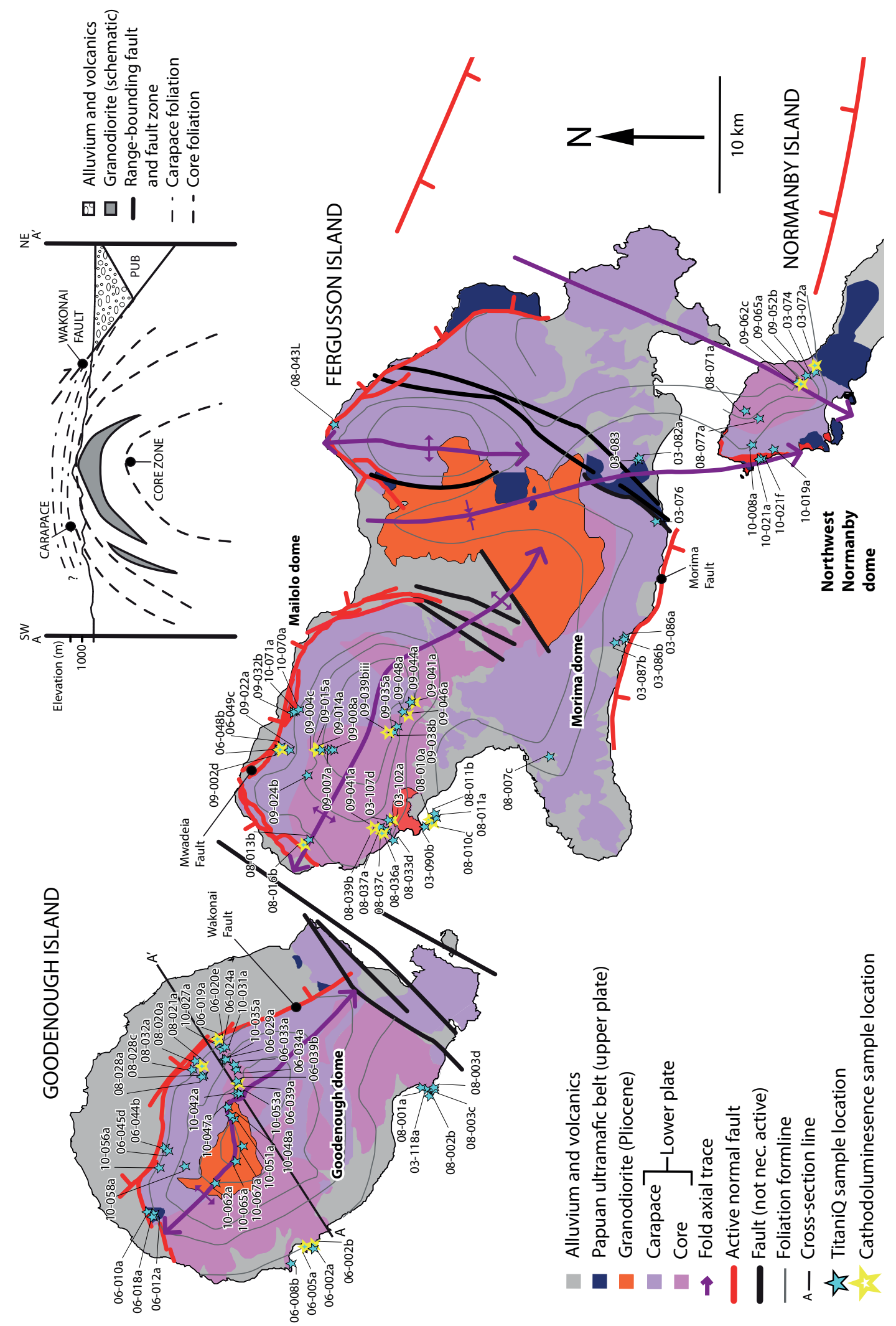

Figure 2.3 Simplified tectonic and geologic map of the northwest $D^{\prime}$ Entrecasteaux Islands showing sample locations, adapted from Hill (1994) and Little et al. (2011): PUB, Papua Ultramafic Belt; Volc., volcanics. See Figure $2.1 \mathrm{~b}$ for location. Inset: Schematic cross section along profile A-A' (no vertical exaggeration) after Little et al. (2011). 


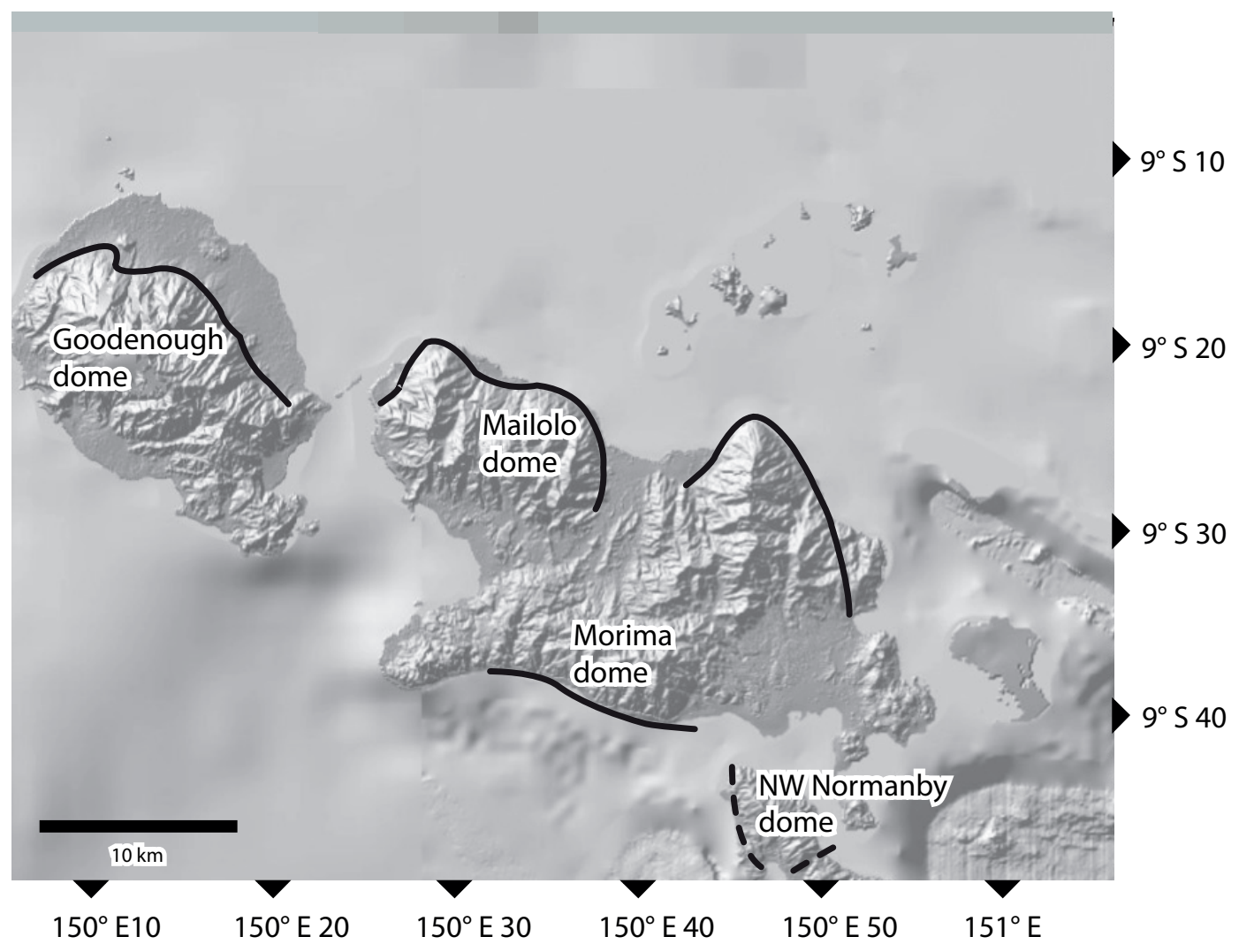

Figure 2.4 Digital Elevation Model of the northwest D'Entrecasteaux Islands from GeoMapApp (http://www.GeoMapApp.org). Note locations of main dome-bounding normal faults (solid black lines) and faults zones (dashed black lines). See Figure $2.1 \mathrm{~b}$ for location. Note locations of gneiss domes described in text. 
into two structural zones: a structurally higher carapace zone (up to $\sim 1.5 \mathrm{~km}$ thick), and a structurally deeper core zone (Fig. 2.3; Hill, 1994; Little et al., 2011). The carapace zone strongly resembles the core zone in protolith compositions and the presence of meter-scale eclogite boudins, and both share the same domal foliation that is outwardly dipping and defines the gneiss dome culminations (Little et al., 2011). The carapace differs from the core in that it is characterized by a more planar, thinly laminated, and strongly lineated solid-state tectonic fabric relative to the subjacent core rocks (Little et al., 2011).

The gneiss domes are composed primarily ( $90 \%)$ of quartzofeldspathic gneiss, much of it orthogneiss (Fig. 2.5; Little et al., 2011 and ref. therein). It has been inferred that the gneisses are derived from Cretaceous or older Australian continental margin protoliths, and probably represent a once deeply subducted part of the collisional Papuan Orogeny (Davies and Jaques, 1984; Davies and Warren, 1988; Little et al., 2011; Zirakparvar et al., 2010). Marbles and pelites are rare $(<1 \%)$, and eclogite constitutes $5-10 \%$ of the terrane (Fig. 2.5d; Little et al., 2011 and ref. therein).

The eclogite blocks in the D'Entrecasteaux Islands originate from meter-thick basaltic dikes that intrusively crosscut the quartzofeldspathic host gneiss (Baldwin et al., 2008). These mafic dikes were later metamorphosed under eclogite-facies conditions prior to final boudinage and retrogression in upper amphibolite-facies conditions (Baldwin et al., 2008). The verification of coesite in one sample of mafic eclogite (08-010a) from the west of the Mailolo dome implies that certain portions, or perhaps all, of the metamorphic terrane was subducted to depths of $>90 \mathrm{~km}$ (Baldwin et al., 2008; Monteleone et al., 2007). In the cores of the mafic boudins the unretrogressed (U)HP eclogites-facies metamorphic assemblage consists of garnet, omphacite, phengite, quartz, and rutile (Brownlee et al., in prep.). The rinds of the boudins have typically been retrogressed to amphibolite-facies metamorphic assemblage (hornblende and plagioclase symplectite, garnet, quartz, and ilmenite) together with the quartzofeldspathic gneiss that wraps around the relict (U)HP boudins. The degree of amphibolite-facies retrogression is variable, with some mafic blocks preserving the unretrogressed UHP eclogite-facies assemblage, and others 

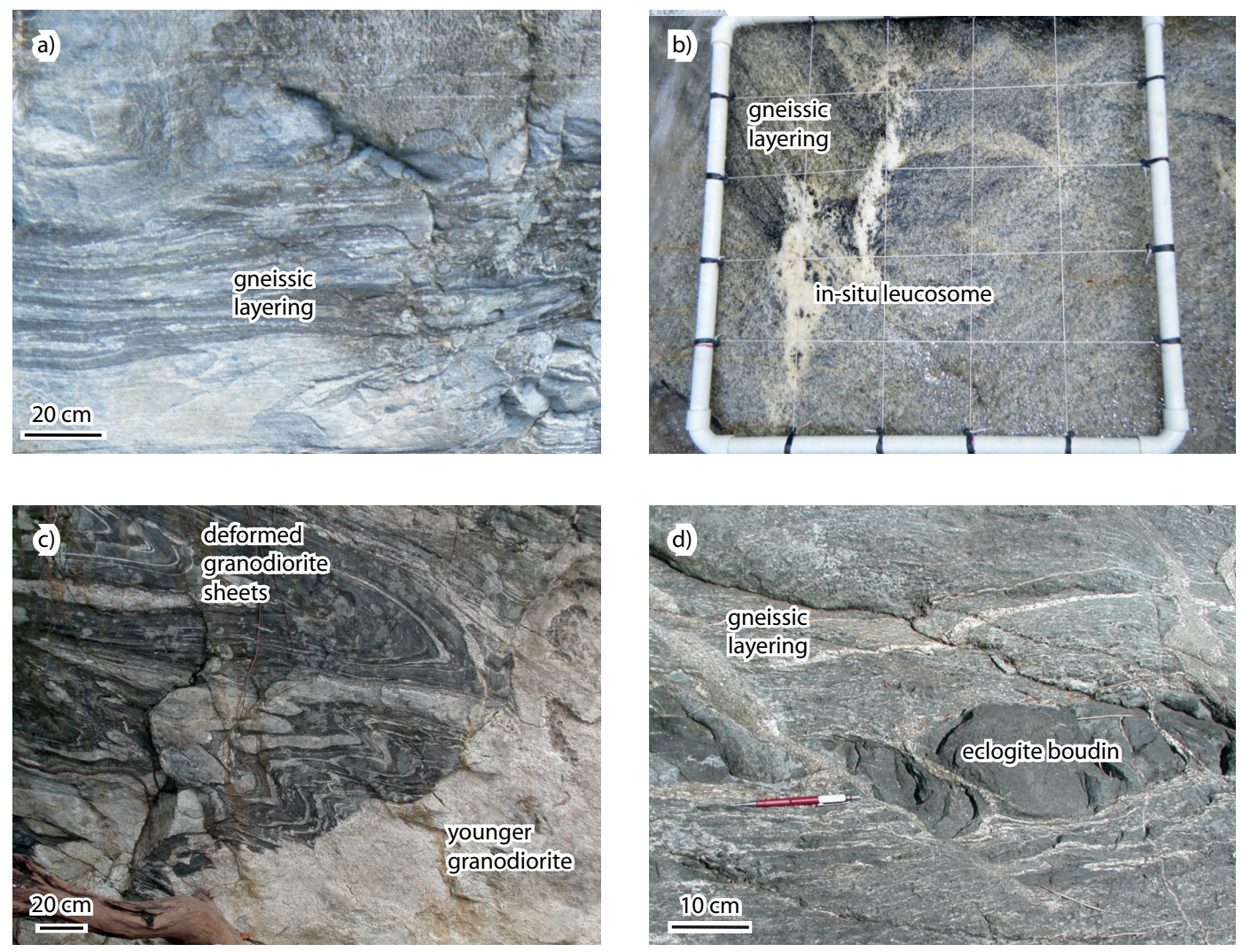

Figure 2.5 Photographs of typical lithologies in the D'Entrecasteaux Islands. Foliations have been rotated to the horizontal in the photographs. (a) Strongly foliated and lineated carapace zone quartzofeldspathic gneiss (lower Gulawata River gorge, Goodenough Island). (b) Quartzofeldspathic core zone gneiss (southeast Mailolo dome). Note patch of leucosome within the $0.25 \mathrm{~m} x$ $0.25 \mathrm{~m}$ grid. (c) Strongly deformed dm-thick granodiorite foliation-parallel sheets (upper left) with zircon U-Pb age of $3.00 \pm 0.02 \mathrm{Ma}$ ( $2 \sigma$; Gordon et al., in review). Relatively less deformed (younger) granodiorite intrusion with zircon $\mathrm{U}-\mathrm{Pb}$ ages of $\sim 2.4 \mathrm{Ma}$ (single zircon ages range from $2.418 \pm 0.004$ Ma to $2.482 \pm 0.007 \mathrm{Ma}$; $2 \sigma$; Gordon et al., in review). Lower Mwadeia River gorge, Mailolo dome. (d) Core zone quartzofeldspathic gneiss with mafic eclogite boudins (southwest Goodenough Island). 
being thoroughly retrogressed to an amphibolite-facies assemblage (Baldwin and Ireland, 1995).

The timing of the main phase of amphibolite-facies metamorphism and ductile deformation in the lower crust in the Goodenough and Mailolo domes has been constrained to $3.5-2.4 \mathrm{Ma}$. Baldwin and Ireland (1995) dated zircons from two samples of felsic gneiss in the Goodenough dome by the U-Pb method using a sensitive high-resolution ion microprobe, and determined ages of $2.63 \pm 0.16 \mathrm{Ma}$ $(2 \sigma)$ and $2.72 \pm 0.28 \mathrm{Ma}(2 \sigma)$ respectively. These ages are interpreted to represent the timing of metamorphic zircon growth subsequent to the eclogite-facies metamorphism (Baldwin and Ireland, 1995). Gordon et al. (in review) dated zircons from pre- to syn-kinematic granodioritic gneiss from the Mailolo dome by $\mathrm{U}-\mathrm{Pb}$ chemical-abrasion thermal ionization mass spectrometry, thereby bracketing the timing of the main phase of the amphibolite-facies deformation. A strongly deformed granodioritic orthogneiss from the core zone of the Mailolo dome yielded a $\mathrm{U}-\mathrm{Pb}$ age range of $3.41 \pm 0.02 \mathrm{Ma}$ to $3.50 \pm 0.01 \mathrm{Ma}(2 \sigma)$. A deformed granodioritic orthogneiss (expressed in foliation-parallel sheets) from the carapace zone of the Mailolo dome yielded a weighted mean U-Pb zircon age of $3.082 \pm 0.007 \mathrm{Ma}(2 \sigma$; MSWD $=0.56$; five zircons), and a nearby granodioritic dike yielded a U-Pb zircon age of $3.00 \pm 0.02 \mathrm{Ma}(2 \sigma$; two zircons). A relatively undeformed granodioritic dike from the same location yielded a U-Pb zircon age range of $2.418 \pm 0.004 \mathrm{Ma}$ to $2.482 \pm 0.007 \mathrm{Ma}(2 \sigma)$. The latter ages are interpreted to date the timing of the final stages of the amphibolite-facies foliation development in the gneiss domes (Gordon et al., in review).

These domes were intruded by granodiorite and leucogranodiorite dikes and plutons of Pilocene age during the main deformation event in the lower crust (Fig. 2.5b,c; Hill et al., 1995; Little et al., 2011 and ref. therein). Outcrop and microscale observations indicate that partial melting and granitic dike intrusion took place at the same time as amphibolite-facies deformation, and continued as the rocks were emplaced in the upper crust as gneiss domes (Little et al., 2011). The host gneisses preserve segregated partial melt as leucosomes, which are more abundant in the core region of the domes relative to the carapace zone (Fig. 2.5b). I have quantitatively estimated the amount of crystallized melt in leucosomes exposed in outcrop using a 
$0.25 \mathrm{~m} \times 0.25 \mathrm{~m}$ grid after Solar (2008; Fig. 2.5b). The percentage of total leucosome content in outcrop was determined for 11 outcrops of quartzofeldspathic gneiss in the Goodenough and Mailolo gneiss domes. The ImageJ image analysis software package was used to calculate the area of crystallized partial melt in images of two outcrops of core zone rock from the Goodenough dome, one outcrop of carapace zone rock from the Goodenough dome, and eight outcrops of core zone rock from the Mailolo dome (Abramoff et al., 2004). I assume that the 2-D amount of partial melt at outcrop is an accurate representation of the 3-D volume percent of the migmatite component at each outcrop. If this assumption is valid, the calculated area of crystallized partial melt represents the percentage that the bulk rock was affected by partial melting (Solar, 2008). These percentages are biased by the location of rock exposure throughout the Goodenough and Mailolo dome that was free of plant material and available for imaging. The Goodenough dome contains $\sim 2 \%$ in-situ crystallized melt content in the carapace zone, increasing to $>20 \%$ in the dome's central core zone. The carapace and core zone in the Mailolo dome contains $5-15 \%$ in-situ crystallized melt; these data do not allow me to differentiate between the percentage of in-situ crystallized melt between the core and carapace zones of that dome. The widespread presence of a melt phase (leucosomes) in the migmatitic rocks in the D'Entrecasteaux Islands suggests that rocks with a granodioritic composition (gneiss protolith) were once heated to temperatures of $>650{ }^{\circ} \mathrm{C}$, based on the solidi for $\mathrm{H}_{2} 0$-saturated crustal rocks (Hacker, 2006 and ref. therein), and thermal and petrological modeling (Fig. 2.6; Brown, 2008; White, 2008). Crustal rocks will melt is $\sim 700{ }^{\circ} \mathrm{C}$ if an aqueous phase is present, and at $\sim 800{ }^{\circ} \mathrm{C}$ if the crustal rock is 'dry' (Fig. 2.6; Brown, 2008; Clemens and Watkins, 2001; England and Thompson, 1986; White, 2008). Little et al., (2011) interpret the crystallized partial melt to have been the result of decompression melting of the rocks during their rapid ascent. The last stage of granodioritic dike intrusion may have occurred at $\sim 2 \mathrm{Ma}$, when large (km-scale) granitic plutons such as the Omara pluton in Fergusson Island were intruded (U-Pb ion microprobe zircon ages of $1.98 \pm 0.08 \mathrm{Ma}$;

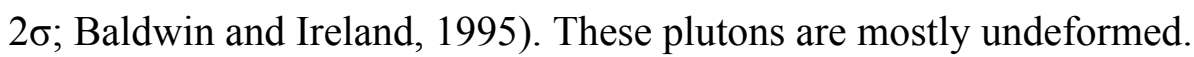

${ }^{40} \mathrm{Ar} /{ }^{39} \mathrm{Ar}$ ages calculated by Baldwin et al. (1993) on white mica and biotite imply rapid cooling of the lower plate gneisses through $400-300{ }^{\circ} \mathrm{C}$, after they arrived in the upper crust and became emergent in the Plio-Pleistocene (Little et al., 2011). 


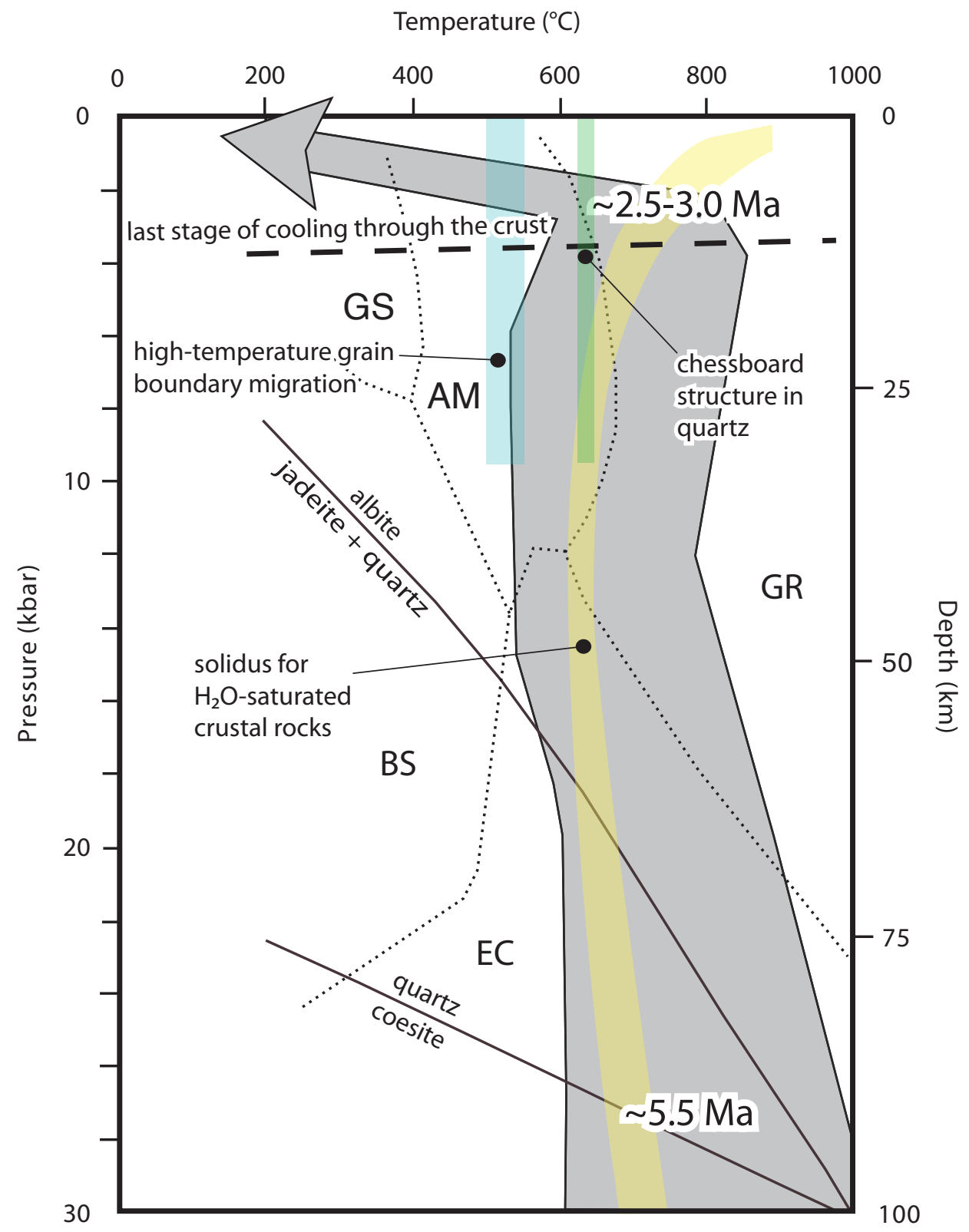

Figure 2.6 Grey shaded area shows pressure-temperature (P-T) path from the mantle to the surface of the ultrahigh-pressure gneisses in the Mailolo dome in the D'Entrecasteaux: GS, greenschist; AM, amphibolite; BS, blueschist; EC, eclogite; GR, granulite. Adapted from Baldwin et al. (2004, 2008) and Little et al. (2011). Timing of eclogite-facies ( $5 \mathrm{Ma}$ ) and amphibolite-facies metamorphism (2.5 - $3.0 \mathrm{Ma}$ ) after Chapter 3 this thesis and Gordon et al. (in review). Exhumation path after P-T data from Hill and Baldwin (1993). P-T data of high-temperature grain boundary migration ( $>500-$ $\left.550^{\circ} \mathrm{C}\right)$ and chessboard subgrains structure $\left(630 \pm 30^{\circ} \mathrm{C}\right)$ after Stipp et al. (2002). P-T data for the solidus for $\mathrm{H}_{2} \mathrm{O}$-saturated crustal rocks after Hacker (2006) and Little et al. (2011). Note that this study is specifically concerned with the last stage of cooling through the crust, above the thick black dashed line. 
White mica and biotite typically yield ${ }^{40} \mathrm{Ar} /{ }^{39} \mathrm{Ar}$ plateau and isochron ages of $3.0-$ 1.5 Ma and 1.9 - 1.4 Ma respectively, a near concordance that indicates rapid cooling of the granodiorites and basement rock after 3.0 - 2.0 Ma (Baldwin et al., 1993). The similarity between the white mica and phengite ${ }^{40} \mathrm{Ar} /{ }^{39} \mathrm{Ar}$ cooling ages and the biotite ${ }^{40} \mathrm{Ar} /{ }^{39} \mathrm{Ar}$ cooling ages indicates that this final cooling was rapid $\left(>100{ }^{\circ} \mathrm{C} \mathrm{Ma}^{-1}\right.$; Baldwin et al., 1993). Apatite fission track analysis yields ages of 0.4 $-0.1 \mathrm{Ma}$, suggesting a late deceleration in cooling rates such that final cooling of the rocks to below $130^{\circ} \mathrm{C}$ was at $<0.4 \mathrm{Ma}$.

Quartz in the gneisses has abundant deformation bands or sweeping undulose extinction structures, and typically exhibits strongly interlobate to amoeboid grainboundary microstructures. These microstructures imply recovery via hightemperature grain-boundary migration recrystallization (GBM), followed by rapid textural quenching and little or no subsequent static recrystallization (Fig. 2.7a; Little et al., 2011). Quartz grains are typically inequigranular and range in diameter from 75 to $>1000 \mu \mathrm{m}$, with an average grain size range of $200-500 \mu \mathrm{m}$. Chessboard subgrain structures are common. The latter microstructure is through to form at deformational temperatures of $630 \pm 30^{\circ} \mathrm{C}$ (Fig. 2.6, 2.7b; Blumenfeld et al., 1986; Kruhl, 1996; Stipp et al., 2002). Quartz in the quartzofeldspathic gneiss commonly occurs as aggregates. In contrast, quartz grains in the eclogites are isolated by eclogite-facies minerals and are therefore sparse and generally isolated from one another.

\subsection{Models for gneiss dome emplacement}

Gneiss domes, including metamorphic core complexes, can be defined as domal structures cored by metamorphic rocks that exhibit an outwardly dipping foliation or gneissic layering (Whitney et al., 2004; Yin, 2004). A high-grade core mantled by a carapace typically characterizes such structures, the latter of which may be lowergrade (Tirel et al., 2004; Whitney et al., 2004). Gneiss domes and metamorphic core complexes are common in exhumed orogenic belts dating back to the Archean, and 

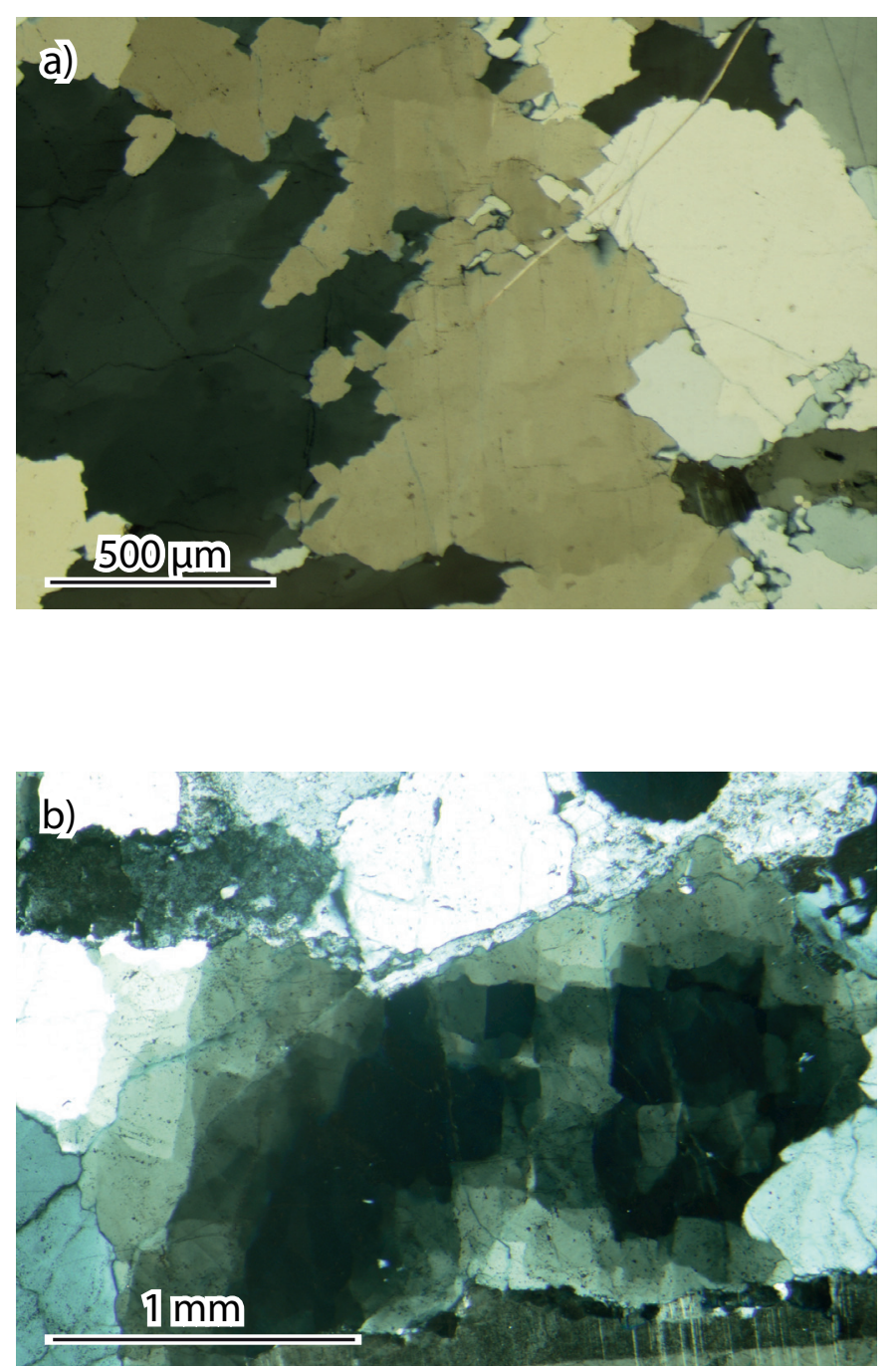

Figure 2.7 (a) Photomicrograph of quartz grains showing strongly interlobate to amoeboid grain boundary microstructures, suggesting recovery via high-temperature grain boundary migration recrystallisation (09-022a; quartz band from the core zone of the Mailolo dome, northern Fergusson Island). (b) Photomicrograph of quartz grains showing chessboard subgrain structure (09-062c; granodioritic dike from the core zone of the northwest Normanby dome, northwest Normanby Island). 
reflect the flow of mobile lower crustal rocks as a result of buoyant and isostatic stresses (Teyssier and Whitney, 2002; Tirel et al., 2004; Whitney et al., 2004).

Previous workers have proposed differing models for how the UHP-bearing gneiss domes in the D'Entrecasteaux Islands were emplaced from the lower crust to shallow crustal depths. Hill et al. $(1992,1994,1995)$ and Baldwin et al. (2005) argue that normal slip on long-lived and deeply penetrating detachment faults has translated the (U)HP rocks from the mantle to the surface to form Cordillera-style asymmetric metamorphic core complexes (Fig. 2.2b). These authors suggest that the juxtaposition of the nearly un-metamorphosed Cenozoic Papuan Ultramafic Body in the hanging wall of these detachments structures against the complexly deformed metamorphic rocks in the footwall implies huge displacement along the detachment surface (enough to exhume the UHP eclogites). Assuming a fault dip of $40^{\circ}$ and an original depth of $90 \mathrm{~km}$ from the presence of coesite in one sample, the displacement could be $>100 \mathrm{~km}$ (Baldwin et al., 2008). More recently, Webb et al. (2008) suggest that counterclockwise rotation of the Woodlark microplate relative to the Australian plate has caused Neogene subduction inversion and exhumation of the (U)HP rocks along the inactive Papuan suture (Owen Stanley fault zone). By contrast, pure-shear dominated symmetric doming was first suggested for crustal emplacement by Davies and Warren (1988; Fig. 2.2a), and was modeled by Martinez et al. (2001). A recent field-based structural and microstructural study by Little et al. (2011) suggests that the exhumation of the gneiss domes through the crust was accomplished by pureshear symmetric doming in conjunction with diapirism. These latter workers interpret the normal faults that currently bound sections of the D'Entrecasteaux Islands as relatively late-stage, normal faults that are related to the Woodlark Rift and post-date most of the (U)HP exhumation and dome formation. This interpretation implies that these faults are not long-lived, high-displacement detachment faults, and were not responsible for exhumation of rocks from mantle depths in the D'Entrecasteaux Islands.

The key difference between these two end-member models is the ratio of vertical to horizontal flow within the domes and the asymmetry of the expected crustal exhumation patterns (Whitney et al., 2004). Pure-shear symmetric doming (including diapirism) is the result of largely upward flow that results from buoyancy and 
isostatic stresses of the upwardly emplaced, partially molten gneisses (Teyssier and Whitney, 2002; Whitney et al., 2004; Yin, 2004). By contrast, detachment-style asymmetric metamorphic core complexes are thought to result largely from lateral movement of the lower plate along a dipping major detachment fault (Tirel et al., 2004; Yin, 2004). This motion may result in tectonic unloading of the footwall, causing a corresponding isostatic uplift of the footwall relative to the hangingwall (Tirel et al., 2004). This uplift can potentially lead to a 'rolling hinge' evolution of a back-tilted detachment surface, which becomes inactive (Tirel et al., 2004; Tirel et al., 2008). This latter model therefore has a high component of horizontal flow. Where the degree of partial melting and/or magmatism is high or where exhumation rates are rapid, thermomechanical modeling suggests that pure-shear doming is dominant (Rey et al., 2009; Teyssier and Whitney, 2002; Tirel et al., 2008; Whitney et al., 2004).

The previously discussed kinematic models predict contrasting patterns of relative exhumation and cooling rates in gneiss domes. In pure-shear dominated symmetric doming the rates of exhumation are predicted to be fastest near the center of the dome where the deepest exhumation levels will occur and to decrease outwardly in all directions away from this central exhumational locus (Fig. 2.2a; Burg et al., 2004; Whitney et al., 2004). Pure-shear doming may therefore lead to a concentric or "bulls-eye" pattern of relative exhumation levels in map view (Burg et al., 2004). By contrast, gneiss domes that have been exhumed asymmetrically through the crust in the footwall of a Cordillera-style metamorphic core complex are predicted to expose the deepest and most recently exhumed structural levels adjacent to the major detachment that bounds the dome on one side (Burg et al., 2004; Tirel et al., 2004). Shallower exhumation levels within metamorphic core complexes will crop out in the footwall with increasing distance away from the dome-bounding fault in the direction of fault transport (Fig. 2.2b; Tirel et al., 2004). 


\subsection{Theory of the Ti-in-quartz geothermometer and analytical technique}

\subsubsection{The Ti-in-quartz geothermometer (TitaniQ)}

The chemical potential of $\mathrm{Ti}$ and the extent of Ti substitution into the tetrahedral site within quartz are predicted to vary systematically with temperature and pressure (Thomas et al., 2010; Wark and Watson, 2006). The Wark and Watson (2006) experimentally calibrated geothermometer predicts that an increase in Ti content in quartz corresponds to an increase in temperature, based on the exchange reaction $S i^{4+} \Leftrightarrow T i^{4+}$ for quartz and rutile. Based on comparison of TitaniQ results with other data sets such as Zr-in-sphene thermometer, Wark and Watson (2006) inferred that there was no pressure dependency for the temperature range over which they synthesized quartz $\left(600-1000{ }^{\circ} \mathrm{C}\right)$. The TitaniQ was therefore calibrated at a uniform pressure of 10 kbar. Later, Thomas et al. (2010) argued that an increase in pressure would result in volumetric changes affecting the tetrahedral sites within quartz, and therefore in reduced substitution of Ti for Si within quartz. This decrease in the solubility of Ti in quartz with increasing pressure implies that the TitaniQ is both temperature- and pressure-dependent (Thomas et al., 2010). Depending on the geothermal gradient, the decrease in solubility for the pressure-sensitive calibration of the TitaniQ would result in reduced substitution of $\mathrm{Ti}$ for $\mathrm{Si}$ in quartz as a function of temperature, relative to the earlier pressure invariant $(10 \mathrm{kbar})$ experimental calibration (Thomas et al., 2010). Both calibrations predict that an increase in $\mathrm{Ti}$ content in quartz will result in an increase in TitaniQ apparent temperatures. In order to ascertain whether the two TitaniQ calibrations would lead to different spatial gradients in apparent temperatures, I calculated TitaniQ apparent temperatures for the dense suite of samples from the Goodenough gneiss dome using both the Wark and Watson (2006) and the Thomas et al. (2010) calibrations. In this comparison I include an incremental pressure correction to account for the difference in structural depth of the foliation, which is assumed to have once been horizontal (Little et al., 2011).

There are two main assumptions that must be met if an apparent temperature calculated by the TitaniQ can be interpreted as the temperature associated with the 
cessation of Ti mobility in the sampled quartz grains. First, the TitaniQ assumes that there was no diffusion of $\mathrm{Ti}$ after equilibration of $\mathrm{Ti}$ within quartz at the temperature of interest (Wark and Watson, 2006). Secondly, the Ti activity coefficient within quartz must be known (Wark and Watson, 2006). If the Ti activity is poorly constrained in rocks that lack rutile, then the TitaniQ will only yield a minimum temperature estimate (Wark and Watson, 2006). It is possible that the rutile and quartz present in a given rock did not equilibrate at the same time or metamorphic conditions, leading to potential ambiguity in the Ti activity coefficient (Thomas et al., 2010). It is therefore prudent to ensure that the reaction history is fully understood before interpreting spatial gradients in TitaniQ apparent paleotemperatures.

\subsubsection{Analytical procedure and apparent temperature calculation}

Grain-scale physical processes that may have lead to Ti mobility and/or equilibration in quartz grains includes volume diffusion, recrystallization, or quartz grain growth (Kohn and Northrup, 2009; Spear and Wark, 2009; Wark and Watson, 2006). Constraining the microstructural context of any $\mathrm{Ti}$ content variation within or between quartz grains is an important step towards understanding which of these grain-scale processes is dominant in the quartz grains of samples in the D’Entrecasteaux Islands (Spear and Wark, 2009). Cathodoluminescence (CL) imaging was therefore carried out on 20 of the 90 samples analyzed for Ti content here, using the JEOL JXA-8230 electron probe microanalyzer with an XCLent Combined Cathodoluminescence and X-ray microanalyzer at Victoria University of Wellington, New Zealand. Variation in intensity of the CL at the $415 \mathrm{~nm}$ wavelength has been predicted to be proportional to the concentration of Ti within quartz (Spear and Wark, 2009). Thus, this wavelength was used for imaging in order to evaluate the degree of homogeneity and microstructural context of $\mathrm{Ti}$ variation within the quartz grains (intra-granular variation or zoning) and between one grain and another (inter-granular variation). Sharp boundaries between zones of relatively higher and lower Ti content in a single quartz grain may suggest that some partial diffusion of Ti has taken place inside the crystal, or that primary growth zonation is preserved. Insignificant zoning implies homogenization of $\mathrm{Ti}$ content during either growth or recrystallization of the grain at near constant temperatures, or at a later time as a 
result of pervasive diffusion subsequent to that growth (Spear and Wark, 2009). Five representative rock types were analyzed with CL: quartzofeldspathic gneiss, migmatitic quartzofeldspathic gneiss, eclogite, retrogressed eclogite, and metamorphosed granodiorite or leucogranodiorite. Four representative samples of each of these rock types were chosen for CL analysis from localities throughout the Goodenough, Mailolo, and northwest Normanby dome (Fig. 2.3). In order to target variations in $\mathrm{Ti}$ content in quartz, CL images were processed by isolating the best peak near $415 \mathrm{~nm}$ (Appendix A; Spear and Wark, 2009). CL imaging used an accelerating voltage of $20 \mathrm{kV}$, a probe current of $50 \mathrm{nA}$, and a dwell time of 40 seconds.

Ti-in-quartz analyses were carried out on an Agilent 7500 CS inductively coupled plasma mass spectrometer with a New Wave $193 \mu \mathrm{m}$ solid-state Nd-YAG laser at Victoria University of Wellington, New Zealand. This study analyzed 68 samples of metamorphic granitic rock and quartzofeldspathic gneiss, 14 samples of strongly deformed foliation-parallel quartz veins that are embedded within such gneisses, and seven samples of quartz grains in eclogite boudins (Fig. 2.3). Samples were chosen to ensure a complete spread across both the carapace and core structural zones of Goodenough, Mailolo, Morima, and northwest Normanby dome. Samples were cut into $<5 \mathrm{~mm}$ squares and mounted into polished epoxy briquettes $(25 \mathrm{~mm}$; Appendix B.1). The mounts were then carbon-coated and imaged using back-scattered electrons on the JEOL JXA-8230 electron probe microanalyzer at Victoria University of Wellington, New Zealand, to select locations for LA-ICP-MS. Backscattered electron imaging was carried out with an accelerating voltage of $15 \mathrm{kV}$ and a current of $12 \mathrm{nA}$. The quartz grains analyzed by this study were $>75 \mu \mathrm{m}$ in diameter, which is the resolution of the LA-ICP-MS. Analytical spots were scattered as far apart as possible in the mount, in an attempt to obtain a spatially-averaged mean Ti concentration for the sample as a whole.

Mean Ti concentrations were calculated by averaging up to eight spot analyses per sample (Table 2.1). In 54\% of the samples, less than the full suite of eight spot analyses was included in the mean Ti concentrations because inclusion of extraneous mineral phases sometimes led to the rejection of one or more of the spot analyses. On average, seven spots were analyzed per sample. Wherever possible, spot analyses 


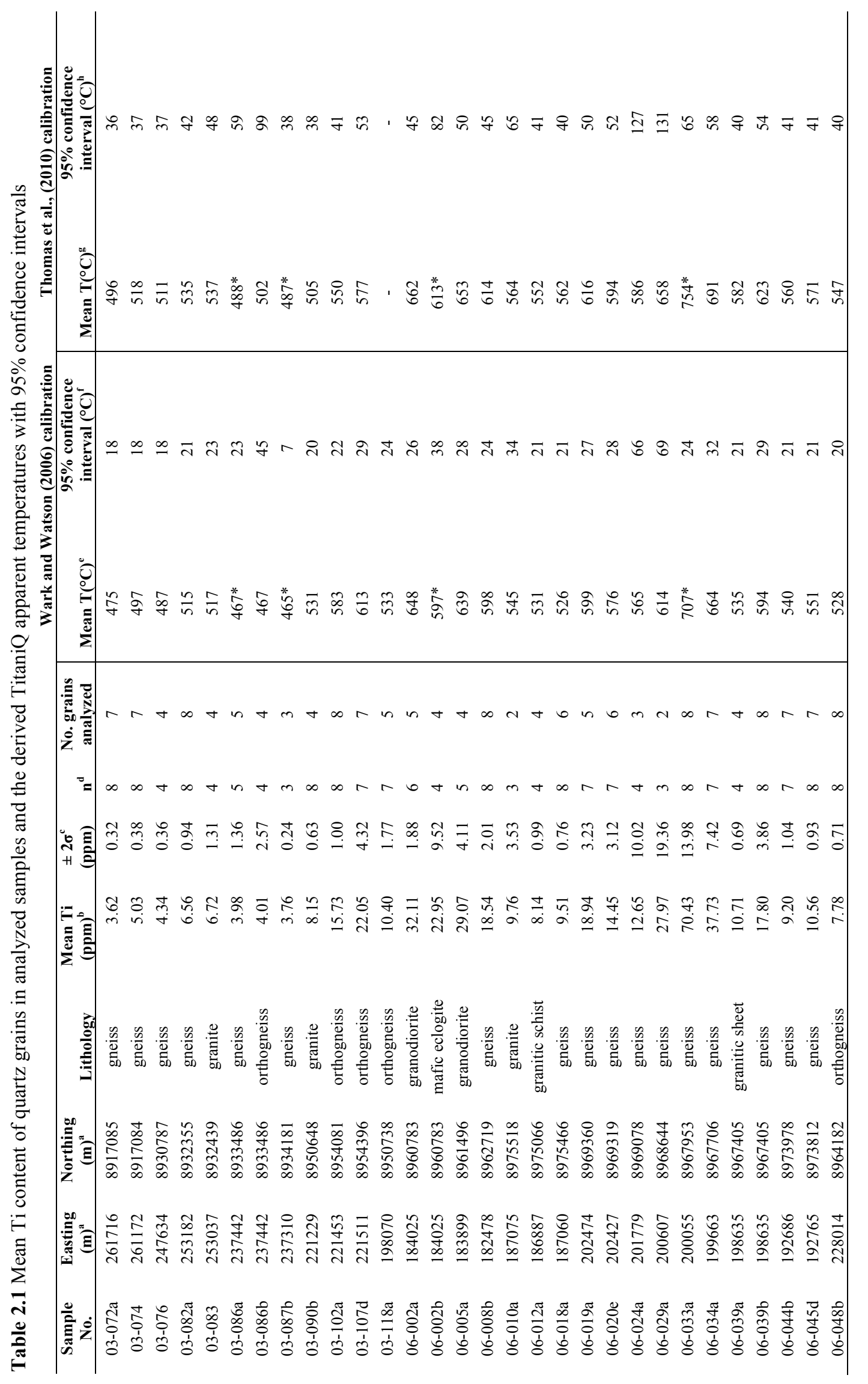




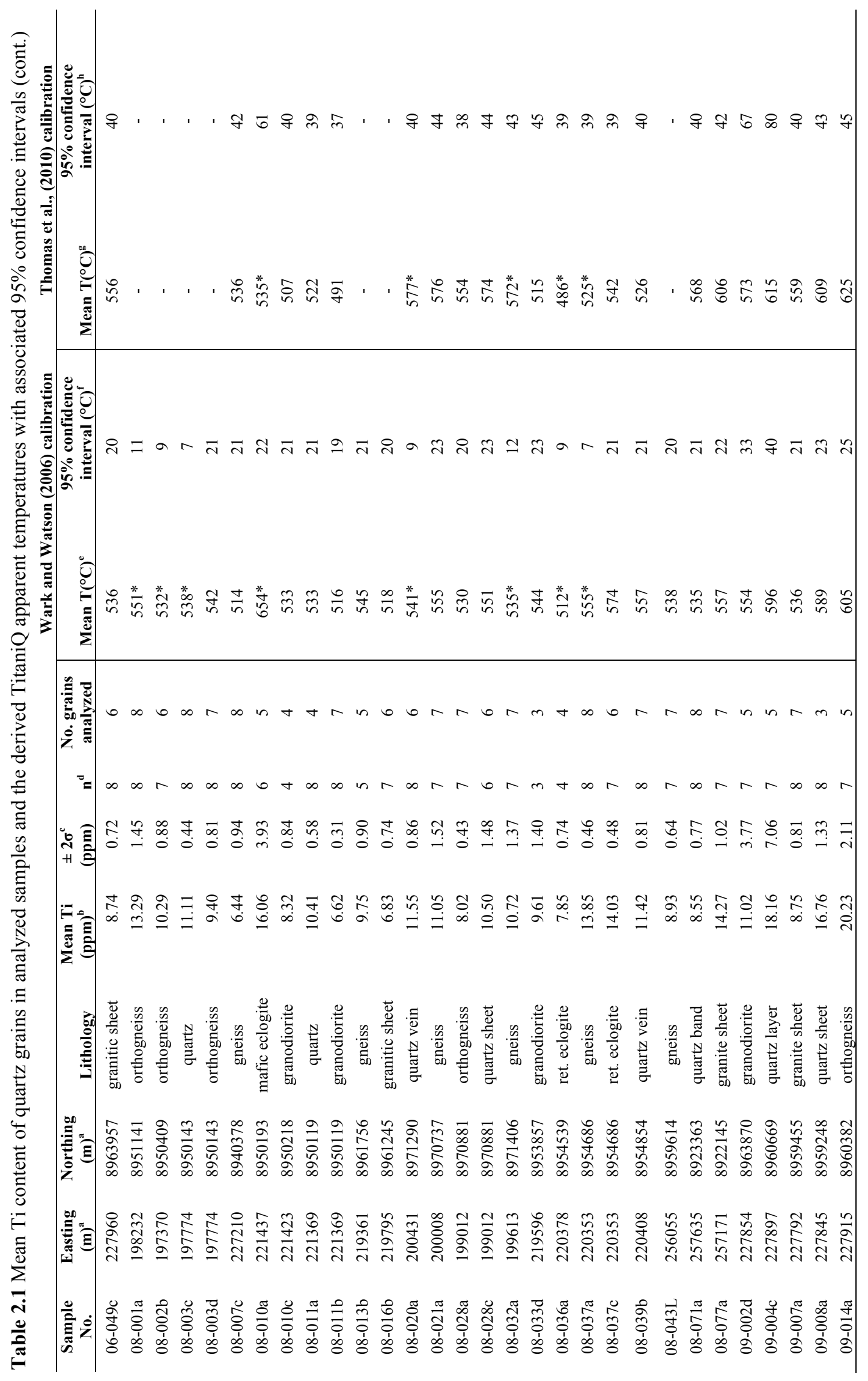




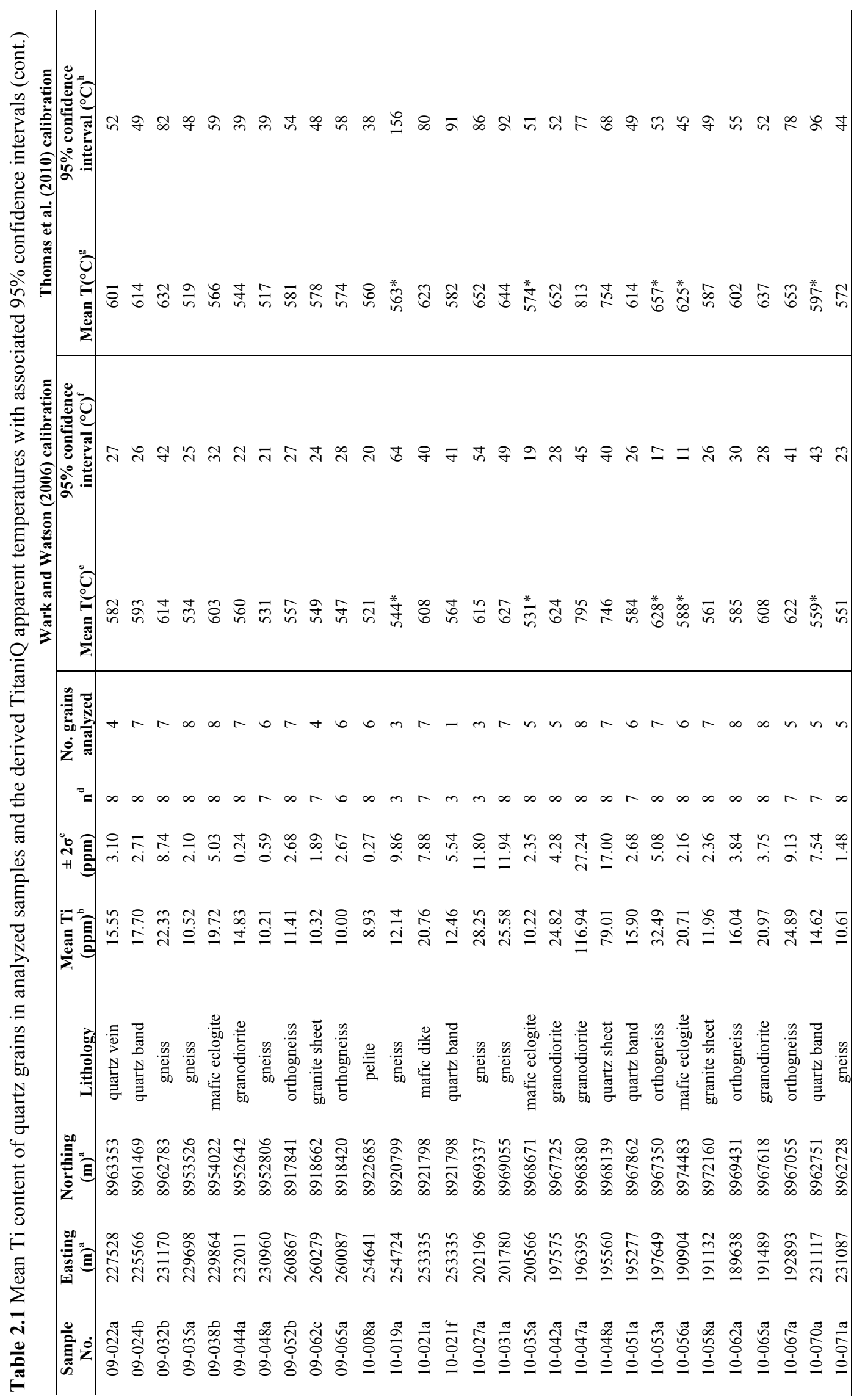




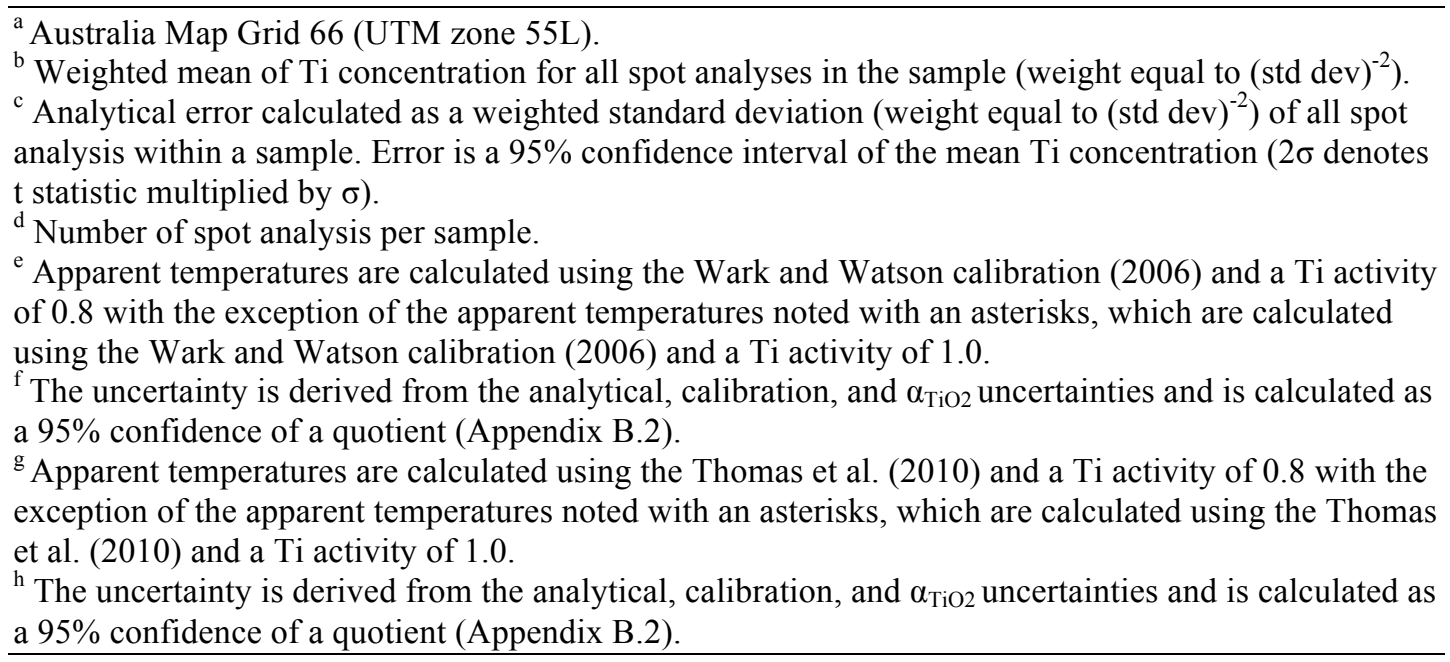

were taken from both the rim and core of up to four different quartz grains to yield eight spot analyses. This was successfully undertaken on $22 \%$ of the samples analyzed here. On average six quartz grains were analyzed per sample (Table 2.1). The high number of quartz grains that do not include separate core and rim spot analyses resulted from several analytical limitations: (1) rejection of contaminated signal ( $42 \%$ ), (2) fracturing during ablation destroying the rim or core of the grain analyzed $(\sim 32 \%)$, and (3) small grain size $(<125 \mu \mathrm{m})$ allowing only one ablation pit per grain $(\sim 26 \%)$.

The mean concentration of $\mathrm{Ti}, \mathrm{Al}, \mathrm{Si}$, and $\mathrm{Ca}$ in quartz was calculated relative to the National Institute of Standards and Technology standard reference material 612 (NIST 612), which was analyzed under near-identical conditions to the quartz grains (Appendix B.1). The LA-ICP-MS was tuned before every analytical run to ensure a high stability and sensitivity of the NIST 612 standard, and a good interaction of the laser with the target (Appendix B.1). Each analytical run was arranged using standard-sample bracketing; four unknown analyses were bracketed by two NIST 612 standard analyses. Consistency of ${ }^{47} \mathrm{Ti} /{ }^{29} \mathrm{Si}$ and ${ }^{43} \mathrm{Ca} /{ }^{29} \mathrm{Si}$ were monitored during data processing as variations in these ratios suggest there was ablation of an undesirable mineral phase.

For each spot analysis, an average signal and (two) standard deviation of the ${ }^{47} \mathrm{Ti}$, ${ }^{27} \mathrm{Al},{ }^{29} \mathrm{Si}$, and ${ }^{43} \mathrm{Ca}$ beam were calculated using an unpublished MATLAB ${ }^{\mathrm{TM}}$ script written by Euan Smith (Victoria University of Wellington). Background for all beams were measured and subtracted from the signal of each spot analysis prior to 
calculation of the Ti concentration. The background-corrected signal for every spot analysis was converted into a Ti concentration using the equation:

Sample $[\mathrm{i}]=($ Sample CPS / average bracketing STD CPS $) \times$ ref. [element]

where [i] is the concentration in ppm by weight of the element of interest, Sample CPS is the counts per second or signal of the element of interest, average bracketing STD CPS is the average of the counts per second or signal of the NIST 612 analyses that bracket the unknown, and the ref. [element] is the GeoReM (http://georem.mpch-mainz.gwdg.de/) preferred concentration of the element of interest. The mean Ti concentration in quartz for each sample quoted in Table 2.1 was calculated as the weighted mean of all analyses (up to eight) of the sample (weight equal to std $\mathrm{dev}^{-2}$ ). The uncertainty of the mean Ti concentration (standard error) was calculated by pooling the weighted residuals. The $95 \%$ confidence interval of the mean Ti concentration (quoted as $2 \sigma$ in Table 2.1) is given by: $\pm \mathrm{t} \times$ (weighted standard error), where $t$ is the Student's $t$ statistic for $95 \%$ with (n-1) degrees of freedom ( $\mathrm{n}$ is the number of data).

Determining the Ti activity $\left(\alpha_{\mathrm{TiO}_{2}}\right)$ is a prerequisite to the use of the TitaniQ to measure paleo-temperatures of $\mathrm{Ti}$ equilibration in quartz. Thin-sections for each sample (90 in total) were examined optically to determine the Ti-bearing phase that co-exists with quartz. Typically, these include rutile, ilmenite, or titanite. If rutile is present, the sample was assigned a $\alpha_{\mathrm{TiO}_{2}}$ of $1.0(\mathrm{n}=17,19 \%$ of the samples analyzed). Previous studies have determined that crustal rocks with have a $\alpha_{\mathrm{TiO}_{2}} \geq$ 0.6 , and felsic rocks with an amphibolite-facies mineral assemblage that includes ilmenite or rutile will have a $\alpha_{\mathrm{TiO}_{2}} \geq 0.8$ (Ghent and Stout, 1984; Wark and Watson, 2006). I assigned titanite- and ilmenite-bearing samples a $\alpha_{\mathrm{TiO}_{2}}$ of 0.8 with an uncertainty \pm 0.2 (inferred as $2 \sigma$ ) to account for possible heterogeneities in $\mathrm{Ti}$ activity within and between samples (Ghent and Stout, 1984; Kohn and Northrup, 2009). Even if the Ti activity values chosen here are not accurate, this study is chiefly concerned with determining spatial gradients in apparent temperatures and does not rely on accurate absolute temperatures. As long as all similar mineral assemblages were assigned the same activity, any inaccuracies in the assigned activity should not adversely affect the spatial trends presented here. 
Ti concentration was internally corrected during data reduction with respect to $\mathrm{Si}$. The equations used for this correction can be written as:

$$
[S i]_{S m p l}=[S i]_{S t d} \times \frac{C P S_{S m p l}}{C P S_{S t d}}
$$

and

$$
[T i]_{S m p l}=[T i]_{S t d} \times \frac{C P S_{S m p l}}{C P S_{S t d}}
$$

where $[i]_{\text {Smpl }}$ is the concentration of the element of interest in the sample or unknown, [i] $]_{\text {Std }}$ is the concentration of the element of interest in the standard, and $\mathrm{CPS}_{\mathrm{i}}$ is the counts per second or signal of the sample or standard. $\mathrm{SiO}_{2}$ is by far the major oxide in quartz and therefore has an assumed value of $100 \%$ for a pure quartz grain. If the measured $\mathrm{Si}$ concentration is less than $100 \%$ during analysis, this secondary internal correction for Si increases the Ti concentration of the unknown by a proportional amount.

After measuring Ti concentrations, TitaniQ apparent temperatures were calculated using the Wark and Watson (2006) calibration:

$$
T\left({ }^{\circ} \mathrm{C}\right)=\frac{-3765}{\log \left[\frac{X_{T i}^{Q t z}}{\alpha_{T i O_{2}}}\right]-5.69}-273
$$

where $X_{T i}^{Q t z}$ is the $\mathrm{Ti}$ concentration in quartz in ppm by weight and $\alpha_{\mathrm{TiO}_{2}}$ is the activity of $\mathrm{TiO}_{2}$ in the system $\left(\alpha_{T_{T i O}}=1\right.$ for rutile; $\alpha_{T i O_{2}}=0.8 \pm 0.2$ for other $\mathrm{Ti}$ phases as above). TitaniQ apparent temperatures were also calculated using the Thomas et al., (2010) calibration:

$$
T\left({ }^{\circ} C\right)=\frac{60952+1741 P}{1.52-R \ln X_{T i O_{2}}^{Q t z}+R \ln \alpha_{T_{i O_{2}}}}-273.15
$$

where $\mathrm{P}$ is the inferred pressure in kbar, $R$ is the gas constant $8.3145 \mathrm{~J} \mathrm{~K}^{-1}, X_{\mathrm{TiO}_{2}}^{Q t z}$ is the mole fraction of $\mathrm{TiO}_{2}$-in-quartz (calculated using the equation given in Thomas et al., 2010), and $\alpha_{\mathrm{TiO}_{2}}$ is the activity of $\mathrm{TiO}_{2}$ in the system (as per above). For the quartzofeldspathic host gneiss, the pressure value input into equation 2.5 was 7-11 kbar in accordance with existing pressure estimates for the amphibolite-facies 
retrogression in the D'Entrecasteaux Islands, after Hill and Baldwin (1993). Moreover, a further incremental pressure correction between samples collected at different relative structural depths in the domes was made by assuming: (1) prior to doming the foliation was originally horizontal (Little et al., 2011), and (2) that the bulk density of the gneiss sequence is $2700 \mathrm{~kg} \mathrm{~m}^{-3}$ (Harkness, 1891; Hinze, 2003 and ref. therein). This pressure correction takes account of the pressure effect on the $\mathrm{Ti}$ equilibration in quartz inferred to exist by Thomas et al. (2010), in order to compare TitaniQ apparent temperatures for samples collected at different structural levels in the domes. The pressure correction was no more than $0.76 \mathrm{kbar}$ between the deepest and shallowest samples, and was thus minor compared to other variances of $\mathrm{Ti}$ content in these quartz grains.

The 95\% confidence interval for each TitaniQ apparent temperature presented here (Table 2.1) represents a combination of three independent sources of uncertainty. First, there is an uncertainty in least-squares regression analysis carried out during calibration of the Wark and Watson (2006) and the Thomas et al., (2010) TitaniQ on the Ti-in-quartz experimental data (calibration uncertainty; Appendix B.2). Second, there is the LA-ICP-MS analytical precision in the measured Ti concentration, which is quoted at the $95 \%$ confidence level (Appendix B.2). Third, there is the \pm 0.2 uncertainty in $\alpha_{\mathrm{TiO}_{2}}$ that I have assigned to those samples that lack rutile. The uncertainty values shown in Table 2.1 were calculated as a $95 \%$ confidence interval of the quotient:

$\operatorname{var}\left(\frac{A}{B}\right)=\frac{1}{B^{2}} \operatorname{var} A+\frac{A^{2}}{B^{4}} \operatorname{var} B$

where $\mathrm{A}$ is the numerator of equation 2.4 and 2.5 , and $\mathrm{B}$ is the denominator of equation 2.4 and 2.5. See Appendix B.2 for full explanation of this uncertainty calculation.

Over 600 Ti-in-Quartz LA-ICP-MS spot analyses were performed on 90 samples collected from four gneiss domes in the D'Entrecasteaux Islands (Fig. 2.3). The analytical precision for a single spot analysis collected during tuning of the LA-ICPMS was $<15 \%$. Fig. 2.8 illustrates the internal and external precision, and accuracy of all analyses of the National Institute of Standards and Technology standard 


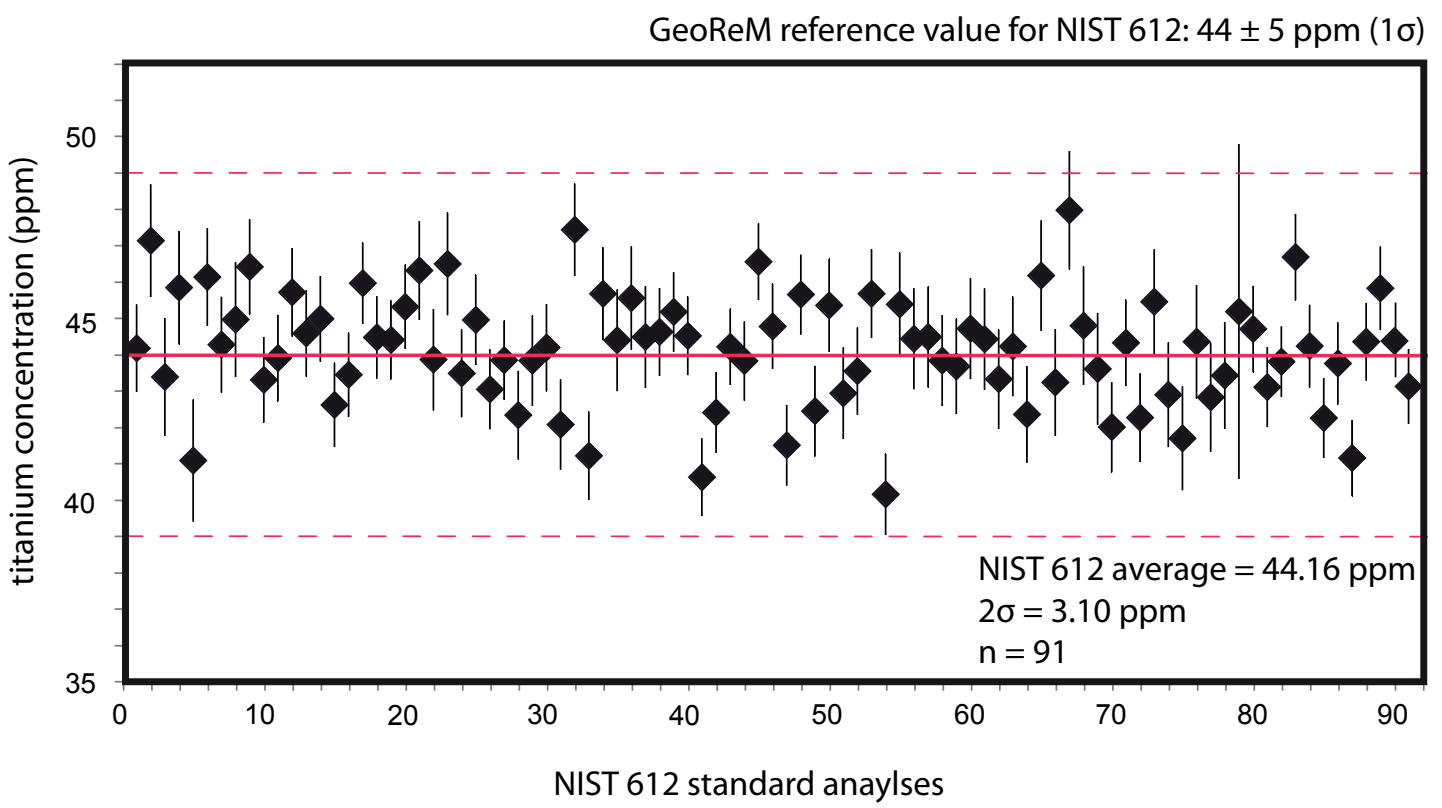

Figure 2.8 Reproducibility of the National Institute of Standards and Technology standard reference material 612 (NIST 612) for all analytical sessions. The internal precision is the $2 \sigma$ of the individual measurements of NIST 612 (error bar for each black diamond), each of which is a repeated measure of $\sim 400 \mathrm{Si}$-corrected Ti integrations. The external precision or reproducibility of analysis is the $2 \sigma$ of all measurement of the NIST 612 titanium concentration $(2 \sigma=3.10 \mathrm{ppm})$. The accuracy of the NIST 612 measurement is the average of all measurements of the NIST $612 \mathrm{Ti}$ concentration (44.16 ppm), and is shown by the solid red line. Reference value and $1 \sigma$ (red dotted line) of the NIST $612 \mathrm{Ti}$ concentration shown here are GeoReM preferred values (http://georem.mpch-mainz.gwdg.de/). 
reference material 612 (NIST 612) standard during the LA-ICP-MS sessions. All measured values of the NIST 612 standard are within the $1 \sigma$ error of the GeoReM preferred value for the Ti concentration in the NIST 612 (44 $\pm 5 \mathrm{ppm})$, and the data exhibit an excellent accuracy of 44.16 ppm (average value of all NIST 612 measurements). Total variation in Ti ppm across all the quartz grains analyzed in this study was 3.76 to $116.94 \mathrm{ppm}$. Analytical results are summarized by sample in Table 2.1, which also lists the calculated TitaniQ apparent temperatures and their associated $95 \%$ confidence intervals.

\subsection{Results of CL Imaging and LA-ICP-MS Ti-in-quartz analysis}

\subsubsection{CL images}

CL images are an efficient way to qualitatively assess any grain-scale variations in $\mathrm{Ti}$ content within and between quartz grains. By analyzing Ti concentrations in selected spots that fall on a given CL image using LA-ICP-MS, I was able to assign a Ti concentration to the CL image intensity scale. The LA-ICP-MS calibrated CL images are used here to estimate the scale of the differences in Ti content, which are implied by the differences in brightness between specific microstructural sites in the CL images. In general, there is no obvious correlation between the microstructural pattern of CL intensity variations and rock type. All five rock types analyzed (quartzofeldspathic gneiss, migmatitic gneiss, eclogite, retrogressed eclogite, leucocratic granodiorite) yielded similar microstructural patterns of CL variation as discussed below.

The CL images imply that the magnitude of intra-granular Ti variation within quartz grains in the D'Entrecasteaux Islands is slight ( $<5$ ppm; Fig. 2.9a,b). In general, the intra-granular CL patterns are typically flat or quasi-homogeneous, with areas of slight higher and lower relative Ti content that I will refer to as "patches" $(<1 \mathrm{ppm}$; Fig. 2.9b). Based on optical microscopy, the patches do not appear to be (sub)grain boundaries. Approximately $35 \%$ of the CL images exhibit resolvable differences of relative Ti content within individual quartz grains. These internal differences in $\mathrm{CL}$ 


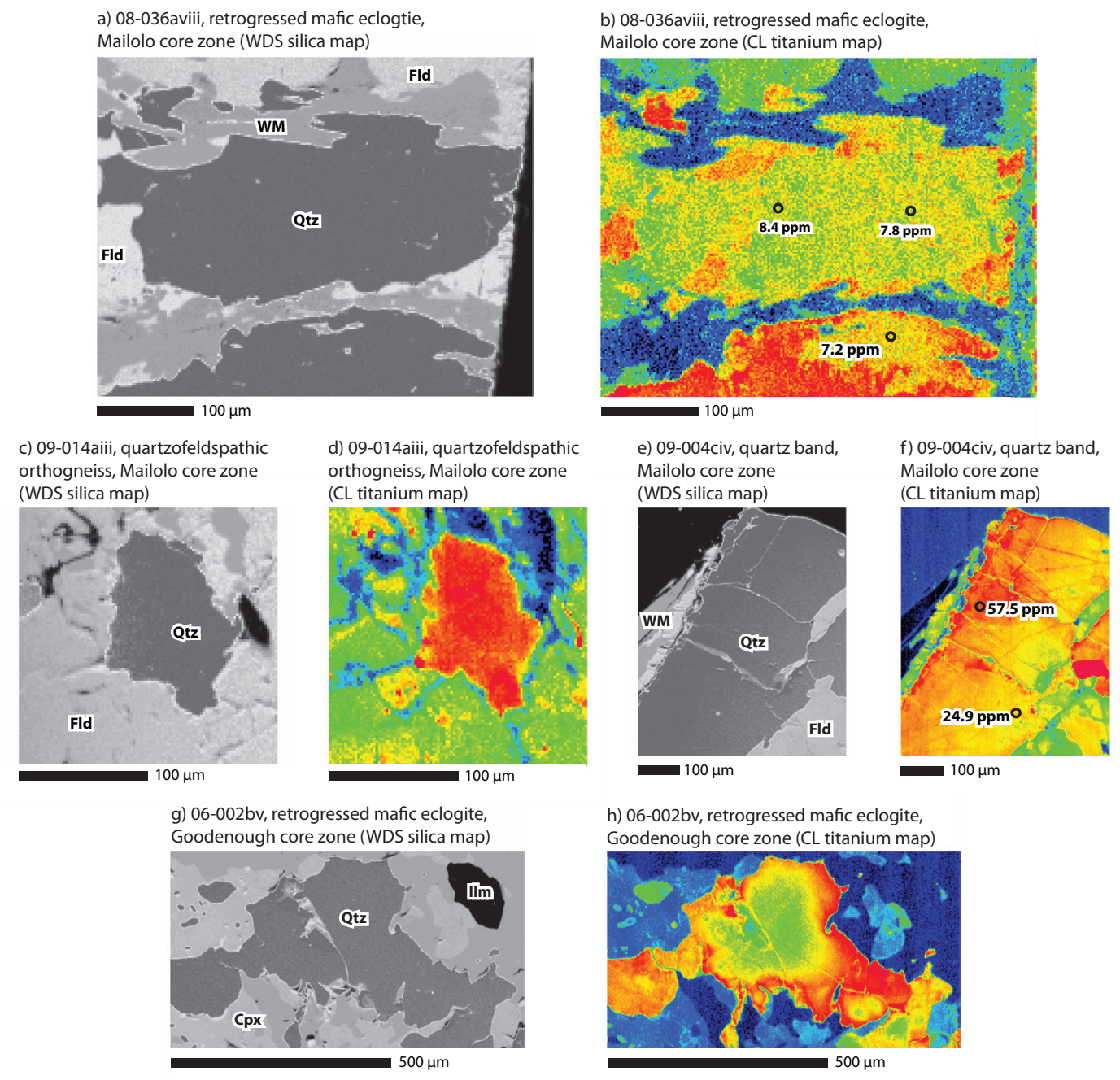

Figure 2.9 Selected wavelength-dispersive spectrometry (WDS; greyscale) and cathodoluminescence (CL; color) images showing intra-granular variation in Ti concentration: Fld, feldspar; Qtz, quartz; WM, white mica; IIm, ilmenite. Warm red colors denote relatively high Ti content and cool blue colors denote relatively low Ti content. Black circles denote locations of LA-ICP-MS analysis sites with $\mathrm{Ti}$ concentration indicated in ppm by weight. (a) WDS Si map for a retrogressed mafic eclogite (08-036aviii). (b) CL Ti image for a retrogressed mafic eclogite (08-036aviii). Note patches of slight $(<1 \mathrm{ppm}) \mathrm{Ti}$ variation described in text. The LA-ICP-MS analyses indicated variations in $\mathrm{Ti}$ concentration between spot analyses that are within error of each other. This is the most common pattern in quartz from the D'Entrecasteaux Islands. (c) WDS Si map for a quartzofeldspathic orthogneiss (09-014aiii). (d) CL Ti image for a quartzofeldspathic orthogneiss (09-014aiii), case a described in text (Section 2.5.1). Note thin rim of lower Ti content possibly caused by minor fluid-driven or volume diffusion of Ti at grain edges. This pattern is seen only in granitic rocks. (e) WDS Si map for a quartzofeldspathic orthogneiss (09-014aiii). (f) CL Ti image for a quartzofeldspathic orthogneiss (09-014aiii), case b described in text (Section 2.5.1). Note the uni-directional increase in Ti content across the four quartz grains separated by high-angle grain boundaries. The LA-ICP-MS analyses corroborate the uni-directional increase, and indicate this variation between spot analyses is not within the $95 \%$ confidence uncertainty in the mean Ti concentration. Also note the white mica near the high Ti content area of the quartz grains, suggesting pinned grain boundaries. (g) WDS Si map for a retrogressed mafic eclogite (06-002bv). (h) CL Ti image for a retrogressed mafic eclogite (06-002bv), case c described in text (Section 2.5.1). Low Ti cores and relatively high Ti rims, across three quartz grains separated by high-angle grain boundaries. This pattern is seen only in retrogressed mafic eclogites and appears to reflect prograde growth at HP conditions. 
brightness correspond to relative variations in $\mathrm{Ti}$ concentration of $5-40 \mathrm{ppm}$ at a spatial scale of $<500 \mu \mathrm{m}$. The intra-grain domains with variable Ti concentrations suggest some zonation of $\mathrm{Ti}$ content as the result of either diffusion or growth. Examples of intra-granular variation in Ti content include: (a) grains with high $\mathrm{Ti}$ cores and thin low Ti rims (Fig. 2.9c,d), (b) large ( 300 $\mu \mathrm{m})$ quartz grains with a unidirectional increase in Ti content in grains (found in six samples of migmatitic gneiss and metamorphic granodiorite; Fig. 2.9e,f), and (c) quartz grains $(100-250 \mu \mathrm{m})$ with low Ti cores and high Ti rims (found in four samples of retrogressed eclogite; Fig. 2.9g,h).

As the boundaries between the high and low zones of Ti content (case a - c above) are diffuse on the CL images, it is difficult to determine if growth zonation or diffusion caused the less common intra-granular variation in Ti content. I measured the distances between these zones as an approximation of potential diffusion lengths, and compared these distances to diffusion lengths for $\mathrm{Ti}$ in quartz predicted by Cherniak et al. (2007). If the maximum duration for volume diffusion of Ti through the quartz lattice I allow is $\sim 2.5-3.0 \mathrm{Ma}$ (age of amphibolite-facies metamorphism), and the maximum estimate of temperature of the amphibolite-facies retrogression is taken to be $\sim 730^{\circ} \mathrm{C}$, then the maximum possible diffusion distance of Ti through the quartz lattice at the temperature of interest would be $\sim 140 \mu \mathrm{m}$ (Chapter 3 this thesis; Baldwin et al., 1993; Gordon et al., in review). This is an overestimate of diffusion distance as the rocks did not remain at $\sim 730{ }^{\circ} \mathrm{C}$ during the entire crustal exhumation, nor did they ascend to the surface instantaneously in the present-day. The high Ti cores and thin low Ti rims (case a above) occur on length scales of $\sim 10 \mu \mathrm{m}$ in 20 samples across all five rock types analyzed here. Based on the length scale of case a, it is possible that volume diffusion of Ti may account for some of the narrower zonation exhibited by the CL images. The low Ti cores and high Ti rims present in samples of retrogressed eclogite occur on a length scale of $\sim 200 \mu \mathrm{m}$ and the unidirectional increases in Ti content occur over distances of $300 \mu \mathrm{m}$ (Fig. 2.9f,h). These latter patterns (case $b$ and $c$ above) cannot be the result of post-growth diffusion and were probably inherited from metamorphic grain growth (relict quartz from previous high-temperature crystallization events). The presence of mica near the edges of one of the quartz grains imaged by CL that exhibits a uni-directional increase in CL brightness (e.g. Fig. 2.9e,f) may suggest that mica grains have pinned 
certain quartz grain boundaries. These grain boundaries may have been sheltered from the otherwise pervasive dynamic recrystallization, resulting in the preservation of growth zonation in some of the relict quartz.

Inter-granular variation in $\mathrm{Ti}$ content is typically much larger relative to the intragranular variation in $\mathrm{Ti}$ content shown in the CL images (Fig. 2.10). Approximately $65 \%$ of the CL images exhibit relative differences in Ti content of $\sim 2-20 \mathrm{ppm}$ between quartz grains (Fig. 2.10). These inter-granular Ti variations imply that the quartz grain assemblage in samples analyzed here consists of mainly internally homogenous quartz grains of variable mean Ti content. The internal homogeneity in Ti content in the quartz grains implied by the LA-ICP-MS calibrated CL images suggests the quartz grains underwent either recrystallization or growth at near constant temperatures, or homogenization as a result of diffusion (Spear and Wark, 2009). The characteristic transport distance for Ti-in-quartz for a time lapse of $2.5-$ 3.0 Ma between the amphibolite-facies metamorphism and emplacement in the upper crust is $\sim 40 \mu \mathrm{m}$ at $600{ }^{\circ} \mathrm{C}$ and $1,300 \mu \mathrm{m}$ at $800{ }^{\circ} \mathrm{C}$, as determined by Cherniak et al., (2007; Chapter 3 this thesis; Gordon et al., in review). Eighty percent of TitaniQ apparent temperatures calculated by this study are $\leq 600{ }^{\circ} \mathrm{C}$ (Table 2.1), suggesting that volume diffusion would only have affected a few tens of microns of the quartz grains. It is therefore unlikely that volume diffusion was the primary factor in the distribution of $\mathrm{Ti}$ within the $200-500 \mu \mathrm{m}$ diameter quartz grains in the D'Entrecasteaux Islands. It is also unlikely that growth at near constant temperatures would cause the homogeneity within the quartz grains, as GBM recrystallization has pervasively affected quartz grains. I therefore suggest that the inter-granular variation in $\mathrm{Ti}$ concentration (typically $2-20 \mathrm{ppm}$ ) and the relatively flat or homogeneous intra-granular variation in $\mathrm{Ti}$ concentration $(<5 \mathrm{ppm})$ records $\mathrm{Ti}$ resetting during this GBM recrystallization. The inter-granular differences in $\mathrm{Ti}$ content may suggest that the quartz grain population is a mixture of older, Ti-rich and more recently recrystallized, Ti-poor quartz grains as a result of ongoing dynamic recrystallization during exhumation of the rocks. 
a) 06-005aii, quartzofeldspathic granodiorite,

Goodenough core (WDS silica map)

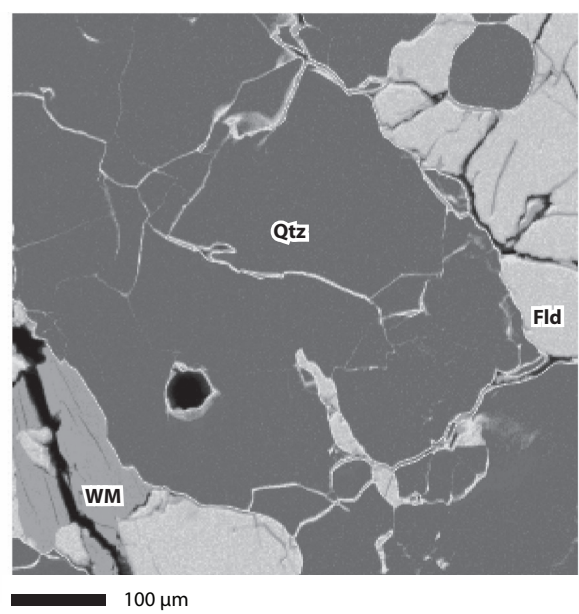

c) 06-020eii, quartzofeldspathic gneiss, Goodenough carapace (WDS silica map)

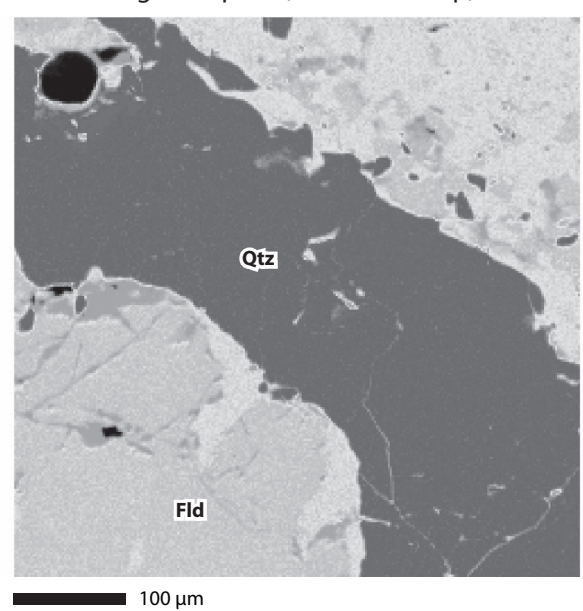

b) 06-005aii, quartzofeldspathic granodiorite,

Goodenough core (CL titanium map)

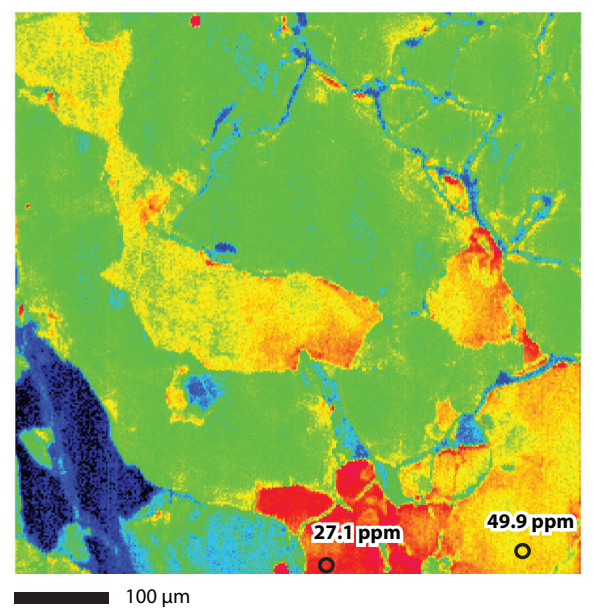

d) 06-020eiii, quartzofeldspathic gneiss, Goodenough carapace (CL titanium map)

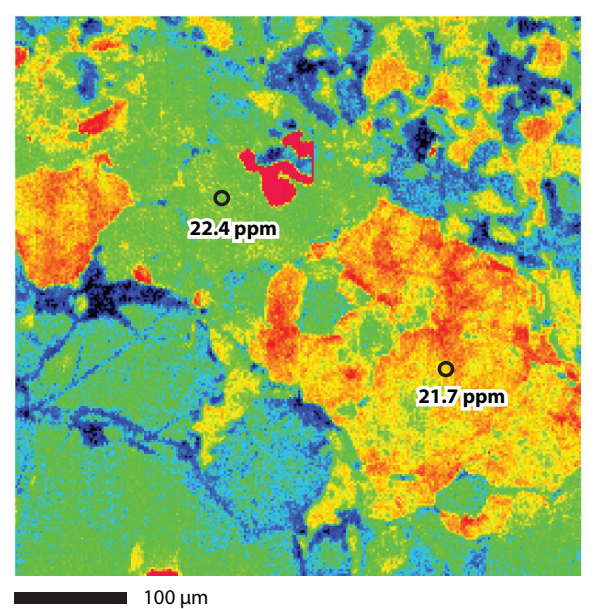

Figure 2.10 Selected wavelength-dispersive spectrometry (WDS; on the left-hand side) and cathodoluminescence $(\mathrm{CL}$; on the right-hand side) images showing inter-granular variation in $\mathrm{Ti}$ content: Fld, feldspar; Qtz, quartz; WM, white mica. Warm red colors denote relatively high Ti content and cool blue colors denote relatively low Ti content. Black circles denote locations of LA-ICP-MS analysis sites with titanium concentration in ppm by weight. (a) WDS Si map for a quartzofeldspathic granodiorite (06-005aii). (b) CL Ti image for a quartzofeldspathic granodiorite (06-005aii). The differences in Ti content are much more significant between quartz grains then within them. The patches of slight ( $<1 \mathrm{ppm}$ ) Ti variation as described in text occur, and are much less significant then the difference in $C L$ brightness between the grains. (c) WDS Si map for a quartzofeldspathic gneiss (06-020eii). (d) CL Ti image for a quartzofeldspathic gneiss (06-020eii). Again, note that the differences in $\mathrm{CL}$ brightness is much more significant between quartz grains then within grains. 


\subsection{2 $\mathrm{Ti}$ content in the quartz grains and TitaniQ apparent temperatures}

Fig. 2.11 illustrates a linear relationship (correlation coefficient $=0.82$ ) between the mean $\mathrm{Ti}$ concentration of each sample in $\mathrm{ppm}$ and the variance of the $\mathrm{Ti}$ concentration ( $95 \%$ confidence interval) in that sample. This relationship implies that a sample with a high apparent temperature will have a high variability of Ti content between quartz grains, relative to samples with low apparent temperatures. The mean Ti concentration for a sample calculated by this study is an average of up to eight analyses, each of which may have a different Ti content. Older quartz grains may preserve a high Ti content inherited from a higher-temperature stage in the history of ultra high pressure-bearing gneisses. The mixture of such Ti-rich relict quartz grains with more newly recrystallized (lower temperature) quartz grains may lead to a high variability of Ti content in the most rapidly exhumed rocks.

To determine if there are obvious first-order effects on the variations in $\mathrm{Ti}$ content within the D'Entrecasteaux Islands, I have compared mean Ti concentrations and TitaniQ apparent temperatures averaged by lithology, structural zone, and location (Fig. 2.12). For the entire data set, the averaged Ti concentrations generally vary from $10-20 \mathrm{ppm}$, corresponding to a calculated range of TitaniQ apparent temperatures of $500-600{ }^{\circ} \mathrm{C}$ (Fig. 2.12). As high-temperature grain-boundary migration recrystallization is thought to require temperatures of $>500-550{ }^{\circ} \mathrm{C}$, the average TitaniQ apparent temperatures calculated here correlate well with deformational temperatures predicted for the final stages of quartz recrystallization (Fig. 2.6; Stipp et al., 2002). Fig. 2.12a and 2.12d illustrate Ti concentrations averaged in categories corresponding to the four main rock types analyzed here (quartz veins, metamorphic granitic rock, eclogite, quartzofeldspathic gneiss). There is no statistical difference in mean Ti concentration between the four different rock types, implying that lithological variation is not the main control on Ti content in quartz. Fig. 2.12c and 2.12f show a comparison of average Ti concentration for samples in the core and carapace zone of the individual gneiss domes. These data reveal that only the Goodenough dome shows a statistically significant difference in the mean Ti concentration between the core and carapace zones as averaged across all samples. The northwest Normanby dome has minimal difference in the $\mathrm{Ti}$ 


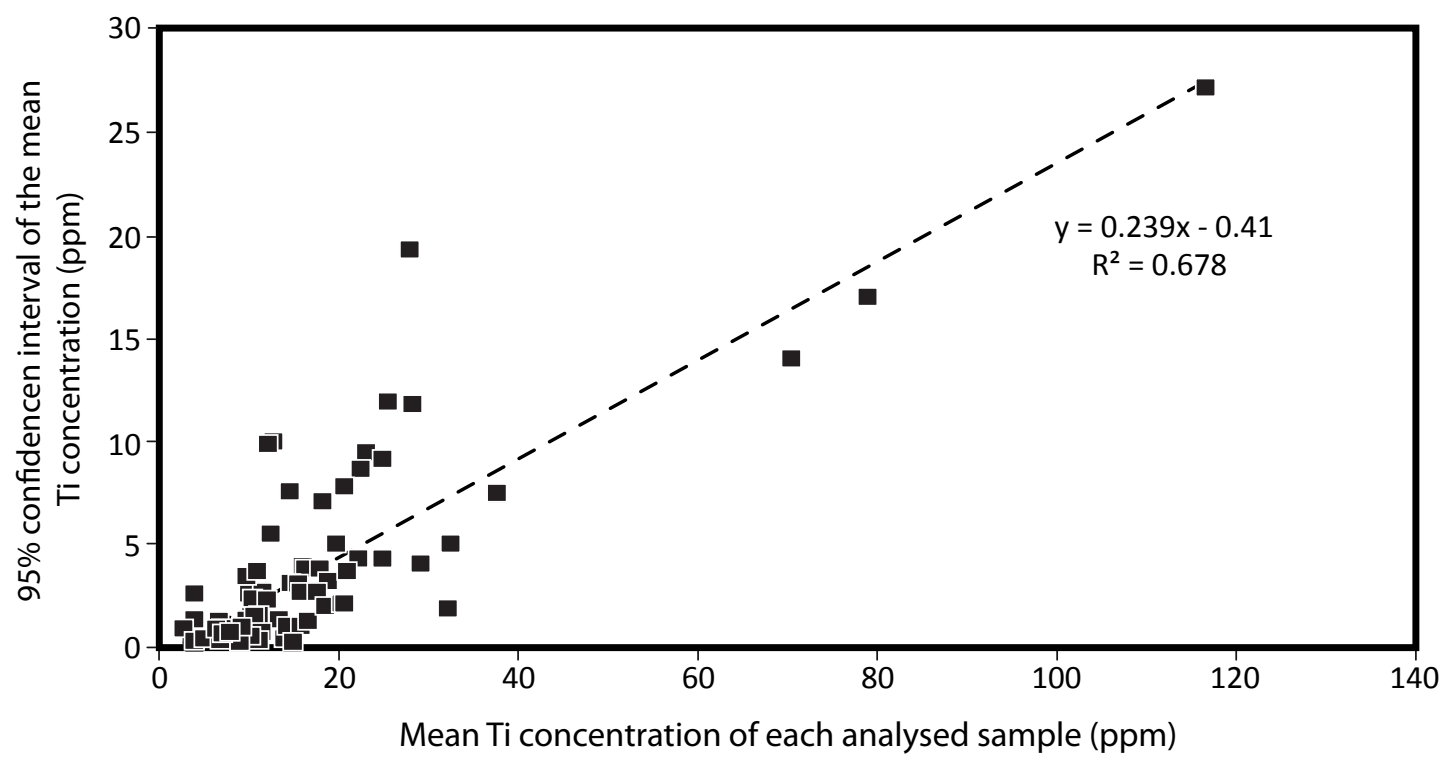

Figure 2.11 95\% confidence interval of each sample's mean Ti concentration measurement as a function of that sample's mean Ti concentration in ppm by weight (correlation coefficient of 0.82). Each mean Ti concentration represents up to eight LA-ICP-MS spot analyses at both core and rim positions of the quartz grain. 

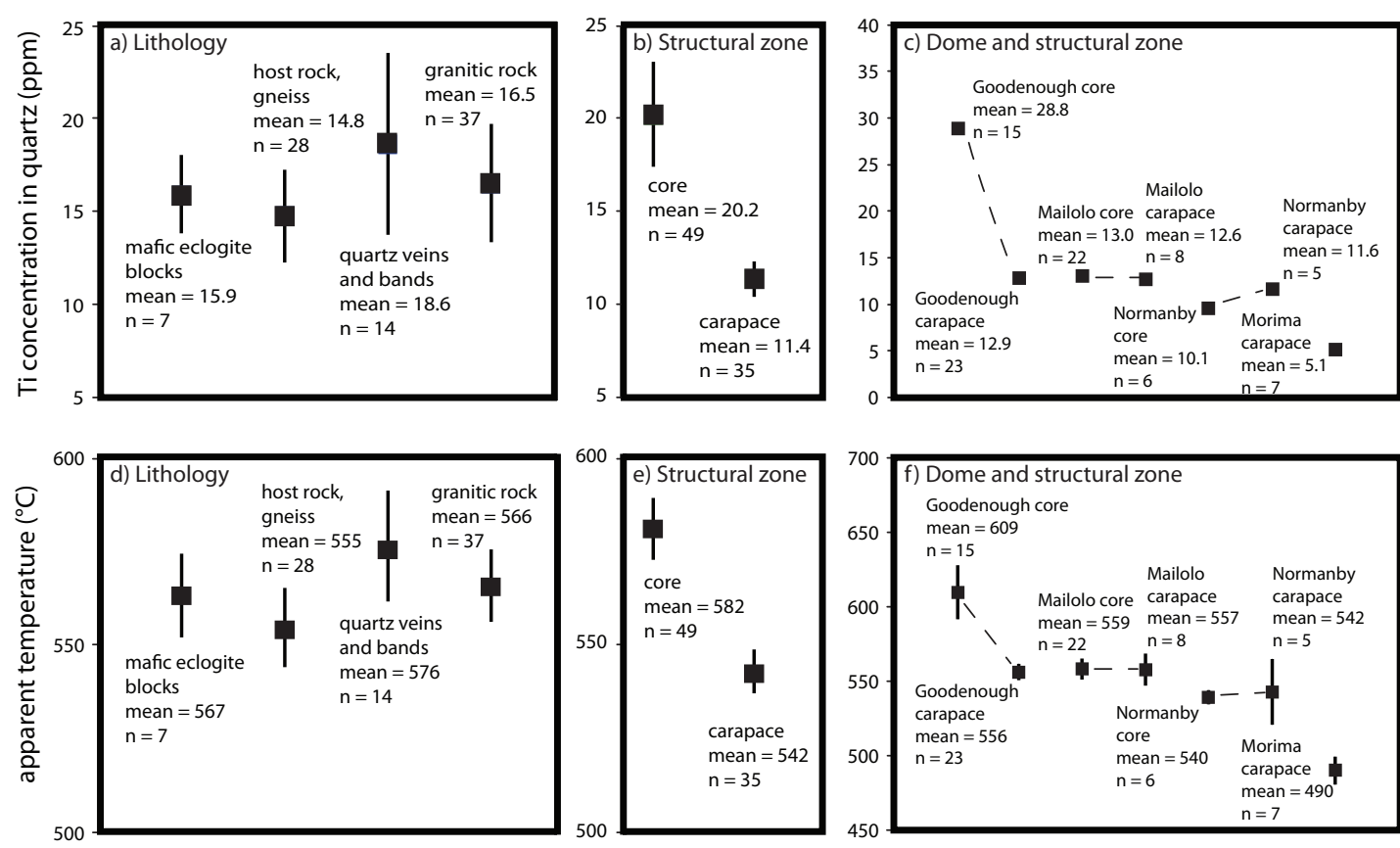

Figure 2.12 (a) and (d) show the averaged Ti concentration in quartz and the averaged TitaniQ apparent temperatures calculated by the Wark and Watson (2006) calibration compared to lithology respectively (error bars represent the two standard errors). Note that averaged Ti concentrations in quartz include both rutile and non-rutile bearing samples and that there is no difference in Ti concentration between lithologies. (b) and (e) show the averaged Ti concentration in quartz and the averaged TitaniQ apparent temperatures calculated by the Wark and Watson (2006) calibration respectively compared to structural zone (error bars represent the two standard errors). (c) and (f) show the averaged $\mathrm{Ti}$ concentration in quartz and the averaged TitaniQ apparent temperatures calculated by the Wark and Watson (2006) calibration respectively, compared to the structural zone within each gneiss dome (error bars represent the two standard errors). Note that averaged Ti concentrations include both rutile and non-rutile bearing samples. The northwest Normanby dome has a negligible slope because of the inclusion of several samples with relatively high $\mathrm{Ti}$ concentrations (e.g. 10-021a; Fig. 2.13, 2.14) into the average Ti concentrations for the core and carapace of this dome. 
concentration or apparent temperature between the core and carapace zones. These similar temperatures in the core and carapace zone of the northwest Normanby dome may result from the proximity of a large body of leucogranodiorite, resulting in several samples of carapace rock with high Ti concentrations (e.g. 10-021a) relative to the majority of samples situated near the dome margins. I note that the high average Ti concentration of samples from the core of the Goodenough dome and the low average Ti concentration of the samples from the carapace of the Morima dome strongly influence the bulk core and carapace zone Ti content in quartz in Fig. 2.12b and $2.12 \mathrm{e}$.

Ti concentrations in quartz are plotted on a map of the northwest D'Entrecasteaux Islands in Fig. 2.13 with warm colors denoting high $\mathrm{Ti}$ concentrations. $\mathrm{Ti}$ concentrations in the northwest Normanby dome are lower $(2.5-7.5 \mathrm{ppm})$ near the coast and higher $(10.0-15.0 \mathrm{ppm})$ in the interior of the dome; however the pattern at the northwest end of the dome is complex with several coastal samples adjacent to the leucogranodiorite body in conflict with the aforementioned trend. The Morima dome shows lower Ti concentrations $(2.5-5.0 \mathrm{ppm})$ near the south-central coast of Fergusson Island close to the bounding normal fault, and higher Ti concentrations $(5.0-7.5 \mathrm{ppm})$ in a sample located closer to the dome's interior. In the Mailolo dome there are low Ti concentrations $(5.0-10.0 \mathrm{ppm})$ near the south and northwest coasts, and higher Ti concentrations $(10.0-20.0 \mathrm{ppm})$ in the interior of the dome. A few samples with relatively high $\mathrm{Ti}$ concentrations $(20.0-25.0 \mathrm{ppm})$ appear scattered throughout this dome. The Goodenough dome has, in general, lower $\mathrm{Ti}$ concentrations $(7.5-12.5 \mathrm{ppm})$ near the dome-bounding fault on its northeast margin and higher Ti concentrations $(20.0->100 \mathrm{ppm})$ in the interior of the dome. Ti concentrations on the southwest margin of the Goodenough dome are higher on the outer southwest margin of the Goodenough dome $(>20 \mathrm{ppm})$ relative to those near the northeast dome-bounding fault, and are generally lower than $\mathrm{Ti}$ concentrations in the interior of this dome. These results have also been projected onto a series of schematic structural cross-sections (Fig. 2.14a-d).

Fig. 2.15a-e illustrates regression analyses of the sample-averaged Ti concentrations as a function of their distance from five of the major dome-bounding normal faults in 

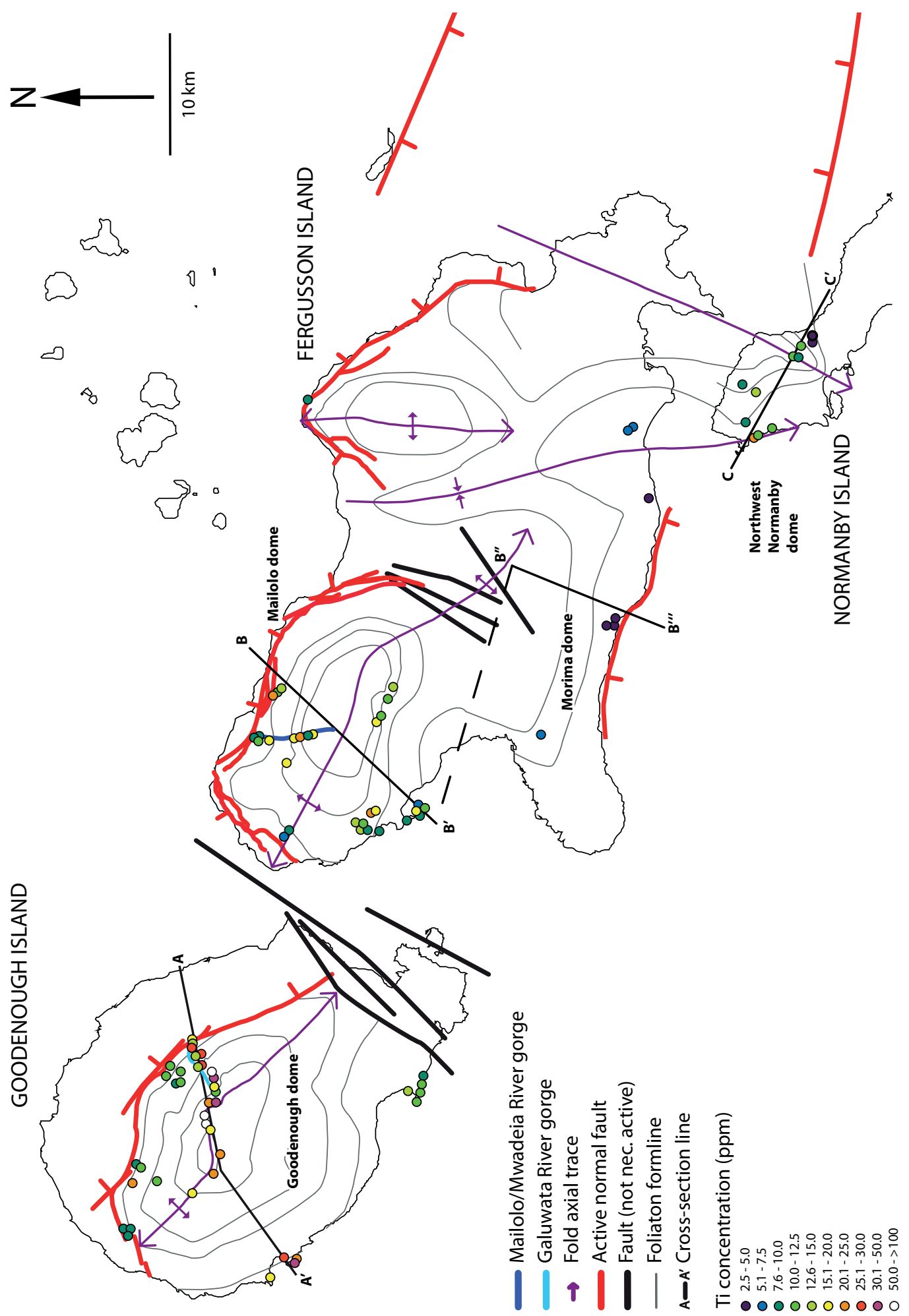

Figure 2.13 Simplified structural map of the northwest D'Entrecasteaux Islands showing spatial pattern of mean Ti concentration as averaged per sample (adapted from Little et al., 2011). See Fig. 2.3 for sample numbers and Fig. 2.1b for figure location. Cross-section lines are shown for Fig. 2.14 and 2.15. Colors are coded by relative Ti concentration, with warmer colors denoting higher Ti. 

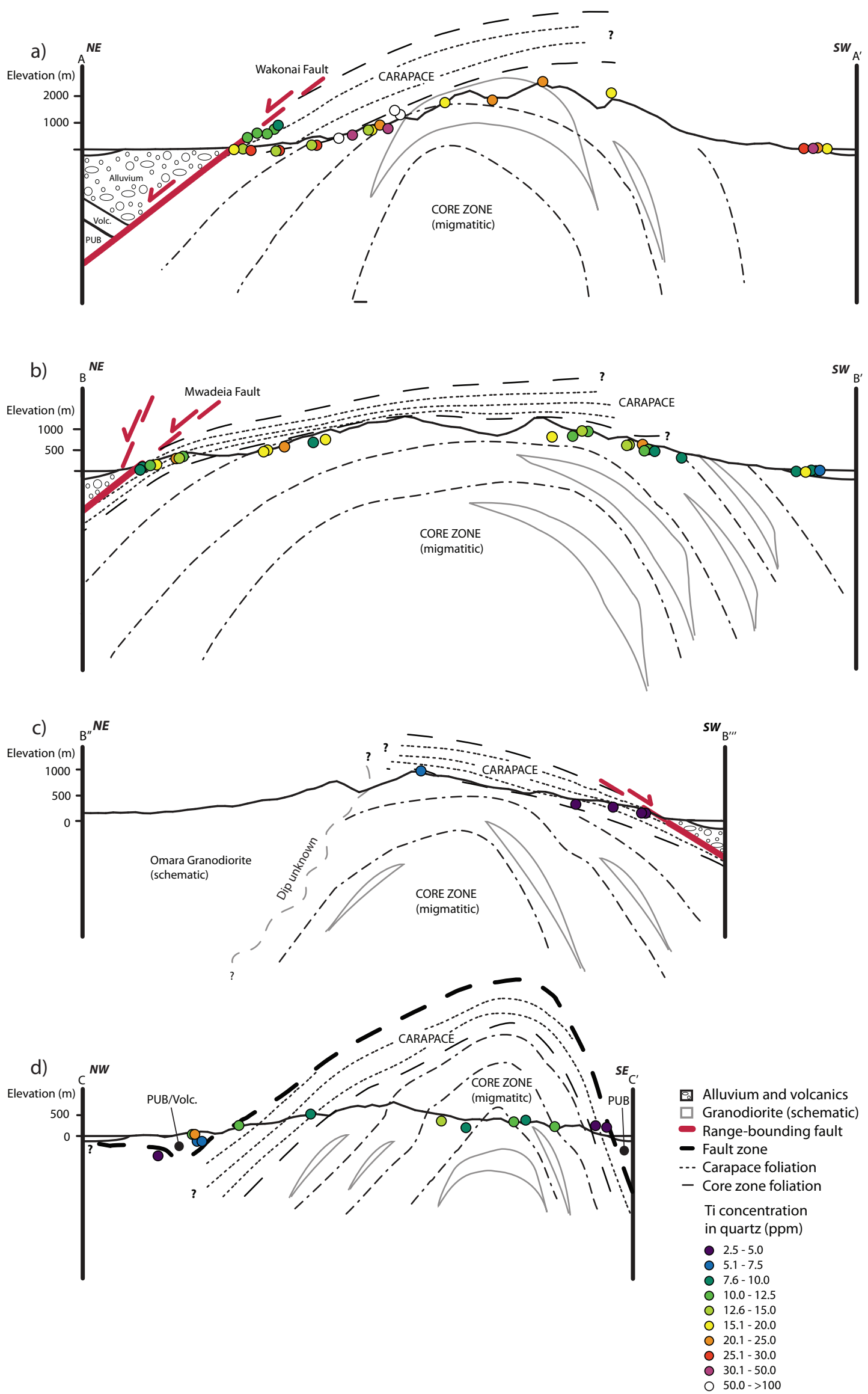
Figure 2.14 Schematic structural cross-sections (no vertical exaggeration) across four gneiss domes in the D'Entrecasteaux Islands after Little et al. (2011): PUB, Papua Ultramafic Belt; Volc., volcanics.. Structural data is from the unpublished GIS database of Tim Little (Victoria University of Wellington). These cross-sections show horizontal pattern of $\mathrm{Ti}$ concentrations as averaged per sample. Line orientations shown in Fig. 2.13. Colors are coded by relative Ti concentration, with warmer colors denoting higher Ti concentrations. (a) $A-A^{\prime}$, northeast-southwest structural crosssection across Goodenough dome. (b) B-B', northeast-southwest structural cross-section across Mailolo dome. (c) B"'-B"', northeast-southwest structural cross-section across Morima dome. (d) C$C^{\prime}$, northwest-southeast structural cross-section across northern Normanby dome. Note that only samples that are within $\sim 5 \mathrm{~km}$ of the cross-section line are included in the horizontal patter of $\mathrm{Ti}$ concentrations portrayed here.

the D'Entrecasteaux Islands. These analyses were carried out on Ti content in quartz for samples that are within $\sim 5 \mathrm{~km}$ of the five normal faults examined here. All of linear regressions in Fig. 2.15 show an inward increase in Ti concentration away from the dome margins. Linear regressions presented here with high $\mathrm{R}^{2}$ values may in part be an artifact of a low sample density or a bias in the sample set toward the carapace (i.e. $\mathrm{R}^{2}=0.97$ for the southwest coast of Morima dome near the Morima Fault; Fig. 2.15c). $\mathrm{R}^{2}$ values for samples on the northeast coast of Goodenough dome near Wakonai Fault $\left(\mathrm{R}^{2}=0.31\right.$; Fig. 2.15a), northeast coast of Mailolo dome near Mwadeia Fault $\left(\mathrm{R}^{2}=0.16\right.$; Fig. 2.15b), and the southeast coast of northwest Normanby dome near the northwest Normanby fault zone $\left(R^{2}=0.06\right.$; Fig. $\left.2.15 \mathrm{~d}\right)$ show a weak fit of the inwardly-increasing regression line to the data points.

As the Goodenough dome has the densest concentration of samples, Ti concentrations measured in this dome were used to calculate TitaniQ apparent temperatures with three different $\mathrm{Ti}$ activity coefficients $(0.4,0.6,0.8)$ for both the Wark and Watson (2006) calibration and the Thomas et al., (2010) calibrations (Fig. 2.16). All linear regressions of the data in Fig. 2.16b and 2.16c have a positive slope with an apparent horizontal (inward) temperature gradient of $26-34{ }^{\circ} \mathrm{C} \mathrm{km}^{-1}$. A comparison between the two calibrations indicates that the Wark and Watson (2006) calibration yields cooler apparent temperatures and produces a lower degree per kilometer gradient. Important here, however, is that the positive slope in apparent temperatures derived from each calibration and activity appears to be a robust feature of both calibrations, as quartz in the interior of each dome has a high Ti content on average relative to quartz grains on the margins of the domes. The Wark and Watson (2006) calibration was established at a pressure of $10 \mathrm{kbar}$, which is within error of the suggested $7-11 \mathrm{kbar}$ pressure for the main amphibolite facies overprint that was 

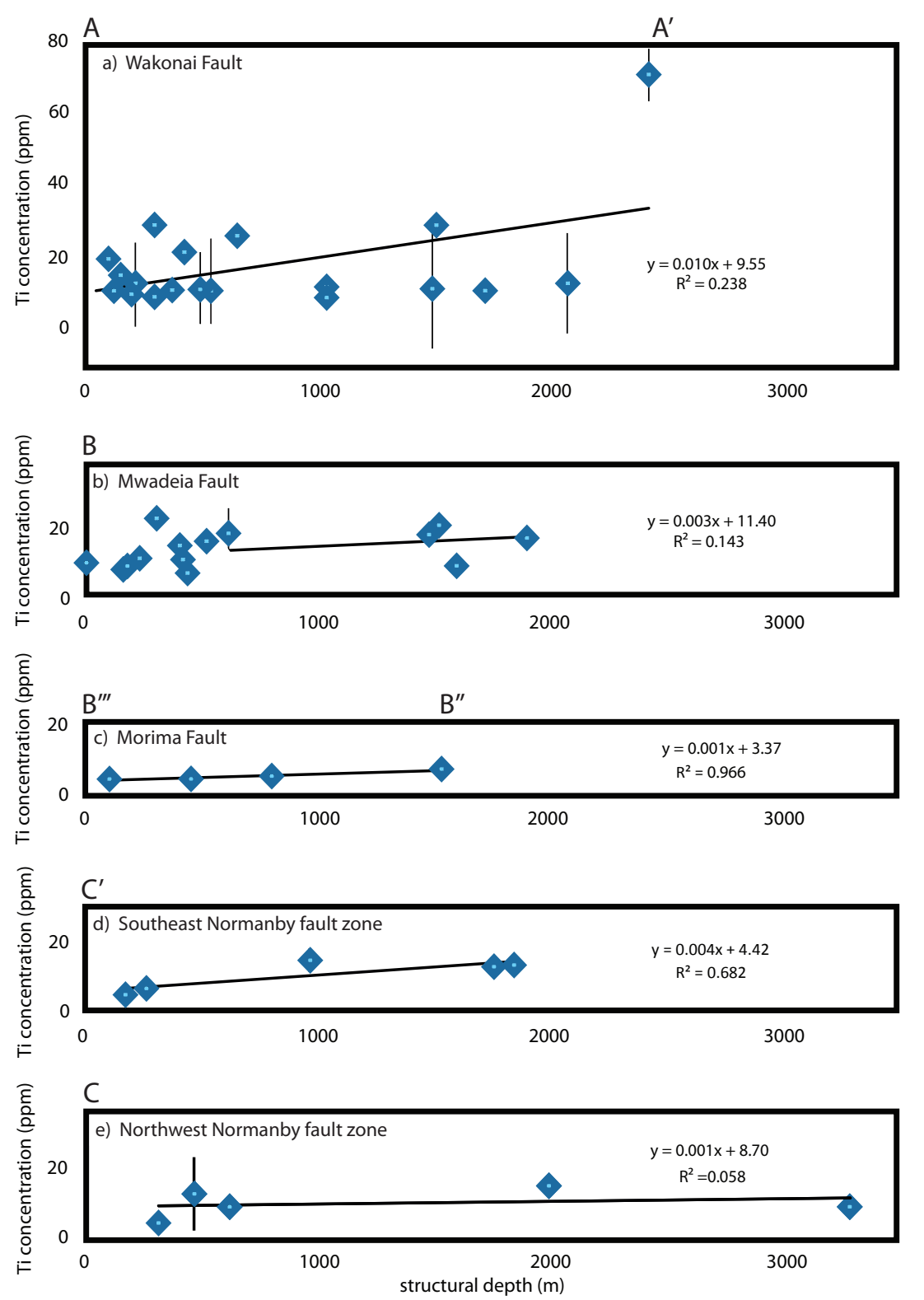

Figure 2.15 Mean Ti concentration as a function of structural depth in the D'Entrecasteaux Islands. Locations of plots a-e are shown in Fig. 2.13 along the cross-section profiles, however samples from further afield (along the coasts of the islands within $~ 5000 \mathrm{~m}$ of the dome-bounding faults) are included in the data set. Errors are 95\% confidence intervals for the mean $\mathrm{Ti}$ concentration (Appendix B.2). (a) Northeast coast of Goodenough dome near Wakonai Fault (A-A', Fig. 2.13). (b) Northeast coast of Mailolo dome near Mwadeia Fault (B, Fig. 2.13). (c) Southwest coast of Morima dome near Morima Fault (B"'-B", Fig. 2.13). (d) Northwest coast of northwest Normanby dome near the northwest Normanby fault zone ( $C^{\prime}$, Fig. 2.13). (e) Southeast coast of northwest Normanby dome near the southeast Normanby fault zone (C, Fig. 2.13). 

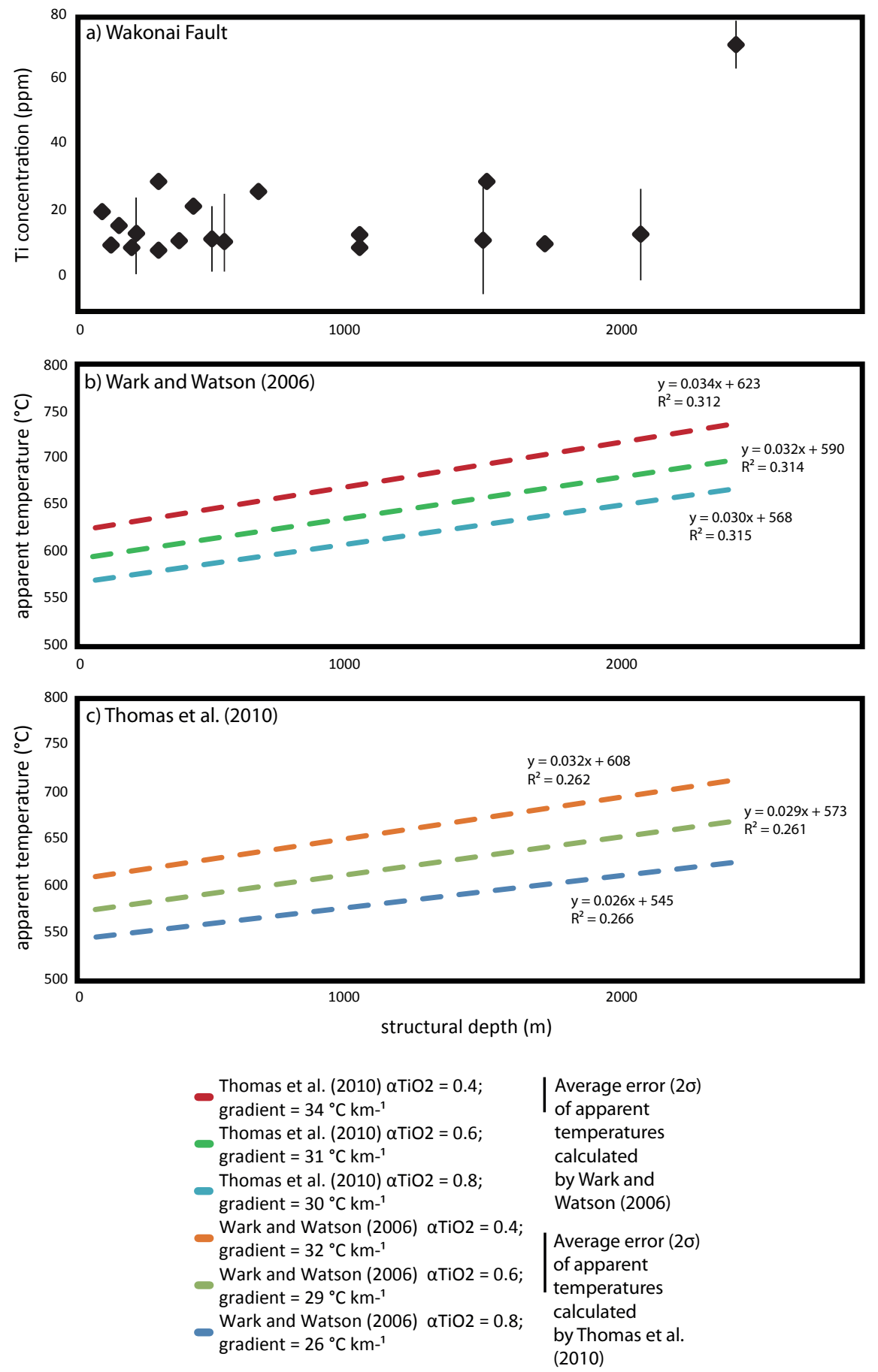

Figure 2.16 Comparison of TitaniQ apparent paleo-temperatures calculated for a Ti concentration data set from the Wakonai Fault, Goodenough dome as a function of assigned activities and calibrations. (a) Mean Ti concentration (in ppm by weight) for each sample within $4000 \mathrm{~m}$ for the Wakonai fault, Goodenough dome. Errors are 95\% confidence intervals. (b) and (c) show linear regression of TitaniQ apparent temperatures calculated using the Ti concentrations in (a) and the Wark and Watson (2006) and Thomas et al. (2010) calibrations respectively. Three different titanium activities were assigned to determine the effect of variations in Ti activity on the gradient in TitaniQ apparent temperatures. Average two standard errors for all data points used for the linear regression is quoted in the legend. The preferred titanium activity for non rutile-bearing quartz grains in the D'Entrecasteaux Islands is 0.8 (see text). Not that the gradient in TitaniQ apparent temperatures does not significantly change for either the two different calibrations or the three different activities assigned here, suggesting that the slope of the regression fit is always positive. 
input into the pressure-sensitive Thomas et al., (2010) calibration (Section 2.4.2). Although I attempted to include the incremental effect of additional structural burial in the direction orthogonal to the main foliation in the Goodenough dome, the change in pressure between the shallowest and deepest samples is small (0.70 kbar) and does not yield an appreciable difference in the overall gradient in apparent temperatures.

\subsection{Discussion}

\subsubsection{Fluid control on the uptake of $\mathrm{Ti}$ into the quartz tetrahedral}

Wilson et al., (in review) undertook a review of the Thomas et al. (2010) calibration of the TitaniQ. These authors argue that the exchange reaction of Ti between quartz and rutile is mediated by a fluid phase that includes dissolved Ti complexes with partition coefficients of $\mathrm{Ti}$ between quartz and rutile not allowed for in the original calibrations. The chemistry of this fluid may therefore exert a first-order control on the uptake of $\mathrm{Ti}$ into the quartz grains (Wilson et al., in review). Such equilibrium reactions between quartz and aqueous $\mathrm{Ti}$ complexes are outside the original experimental conditions used in the Wark and Watson (2006) and the Thomas et al., (2010) experimental calibration studies. Wilson et al., (in review) argue that fluid control on the Ti uptake into quartz would adversely affect the applicability of the TitaniQ, as both calibrations are based on a simple three component system of quartz, rutile, and water, and assume that fluid phase for the $S i^{4+} \Leftrightarrow T i^{4+}$ exchange between quartz and rutile is unimportant. Wilson et al., (in review) suggest that the TitaniQ geothermobarometer is therefore only valid in the pure $\mathrm{SiO}_{2}$ (quartz) - $\mathrm{TiO}_{2}$ (rutile) - $\mathrm{H}_{2} \mathrm{O}$ system and cannot be extrapolated to natural systems, as they are relatively complex with a variable fluid composition.

A possible analogy for the chemical behavior of Ti-in-quartz solubility is the Al-inquartz geothermometer, which was first proposed by Dennen et al. (1970; Wilson et al., in review). Like the TitaniQ, the Al-in-quartz geothermometer assumes that the equilibrium between solid phases defines the solubility of Al within quartz (Dennen et al., 1970). A later study by Scotfeld (1975) found that there is no linear 
relationship between $\mathrm{Al}$ concentration in quartz and a range of apparent temperatures of crystallization determined by geological and mineralogical criteria. Based on this lack of a collinear variation, the uptake of Al into quartz may not be a simple function of the temperature of crystallization and instead may be controlled by physical conditions such as melt and fluid chemistry (Botis and Pan, 2009 and ref. therein; Scotfeld, 1975). Thus, the composition and chemistry of the fluid may control the uptake of $\mathrm{Al}$ into the Si tetrahedral site in quartz. Wilson et al., (in review) and Huang and Audétat (2011) observe a clear linear relationship between Al and $\mathrm{Ti}$ in volcanic and hydrothermally grown quartz crystals. Wilson et al., (in review) argue that this covariance implies that the uptake of $\mathrm{Ti}$ into quartz is controlled by fluid composition, similar to the affect of fluid chemistry on the uptake of Al into quartz. Thus, the fluid or melt composition exerts a control over both elements, and a direct proportionality between $\mathrm{Al}$ and $\mathrm{Ti}$ content in quartz crystals may imply that the uptake of Ti into quartz is primarily controlled by fluid chemistry of the system and is not strictly temperature-dependent (Huang and Audétat, 2011; Wilson et al., in review).

Fig. 2.17 illustrates the relationship between the mean $\mathrm{Al}$ concentration and the $\mathrm{Ti}$ concentration for all samples analyzed by this study. Fig. 2.17 does not show a clear collinear trend between the mean $\mathrm{Al}$ and $\mathrm{Ti}$ concentration for each sample (correlation coefficient $=0.20$ ). This lack of direct proportionality implies the uptake of $\mathrm{Ti}$ into the quartz structure in these dynamically recrystallized quartz grains was not primarily dependent on the solubility of Ti in a host fluid. In addition, this study is focused on interpreting spatial gradients in Ti content and TitaniQ apparent temperatures, and the debate of the thermodynamic validity of the TitaniQ may be less crucial here relative to studies concerned with absolute TitaniQ temperatures.

\subsubsection{Testing the activity model of the calculated apparent temperatures for rutile-bearing and non rutile-bearing samples}

To test the appropriateness of the assigned activity coefficients (Section 2.4.2), I undertook a comparison of TitaniQ apparent temperatures calculated for rutile- and non rutile-bearing samples within $1 \mathrm{~km}$ of each other in the D'Entrecasteaux Islands. This comparison is important as the single variable with the most effect on the $95 \%$ 


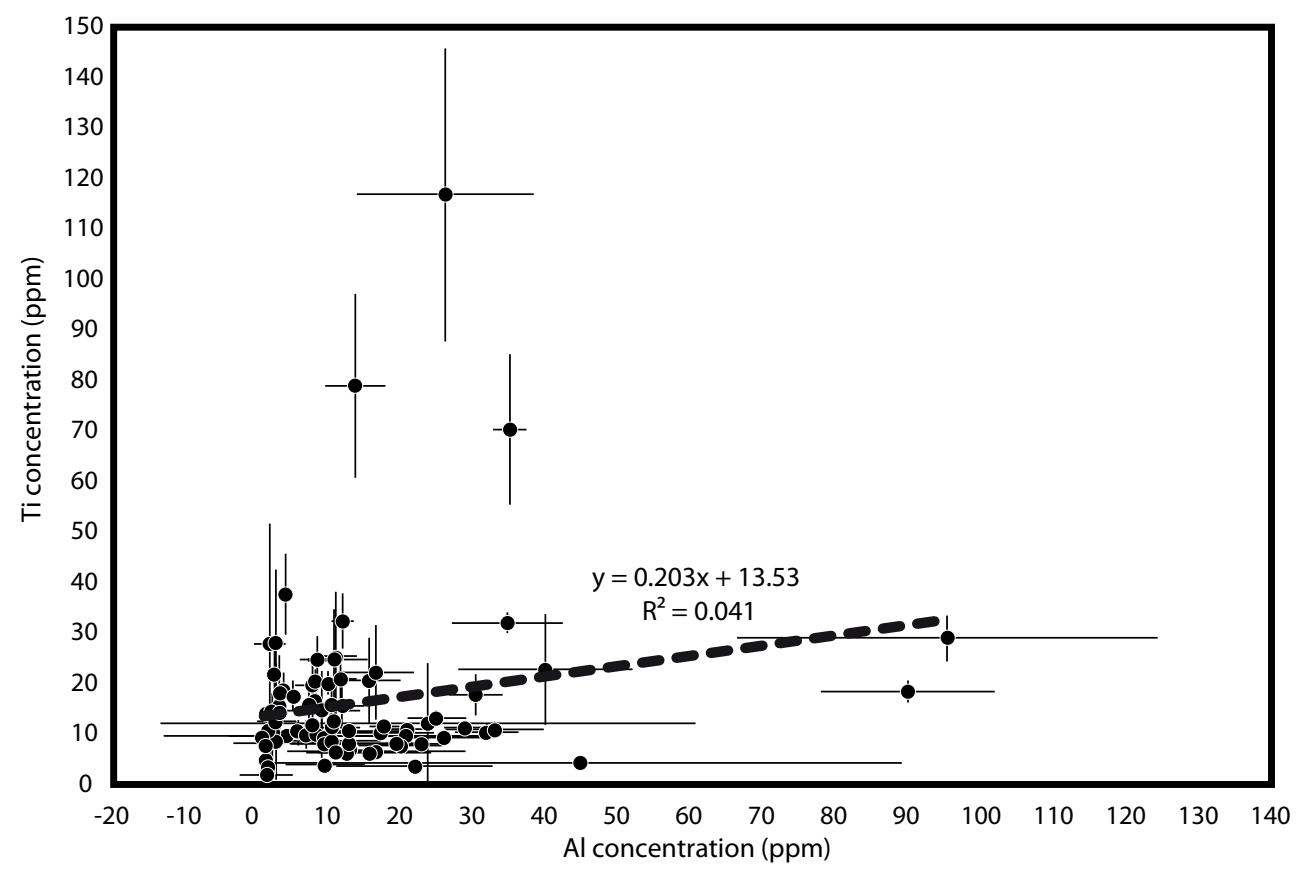

Figure 2.17 Mean Al concentration (in ppm by weight) versus mean Ti concentration (in ppm by weight) for each sample analyzed for Ti content in this study. Note the lack of an obvious co-linear trend (correlation cofficient of 0.20 ). Errors are the analytical error, which is a weighted two standard deviation of the LA-ICP-MS Ti and Al analytical precision. 
confidence interval of the TitaniQ apparent temperatures is the assigned uncertainty in the $\alpha_{\mathrm{TiO}_{2}}( \pm 0.2$; Section 2.4.2). The linear regression in Fig. 2.18a has a slope of 0.94 and a correlation coefficient of 0.74 , which suggests that there is a one-to-one linear relationship, or a proportionally, between the adjacent samples that contain rutile and non-rutile assemblages. Fig. 2.18b compares apparent temperatures calculated from adjacent samples with rutile-bearing assemblages and non-rutile bearing assemblages. All of the rutile-bearing apparent temperatures are within the $95 \%$ confidence interval of the non-rutile bearing apparent temperatures. In addition, the rutile-bearing samples do not exhibit a systematic relationship (i.e. higher or lower apparent temperatures) relative to the non rutile-bearing samples. Thus, the TitaniQ apparent temperatures calculated for the rutile-bearing samples accord well with the apparent temperatures for the non-rutile bearing samples, implying that the assigned activity coefficients are accurate.

\subsubsection{Application of the TitaniQ to metamorphic rocks}

The TitaniQ thermometer was originally calibrated for igneous quartz $(600-1000$ ${ }^{\circ} \mathrm{C}$ ), whereas quartz grains analyzed in this study occur in a ductilely deforming metamorphic context. Ti content in metamorphic quartz can be affected by several different processes: solid-state volume diffusion of $\mathrm{Ti}$ within or between quartz grains and other adjacent minerals, introduction of aqueous Ti-rich fluids along quartz grain boundaries, and static or dynamic recrystallization which may completely reform the quartz grain causing Ti re-equilibration (Spear and Wark, 2009). Mean Ti concentrations and TitaniQ apparent temperatures averaged for different bulk composition are compared in Fig. 2.12a. From this data, I infer that bulk composition does not exert a first-order control on Ti content, nor do the eclogite samples return $\mathrm{Ti}$ concentrations that are significantly higher than other lithologies that were retrogressed in amphibolite-facies conditions. The $\mathrm{Ti}$ concentrations measured in this study are recording Ti equilibration occurring during the final stages of the exhumation history of the migmatitic rocks, presumably in the mid to upper crust at the time of final gneiss dome emplacement (Fig. 2.6; Baldwin et al., 1993). 

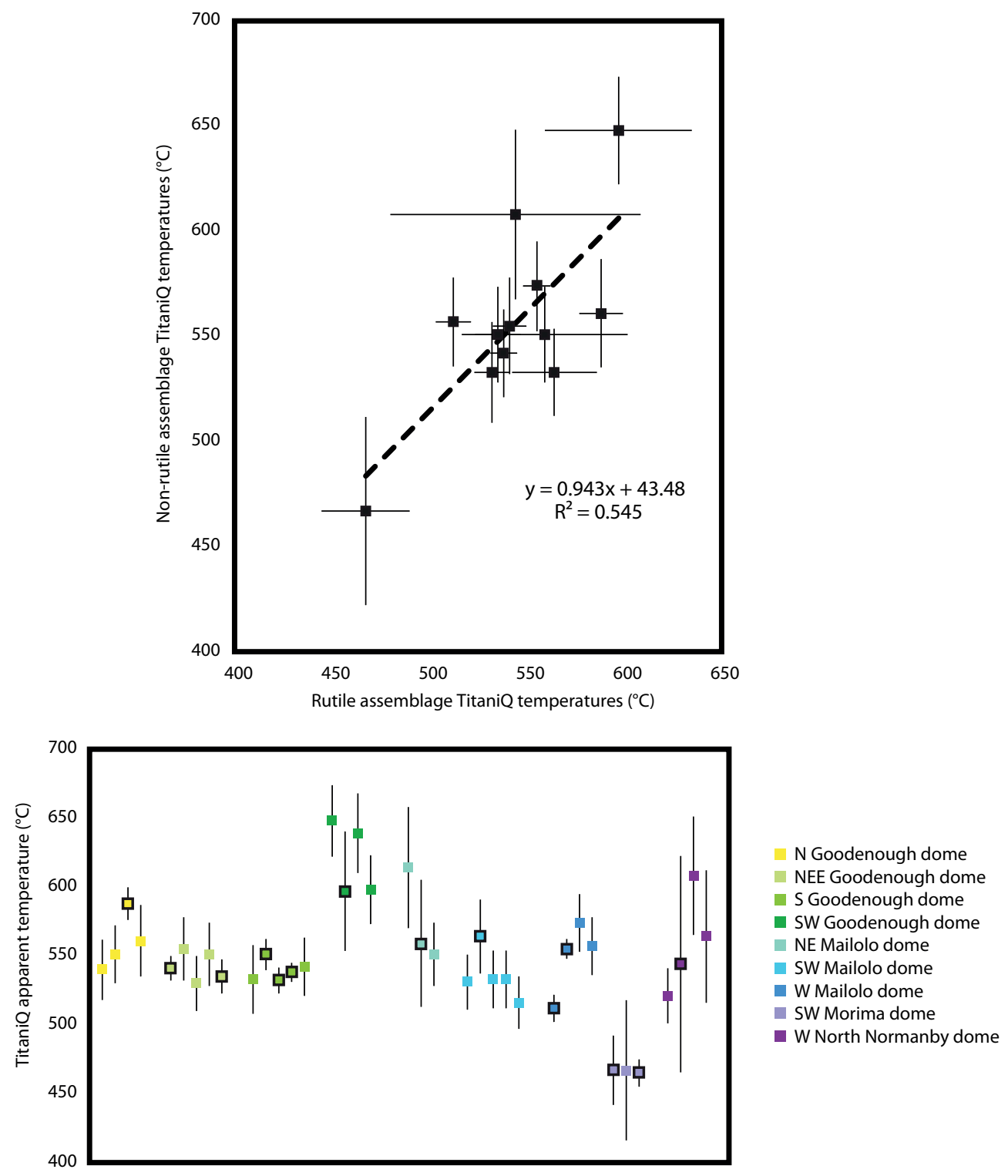

Figure 2.18 (a) TitaniQ apparent temperatures calculated for samples with a non-rutile bearing assemblage as a function of TitaniQ apparent temperatures calculated for samples with a rutilebearing assemblage. Samples are from the same or immediately adjacted localities. All apparent temperatures are calculated by the Wark and Watson (2006) calibration. Note the the slope of the regression line is 0.94 ; this relationship implies a near 1:1 correlation between TitaniQ apparent temperatures calculated for rutile and non-rutile assemblages (correlation coefficient of 0.74). Errors are a $95 \%$ confidence interval of the quotient and include analytical, calibration, and Ti activity uncertainty (Section 2.5.2, Table 2.1). (b) TitaniQ apparent temperatures calculated by the Wark and Watson (2006) calibration as a function of location and Ti phase present in the assemblage. Rutile-bearing samples are outlined in black. Errors are a $95 \%$ confidence interval of the quotient and include analytical, calibration, and Ti activity uncertainty (Section 2.5.2, Table 2.1). Note that all apparent temperatures that we calculated for rutile and non-rutile bearing adjacent samples are within $95 \%$ confidence interval. 
Recrystallized quartz grains analyzed in this study exhibit highly interlobate to amoeboid grain boundaries. These microstructures, along with the typically homogeneous within-grain $\mathrm{Ti}$ variation (Section 2.5.1), imply that the chief mechanism responsible for $\mathrm{Ti}$ distribution within the quartz grains was dynamic recrystallization via high-temperature GBM. Based on this extensive crystallization, and the lack of any clear lithological control on the Ti content in quartz, I infer that the chief physical or chemical process responsible for the equilibration of $\mathrm{Ti}$ in quartz grains was recrystallization by GBM. This GBM may have included diffusion of Ti into grain-boundary fluids during the rapid migration of grain boundaries that accompanied continuing deformation (Grujic et al., 2011). This inference is similar to that of Grujic et al. (2011), who used the TitaniQ to elucidate how Ti equilibrated in quartz grains in the exhumationally static situation of a metamorphic aureole around the Adamello pluton near the Tonale Fault Zone in northern Italy. These authors argue that GBM was the chief process causing re-equilibration of Ti within and between quartz grains, with a possible subordinate contribution by pipe diffusion along dislocation pathways in the deformed quartz grains.

The mean Ti content in quartz and its variance may have been chiefly influenced by the ratio of the rock's rate of cooling and recrystallization during the rapid exhumation of the gneisses. As previously discussed, the widespread presence of a melt phase (leucosomes) in the migmatitic rocks in the D'Entrecasteaux Islands implies that rocks with a granodioritic composition (gneiss protoliths) were once heated to temperatures of $>650{ }^{\circ} \mathrm{C}$ (Fig. 2.6; Brown, 2008; Hacker, 2006; White, 2008). In addition, the common presence of chessboard subgrains structure in quartz implies temperatures of at least $630 \pm 30^{\circ} \mathrm{C}$ during the exhumation history of the rocks (Fig. 2.6; Stipp et al., 2002); however, 93\% of the measured TitaniQ apparent temperatures are $<630{ }^{\circ} \mathrm{C}$ (Table 2.1). Based on these temperature constraints, and the pervasive evidence of GBM in these quartz grains, I suggest that the observed $\mathrm{Ti}$ content in quartz in the exhumed rocks reflects a competition between two processes: a) the rate by which the rocks cooled during their exhumation, leading to a progressively lower $\mathrm{Ti}$ concentration being present in subsequent generations of quartz grains, and b) the rate of dynamic recrystallization, which controls the time scale of Ti-resetting in the deforming aggregate of quartz grains. This relationship may be visualized in newly recrystallized grains as: 
$\left[T i_{q t z}\right] \propto \frac{\text { cooling rate }}{\text { recrystallisation rate }}$

where $\left[T i_{q t z}\right]$ is the mean Ti concentration in a sample of dynamically recrystallized quartz grains (in ppm by weight). As previously discussed, dynamic recrystallization together with diffusion into grain-boundary fluids along merging grains boundaries may have controlled the re-distribution of Ti within and between the assemblage of relict and new quartz grains that compose a sample. Thus, either a fast cooling rate or a low rate of recrystallization would result in the preservation of a large fraction of relict high-temperature grains in a sample. On the other hand, if the rate of cooling is low or the rate of dynamic recrystallization is fast, then few such relict hightemperature grains will be preserved in a rock that has been exhumed from hightemperature conditions at depth. Recrystallization would have terminated abruptly after the rocks were exhumed into the upper crust at $<2 \mathrm{Ma}$, after which the rocks are known to have cooled rapidly below temperatures of $300{ }^{\circ} \mathrm{C}$ at rates of $>100{ }^{\circ} \mathrm{C} \mathrm{Ma}^{-1}$ (Baldwin et al., 1993; Little et al., 2011). After dynamic recrystallization ceased, the amoeboid grain structure would have been frozen in together with the observed $\mathrm{Ti}$ contents of these grains.

My hypothesis that the mean $\mathrm{Ti}$ content in quartz grains is controlled by the ratio of the rate of cooling versus the rate of recrystallization is supported by Fig. 2.11, which illustrates a linear relationship between the mean $\mathrm{Ti}$ concentration of each sample in ppm and the $95 \%$ confidence interval of the mean Ti concentration for each sample (correlation coefficient $=0.82$ ). Assuming a constant rate of recrystallization, a sample with a relatively fast cooling rate would contain not only a sub-population of newly formed low-temperature grains, but also a relict population of grains with high $\mathrm{Ti}$ content. As recrystallization is continuous, the quartz assemblage in this fast-cooling sample would include quartz grains with relatively lower $\mathrm{Ti}$ content, resulting in a diverse quartz assemblage and a high standard deviation of Ti concentration within this sample. By contrast, a population of quartz grains with a more uniform $\mathrm{Ti}$ content might dominate a thoroughly recrystallized sample that has experienced a slow cooling rate. The recent study by Grujic et al. (2011) suggests that there is a wider within-sample spread of Ti in zones with GBM, relative to zones with low-temperature deformation regimes (bulging recrystallization and subgrain rotation recrystallization). This relationship supports 
my conclusion that a shorter equilibration period (and/or a fast cooling rate) results in large scatter of Ti content between individual quartz grains in a single sample.

\subsubsection{Interpretation of the spatial pattern of TitaniQ apparent temperatures}

If equation 2.7 is approximately correct, and if I assume the rate of recrystallization varies less than the rate of cooling across the gneiss domes in the D'Entrecasteaux Islands, then gradients in mean Ti concentrations and TitaniQ apparent temperatures may be interpreted as a proxy for gradients in cooling rates within these domes. Thus, in a rapidly exhuming body an area with predominantly high mean $\mathrm{Ti}$ concentrations would signify a zone of high cooling rate, and an area with predominantly low mean Ti concentrations could signify a zone of low cooling rate. For a steady-state scenario, such relative differences in cooling rates might also correspond to zones of higher and lower exhumation rates, and higher and lower finite exhumation levels. Exhumation in the D'Entrecasteaux Islands was nearisothermal from the mantle to the middle crust (Fig. 2.6), therefore any gradients in cooling rates observed across the domes (via proxy) would have been created as the gneiss domes in the middle to upper crust (Baldwin et al., 1993; Baldwin et al., 2004; Baldwin et al., 2008). At the time of final dome emplacement, the Ti content was locked in when dynamic recrystallization by high-temperature GBM ceased, preserving the gradients in cooling rates and exhumation rates.

The inwardly increasing pattern of mean $\mathrm{Ti}$ concentrations across the D'Entrecasteaux Island gneiss domes implies that the most rapid rates of cooling and exhumation did not occur in proximity to the dome-bounding normal faults, but in the central part of each gneiss dome (Fig. 2.15a-e). When all samples are divided into core zone and carapace zone categories, the former averages a Ti concentration of $\sim 20 \pm 3 \mathrm{ppm}(2 \sigma)$ and the latter averages $11 \pm 1 \mathrm{ppm}(2 \sigma)$, implying that the core zones were "hotter" at the time of final quartz recrystallization relative to the carapace samples (Fig. 2.12b, 2.12e). Although the Ti concentrations gradients include significant variability or "noise", all mean Ti concentrations gradients in Fig. 2.15 indicate a statistically robust increase of $\mathrm{Ti}$ content in quartz away from the dome margins. The dome with the highest increase in apparent cooling rates from the 
margin into the interior is the Goodenough dome (Wakonai Fault; Fig. 2.15a), possibly because samples here originate from the Goodenough gorge (Fig. 2.13). This 200 meter deep gorge has eroded the Goodenough dome more deeply than any of the other gorges sampled here. In other words, the samples from the Goodenough gorge represent the deepest exposed structural level in a dome, which has not been sampled in the other less eroded domes of the D'Entrecasteaux Islands. Alternatively, the high $\mathrm{Ti}$ content in the interior of the Goodenough dome may suggest that this area experienced a fast cooling and exhumation rate that relative to the other dome interiors. The second highest increase in relative cooling rates is seen in the southeast of the northwest Normanby dome (Fig. 2.15d), a locality that has five analyzed samples that are closely spaced. The transect orientation in the latter dome is nearly orthogonal to the main foliation, which dips particularly steeply on the dome margins. This steep dip would decrease the horizontal separation between samples of contrasting original structural depth. The other three transects (Fig. $2.15 \mathrm{~b}, \mathrm{c}, \mathrm{e})$ yielded similar inward increases in mean Ti content in quartz and apparent relative cooling rates. The low increase in mean Ti concentration within the Mailolo dome (Fig. 2.15b) may be the result of the shallow foliation dips within this dome relative to the other domes, and a low amount of erosion of that dome relative to the more deeply incised Goodenough dome.

I acknowledge that the linear relationship between Ti content and horizontal position in the domes (Fig. 2.15) is not strong, as is expressed by the small $\mathrm{R}^{2}$ values for the regressed lines $\left(\mathrm{R}^{2}=0.03-0.36\right)$. The statistical probability that the signs of the slopes of the regressed lines in Fig. 2.15 are actually zero or negative was assessed using a one-sided t distribution. See Appendix B.3 for slope standard deviation and probabilities. This analysis indicates that the linear relationship between $\mathrm{Ti}$ concentration and distance from the fault has a $<8 \%$ probability of having a negative slope (with Ti concentration increasing towards the dome margins) for the Wakonai, Mwadeia, Morima, and southeast Normanby faults and fault zones. The northwest Normanby regression has a $35 \%$ probability of an increase in Ti concentration towards the dome margins.

The low $\mathrm{R}^{2}$ values of the linear regressions in Fig. 2.15 reflect up to $30 \mathrm{ppm}$ of sample-to-sample variation in mean Ti concentration. The causes of such variability 
include infiltration of local, chemically diverse Ti-bearing fluids, the composition of which affected the Ti content of quartz grains in the certain samples prior to the final high-temperature GBM recrystallization. Additionally, inclusions of Ti-bearing impurity phases (e.g. rutile exsolution needles) in the material measured by the LAICP-MS would have caused apparent differences in $\mathrm{Ti}$ concentrations that are unrelated to the temperature of quartz growth or recrystallization. Another possible source of sample-to-sample variation in $\mathrm{Ti}$ is the core and rim variations in $\mathrm{Ti}$ content in the quartz grains (Section 2.5.1). This zonation implies that post-growth GBM recrystallization did not cause a complete $\mathrm{Ti}$ equilibration to a uniform $\mathrm{Ti}$ concentration for all quartz grains in every lithology of the D'Entrecasteaux Islands. The thin rims (pattern a, Section 2.5.1) have a length scale of a few tens of microns at the extreme; therefore this within-grain $\mathrm{Ti}$ content variation is volumetrically insignificant and could not cause the observed sample-to-sample variation in $\mathrm{Ti}$ concentration (Fig. 2.15). Where observed, the relict growth zoning (pattern b and c, Section 2.5.1) has a length scale of $300-500 \mu \mathrm{m}$ (Fig. 2.9f,h). Across one such zone in a sample of migmatitic gneiss the relative difference in Ti concentration is $\sim 22$ ppm (09-004civ; Fig. 2.9e,f). Relict (unrecrystallized) quartz grains in analyzed samples of metamorphic granodiorite (Fig. 2.9e,f) and retrogressed eclogite (Fig. $2.9 \mathrm{~g}, \mathrm{~h}$ ) would therefore contribute spot analyses with Ti concentrations that are high relative to the mean Ti content in a sample, which is volumetrically dominated by recrystallized quartz grains that are younger and have a lower Ti content.

\subsubsection{Comparison of TitaniQ apparent temperatures to ${ }^{40} \mathrm{Ar} /{ }^{39} \mathrm{Ar}$ cooling ages}

The majority of the ${ }^{40} \mathrm{Ar} /{ }^{39} \mathrm{Ar}$ cooling ages for white mica and biotite determined by (Baldwin et al., 1993) for samples in the D'Entrecasteaux Islands exhibit relatively flat age spectra, implying that the samples cooled rapidly $\left(200-400{ }^{\circ} \mathrm{C} \mathrm{Ma}^{-1}\right)$ and were not disturbed once they cooled below the closure temperature (Dodson, 1973). The closure temperature for $\mathrm{Ar}$ is $350-450{ }^{\circ} \mathrm{C}$ in white mica, and $300-350{ }^{\circ} \mathrm{C}$ in biotite (Baldwin et al., 1993; McDougall and Harrison, 1999). Fig. 2.19 exhibits a plot of TitaniQ apparent temperatures as a function of white mica and biotite ${ }^{40} \mathrm{Ar} /{ }^{39} \mathrm{Ar}$ cooling ages for samples adjacent to samples used in the Baldwin et al., (1993) study. Fig. 2.19 implies a correlation may exist between the white mica and biotite ${ }^{40} \mathrm{Ar} /{ }^{39} \mathrm{Ar}$ cooling ages and the TitaniQ apparent temperatures (correlation 


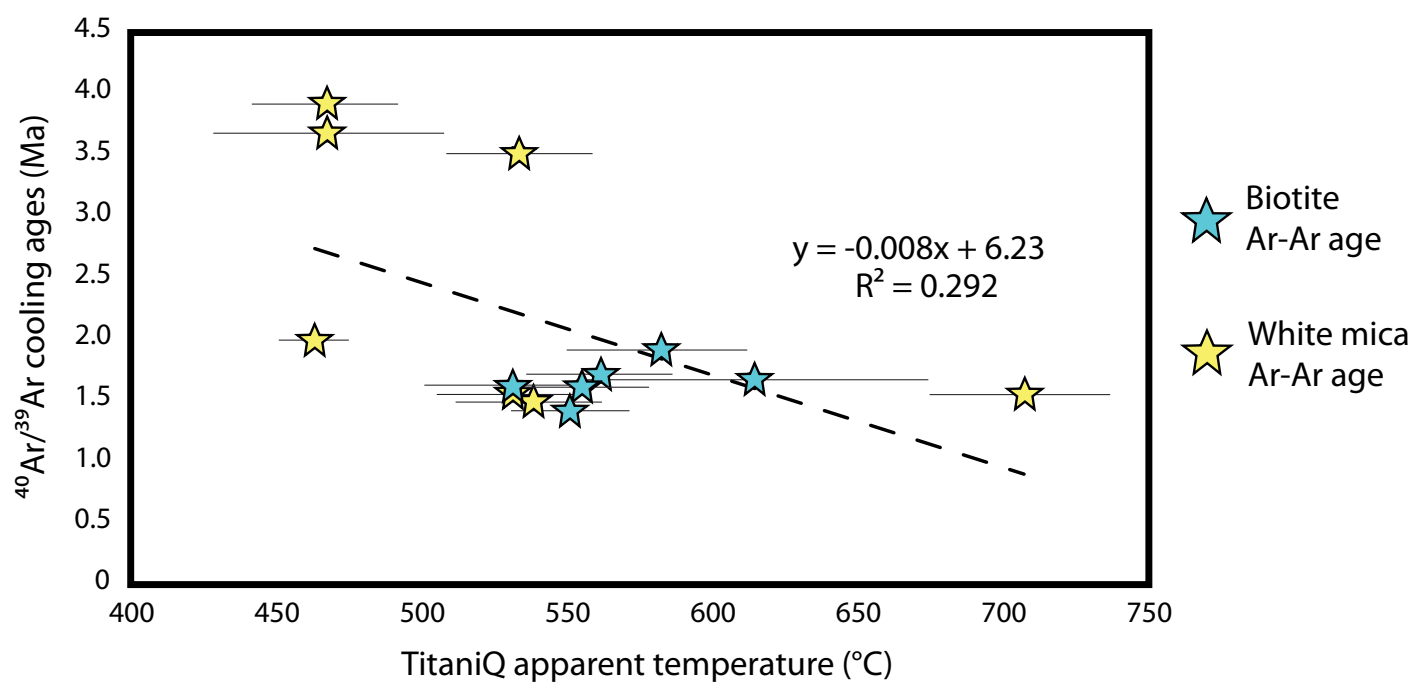

Figure 2.19 ${ }^{40} \mathrm{Ar} /{ }^{39} \mathrm{Ar}$ cooling ages from Baldwin et al. (1993) as a function of TitaniQ apparent temperatures calculated in this study using the Wark and Watson (2006) calibration. There is $<1 \mathrm{~km}$ vertical seperation between the samples from which the ${ }^{40} \mathrm{Ar} /{ }^{39} \mathrm{Ar}$ cooling ages were calculated and the TitaniQ samples presented in this graph. Note that the higher TitianiQ apparent temperatures correspond to younger cooling ages (correlation coefficient $=-0.54$ ). The errors in the TitaniQ apparent temperatures are $95 \%$ confidence intervals and include analytical, calibration, and Ti activity uncertainty (Section 2.5.2, Table 2.1). 
coefficient $=-0.54)$. In other words, samples with the youngest cooling ages experienced the most rapid cooling and yielded the highest TitaniQ apparent temperatures. This relationship supports my inference that the Ti content in quartz was chiefly controlled by the rate of cooling in the rocks as they dynamically recrystallized. The ${ }^{40} \mathrm{Ar} /{ }^{39} \mathrm{Ar}$ data is, however, currently too sparse to make any clear inferences regarding spatial gradients in ${ }^{40} \mathrm{Ar} /{ }^{39} \mathrm{Ar}$ cooling ages across the gneiss domes (Baldwin et al., 1993).

\subsubsection{Kinematics of gneiss dome emplacement in the D'Entrecasteaux Islands}

The lack of evidence for any increase in exhumation rates or cooling rates outward towards the dome-bounding faults supports a symmetric doming (or diapiric) model of gneiss dome formation (Fig. 2.2a). Cooling rates within a rising diapir will be relatively slow compared to those near their margins (Faydon et al., 2004). Within an asymmetrical metamorphic core complex, cooling rates are predicted to be fastest immediately adjacent to the detachment, where the most rapidly exhumed and hottest footwall rocks will be juxtaposed against the relatively cold hanging wall (Faydon et al., 2004). This asymmetrical juxtaposition will result in a maximum predicted cooling rate immediately adjacent to the detachment faults. In the D'Entrecasteaux Islands, however, the highest $\mathrm{Ti}$ content and TitaniQ apparent temperatures are located in the interiors of the gneiss domes (Fig. 2.13).

The two models I have compared here are end-members and a continuum between detachment-related metamorphic core complexes and the pure-shear symmetric doming is likely to exist in nature (Leech, 2001; Little et al., 2011; Norlander et al., 2002; Whitney et al., 2004). This continuum may in part result from competition between localized slip on the normal dome-bounding faults and gravitational forces that affect the gneiss domes and metamorphic core complexes (Little et al., 2011). For example, Whitney et al. (2004) state that diapirism may have a passive role in extension, resulting in the exhumation of metamorphic core complexes. It is also possible for gneiss domes to be nested within metamorphic core complexes (i.e. the Thor-Odin dome within the Shuswap metamorphic core complex; Hinchey and Carr, 2006; Norlander et al., 2002; Whitney et al., 2004). For example, the Mailolo dome 
contains a partial melt component that is low compared to that of the Goodenough dome (Section 2.2.2). This apparent difference in partial melt may have resulted in a lower buoyancy force and a greater component of localized slip affecting the uplift of the gneisses, and may have contributed to the unclear pattern of TitaniQ apparent temperatures shown in Fig. 2.13 and 2.15b.

A dominantly pure-shear symmetric diapiric origin for the gneiss domes is supported by the structural geology of the D'Entrecasteaux Islands (Little et al., 2011). Evidence for this includes stretching lineation trends that are nearly orthogonal to the direction of the rifting of the Woodlark and Australian plates, implying a gravitational driving force for the dome emplacement and decoupling of the domes from extensional plate tractions in the rift (Little et al., 2011). Moreover, shearsenses in the domes are bivergent, implying an approximate bulk pure-shear deformation (Little et al., 2011). In addition, the rocks in the D'Entrecasteaux Islands contain structural evidence of a pure-shear dominated deformation, including lattice preferred orientations of quartz that exhibits orthorhombic symmetry (Little et al., in prep.). In parallel with the TitaniQ apparent temperature trends shown here, quartz crystallographic preferred orientations suggest an inward temperature increase from $400-500{ }^{\circ} \mathrm{C}$ (type 1 crossed girdle) to temperatures of $>650{ }^{\circ} \mathrm{C}$ (prism-c) from the dome margins to their interiors (Little et al., 2010; Little et al., 2011). Also the inward increase in abundance of leucosomes and pluton volume into the core of the gneiss domes implies higher temperatures (and greater exhumation rates) in the cores of the domes relative to the dome margins.

It is important to note that the models for dome development I have considered are concerned only with the mode of final emplacement into the crust, rather than any of the older and deeper UHP history. The recrystallization of quartz grains within the crust represents only the final phase of a progression in recrystallization, beginning at the original eclogite-facies crystallization and metamorphism at UHP depths in the mantle (Fig. 2.6). The dominant model proposed here for the crustal exhumation accords with the diapiric exhumation from the mantle to the lower crust inferred by Little et al. (2011) on the basis of structural data. 


\subsection{Conclusions}

Based on the predominantly homogenous intra-granular Ti distribution observed here by $\mathrm{CL}$, and the pervasive evidence of dynamic recrystallization by high-temperature GBM, I conclude that the Ti content in quartz in rocks from the D'Entrecasteaux Islands are related to the final crustal emplacement of the gneiss domes. The presence of a pervasive melt phase and of chessboard microstructures in quartz implies that the rocks in the D'Entrecasteaux islands were once heated to temperatures $>630^{\circ} \mathrm{C}$. Based on these temperature constraints, and the evidence of dynamic recrystallization, I suggest that the sample-averaged Ti content within the quartz grains in a hot and rapidly exhuming body depend on the relative rates of cooling and recrystallization in the body in the final phase of its ascent. Where the recrystallization rate varies less than the cooling rate across the rising body, $\mathrm{Ti}$ concentrations in quartz and TitaniQ apparent temperatures may be used as a proxy for relative cooling rates and may help constrain the exhumational processes.

Spatial gradients in $\mathrm{Ti}$ concentrations and deformational TitaniQ apparent temperatures are used here to constrain exhumation and cooling rates across the D'Entrecasteaux Islands. This is a novel application of the TitaniQ, and is particularly useful given the absence of mappable metamorphic isograds or metamorphic field gradients in these domes. I have demonstrated that higher mean $\mathrm{Ti}$ concentrations $(20->100 \mathrm{ppm})$ are found in the interior of the gneiss domes and relatively low mean Ti concentrations $(2.5-25 \mathrm{ppm})$ are found near their margins. The Ti content in quartz is intrinsically variable from one sample to the next, suggesting competing causes for $\mathrm{Ti}$ variation. I conclude, however, that the mean $\mathrm{Ti}$ concentrations and TitaniQ apparent temperatures in all four of the gneiss domes studied here increase inward into the dome core and away from the dome-bounding normal faults in a statistically robust way. The occurrence of the highest cooling rates in the interior of the gneiss domes, and in particular the lack of any unidirectional increase in $\mathrm{Ti}$ concentration toward the bounding normal faults, suggests that the gneiss domes in the D'Entrecasteaux Islands are not detachment-driven but are diapiric in origin. The data presented here supports previous structurally based 
arguments by Little et al. (2011) that these gneiss domes were emplaced within the crust by predominantly pure-shear symmetric doming. 


\section{Rb-Sr dating of eclogite- and amphibolite-facies metamorphism in the D'Entrecasteaux Islands, southeastern Papua New Guinea}

\subsection{Introduction}

The exhumation of coesite-bearing eclogite-facies rocks from ultrahigh-pressure (UHP) depths can occur at plate tectonic rates ( $\mathrm{cm} \mathrm{yr}^{-1}$; Baldwin et al., 2008; Chopin, 1984; Chopin, 2003; Glodny et al., 2005b; Parrish et al., 2006; Rubatto and Hermann, 2001; Smith, 1984). For example, the Dora Maira UHP terrane in the western Alps was exhumed from depths of $110 \mathrm{~km}$ to depths of $<20 \mathrm{~km}$ at rates of $3.4-1.6 \mathrm{~cm} \mathrm{yr}^{-1}$ (Rubatto and Hermann, 2001). This rapid speed of exhumation from UHP conditions ( $>28 \mathrm{kbar}$ ) to the lower crust results in a short time lag between the original eclogite-facies crystallization at $>90 \mathrm{~km}$ and any subsequent metamorphic retrogression in the lower crust (Baldwin et al., 2008; Gordon et al., in review; Holm et al., 1967; Monteleone et al., 2007). Because of the short time lag between metamorphism in the mantle and emplacement in the upper crust for rapidly exhumed UHP terranes, a single process may be predominantly responsible for the bulk of this exhumation (Little et al., 2011).

The D'Entrecasteaux Islands in southeastern Papua New Guinea (PNG) are comprised of several gneiss domes that consist chiefly of amphibolite-facies quartzofeldspathic gneiss (Fig. 3.1, 3.2; Chapter 2 this thesis). This metamorphic terrane includes mafic blocks that preserve an eclogite-facies mineral assemblage ( 5 - 10\% volume; Little et al., 2011). To date, U-Pb geochronology on zircons and LuHf geochronology on garnets yields age estimates of 8 to $4 \mathrm{Ma}$ for the timing of the (U)HP metamorphic crystallization in these regionally metamorphosed gneisses (Baldwin et al., 2004; Gordon et al., in review; Monteleone et al., 2007). One particularly well-preserved block of eclogite on west Fergusson Island contains coesite inclusions in garnet, which implies that some, or perhaps all, of the D'Entrecasteaux Island metamorphic terrane was subducted to UHP conditions (Baldwin et al., 2008; Little et al., 2011; Monteleone et al., 2007). Subsequent to

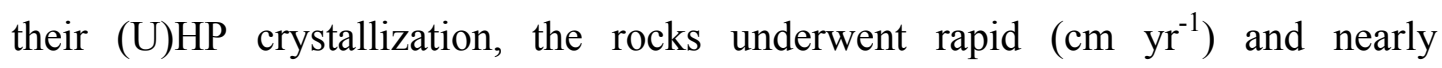




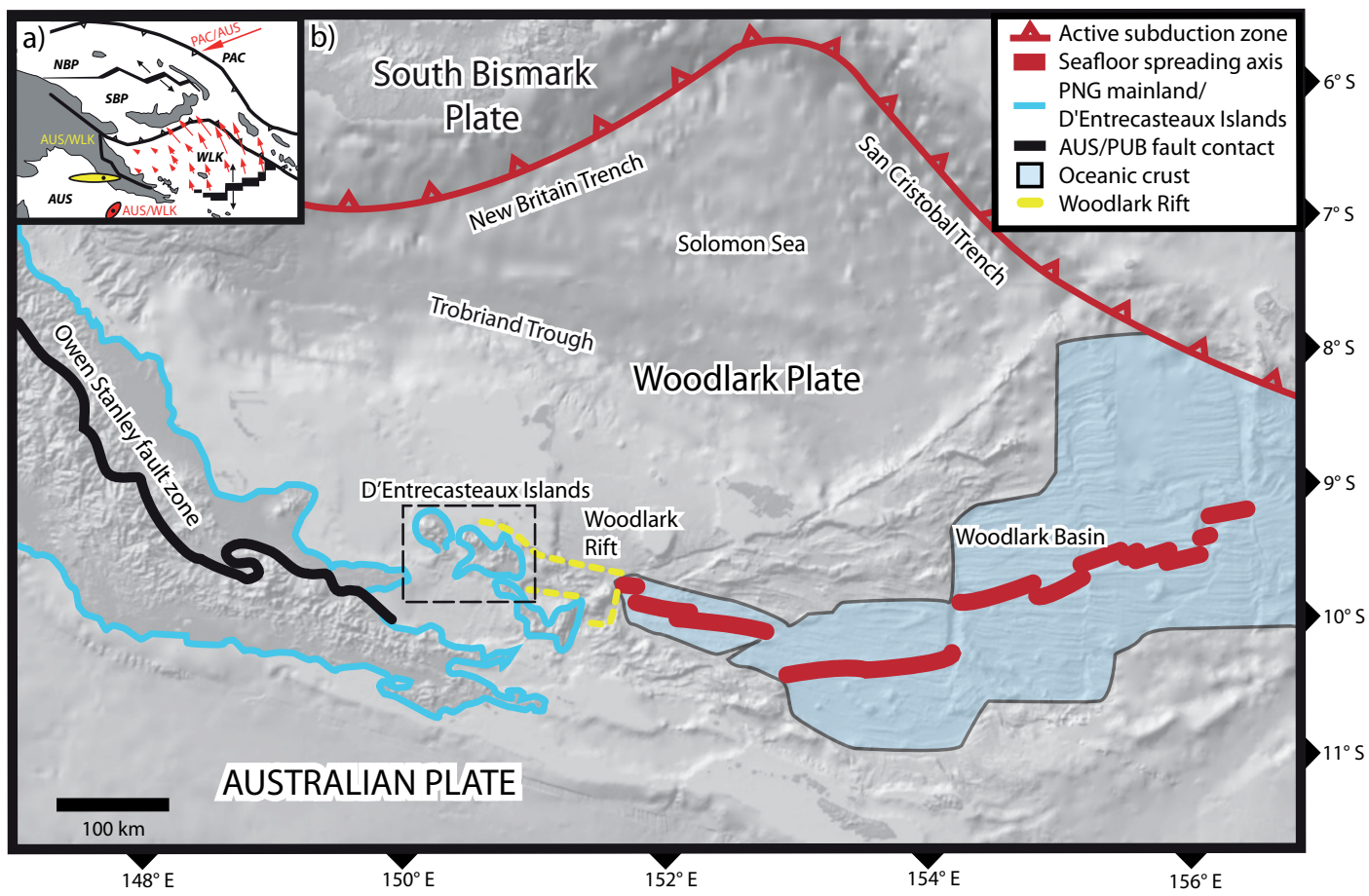

Figure 3.1 (a) Plate tectonic map of eastern Papua New Guinea. Adapted from Wallace et al. (2004), Webb et al. (2008), and Little et al. (2011): PAC, Pacific Plate; AUS, Australian Plate; WLK, Woodlark Plate, NBP; North Bismark Plate, SBP; South Bismark Plate. Direction of movement of the Pacific Plate relative to the Australian Plate shown by the bold red arrow. Pole of WLK-AUS relative rotation (with error ellipse) for the present-day (after Wallace et al., 2004). Pole of WLK-AUS relative rotation (with error ellipse) for 3.6-0.5 Ma (after Taylor et al., 1999). The small red arrows depict the current velocities of the Woodlark Plate relative to the Australian Plate (after Wallace et al., 2004). (b) Simplified tectonic map of southeastern Papua New Guinea. Background is a Digital Elevation Model from GeoMapApp (http://www.GeoMapApp.org). Location for figures 3.2 and 3.4 is shown in the dashed box. Location of Woodlark Rift zone after Baldwin and Ireland (1995). 


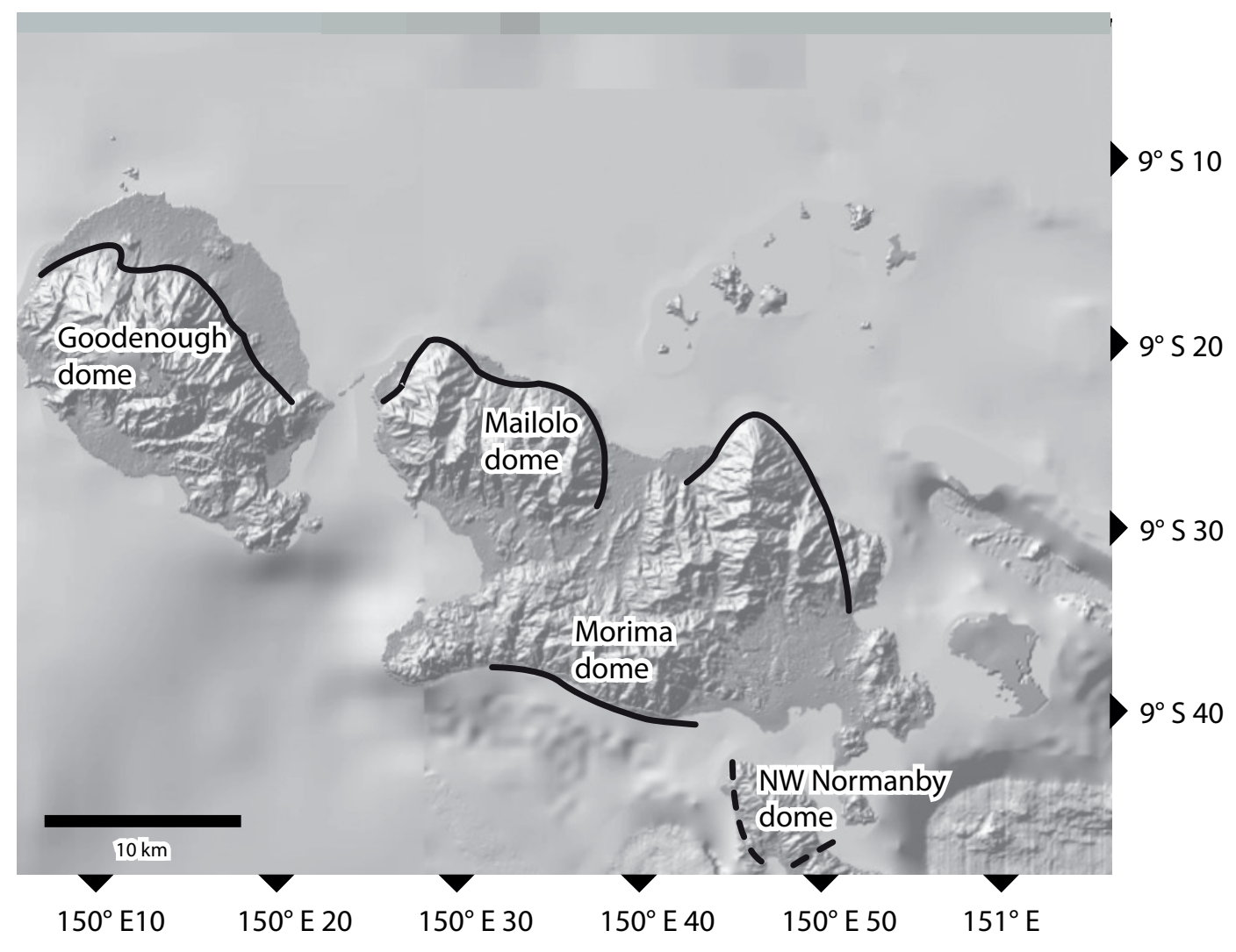

Figure 3.2 Digital Elevation Model of the northwest D'Entrecasteaux Islands from GeoMapApp (http://www.GeoMapApp.org). Note locations of main dome-bounding normal faults (solid black lines) and faults zones (dashed black lines). See Figure 3.1b for location. Note locations of gneiss domes described in text. 
isothermal decompression from mantle to lower crustal depths, arriving in the lower crust by 4 - 2 Ma (Baldwin et al., 1993; Baldwin et al., 2004; Baldwin et al., 2008). The (U)HP terrane was finally emplaced into the upper crust as gneiss domes from $\sim 2 \mathrm{Ma}$, at which time they underwent rapid cooling $\left(>100{ }^{\circ} \mathrm{C} \mathrm{Ma}^{-1}\right.$; Baldwin et al., 2004). As these eclogites are late Neogene in age, this is the youngest known age of UHP metamorphic rocks on Earth. By contrast, other global examples of (U)HP terranes are generally Oligocene in age or older; for example the Western Gneiss Region in Norway experienced UHP conditions in the late Silurian and early Devonian ( 425 - 400 Ma; e.g. Kylander-Clark et al., 2008) and the Dabie-Sulu UHP terrane in China in the mid-Triassic (235 - $225 \mathrm{Ma}$; e.g. Liu and Liou, 2011). The active, well-constrained geodynamic context and the limited metamorphic or deformational overprinting unrelated to the UHP exhumation process in the D'Entrecasteaux Islands, provides an opportunity to refine the current understanding of the kinematics of the (U)HP exhumation process.

The timing of the UHP eclogite-facies crystallization and the subsequent upper amphibolite-facies overprint in the lower crust within gneiss domes of the D'Entrecasteaux Islands (Fig. 3.3) has previously been approached by $\mathrm{U}-\mathrm{Pb}$ and $\mathrm{Lu}-$ Hf geochronology. The U-Pb method has been used to date crystallization of zircon during both the eclogite- and amphibolite-facies metamorphism (i.e. Baldwin and Ireland, 1995; Baldwin et al., 2004; Gordon et al., in review; Monteleone et al., 2007), and Lu-Hf dating has constrained the timing of garnet crystallization at UHP conditions (Zirakparvar et al., 2011). In addition, white mica and biotite ${ }^{40} \mathrm{Ar} /{ }^{39} \mathrm{Ar}$ cooling ages and apatite fission track dating has constrained the timing of cooling through the crust (Baldwin et al., 1993; Fitzgerald et al., 2008). These techniques have dated either the growth or crystallization of zircon and garnet, or the late-stage cooling of the rocks through the crust. Direct dating of the deformation that accompanied the formation of eclogite- and amphibolite-facies rock fabrics of the youngest known UHP terrane on Earth has so far not been attempted.

The $\mathrm{Rb}-\mathrm{Sr}$ internal mineral isochrons dating technique may be used to date syndeformational mineral growth that results in the formation of a polyphase rock fabric (Glodny et al., 2002; Glodny et al., 2005b). Grain-scale fluid-rock interactions that take place during deformation and metamorphism are thought to cause $\mathrm{Sr}$ isotope re- 


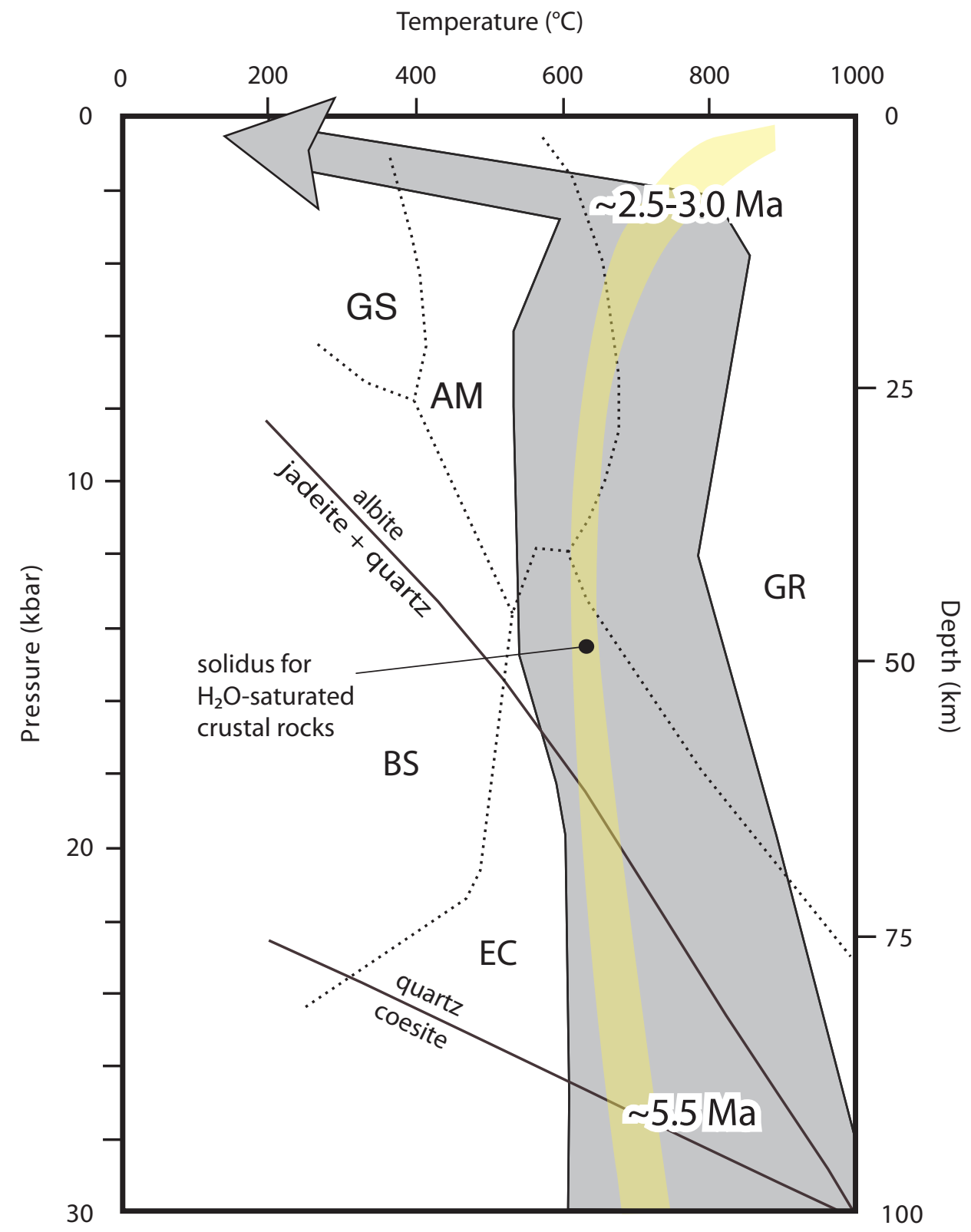

Figure 3.3 Grey shaded area shows pressure-temperature (P-T) path from the mantle to the surface of the ultra-high pressure gneiss in the Mailolo dome in the D'Entrecasteaux Islands: GS, greenschist; AM, amphibolite; BS, blueschist; EC, eclogite; GR, granulite.. Adapted from Baldwin et al. (2004, 2008) and Little et al. (2011). Timing of eclogite-facies ( 5 Ma) and amphibolite-facies metamorphism ( 2.5 - 3.0 Ma) after Rb-Sr ages presented here and Gordon et al. (in review). Note that the $3.0 \mathrm{Ma}$ upper bound of this metamrophic reation represents the oldest syn-tectonic granitic dikes dated by $\mathrm{U}-\mathrm{Pb}$ zircon ages, and the $\sim 2.5 \mathrm{Ma}$ lower bound represents $\mathrm{Rb}$-Sr closure and late dike intrusion (see text). Exhumation path after P-T data from Hill and Baldwin (1993). P-T data for the solidus for $\mathrm{H}_{2} \mathrm{O}$-saturated crustal rocks after Hacker (2006) and Little et al. (2011). 
distribution and re-equilibration between mineral phases (Glodny et al., 2003). Any preservation of minerals and fabrics attributed, to a particular metamorphic phase or fabric-forming event implies a corresponding $\mathrm{Sr}$ relict isotopic signature may also be preserved, provided that: (1) the sample selection allows differentiation between rock fabrics of different ages, and (2) the Sr isotopic system has remained closed (Glodny et al., 2002; Glodny et al., 2003) Dating by Rb-Sr internal mineral isochrons may therefore be used to constrain the timing of deformation and metamorphic events in poly-metamorphic terranes (Glodny et al., 2003; Glodny et al., 2005b).

I have analyzed nine samples from the D'Entrecasteaux Islands using $\mathrm{Rb}$-Sr internal mineral isochrons. Constraints on the timing of the prograde UHP metamorphism and the retrogressive amphibolite-facies events allow us to measure the time lag between earlier and later metamorphic events, and apply a previously untried radiometric technique to the gneiss and eclogites in the D'Entrecasteaux Islands. Moreover, it provides a means of dating the ductile deformation that was coincident with these metamorphic phases. These new data sets are used here to place constraints on the unroofing rate during exhumation of the gneiss domes. In addition, I present new geothermobarometric estimates from five samples of quartzofeldspathic gneiss and quartzose rock, which refine the current constraints on pressure and temperature conditions that prevailed in the lower crust during the amphibolite-facies retrogression of the (U)HP terrane.

\subsection{Geologic and tectonic setting}

\subsubsection{Regional tectonics}

Eastern PNG is situated within a mosaic of microplates between the Pacific and Australian plates, which includes the Woodlark microplate (Fig. 3.1; Wallace et al., 2004). Motion between these microplates accommodates $\sim 110 \mathrm{~mm} \mathrm{yr}^{-1}$ of northnorthwest to south-southeast horizontal motion (Wallace et al., 2004). The continental Woodlark Rift separates the Woodlark Plate to the north from the Australian plate to the south, and transitions eastward along strike into the Woodlark 
Basin oceanic spreading center (Fig. 3.1; Taylor et al., 1999; Wallace et al., 2004). The D'Entrecasteaux Islands are situated $\sim 100 \mathrm{~km}$ to the west of the tip of the Woodlark Basin spreading center (Fig. 3.1). This spreading center has been actively spreading since $\sim 6 \mathrm{Ma}$ and has propagated westward through previously thickened orogenic continental crust of the Papuan Orogen at a rate of $\sim 150 \mathrm{~km} \mathrm{Ma}^{-1}$ (Taylor et al., 1999). The Papuan Orogen developed in the early to middle Eocene as the result of an arc-continent collision that emplaced the Cenozoic Papuan Ultramafic Body over Australian crustal material along the Owen Stanley Fault zone (Davies and Jacques, 1984; Lus et al., 2004). The shedding of metamorphic debris as conglomerate in the offshore region to the north of the D'Entrecasteaux Islands indicates that the gneiss domes had become emergent in the Pliocene (Baldwin et al., 1993; Davies and Warren, 1988). Elevated coral platforms of probable Holocene age on the southeast coast of Goodenough Island and incised flights of river terraces on the northeastern coastal plains of Goodenough Island indicate that uplift of the D'Entrecasteaux Islands has persisted, if only slowly, into the Late Quaternary (Little et al., 2011).

\subsubsection{Structural geology of the D'Entrecasteaux Islands}

The Goodenough, Mailolo, and Oiatabu gneiss domes are bounded by active north or northeast-dipping normal faults on the northeast margins of the domes (Fig. 3.2. 3.4). The Morima dome is bounded to the southwest by an active southwest-dipping normal fault (Fig. 3.2. 3.4). These faults separate un-metamorphosed late Quaternary alluvial sediments and volcanic rock in the hangingwall, from erosional remnants of the Cenozoic Papuan Ultramafic Body and underlying amphibolite-facies gneisses in their footwall (Fig. 3.4; Hill, 1994; Little et al., 2011). These normal faults are interpreted as late-stage faults that are related to the Woodlark Rift and post-date the UHP exhumation and most of the dome formation (Little et al., 2011). Where exposed in the northeast of Goodenough Island the Wakonai normal fault dips 35 $40^{\circ}$ (Fig. 3.4; Little et al., 2011). Structural data suggest that Goodenough and Mailolo Domes have been back-tilted $\sim 20^{\circ}$ to the southwest as a result of slip on the dome-bounding faults, implying an original dip for the faults of $\sim 55-60^{\circ}$ (Little et al., 2011). 


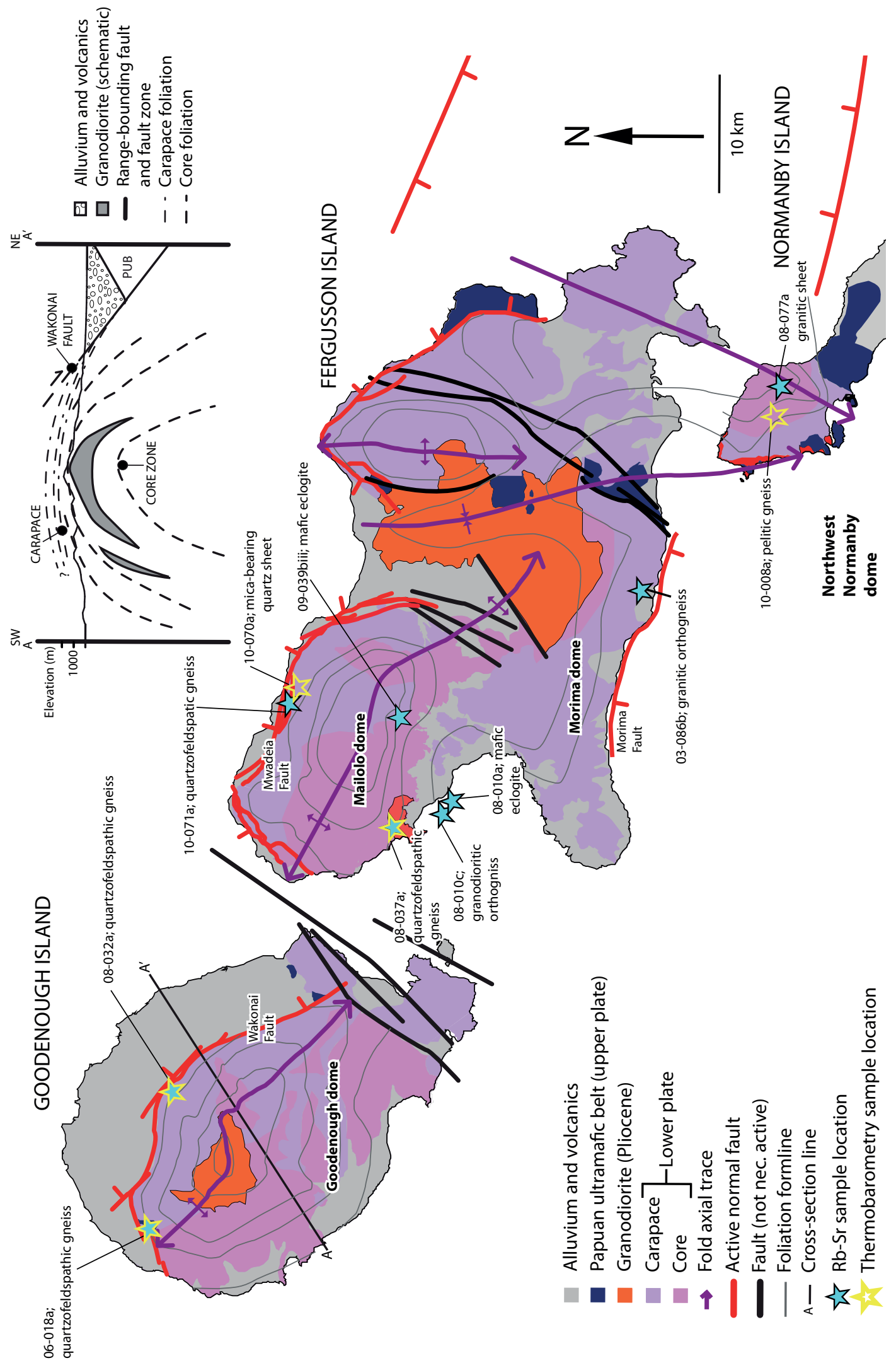

Figure 3.4 Simplified tectonic and geologic map of the northwest D'Entrecasteaux Islands showing sample locations and sample lithology, adapted from Hill (1994) and Little et al. (2011): PUB, Papua Ultramafic Belt; Volc., volcanics. See Figure 3.1b for location. Inset: Schematic cross section along profile A-A' (no vertical exaggeration) after Little et al. (2011). 
The footwalls of these normal faults consist of high-grade gneiss domes that are $2-$ $2.5 \mathrm{~km}$ high at their crests (Chapter 2 this thesis). These domal culminations of gneiss are topographically well expressed, and are rounded or elongate in map view. The gneiss domes are separated by tight synforms (Fig. 3.4), and are comprised of amphibolite-facies quartzofeldspathic gneiss $(\sim 60 \%)$, much of it orthogneiss, and younger Pliocene-aged granodiorite to granitic dikes and plutons (35\%; Fig. 3.5; Little et al., 2011 and ref. therein). Marbles and pelites are rare $(<1 \%$; Little et al., 2011 and ref. therein). The once continuously overlying sheet of ultramafic rock of the Cenozoic Papuan Ultramafic Body has now largely been eroded from the uplifted centers of the gneiss domes and is preserved in a scatter of small remnants exposed in structural lows (Fig. 3.4; Little et al., 2011). On the basis of their structural fabrics, the domes can be divided into two structural zones: a structurally higher carapace zone (up to $\sim 1.5 \mathrm{~km}$ thick) and a deeper core zone (Fig. 3.4; Hill, 1994; Little et al., 2011). The migmatitic core rocks are typically banded on a cm-scale with an anastomosing foliation, and are cross-cut by granitic dikes (Fig. 3.5b,c; Little et al., 2011). By contrast, the carapace zone, which is also migmatitic and crosscut by granitic dikes, is characterized by a more planar, thinly laminated (mm-scale), and strongly lineated solid-state deformational fabric (Fig. 3.5a). The carapace and core zones have similar quartzofeldspathic and mafic protoliths. Thus, both preserve eclogite-facies assemblages in meter-scale eclogite boudins, and share an amphibolite-facies foliation that defines the gneiss dome culminations (Little et al., 2011). The foliation is sub-horizontal at the crest of the gneiss domes and elsewhere dips outward at $30-70^{\circ}$ (Little et al., 2011). The main dome-defining foliation developed during a regionally widespread syn-exhumational upper amphibolitefacies metamorphism that widely retrogressed the gneiss terrane after it had risen from the mantle to the lower crust (Little et al., 2011).

The relict eclogites-facies metamorphic assemblage is preserved in the cores of mafic boudins, where it consists of garnet, omphacite, phengite, quartz, and rutile (Brownlee et al., in prep). The rinds of the boudins are generally retrogressed to an amphibolite-facies metamorphic assemblage (hornblende and plagioclase symplectite, garnet, quartz and ilmenite). The degree of this retrogressive event is quite variable as some boudins are completely retrogressed, whereas others preserve the eclogite-facies mineral assemblage (Baldwin and Ireland, 1995). Field 

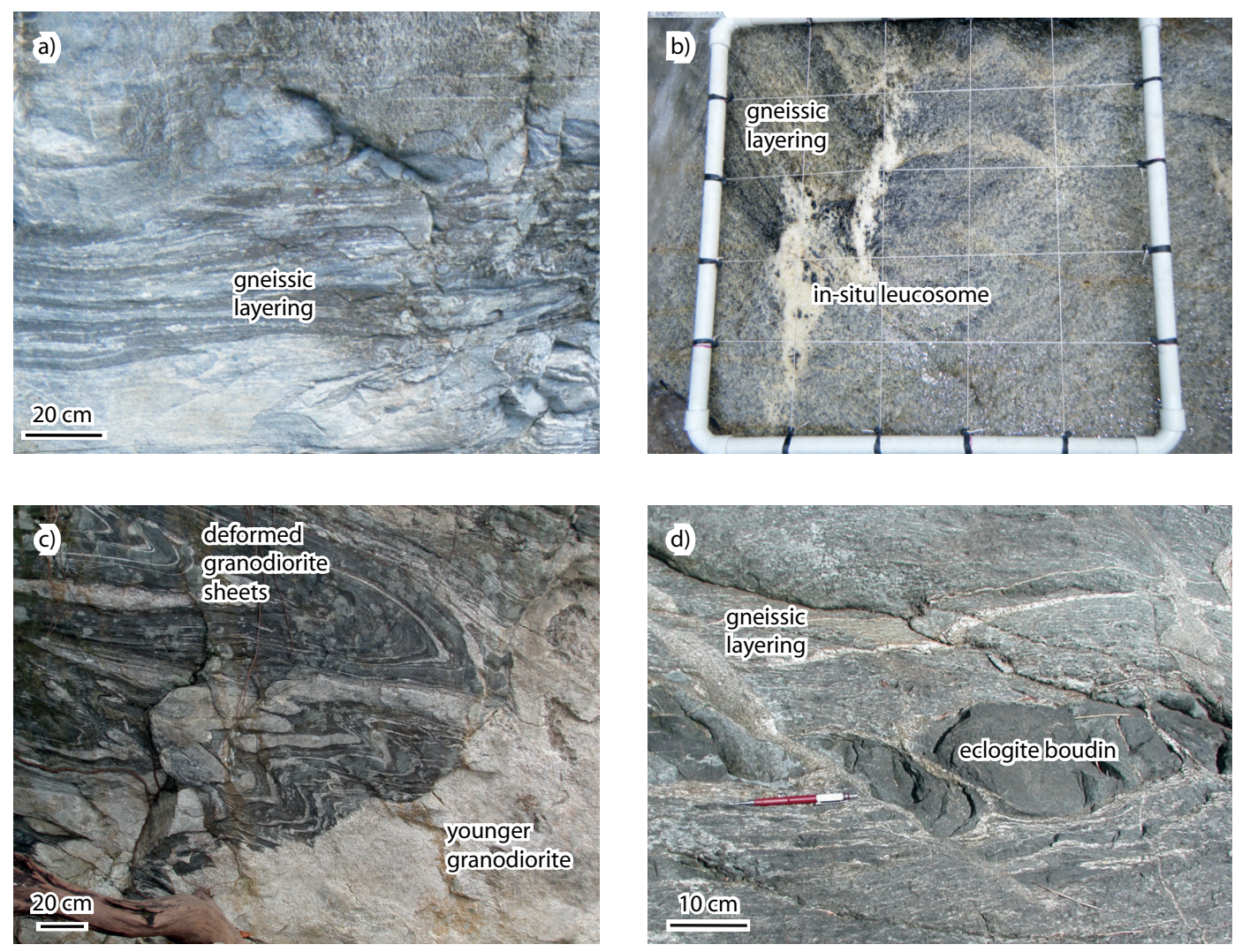

Figure 3.5 Photographs of typical lithologies in the D'Entrecasteaux Islands. Foliations have been rotated to the horizontal in the photographs. (a) Strongly foliated and lineated carapace zone quartzofeldspathic gneiss (lower Gulawata River gorge, Goodenough Island). (b) Quartzofeldspathic core zone gneiss (southeast Mailolo dome). Note patch of leucosome within the $0.25 \mathrm{~m} \mathrm{x}$ $0.25 \mathrm{~m}$ grid. (c) Strongly deformed dm-thick granodiorite foliation-parallel sheets (upper left) with zircon U-Pb ages of $3.00 \pm 0.02 \mathrm{Ma}(2 \sigma$; Gordon et al., in review). Relatively less deformed (younger) granodiorite intrusion with zircon $\mathrm{U}-\mathrm{Pb}$ ages of $\sim 2.4 \mathrm{Ma}$ (single zircon ages range from $2.418 \pm 0.004$ Ma to $2.482 \pm 0.007 \mathrm{Ma}$; $2 \sigma$; Gordon et al., in review). Lower Mwadeia River gorge, Mailolo dome. (d) Core zone quartzofeldspathic gneiss with mafic eclogite boudins (southwest Goodenough Island). 
relationships indicate that the eclogite boudins originated from meter-scale basaltic dikes that intrusively crosscut the quartzofeldspathic host gneiss (Baldwin et al., 2008). Both were later metamorphosed in eclogite-facies conditions prior to onset of the subsequent amphibolite-facies retrogression, at which time the mafic dikes were boudinaged and developed their retrogressed rinds (Baldwin et al., 2008). Although only the cores of these boudins preserve the eclogite-facies mineral assemblage, the entirety of the quartzofeldspathic gneisses in the D'Entrecasteaux Islands may once have experienced (U)HP eclogite-facies conditions (Little et al., 2011; Monteleone et al., 2007).

The gneiss domes were intruded by granodiorite and leucogranodiorite dikes and plutons of Pliocene age during the main amphibolite-facies deformation event in the lower crust (Fig. 3.5b,c; Hill et al., 1995; Little et al., 2011 and ref. therein). These dikes and plutons intruded both the carapace and core zones and are variably strongly to weakly deformed, with older phases being more deformed relative to younger melt phases. Little et al. (2011) interpret the youngest granodiorites as being intruded after the domes were emplaced in the upper crust. In addition, segregated partial melt is present as leucosomes. These partial melts are most abundant in the core region of the domes and may have been the result of decompression melting during the rapid ascent of the rocks (Chapter 2 this thesis; Little et al., 2011).

\subsubsection{Previous thermobarometric studies in the D'Entrecasteaux Islands}

Table 3.1 presents a summary of previously published pressure and temperature estimates for the UHP and high-pressure (HP) eclogite-facies metamorphism in the D'Entrecasteaux Islands. Previous temperature estimates for the UHP eclogite-facies metamorphism have a wide range of $612{ }^{\circ} \mathrm{C}$ to $930{ }^{\circ} \mathrm{C}$. Pressure estimates for the eclogite-facies UHP metamorphism range between 18 and 27 kbar; however, the presence of coesite in one sample of eclogite (08-010a) implies a minimum pressure of $28 \mathrm{kbar}$ for UHP conditions. Thus, the lower end of the range of UHP conditions shown in Table 3.1 may be an underestimate of the pressure during the UHP metamorphism (Baldwin et al., 2008; Holm et al., 1967; Monteleone et al., 2007). Temperature estimates for the HP (coesite not preserved or recognized) eclogite- 
facies metamorphism range from $530-900^{\circ} \mathrm{C}$. These estimates are slightly lower but similar to the range of temperature estimates for UHP conditions. Note that the upper end of the temperature estimates for the HP metamorphism $\left(935-1015{ }^{\circ} \mathrm{C}\right)$ determined by Monteleone et al. (2007) was calculated using the Zr-in-rutile thermometer, and has not been reproduced by any other geothermometry study of the eclogite-facies rocks in the D'Entrecasteaux Islands. The range of pressure estimated for the HP eclogites is $12-25 \mathrm{kbar}$, which is considerably less than the minimum pressure estimate of $28 \mathrm{kbar}$ required to stabilize coesite at UHP conditions.

Table 3.1 Summary of published pressure and temperature estimates for eclogite-facies metamorphism in the D'Entrecasteaux Islands.

\begin{tabular}{|c|c|c|c|c|c|}
\hline Authors & Method & $\begin{array}{l}\text { Temperature } \\
\text { estimate }\left({ }^{\circ} \mathrm{C}\right)\end{array}$ & $\begin{array}{c}\text { Pressure } \\
\text { estimate (kbar) }\end{array}$ & $\begin{array}{l}\text { Sample } \\
\text { location }\end{array}$ & $\begin{array}{l}\text { HP or } \\
\text { UHP }\end{array}$ \\
\hline \multirow{2}{*}{$\begin{array}{c}\text { Davies and } \\
\text { Warren (1992) }\end{array}$} & $\begin{array}{l}\text { garnet-cpx Fe-Mg exchange } \\
\text { thermometer, two pyroxene } \\
\text { thermometer }(\mathrm{Na})\end{array}$ & $530-840$ & - & $\begin{array}{l}\text { G, Mai, Mor, } \\
\text { Oia, Kukuia }\end{array}$ & HP \\
\hline & $\begin{array}{l}\text { jadeite component in } \\
\text { omphacite, phengite } \mathrm{Si}-\mathrm{Al}^{\mathrm{IV}} \\
\text { exhange (minimum); } \mathrm{Al} \\
\text { content of opx }\end{array}$ & - & $12-25$ & $\begin{array}{l}\text { G, Mai, Mor, } \\
\text { Oia, Kukuia }\end{array}$ & HP \\
\hline \multirow{2}{*}{$\begin{array}{c}\text { Hill and } \\
\text { Baldwin (1993) }\end{array}$} & $\begin{array}{l}\text { jadeite component in } \\
\text { omphacite }\end{array}$ & - & 21 (minimum) & Mai, Oia & HP \\
\hline & $\begin{array}{l}\text { garnet-cpx Fe-Mg exchange } \\
\text { thermometer }\end{array}$ & $730-900$ & - & Mai, Oia & HP \\
\hline \multirow{2}{*}{$\begin{array}{l}\text { Baldwin et al. } \\
\qquad(2004)\end{array}$} & $\begin{array}{l}\text { garnet-cpx Fe-Mg exchange } \\
\text { thermometer }\end{array}$ & $870-930$ & - & Mai & UHP \\
\hline & $\begin{array}{l}\text { jadeite-albite-quartz } \\
\text { barometer }\end{array}$ & - & $20-24$ & Mai & UHP \\
\hline \multirow{7}{*}{$\begin{array}{l}\text { Monteleone et } \\
\text { al. (2007) }\end{array}$} & $\begin{array}{l}\text { garnet-cpx Fe-Mg exchange } \\
\text { thermometer }\end{array}$ & $677-810$ & - & G, Mai & $\mathrm{UHP} / \mathrm{HP}$ \\
\hline & Zr-in-rutile thermometer & $677-1015$ & - & G & HP \\
\hline & Zr-in-rutile thermometer & $612-740$ & - & Mai & UHP \\
\hline & Ti-in-zircon thermometer & $740-870$ & - & G & HP \\
\hline & Ti-in-zircon thermometer & $650-680$ & - & Mai & UHP \\
\hline & $\begin{array}{l}\text { garnet-omphacite-phengite } \\
\text { barometer }\end{array}$ & - & $\begin{array}{l}18-26 \text { (coesite- } \\
\text { bearing sample) }\end{array}$ & Mai & UHP \\
\hline & $\begin{array}{l}\text { jadeite component in } \\
\text { omphacite }\end{array}$ & - & 14 (minimum) & G & $\mathrm{UHP} / \mathrm{HP}$ \\
\hline \multirow{4}{*}{$\begin{array}{l}\text { Baldwin et al. } \\
\qquad(2008)\end{array}$} & garnet-pyroxene thermometer & $600-760$ & - & Mai & UHP \\
\hline & $\mathrm{Zr}$-in-rutile thermometer & $695-743$ & - & Mai & UHP \\
\hline & Ti-in-zircon thermometer & $650-675$ & - & Mai & UHP \\
\hline & $\begin{array}{l}\text { garnet-pyroxene-phengite } \\
\text { barometer }\end{array}$ & - & $18-27$ & Mai & UHP \\
\hline
\end{tabular}

G, Goodenough dome; Mai, Mailolo dome; Mor, Morima dome.

The diversity in pressure and temperature estimates for the eclogite-facies metamorphism may reflect: (1) disequilibrium between mineral phases, (2) invalid 
assumptions regarding the $\mathrm{Fe}^{2+} / \mathrm{Fe}^{3+}$ ratio, or (3) a diversity of pressure and temperature conditions during the (U)HP events (Monteleone et al., 2007). In addition, the exhumation from the mantle to the crust in the D'Entrecasteaux Islands is known to have been nearly isothermal, or associated with a slight increase in temperature during decompression (Baldwin et al., 1993; Baldwin et al., 2004; Baldwin et al., 2008). Thus, temperatures of the eclogite-facies metamorphism were similar to the temperature of the subsequent amphibolite-facies metamorphism in the (U)HP terrane. This isothermal exhumation may have contributed to the poor preservation of eclogite-facies temperatures in the eclogites that are now strongly overprinted.

Table 3.2 presents a summary of previously published pressure and temperature estimates for the amphibolite-facies metamorphic retrogression in the D'Entrecasteaux Islands. Temperature estimates for the amphibolite-facies metamorphism have a range of $550-740{ }^{\circ} \mathrm{C}$. I discount the lower bound of the paragonite to muscovite solubility temperature estimate by Davies and Warren (1992), as the paragonite component in the white mica analyzed in this study is minor (i.e. $\mathrm{Na} /(\mathrm{Na}+\mathrm{K})<0.17$; Appendix D). Previous pressure estimates for the amphibolite-facies metamorphism have a range of $5-11 \mathrm{kbar}$, which is lower than the range in pressure estimates for the UHP or HP eclogite-facies metamorphic events.

Table 3.2 Summary of current pressure and temperature estimates for amphibolite-facies metamorphism in the D'Entrecasteaux Islands

\begin{tabular}{|c|c|c|c|c|c|}
\hline Authors & Method & $\begin{array}{l}\text { Temperature } \\
\text { estimate }\left({ }^{\circ} \mathrm{C}\right)\end{array}$ & $\begin{array}{c}\text { Pressure } \\
\text { estimate (kbar) }\end{array}$ & $\begin{array}{l}\text { Sample } \\
\text { location }\end{array}$ & $\begin{array}{c}\text { Structural } \\
\text { zone }\end{array}$ \\
\hline \multirow{3}{*}{$\begin{array}{l}\text { Davies and } \\
\text { Warren } \\
(1992)\end{array}$} & $\begin{array}{l}\text { paragonite/muscovite } \\
\text { solubility (A schist) }\end{array}$ & $500-600$ & 10 & $\begin{array}{l}\text { G, Mai, } \\
\text { Mor }\end{array}$ & Core/ Carapace \\
\hline & $\begin{array}{l}\text { amphibole and rutile } \\
\text { stability (amphibolite } \\
\text { gneiss) }\end{array}$ & $550-650$ & $5-10$ & $\begin{array}{l}\text { G, Mai, } \\
\text { Mor }\end{array}$ & Core/ Carapace \\
\hline & $\begin{array}{l}\text { Si substitution for } \mathrm{Al}^{\mathrm{IV}} \text { in } \\
\text { phengite ( } \mathrm{Q} \text { gneiss) }\end{array}$ & - & $8-11$ & $\begin{array}{l}\text { G, Mai, } \\
\text { Mor }\end{array}$ & Core/ Carapace \\
\hline \multirow{4}{*}{$\begin{array}{l}\text { Hill and } \\
\text { Baldwin } \\
(1993)\end{array}$} & $\begin{array}{l}\text { Fe-Mg garnet-biotite } \\
\text { thermometer }(\mathrm{C}, \mathrm{A}, \mathrm{M}, \mathrm{Q} \\
\text { gneiss) }\end{array}$ & $570-730$ & - & G, Mai & Carapace \\
\hline & $\begin{array}{l}\text { Fe-Mg garnet-biotite } \\
\text { thermometer (C, A, M, Q } \\
\text { gneiss) }\end{array}$ & $640-740$ & - & G & Core \\
\hline & $\begin{array}{l}\text { GASP barometer (C, A, M, } \\
\text { Q gneiss) }\end{array}$ & - & $7-11$ & Mai & Core/ Carapace \\
\hline & $\begin{array}{l}\text { GRIPS barometer }(\mathrm{C}, \mathrm{A}, \\
\mathrm{M}, \mathrm{Q} \text { gneiss) }\end{array}$ & - & $9-11$ & Mai & Carapace \\
\hline
\end{tabular}

C, calcic; A, aluminous; Q, quartzofeldspathic; M, micaceous; G, Goodenough dome; Mai, Mailolo dome; Mor, Morima dome. 


\subsubsection{Previous geochronological studies in the D'Entrecasteaux Islands}

Current estimates for the timing of the eclogite-facies metamorphism within the D'Entrecasteaux Islands range from 8 to 4 Ma. Baldwin et al. (2004) dated in-situ zircons from a eclogite sample from the Mailolo dome UHP locality by the U-Pb method using a sensitive high-resolution ion microprobe. These authors determined a metamorphic age of $4.33 \pm 0.36 \mathrm{Ma}(2 \sigma, \mathrm{MSWD}=3.3)$, which they infer to date the timing of zircon growth at eclogite-facies conditions. Monteleone et al. (2007) dated in-situ zircons from five samples of variably retrogressed eclogite from the Mailolo and Goodenough dome by the U-Pb method using a sensitive high-resolution ion microprobe. They determined a metamorphic age for UHP zircon growth of $7.9 \pm 1.9$ $\operatorname{Ma}(2 \sigma ; \operatorname{MSWD}=9.2$; four zircon grains) for the coesite-bearing eclogite from the UHP locality in the Mailolo dome. They also calculated a metamorphic age of $7.0 \pm$ $1.0 \mathrm{Ma}(2 \sigma ; \mathrm{MSWD}=2.0$; three zircon grains) for a eclogite that has been retrogressed under amphibolite-facies conditions. In addition, Monteleone et al. (2007) determined $\mathrm{U}-\mathrm{Pb}$ zircon ages of $2.94 \pm 0.41 \mathrm{Ma}(2 \sigma ; \mathrm{MSWD}=1.02$; six zircon grains), $2.82 \pm 0.27 \mathrm{Ma}(2 \sigma ; \mathrm{MSWD}=2.6$; three zircon grains), and $2.09 \pm$ $0.49 \mathrm{Ma}(2 \sigma ; \mathrm{MSWD}=4.2$; three zircon grains) for three samples of retrogressed eclogites from the carapace zone of the Goodenough dome. Zirakparvar et al. (2011) dated garnets from the coesite-bearing eclogite sample from the Mailolo dome by the Lu-Hf method using a multi-collector inductively coupled plasma mass spectrometer (ICP-MS). These authors determined a Lu-Hf age of $7.1 \pm 0.7 \mathrm{Ma}(2 \sigma, \mathrm{MSWD}=$ 1.5), and interpret this age as the timing of garnet crystallization at UHP eclogitefacies conditions. Gordon et al. (in review) also dated zircons from a eclogite sample from the UHP locality in the Mailolo dome using U-Pb chemical-abrasion thermalionization mass spectrometry (TIMS), and determined a U-Pb zircon age range of $5.82 \pm 0.20 \mathrm{Ma}$ to $4.78 \pm 0.17 \mathrm{Ma}$. In addition, Gordon et al. (in review) carried out 70 spot measurements of $\mathrm{U}-\mathrm{Th}-\mathrm{Pb}$ on zircon grains using a multi-collector ICP-MS. They determined that zircons in the fresh portion of the eclogite sample yield ${ }^{238} \mathrm{U} /{ }^{206} \mathrm{~Pb}$ ages that range from 16.0 to $5.5 \mathrm{Ma}$, and zircons in the altered portion of the eclogite sample yield ${ }^{238} \mathrm{U} /{ }^{206} \mathrm{~Pb}$ ages that range from 11.4 to 3.9 Ma. The two age ranges for the fresh and altered portions of the eclogite are within error of each other, and cluster around the more precise TIMS eclogite-facies U-Pb ages $(\sim 5 \mathrm{Ma}$; 
Gordon et al., in review). Trace elements of zircons are similar between the core and the rim of the eclogite boudins (Gordon et al., in review). Based on the evidence from the $\mathrm{U}-\mathrm{Th}-\mathrm{Pb}$ spot measurements and the trace-element compositions of the zircons, Gordon et al. (in review) infer that the precise $\sim 5 \mathrm{Ma}$ TIMS U-Pb zircon age records the timing of the UHP metamorphism.

Previous geochronological studies have constrained the timing of the amphibolitefacies metamorphism for rocks in the Goodenough and Mailolo domes to $3.5-2.4$ Ma. Baldwin and Ireland (1995) dated zircons from two samples of felsic gneiss in the Goodenough dome by the U-Pb method using a sensitive high-resolution ion microprobe, and determined ages of $2.63 \pm 0.16 \mathrm{Ma}(2 \sigma)$ and $2.72 \pm 0.28 \mathrm{Ma}(2 \sigma)$ respectively. These ages are interpreted as amphibolite-facies growth ages (Baldwin and Ireland, 1995). Gordon et al. (in review) carried out U-Pb chemical-abrasion TIMS for zircons extracted from a suite of variably deformed granodioritic dikes from the core and carapace of the Mailolo dome. A strongly deformed granodioritic orthogneiss from the core zone of the Mailolo dome (UHP locality) yielded $\mathrm{U}-\mathrm{Pb}$ zircon ages that range from $3.50 \pm 0.01 \mathrm{Ma}$ to $3.41 \pm 0.02 \mathrm{Ma}$ (Gordon et al., in review). The most strongly deformed granodioritic orthogneiss dated by Gordon et al. (in review) is from the carapace zone of the Mailolo dome, and yielded a weighted mean TIMS U-Pb age of $3.082 \pm 0.007 \mathrm{Ma}(\mathrm{MSWD}=0.56$; five zircon grains). Two nearby deformed granodioritic dikes yielded a TIMS U-Pb zircon age of $3.00 \pm 0.02 \mathrm{Ma}(2 \sigma$; two zircon grains), with an age range of $2.418 \pm 0.004 \mathrm{Ma}$ to $2.482 \pm 0.007 \mathrm{Ma}(2 \sigma)$, respectively. The $\sim 2.4 \mathrm{Ma}$ age for the relatively undeformed granodioritic gneiss is interpreted to date the timing of the final stages of the retrogressive amphibolite-facies ductile deformation in the Mailolo gneiss domes (Gordon et al., in review). The $2.09 \pm 0.49 \mathrm{Ma}(2 \sigma ; \mathrm{MSWD}=4.2) \mathrm{U}-\mathrm{Pb}$ ion microprobe ages for zircons from eclogite samples from the Goodenough dome calculated by Monteleone et al. (2007) are younger than those attributed to the amphibolite-facies metamorphic growth in the Goodenough dome by Baldwin and Ireland (1995). Gordon et al. (in review) argue that the $<3 \mathrm{Ma} \mathrm{U}-\mathrm{Pb}$ zircon ages cannot date the growth of zircons at HP conditions.

White mica and biotite in gneiss samples from the Goodenough, Mailolo, Oiatabu, and Morima domes have yielded plateau and isochron ${ }^{40} \mathrm{Ar} /{ }^{39} \mathrm{Ar}$ cooling ages with a 
spread of 3.0 - 1.5 Ma (white mica) and 1.9 - 1.4 Ma (biotite; Baldwin et al., 1993). These ages imply that there was rapid cooling of the rocks in the D'Entrecasteaux Islands below $400-300{ }^{\circ} \mathrm{C}$ in the crust over the $3.0-1.5$ Ma time interval $\left(>100{ }^{\circ} \mathrm{C}\right.$ $\mathrm{Ma}^{-1}$; Baldwin et al., 1993). Gneiss in the D'Entrecasteaux Islands yielded apatite fission track ages of $1.0-0.4 \mathrm{Ma}$, suggesting that final cooling of the rocks to below $130{ }^{\circ} \mathrm{C}$ took place during the last 1.0 Ma or less (Baldwin et al., 1993; Fitzgerald et al., 2008).

\section{3 $\mathrm{Rb}-\mathrm{Sr}$ dating of rocks by internal mineral isochrons}

\subsubsection{Rb-Sr isotope systematics}

The exchange and interaction of isotopes between an intergranular fluid phase and rock-forming minerals during metamorphism and mineral growth is predicted to redistribute and re-equilibrate $\mathrm{Sr}$ between the co-existing mineral phases (Freeman et al., 1997; Glodny et al., 2002; Glodny et al., 2003). Dynamic recrystallization and metamorphic mineral growth in a chemical system open to grain-scale fluid flow is predicted to cause homogenization of $\mathrm{Sr}$ during ductile deformation (Freeman et al., 1997). In such a case, the $\mathrm{Rb}-\mathrm{Sr}$ isochron will reveal the timing of the metamorphic recrystallization event that caused final homogenization of the Rb-Sr system, provided that two conditions are met: (1) the temperatures during the $\mathrm{Sr}$ homogenization event were less than the effective blocking temperature for $\mathrm{Sr}$ in the mineral assemblage present in the rock, and (2) the blocking temperature of $\mathrm{Sr}$ was not exceeded during the later thermal history (Freeman et al., 1997). If the mineral fabric in a deformed metamorphic rock grew syn-tectonically, and there was no fluid access after mineral growth, then the $\mathrm{Rb}-\mathrm{Sr}$ isotopic compositions would record the timing of mineral growth during ductile deformation regardless of the thermal history (Freeman et al., 1997). Because the eclogites boudin cores analyzed here were not retrogressed or hydrated by fluids during the fluid-present amphibolitefacies overprint, $\mathrm{Rb}-\mathrm{Sr}$ ages for these eclogites should date the timing of their original eclogite-facies crystallization. The quartzofeldspathic gneiss and granitic rock that surrounds these boudins cores were retrogressed and hydrated during the 
amphibolite-facies overprint; therefore, these rocks should yield $\mathrm{Rb}-\mathrm{Sr}$ isochrons that date the timing of the final phase of fluid-present amphibolite-facies deformation during exhumation from the lower crust. The $\mathrm{Rb}-\mathrm{Sr}$ method is thus an appropriate technique to date both the (U)HP metamorphism and the fluid-present amphibolitefacies overprint in the D'Entrecasteaux Islands, by careful selection of samples that preserve the eclogite- and amphibolite-facies mineral assemblages and fabrics.

The Sr blocking temperature of white mica is $550-650{ }^{\circ} \mathrm{C}$ (Blanckenburg et al., 1989; Giorgis et al., 2000; Glodny et al., 2005a). Rb-Sr diffusion within a rock is predicted to have modally-controlled closed system behavior so that the next-mostdiffusive phase will determine the blocking temperature of $\mathrm{Sr}$ in the rock's multiphase system, rather than the least retentive phase (Glodny et al., 2003; Glodny et al., 2002). Minerals with Sr blocking temperatures that are higher than that of white mica in the eclogites and quartzofeldspathic gneiss analyzed here include: apatite, $\sim 650^{\circ} \mathrm{C}$ (Cherniak and Ryerson, 1993); Na-feldspar, $425-750{ }^{\circ} \mathrm{C}$ (Cherniak and Watson, 1992; Cherniak and Watson, 1994); K-feldspar, 650 - $900{ }^{\circ} \mathrm{C}$ (Cherniak and Watson, 1992; Cherniak and Watson, 1994); Ca-feldspar, $600-1000{ }^{\circ} \mathrm{C}$ (Cherniak and Watson, 1992; Cherniak and Watson, 1994); clinopyroxene and garnet, $800-1100^{\circ} \mathrm{C}$ (Burton et al., 1995; Cherniak, 1998; Sneeringer et al., 1984). As all samples analyzed here contain $\mathrm{K}$-feldspar with the exception of the eclogites, the $\mathrm{Rb}$-Sr ages may be interpreted as the time since the rock cooled to below $\sim 650{ }^{\circ} \mathrm{C}$ (minimum closure temperature for K-feldspar), and would therefore be predicted to date the white mica mineral growth (formation age) rather than any later cooling event (Glodny et al., 2003).

\subsubsection{Requirements for isotopic dating via $\mathrm{Rb}-\mathrm{Sr}$ internal mineral isochrons}

An internal mineral isochron plots ${ }^{87} \mathrm{Rb} /{ }^{86} \mathrm{Sr}$ and ${ }^{87} \mathrm{Sr} /{ }^{86} \mathrm{Sr}$ ratios for rock-forming minerals that are inferred to be in textural equilibrium with each other, in order to calculate a $\mathrm{Rb}-\mathrm{Sr}$ isochron. For metamorphic rocks the existence of a valid multimineral isochron indicates closed system behavior and precludes the possibility that there has been post-recrystallization and re-distribution of radiogenic $\mathrm{Sr}$ between different mineral phases (Glodny et al., 2003; Glodny et al., 2005b). If, by contrast, 
the internal mineral isochron yields a positive correlation between apparent age of white mica and the grain size of that white mica, this observation implies that there was post-growth diffusion of Sr from the crystal lattice (Glodny et al., 2002; Glodny et al., 2005b; Glodny et al., 2008b). Two advantages of the Rb-Sr internal mineral include: (1) the close tie between metamorphic reaction kinetics, ductile deformation, and isotopic re-equilibration implies that the isotopic distribution of $\mathrm{Sr}$ within coexisting minerals was homogenized during the metamorphic and deformation event that created the rock fabric in the sample; and (2) if the isotopic compositions do not plot on a linear isochron, the assumption of isotopic homogeneity and closed system behavior between the assemblage-forming minerals is known to be invalid (Glodny et al., 2002; Glodny et al., 2003; Glodny et al., 2008a; Thomson et al., 2009). Rb-Sr internal mineral isochrons therefore allow identification of relict isotopic signatures from previous growth events (i.e. a mixed white mica population), or of later resetting of the isotopic composition as a result of fluid-flux and diffusion or recrystallization (Glodny et al., 2008b).

Glodny et al. (2008c) argues that there are three key requirements for successful isotopic dating of deformation by $\mathrm{Rb}$-Sr internal mineral isochrons. First, there must have been complete inter-mineral isotopic equilibration during the mineral growth event that created the rock fabric. The close link between textural and isotopic equilibration implies that samples that lack any textural relicts from earlier metamorphic events (such as boudins, porphyroclasts, or coarse mica fish) will contain a mineral assemblage that was homogenized with respect to $\mathrm{Sr}$ isotopes at the time of their growth. This isotopic equilibrium would have been established during the growth of the minerals that form the rock fabric, before closed system behavior began. Thus, $\mathrm{Rb}$-Sr isotopic ages are interpreted as recording the end stages of deformation-induced recrystallization that created the mineral fabric of interest. Second, thermally driven diffusion subsequent to the fabric forming metamorphic growth must not have caused later alterations to the $\mathrm{Sr}$ isotopic composition of the constituent minerals. Third, there must not have been any post-growth alteration of the $\mathrm{Sr}$ isotopic composition of the mineral as a result of fluids or weathering. If latestage fluid-present conditions occur within the two least retentive minerals in a sample, then $\mathrm{Sr}$ isotopes will be exchanged between these phases and a valid isochron will not be obtained (Freeman et al., 1997; Glodny et al., 2002; Glodny et 
al., 2003). If no fluid is present, isotopic exchange between minerals is not possible regardless of the temperature (Freeman et al., 1997; Glodny et al., 2002; Glodny et al., 2003). In a poly-metamorphic rock, care must be taken to exclude late-stage phases such as biotite and chlorite that may have grown during retrogression and low-temperature fluid alteration, particularly along areas that act as fluid pathways (i.e. grain boundaries; Glodny et al., 2008c and ref. therein).

\subsection{Analytical techniques}

\subsubsection{Thermobarometric and major element analytical technique}

Quantitative major element analyses for white mica in eleven samples, and garnet, plagioclase, and ilmenite in five samples from the D'Entrecasteaux Islands were carried out on the JEOL JXA-8230 electron probe microanalyzer (EPMA) at Victoria University of Wellington, New Zealand. Quantitative standardization was carried out with 15 seconds for background measurement and 30 seconds for standard measurement with the exception of $\mathrm{Ti}$ for the white mica analyses, which was carried out with 30 second of background and 60 second of measurements. Analysis of unknowns included a background measurement of 15 seconds and a standard measurement of 30 seconds. Alkali elements were measured by the EPMA first. To ensure matrix effects of mass number $(Z)$, absorbance (A), and fluorescence (F) did not lead to incorrect element concentration, a ZAF correction was used to automatically correct for these matrix effects.

All quantitative analyses were by wavelength dispersive spectrometry, which was calibrated with international mineral standards similar in composition to the phase analyzed for major elements, or with synthetic oxide standards for elements with $<1$ wt $\%$ (Table 3.3). The percent two standard deviation or analytical precision calculated from repeat analysis of calibrated standards was $<3 \%$ for the oxides that are present in the standard at $>1 \mathrm{wt} \%$. Oxides analyzed for the Biotite PSU 5-110 standard yielded a range of percent two standard deviation of $<5 \%$ for the oxides that are present in the standard at $>1 \mathrm{wt} \%$; with the exception of $\mathrm{K}_{2} \mathrm{O}$, which yielded 
$11.56 \%$. The accuracy of the repeated analyses of oxides was $<2.5 \mathrm{wt} \%$ (average of all repeat analyses of oxides in calibrated standards) for oxides that were present in the calibrated standards at $>1 \mathrm{wt} \%$. Precision and accuracy of all calibrated samples analyzed as unknowns is shown in Table 3.4 to 3.8 by oxide.

Table 3.3 Calibrated standards for quantitative major element analysis on the EMPA

\begin{tabular}{|c|c|c|}
\hline Mineral Phase & Matrix-matched standards & Synthetic oxides \\
\hline White mica & VG-A99 Basaltic Glass ${ }^{\mathrm{a}}\left(\mathrm{Ti}^{*}, \mathrm{Na}, \mathrm{Si}\right.$, & Wollastonite $(\mathrm{Ca}), \mathrm{MgO}, \mathrm{MnO}$, Orthoclase Or- \\
\hline & $\begin{array}{l}\text { Biotite PSU } 5-110^{\mathrm{a}}\left(\mathrm{Ti}^{*}, \mathrm{Mg}, \mathrm{Si}, \mathrm{Al},\right. \\
\mathrm{Fe}, \mathrm{K})\end{array}$ & 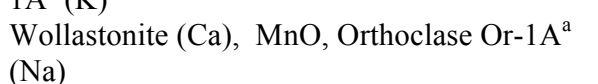 \\
\hline Garnet & $\begin{array}{l}\text { Garnet USNM } 110752^{\mathrm{b}}(\mathrm{Ca}, \mathrm{Mg}, \mathrm{SI} \\
\mathrm{Al}, \mathrm{Fe})\end{array}$ & $\mathrm{MnO}, \mathrm{TiO}_{2}$ \\
\hline Plagioclase & Plagioclase $^{\mathrm{b}}(\mathrm{Na}, \mathrm{Si}, \mathrm{Al}, \mathrm{Ca})$ & $\mathrm{TiO}_{2}$, Orthoclase Or- $1 \mathrm{~A}^{\mathrm{a}}(\mathrm{K}), \mathrm{MgO}, \mathrm{Fe}_{2} \mathrm{O}_{3}$ \\
\hline Fe-Ti oxides & Ilmenite $^{\mathrm{b}}(\mathrm{Ti}, \mathrm{Fe}, \mathrm{Mn})$ & Wollastonite $(\mathrm{Ca}), \mathrm{MgO}, \mathrm{Al}_{2} \mathrm{O}_{3}$ \\
\hline
\end{tabular}

All elements were analyzed with 30 seconds of standard/sample measurement and 30 seconds of background measurements except were noted with an asterisk.

*, 60 seconds of standard/sample measurement and 30 seconds of background measurements.

angamells, 1980

${ }^{\mathrm{b} J a r o s e w i c h}$ et al., 1980

Table 3.4 Accuracy and precision of white mica major element analysis by EPMA

Standard: VG-A99 standard $(n=4)$

\begin{tabular}{rrrrrrrrrrr}
\hline & $\mathrm{SiO}_{2}$ & $\mathrm{TiO}_{2}$ & $\mathrm{Al}_{2} \mathbf{O}_{3}$ & $\mathbf{F e O}$ & $\mathbf{M n O}$ & $\mathbf{M g O}$ & $\mathbf{C a O}$ & $\mathbf{N a}_{2} \mathbf{O}$ & $\mathbf{K}_{2} \mathbf{O}$ & $\mathbf{T o t a l}$ \\
\hline Average & 51.80 & 4.11 & 12.38 & 13.39 & 0.20 & 5.09 & 9.18 & 2.66 & 0.82 & 99.61 \\
$\mathbf{M i n}$ & 50.80 & 4.08 & 12.23 & 13.35 & 0.18 & 4.99 & 9.16 & 2.63 & 0.81 & 98.34 \\
Max & 52.78 & 4.16 & 12.64 & 13.44 & 0.22 & 5.20 & 9.19 & 2.68 & 0.83 & 101.09 \\
2 std. dev. & 1.63 & 0.08 & 0.36 & 0.08 & 0.04 & 0.17 & 0.03 & 0.04 & 0.02 & 2.26 \\
\% 2 std. dev. & 3.1 & 1.9 & 2.9 & 0.6 & 20.5 & 3.4 & 0.3 & 1.4 & 2.4 & 2.3 \\
Ref. value & 51.15 & 4.11 & 12.38 & 13.35 & 0.20 & 5.07 & 9.36 & 2.68 & 0.83 & 99.40 \\
\% offset & 1.2 & 0.1 & 0.0 & 0.3 & -2.6 & 0.3 & -2.0 & -0.9 & -1.2 & 0.2 \\
\hline a Jarosewich et al., 1980 & & & & & & & &
\end{tabular}

Table 3.5 Accuracy and precision of white mica major element analysis by EPMA

Standard: Biotite PSU 5-110 $(n=115)$

\begin{tabular}{rrrrrrrrrrr}
\hline & $\mathrm{SiO}_{2}$ & $\mathrm{TiO}_{2}$ & $\mathrm{Al}_{2} \mathbf{O}_{3}$ & $\mathbf{F e O}$ & $\mathbf{M n O}$ & $\mathbf{M g O}$ & $\mathbf{C a O}$ & $\mathbf{N a}_{2} \mathbf{O}$ & $\mathbf{K}_{2} \mathbf{O}$ & $\mathbf{T o t a l}$ \\
\hline Average & 38.80 & 1.61 & 13.07 & 10.96 & 0.14 & 19.90 & 0.08 & 0.32 & 10.01 & 94.89 \\
$\mathbf{M i n}$ & 36.85 & 1.44 & 12.30 & 10.27 & 0.10 & 18.61 & 0.02 & 0.03 & 8.22 & 92.85 \\
$\mathbf{M a x}$ & 41.86 & 1.85 & 13.60 & 11.51 & 0.18 & 21.30 & 0.29 & 0.48 & 11.57 & 98.11 \\
2 std. dev. & 1.59 & 0.20 & 0.58 & 0.50 & 0.04 & 1.03 & 0.07 & 0.22 & 1.16 & 2.35 \\
\% 2 std. dev. & 4.1 & 12.7 & 4.4 & 4.5 & 26.43 & 5.17 & 87.8 & 67.0 & 11.56 & 2.48 \\
Ref. value & 38.63 & 1.55 & 13.08 & 11 & 0.14 & 19.94 & 0.18 & 0.26 & 10 & 95.76 \\
\% offset & 0.4 & 3.44 & -0.1 & -0.4 & -0.56 & -0.2 & -128.6 & 19.45 & 0.09 & -0.91 \\
\hline
\end{tabular}

${ }^{\mathrm{a}}$ Ingamells, 1980 
Table 3.6 Accuracy and precision of garnet major element analysis by EPMA Standard: Garnet USNM $110752(\mathrm{n}=24)$

\begin{tabular}{rrrrrrrrr}
\hline & $\mathrm{SiO}_{2}$ & $\mathrm{TiO}_{2}$ & $\mathrm{Al}_{2} \mathbf{O}_{3}$ & $\mathbf{F e O}$ & $\mathrm{MnO}$ & $\mathrm{MgO}$ & $\mathbf{C a O}$ & Total \\
\hline Average & 39.96 & 0.36 & 22.65 & 11.36 & 0.19 & 7.11 & 18.06 & 99.69 \\
Min & 39.34 & 0.32 & 22.38 & 11.18 & 0.16 & 6.94 & 17.85 & 99.08 \\
Max & 40.55 & 0.39 & 22.92 & 11.54 & 0.24 & 7.24 & 18.31 & 100.22 \\
2 std. dev. & 0.55 & 0.03 & 0.27 & 0.19 & 0.04 & 0.16 & 0.23 & 0.65 \\
\% 2 std. dev. & 1.4 & 9.1 & 1.2 & 1.6 & 21.2 & 2.3 & 1.2 & 0.7 \\
Ref. value & 40.16 & 0.35 & 22.70 & 11.31 & 0.19 & 7.17 & 18.12 & 100.00 \\
\%o offset & -0.5 & 3.0 & -0.2 & 0.4 & -0.6 & -0.8 & -0.3 & -0.3 \\
\hline a Jarosewich et al & 1980 & & & & & & &
\end{tabular}

${ }^{\mathrm{a} J a r o s e w i c h}$ et al., 1980

Table 3.7 Accuracy and precision of plagioclase major element analysis by EPMA Standard: Plagioclase $(\mathrm{n}=25)$

\begin{tabular}{rrrrrrrrrr}
\hline & $\mathbf{S i O}_{2}$ & $\mathbf{T i O}_{2}$ & $\mathbf{A l}_{2} \mathbf{O}_{3}$ & $\mathbf{F e O}$ & $\mathbf{M g O}$ & $\mathbf{C a O}$ & $\mathbf{N a}_{2} \mathbf{O}$ & $\mathbf{K}_{2} \mathbf{O}$ & Total \\
\hline Average & 50.74 & 0.03 & 30.60 & 0.45 & 0.15 & 13.74 & 3.39 & 0.11 & 99.22 \\
$\mathbf{M i n}$ & 49.29 & 0.00 & 29.89 & 0.40 & 0.12 & 13.43 & 3.25 & 0.10 & 97.05 \\
Max & 51.56 & 0.05 & 31.11 & 0.53 & 0.19 & 14.02 & 3.57 & 0.12 & 100.32 \\
2 std. dev. & 1.22 & 0.02 & 0.68 & 0.07 & 0.03 & 0.27 & 0.18 & 0.01 & 1.85 \\
\% 2 std. dev. & 2.4 & 85.5 & 2.2 & 15.5 & 19.5 & 2.0 & 5.4 & 12.7 & 1.9 \\
Ref. value & 51.52 & 0.35 & 30.91 & 0.46 & 0.14 & 13.64 & 3.45 & 0.18 & 100.17 \\
\% offset & -1.5 & -1244.1 & -1.0 & -2.1 & 5.0 & 0.7 & -1.7 & -59.4 & -1.0 \\
\hline${ }^{a}$ Jarosewich et al., 1980 & & & & & & &
\end{tabular}

Table 3.8 Accuracy and precision of ilmenite major element analysis by EPMA Standard: Ilmenite $(\mathrm{n}=12)$

\begin{tabular}{rrrrrrrr}
\hline & $\mathbf{T i O}_{2}$ & $\mathbf{A l}_{2} \mathbf{O}_{3}$ & FeO & MnO & MgO & CaO & Total \\
\hline Average & 45.48 & 0.01 & 46.39 & 4.70 & 0.31 & 0.02 & 96.91 \\
Min & 44.02 & 0.00 & 45.72 & 4.44 & 0.26 & 0.00 & 96.25 \\
Max & 46.15 & 0.02 & 47.47 & 4.87 & 0.35 & 0.10 & 97.64 \\
2 std. dev. & 1.08 & 0.02 & 0.89 & 0.24 & 0.05 & 0.06 & 0.94 \\
\% 2 std. dev. & 2.4 & 175.1 & 1.9 & 5.2 & 14.9 & 334.5 & 1.0 \\
Ref. value & 45.70 & $\mathrm{n} / \mathrm{d}$ & 46.50 & 4.77 & 0.31 & $\mathrm{n} / \mathrm{d}$ & 97.28 \\
\%o offset & -0.5 & - & -0.2 & -1.5 & -0.7 & - & -0.4 \\
\hline a Jarosewich et al., 1980 & & & & & &
\end{tabular}

Four samples of gneiss and one sample of quartzose rock were selected for thermobarometric analysis from the northwestern D'Entrecasteaux Islands (Fig. 3.4, 3.6). These samples were selected on the basis of identification of a mineral fabric that formed during the amphibolite-facies metamorphism. The location of all analyzed samples is shown in Fig. 3.4. A complete petrographic characterization for each sample analyzed by this study for thermobarometry is presented in Appendix D. 
Pressure and temperature estimates on co-existing mineral assemblages were obtained using the computer program GeoThermoBarometry (Spear and Kohn, 1999). For kyanite-bearing samples (08-037a, 10-008a, 10-070a) pressures were estimated using the Newton and Haselton (1981), the Hodges and Spear (1982), the Ganguly and Sazena (1984), the Hodges and Crowley (1985), and the Kozoil (1989) calibrations of the garnet- $\mathrm{Al}_{2} \mathrm{SiO}_{5}$-plagioclase-quartz barometer. For non-kyanite bearing samples (06-018a, 08-032a), pressures were estimated using Hodges and Crowley (1985) and the Hoisch (1990) calibrations of the garnet-plagioclasemuscovite-quartz barometer. Temperatures for the five samples were estimated using the Krogh and Raheim (1978) and the Green and Hellman (1982) calibrations of the garnet-phengite Fe-Mg exchange thermometer. All gneiss and quartzose samples analyzed for pressure and temperature estimates contain an amphibolite-facies mineral assemblage and deformational fabric. Based on these fabrics garnet rim analyses, plagioclase matrix or rim analyses and white mica rim analyses (presented in Appendix D) were input into the GeoThermoBarometry program using the above cited calibrations.

\subsubsection{Rb-Sr dating analytical technique}

Five samples of quartzofeldspathic gneiss, two samples of granitic rock, and two samples of eclogites were selected for $\mathrm{Rb}-\mathrm{Sr}$ analysis from the northwestern D'Entrecasteaux Islands (Fig. 3.4, 3.6). These samples were selected on the basis of identification of a mineral fabric that formed during either the amphibolite- or eclogite-facies metamorphism. A complete petrographic characterization for each sample analyzed for $\mathrm{Rb}-\mathrm{Sr}$ isotopic composition in this study is presented in Appendix D.

Small (10-100 mg) lithologically homogeneous samples were analyzed for their ${ }^{87} \mathrm{Rb} /{ }^{86} \mathrm{Sr}$ and ${ }^{87} \mathrm{Sr} /{ }^{86} \mathrm{Sr}$ isotopic composition. A small rock sample size may ensure isotopic homogenization during metamorphism was effective throughout the entirety of the sample (Glodny et al., 2002; Glodny et al., 2008b; Glodny et al., 2008c). Rock samples of $>100 \mathrm{mg}$ were avoided as a larger size may introduce pre-metamorphic $\mathrm{Sr}$ compositional variations that are too significant to be canceled out by subsequent metamorphic events (Glodny et al., 2002). Crushed sample was separated into high 

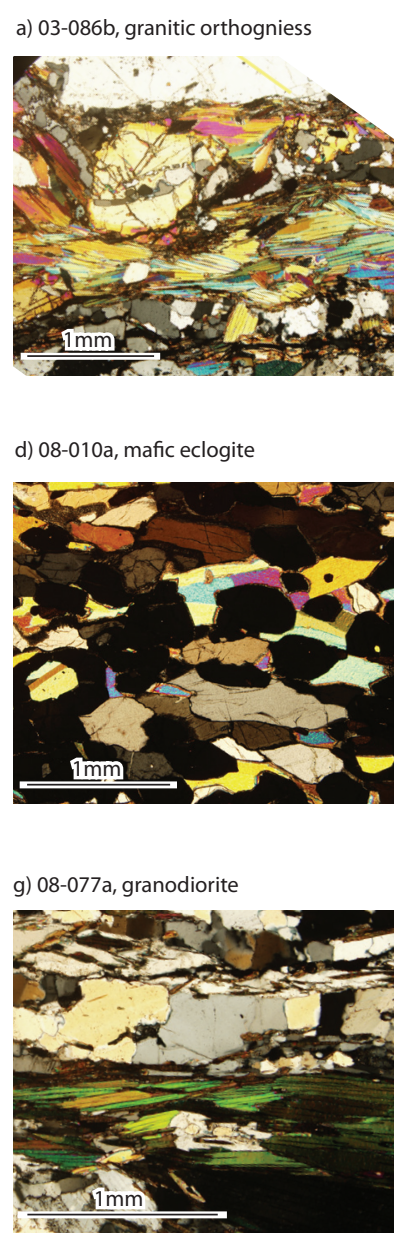

j) 10-070a, mica-bearing quartz sheet

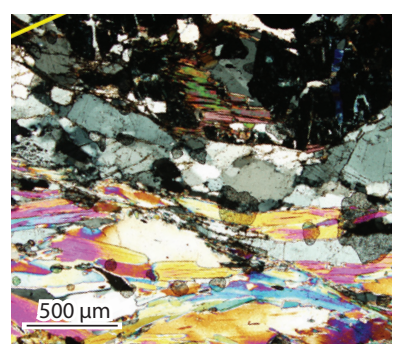

b) 06-018a, quartzofeldspathic gneiss

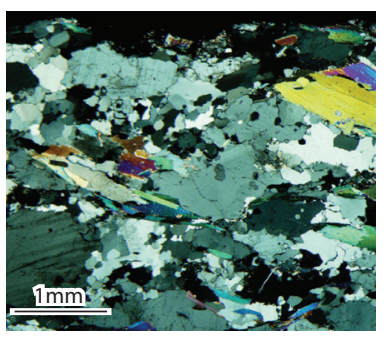

e) 08-032a, quartzofeldspathic gneiss

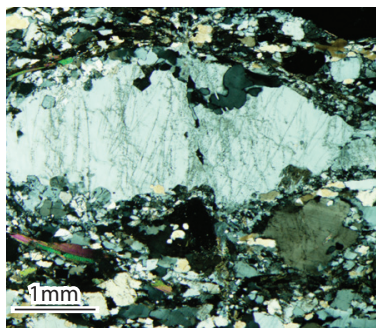

h) 09-039biii, mafic eclogite

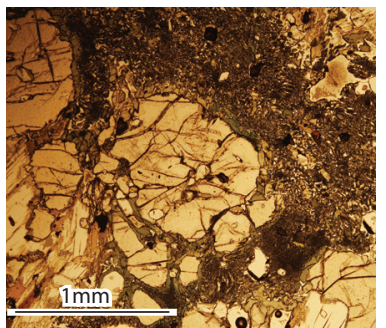

c) $08-010$ c, granodioritic orthogneiss

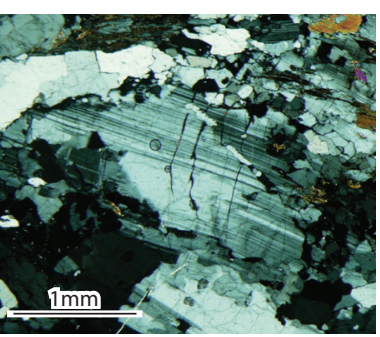

f) 08-037a, quartzofeldspathic gneiss

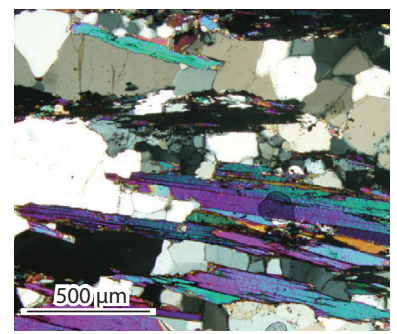

i) 10-008a, pelitic gneiss

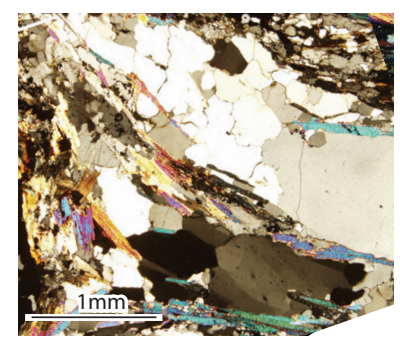

k) 10-071a, quartzofeldspathic gneiss

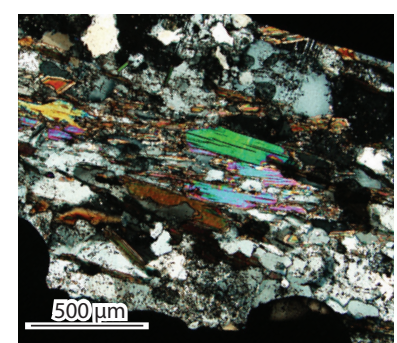

Figure 3.6 Photomicrographs of samples analyzed for $\mathrm{Rb}-\mathrm{Sr}$ isotopic composition and pressure/temperature estimates. Sample locations shown in Fig. 3.4. Foliations have been rotated to the horizontal. (a) 03-086b, Rb-Sr sample, carapace zone of the Morima dome. (b) 06-018a, Rb-Sr and thermobarometry sample, from the Goodenough dome. (c) 08-010c, Rb-Sr sample, ultra-high pressure locality, core zone of the Mailolo dome. (d) 08-010a, Rb-Sr sample, ultra-high pressure locality, core zone of the Mailolo dome. Note that this sample preserves coesite (Baldwin et al., 2008). (e) 08-032a, Rb-Sr and thermobarometry sample, carapace of the Goodenough dome. (f) 08-037a, Rb-Sr and thermobarometry sample, core of the Mailolo dome. (g) 08-077a, Rb-Sr sample, core of the northwest Normanby dome. h) 09-039biii, Rb-Sr sample, river cobble from the core of the Mailolo dome. Note the radial fractures surrounding the quartz inclusion in the central garnet grain, implying the possible presence of coesite. (i) 10-008a, thermobarometry sample, carapace of the northwest Normanby dome. (j) 10-070a, thermobarometry sample, carapace of the Mailolo dome. (k) 10-071a, Rb-Sr sample, carapace of the Mailolo dome. Note that all images were taken with crossed polars, with the exception of 09-039biii, which was taken in uncrossed polars to better illustrate the radial fractures. 
(white mica) and low $\mathrm{Rb}-\mathrm{Sr}$ isotopic ratio (plagioclase/quartz, omphacite) mineral splits using standard magnetic separation techniques. These mineral splits were hand picked to $99.9 \%$ purity under a binocular microscope, ground in ethanol, and sieved to further reduce any included impurities. A powdered whole rock specimen was prepared in a Tema mill to provide a weighted average isotopic composition of all minerals present within the rock (Glodny et al., 2003). All samples and standards were dissolved in a mixture of concentrated nitric (16M) and hydrofluoric (29 M) acid in a 1:3 ratio by volume. The hydrofluoric acid used here is Seastar ${ }^{\mathrm{TM}}$ grade ultra-pure (all key metals $<10$ ppt). All other acids are sub-boil distilled in Teflon (12 $\mathrm{M} \mathrm{HCl})$ and quartz $\left(16 \mathrm{M} \mathrm{HNO}_{3}\right)$ stills. The resultant solutions were brought to incipient dryness on a hot plate and were then re-dissolved in $3 \mathrm{M}$ nitric acid before being separated into two aliquots: one for measurement of the ${ }^{87} \mathrm{Rb} /{ }^{86} \mathrm{Sr}$ isotopic ratio ( $25 \%$ of solution), and one for measurement of the ${ }^{87} \mathrm{Sr} /{ }^{86} \mathrm{Sr}$ isotopic ratio (75\% of solution). Purification of the ${ }^{87} \mathrm{Sr} /{ }^{86} \mathrm{Sr}$ isotopic ratio aliquot was carried out using pipette-tip columns with Eichrom ${ }^{\mathrm{TM}} \mathrm{Sr}-\mathrm{spec}$ resin. $\mathrm{Rb}$ was washed out of the columns with $5 \mathrm{ml}$ of $3 \mathrm{M}$ nitric acid and the purified $\mathrm{Sr}$ cut was collected in $5 \mathrm{ml}$ of ultrapure Millipore water (resistivity $>18.2 \mathrm{MW}$ ). The Sr separation step was carried out twice to ensure maximum separation of $\mathrm{Sr}$ from $\mathrm{Rb}, \mathrm{Ba}$ and $\mathrm{Ca}$. See Appendix E. 2 for complete description of the chemical purification technique.

All ${ }^{87} \mathrm{Rb} /{ }^{86} \mathrm{Sr}$ values were analyzed with an Agilent $\mathrm{C} 7500 \mathrm{CS}$ inductively coupled plasma mass spectrometer at Victoria University of Wellington, New Zealand (Appendix E.3). A 1 ppb Rb-Sr standard in $1 \% \mathrm{HNO}_{3}$ (Seastar ${ }^{\mathrm{TM}}$ ) was used to tune the lens parameters, torch position, and carrier gas flow of the ICP-MS to optimize instrument sensitivity and beam stability. Measurement of the $1 \mathrm{ppb} \mathrm{Rb}-\mathrm{Sr}$ standard was repeated during analysis to correct for instrumental mass bias. Elemental oxide production was monitored $(<1.5 \%)$ during the tuning of the plasma torch conditions using a $1 \mathrm{ppb}$ Ce solution. Samples and standards were run on a looping sequence during analysis on the ICP-MS; each run of $2-4$ mineral separates was bracketed with two measurements of the $1 \mathrm{ppb} \mathrm{Rb}-\mathrm{Sr}$ standard. Each analytical run included one BHVO-2 measurement analyzed under conditions identical to those used to analyze the unknowns. Total procedural blanks were below background levels. An error of $1 \%$ was assigned to all ${ }^{87} \mathrm{Rb} /{ }^{86} \mathrm{Sr}$ values (i.e. Kullerud, 1991). 
The international rock standard US Geological Survey Hawaiian basalt BHVO-2 was used as a secondary standard to ensure that the accuracy and precision of the solution ICP-MS was within acceptable levels. GeoReM preferred elemental compositions (http://Georem.mpch-mainz.gwdg.de/) were used to calculate the ${ }^{87} \mathrm{Rb} /{ }^{86} \mathrm{Sr}$ value for BHVO-2. The average of all measured BHVO- $2{ }^{87} \mathrm{Rb} /{ }^{86} \mathrm{Sr}$ values is $0.062 \pm 0.001$ $(2 \sigma ; \mathrm{n}=9)$, which is within error of the reference value of $0.066 \pm 0.007$. This reference value was calculated from $\mathrm{Rb}$ and $\mathrm{Sr}$ values in $\mathrm{ppm}$ by weight from the GeoReM website, and the error is a $1 \%$ error assigned by this study.

${ }^{87} \mathrm{Sr} /{ }^{86} \mathrm{Sr}$ isotopic ratios were measured on a $\mathrm{Nu}$ Plasma $\odot$ multi-collector inductively coupled plasma mass spectrometer (MC-ICP-MS) at Victoria University of Wellington, New Zealand. MC-ICP-MS measurements were carried out in wet plasma conditions, and instrument sensitivity was tuned to attain $\sim 5 \mathrm{~V}$ on the ${ }^{88} \mathrm{Sr}$ ion beam for a $300 \mathrm{ppb} \mathrm{Sr}$ solutions. The ${ }^{87} \mathrm{Sr} /{ }^{86} \mathrm{Sr}$ isotopic composition of BHVO-2 reference material was processed and analyzed in the same way as the unknowns during each analytical run, to assess the reproducibility and accuracy of the MC-ICPMS. The average value of BHVO-2 obtained during the analytical period was $0.703472 \pm 0.000017(2 \sigma, \mathrm{n}=9)$, which is within error of the GeoReM preferred reference value $(0.703469 \pm 0.000017 ; 1 \sigma)$. Instrumental mass bias was internally corrected for by tuning the MC-ICP-MS to an ${ }^{86} \mathrm{Sr} /{ }^{88} \mathrm{Sr}$ value of 0.1194 . Repeated measurements of the bracketing Standard Reference Material NBS987 standard were carried out to correct for non-exponential mass bias $\left({ }^{87} \mathrm{Sr} /{ }^{86} \mathrm{Sr}=0.710248\right)$. Errors for the ${ }^{87} \mathrm{Sr} /{ }^{86} \mathrm{Sr}$ values are the internal error, which represents the precision of all measurements within a single analysis of a mineral separate solution. Procedural blanks were $<30 \mathrm{pg}$ and are therefore considered negligible. Isochron parameters and regression lines were calculated using Isoplot/Ex 3.71 (Ludwig, 2008). 


\subsection{Results of thermobarometry and white mica major element analyses}

\subsubsection{Petrography}

Analysis on the electron probe microanalyzer (EPMA) was carried out to determine the major element composition of the white mica phase present in each sample analyzed. Representative major element composition data for the white mica phase is presented in Appendix D. All samples analyzed contain a white mica phase that plots between the muscovite and phengite end-member components (Fig. 3.7; Glodny et al., 2005b). The three white mica analytical categories $(>500 \mu \mathrm{m}$ core analysis, $>500$ $\mu \mathrm{m}$ rim analysis, and $<500 \mu \mathrm{m}$ analysis) are generally compositionally uniform with regards to their $\mathrm{Al}^{\mathrm{IV}}, \mathrm{Al}^{\mathrm{VI}}$, and $\mathrm{Mg}+\mathrm{Fe}_{\text {total }}$ compositions. Thus, there is no clear relationship between grain-size category and mineral composition. This homogeneity between grain size splits suggest that the white mica grains grew at the same time in each sample, and therefore yielded similar major element compositions. For example, for a case where phengite is present as coarse grains surrounded by a matrix of relatively finer grained muscovite, I would expect there to be a prevalence of $>500 \mu \mathrm{m}$ core grains that are phengitic in composition; the $<500 \mu \mathrm{m}$ grain analyses might be more muscovite-rich.

Garnet and plagioclase in five samples of gneiss and quartzose rock (06-018a, 08032a, 08-037a, 10-008a, 10-070a) were analyzed for major element mineral compositions on the EPMA. Plagioclase was unzoned in most cases $(95 \%$ of analyzed grains), with the albite number showing very little within-sample variation. The albite component varies between $75 \%$ and $80 \%$ for three samples of quartzofeldspathic gneiss (06-018a, 08-032a, 08-037a), and between 80 and 90\% for the one sample of pelitic gneiss and one sample of quartzose rock (10-070a, 10008a). Where zonation is present, there is a slight increase in albite number from the core to the rim of the grain (e.g. $\sim 84 \%$ at the core and $\sim 90 \%$ at the rim of one plagioclase grain; 10-008a). All garnets analyzed by this study are almandine-rich with $57-63 \mathrm{~mol} \%$ almandine, with the exception of garnets in one sample of pelitic gneiss (10-008a), which contains $66-72 \mathrm{~mol} \%$ almandine. Garnets in the three samples (10-008a, 10-070a, 06-18a) contain $8-13$ mol\% pyrope and $18-24$ mol\% 


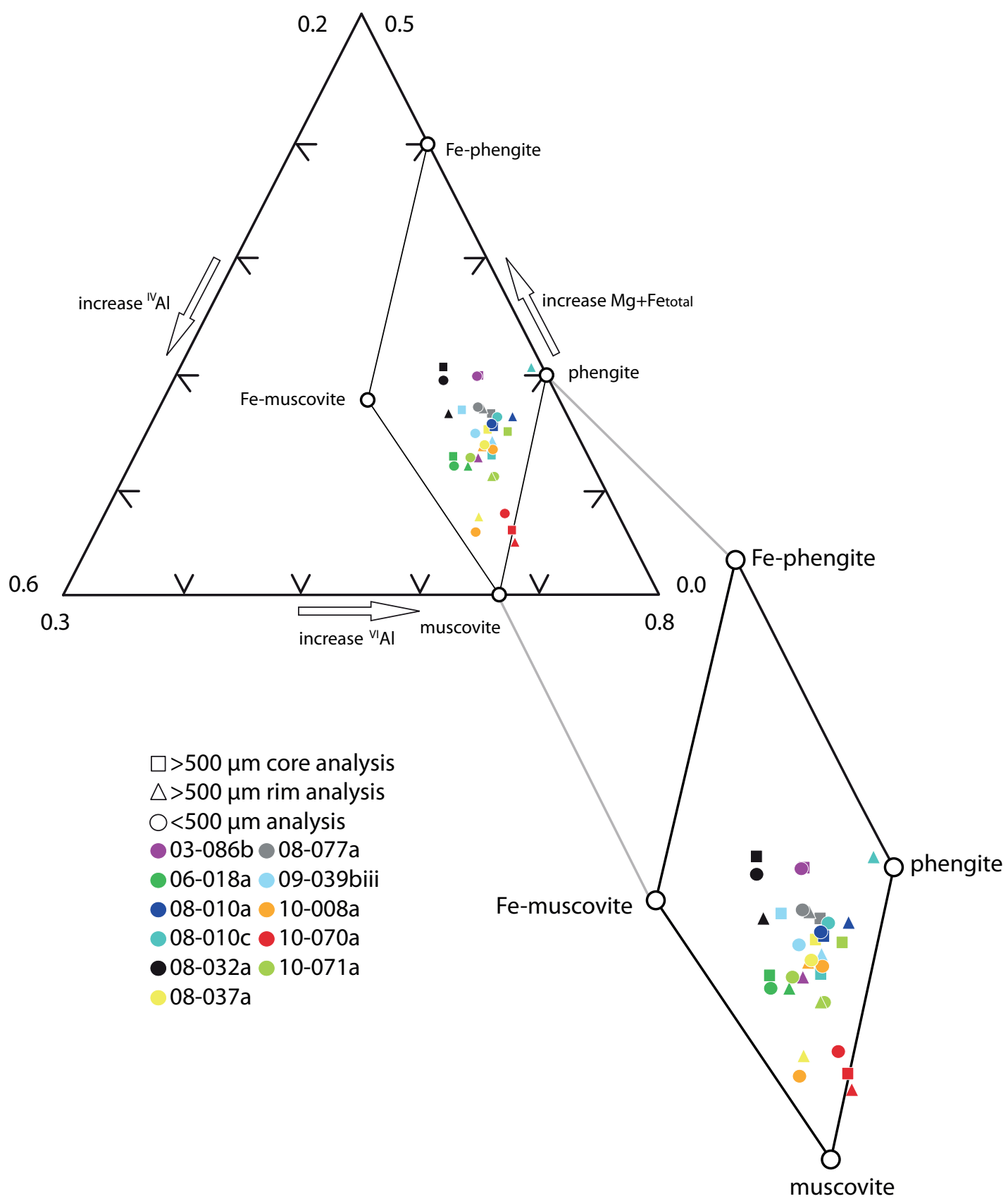

Figure 3.7 Ternary composition plot for phengite and white mica after Glodny et al. (2005). Note that the three white mica analytical categories are shown with three different symbols, and that the analyzed samples are shown with different colors. There is a large spread between the three white mica analytical categories and between analyzed samples; most plot between the phengite and muscovite end-member. 
grossular in their cores and $15-20 \mathrm{~mol} \%$ pyrope and $17-23 \mathrm{~mol} \%$ grossular at their rims. Spessartine was a minor constituent in garnets from these latter three samples $(1-5 \mathrm{~mol} \%$ spessartine in their cores, $0.8-4 \mathrm{~mol} \%$ spessartine at their rims). The garnets in these three samples (10-008a, 10-070a, 06-18a) therefore display prograde compositional zoning with a decrease in spessartine and an increase in pyrope components from core to rim. Garnets in a sample of quartzofeldspathic gneiss from the core zone of the Mailolo dome (08-037a) have a similar composition to the previously described three samples, but with a reversed core to rim relationship. Garnets in this sample yielded a high pyrope composition in the core relative to the rim, and spessartine and grossular components that are higher in the rim relative to the core. Garnet composition variations in this sample (08-037a) therefore imply a decrease in pressure during garnet crystallization. Garnets in a sample of quartzofeldspathic gneiss from the carapace of the Goodenough dome exhibit little zonation (08-032a; $\sim 3.6 \mathrm{~mol} \%$ pyrope, $\sim 12.5 \mathrm{~mol} \%$ spessartine, and $\sim 23.5 \mathrm{~mol} \%$ grossular component). Thus, garnets analyzed here are generally pyrope-almandine-grossular solid solutions and are weakly zoned, similar in compositions and zonation patterns to garnets hosted in eclogites from Goodenough and Fergusson Island (Davies and Warren, 1992).

\subsubsection{Thermobarometry}

Pressure and temperature estimates were determined for five samples of quartzofeldspathic gneiss and quartzose rock (06-018a, 08-032a, 08-037a, 10-008a, 10-070a) from the northwestern D'Entrecasteaux Islands. All analyzed samples were retrogressed during the amphibolite-facies overprint, so the pressure and temperature estimates presented below relate specifically to that syn-exhumational metamorphic event. Samples 06-018a, 08-032a, and 08-037a are amphibolite-facies retrogressed quartzofeldspathic gneiss from the Goodenough and Mailolo domes, with a mineral assemblage of quartz, plagioclase, K-feldspar, white mica, garnet (06-018a, 08037a), biotite, and trace amounts of chlorite (06-018a, 08-037a). Sample 10-008a is a pelitic gneiss from the carapace of the northwest Normanby dome, Normanby Island, which contains plagioclase, K-feldspar, garnet, quartz, white mica, biotite and minor kyanite and oxides. Sample 10-070a is a strongly deformed quartzose sheet from the 
carapace of the Mailolo dome, Fergusson Island, which contains quartz, K-feldspar, plagioclase, white mica, garnet, kyanite, biotite, and chlorite.

Pressure and temperature estimates for the amphibolite-facies metamorphism calculated here are presented in Table 3.9 and Fig. 3.8. The Krogh and Raheim (1978) calibration for the garnet-phengite thermometer yielded temperature estimates of $450-700{ }^{\circ} \mathrm{C}$. The Green and Hellman (1982) calibration for the garnet-phengite thermometer yields temperature estimates of $560-760{ }^{\circ} \mathrm{C}$. The Green and Hellman (1982) temperature estimate for sample 10-008a is lower than the other temperature estimates here by $>100^{\circ} \mathrm{C}$. This sample was collected in the northwest corner of the northwest Normanby dome, a location that is inferred to be subjacent to the contact between the upper plate and the lower plate of the northwest Normanby dome fault zone (Fig. 3.2, 3.4; Little et al., 2011). The low temperature estimate for sample 10008 may have been the result of conductive cooling against the upper plate, and would therefore not represent an accurate estimate for the temperature during amphibolite-facies conditions in the D'Entrecasteaux Islands. I suggest a temperature range of $640-720{ }^{\circ} \mathrm{C}$ for the Green and Hellman (1982) calibration, which is slightly higher than the estimates calculated by the Krogh and Raheim (1978) calibration and is in better agreement with previous thermobarometric studies of the amphibolite-facies metamorphism (Section 3.2.3). The garnet-plagioclasemuscovite-quartz barometer yielded pressure estimates of $4-11 \mathrm{kbar}$ for the Hodges and Crowley (1985) calibration and 12 - 17 kbar for the Hoisch (1990) calibration. These results are not as precise as the pressure estimates calculated for kyanitebearing samples using the garnet- $\mathrm{Al}_{2} \mathrm{SiO}_{5}$-plagioclase-quartz barometer, which yielded pressure estimates of $10-17$ kbar across all five calibrations and the five samples analyzed here. 

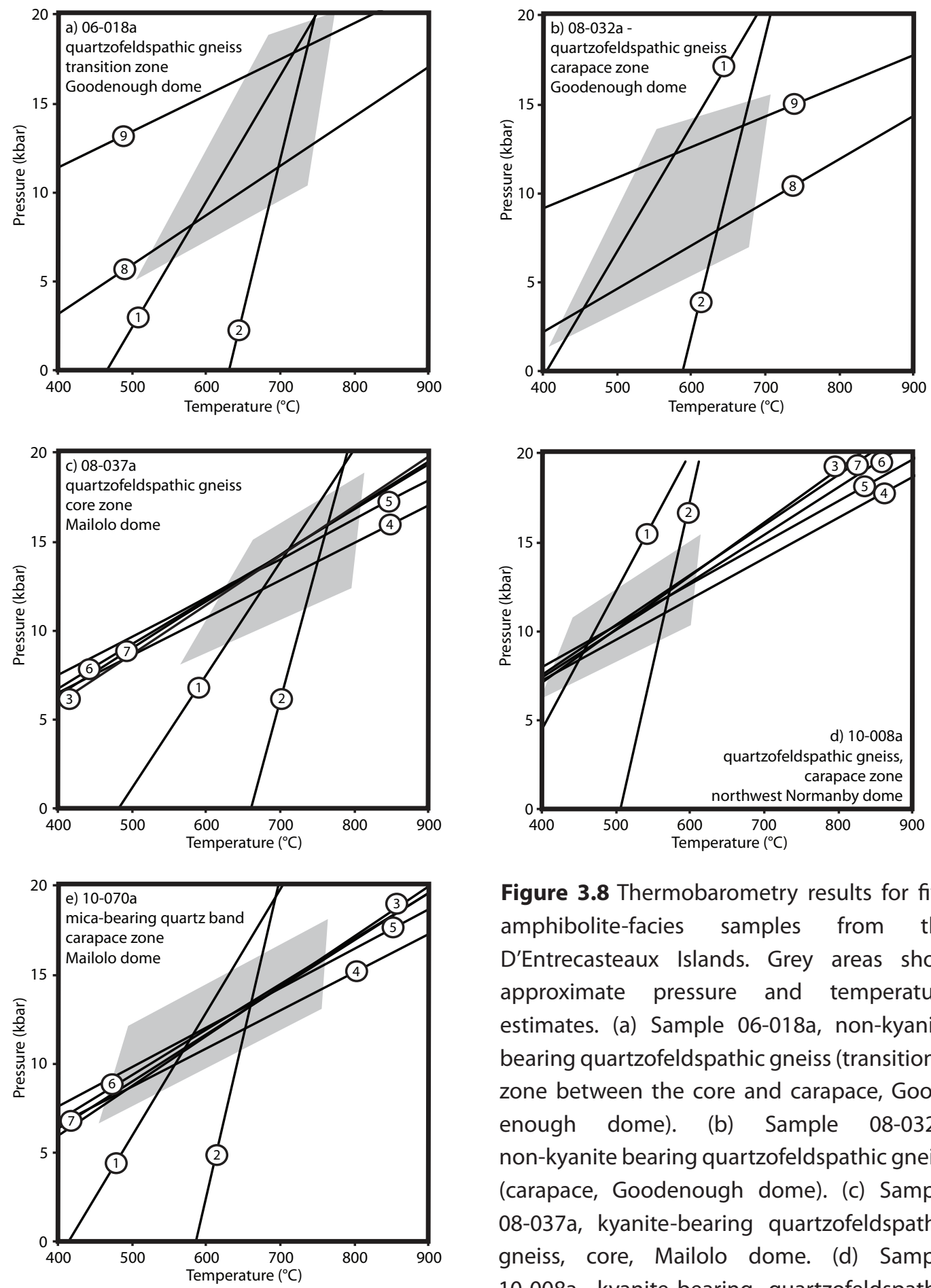

Figure 3.8 Thermobarometry results for five amphibolite-facies samples from the D'Entrecasteaux Islands. Grey areas show approximate pressure and temperature estimates. (a) Sample 06-018a, non-kyanite bearing quartzofeldspathic gneiss (transitional zone between the core and carapace, Goodenough dome). (b) Sample 08-032a, non-kyanite bearing quartzofeldspathic gneiss (carapace, Goodenough dome). (c) Sample 08-037a, kyanite-bearing quartzofeldspathic gneiss, core, Mailolo dome. (d) Sample 10-008a, kyanite-bearing quartzofeldspathic gneiss (carapace, north Normanby dome). (e)

Sample 10-070a, mica-bearing quartz band with garnet and kyanite (carapace, Mailolo dome). For the complete petrographic characterization of each analyzed sample see Appendix D. Calibrations used: (1) garnet-phengite Fe-Mg exchange, Korgh and Raheim (1978); (2) garnet-phengite Fe-Mg exchange, Green and Hellman (1982); (3) garnet- $\mathrm{Al}_{2} \mathrm{SiO}_{5}$-plagioclase-quartz (GASP), Newton and Haselton (1981); (4) GASP, Hodges and Spear (1982); (5) GASP, Ganguly and Saxena (1984); (6) GASP, Hodges and Crowley (1985); (7) GASP, Koziol (1989); (8) garnet-plagioclase-muscovite-quartz (Fe), Hodges and Crowley (1985); (9) garnet-plagioclase-muscovite-quartz (Mg end-member), Hoisch (1990). Temperature and pressure estimates shown on Table 3.9 and sample locations are shown in Fig. 3.4. 
Table 3.9 Summary of thermobarometric results

\begin{tabular}{lcccccc}
\hline & & T $\left({ }^{\circ} \mathbf{C}\right)$ Garnet-phengite & P (kbar) GPMQ & P (kbar) GASP \\
\hline & $\begin{array}{c}\text { Rock } \\
\text { type }\end{array}$ & $\begin{array}{c}\text { 1: Krogh and } \\
\text { Raheim (1978) }\end{array}$ & $\begin{array}{c}\text { 2: Green and } \\
\text { Hellman (1982) }\end{array}$ & $\begin{array}{c}\text { 8: Hodges and } \\
\text { Crowley (1985) }\end{array}$ & $\begin{array}{c}\text { 9: Hoisch } \\
(\mathbf{1 9 9 0})\end{array}$ & $\begin{array}{c}\text { Range of all } \\
\text { calibrations }\end{array}$ \\
\hline 06-018a & QG & $575-700$ & $700-730$ & $8-11$ & $16-17$ & - \\
08-032a & QG & $450-575$ & $640-670$ & $4-8$ & $12-14$ \\
08-037a & QG & $660-700$ & $720-760$ & - & - \\
10-008a & QG & $450-500$ & $560-590$ & - & - & $13-17$ \\
$\mathbf{1 0 - 0 7 0 a}$ & QS & $550-600$ & $650-670$ & - & - & $10-12$ \\
\hline
\end{tabular}

Temperature and pressure estimates have assigned uncertainties of $\pm 50^{\circ} \mathrm{C}$ and $\pm 2 \mathrm{kbar}$ respectively. QG, quartzofeldspathic gneiss; QS, quartz sheet; P, pressure; T temperature; GPMQ, garnetplagioclase-muscovite-quartz barometer.

${ }^{\mathrm{a}}$ Calibrations used for the garnet-plagioclase- $\mathrm{Al}_{2} \mathrm{SiO}_{5}$-quartz (GASP) barometer are: Ganguly and Saxena, 1984; Hodges and Crowley, 1985; Hodges and Spear, 1982; Koziol, 1989; Newton and Haselton, 1981.

\subsection{Results of Rb-Sr dating}

Of the nine samples analyzed here for $\mathrm{Rb}-\mathrm{Sr}$ isotopic compositions, only five yielded statistically-valid $\mathrm{Rb}-\mathrm{Sr}$ isochrons, which I define to be an isochron with a mean square of weighted deviations (MSWD) of $<3.12$ after Kullerud (1991). The MSWD is a measure of the ratio of the observed deviation of the data points from the best-fit line, and the deviation that is expected on the basis of the known errors in the ${ }^{87} \mathrm{Sr} /{ }^{86} \mathrm{Sr}$ ratio (measured by the multi-collector ICP-MS) and the assigned $1 \%$ ${ }^{87} \mathrm{Rb} /{ }^{86} \mathrm{Sr}$ errors (Kullerud, 1991; Ludwig, 2008). This value represents a measure of the quality of linear fit (Kullerud, 1991; Ludwig, 2008). I have assigned a probability of fit of 0.05 , which is the probability that the assigned data-point errors account for the observed scatter of the data-points about the regression line. Rb-Sr analytical results are listed by sample in Table 3.10 and sample locations are shown in Figure 3.4 . 
Table 3.10 Rb-Sr analytical data

\begin{tabular}{|c|c|c|c|c|c|c|}
\hline Sample No. & Material & $\mathbf{R b}(\mathbf{p p m})$ & Sr (ppm) & ${ }^{87} \mathbf{R b} /{ }^{86} \mathrm{Sr}$ & ${ }^{87} \mathrm{Sr} /{ }^{86} \mathrm{Sr}$ & ${ }^{87} \mathrm{Sr} /{ }^{86} \mathrm{Sr} 2 \sigma$ \\
\hline \multicolumn{7}{|c|}{ ECLOGITE-FACIES } \\
\hline \multirow[t]{5}{*}{ 08-010a } & \multicolumn{6}{|c|}{$5.70 \pm 2.00 \mathrm{Ma}, \mathrm{Sr}_{\mathrm{i}}=\mathbf{0 . 7 0 3 9 7 4} \pm 0.000027, \mathrm{MSWD}=2.0$} \\
\hline & $250-355 \mu \mathrm{m}$ white mica & 1591 & 399 & 0.912 & 0.704054 & 0.000021 \\
\hline & $355-500 \mu \mathrm{m}$ white mica & 1232 & 226 & 1.237 & 0.704086 & 0.000023 \\
\hline & $>500 \mu \mathrm{m}$ white mica & 1220 & 231 & 1.208 & 0.704052 & 0.000025 \\
\hline & whole rock & 15 & 152 & 0.237 & 0.703991 & 0.000022 \\
\hline \multirow[t]{6}{*}{ 09-039biii } & \multicolumn{6}{|c|}{$5.60 \pm 1.60 \mathrm{Ma}, \mathrm{Sr}_{\mathrm{i}}=0.704434 \pm 0.000016, \mathrm{MSWD}=1.00$} \\
\hline & Omphacite & 3 & 751 & 0.013 & 0.704431 & 0.000022 \\
\hline & $250-355 \mu \mathrm{m}$ white mica & 772 & 244 & 0.855 & 0.704509 & 0.000023 \\
\hline & $355-500 \mu \mathrm{m}$ white mica & 940 & 275 & 0.928 & 0.704516 & 0.000022 \\
\hline & $>500 \mu \mathrm{m}$ white mica & 1018 & 276 & 1.007 & 0.704499 & 0.000022 \\
\hline & whole rock & 34 & 708 & 0.126 & 0.704447 & 0.000022 \\
\hline \multicolumn{7}{|c|}{ AMPHIBOLOITE-FACIES } \\
\hline \multirow[t]{6}{*}{ 08-010c } & \multicolumn{6}{|c|}{$2.41 \pm 1.40 \mathrm{Ma}, \mathrm{Sr}_{\mathrm{i}}=\mathbf{0 . 7 0 3 8 0 0} \pm \mathbf{0 . 0 0 0 0 3 1}, \mathrm{MSWD}=\mathbf{0 . 5 0}$} \\
\hline & plagioclase/quartz & 1 & 25 & 0.074 & 0.703819 & 0.000041 \\
\hline & $250-355 \mu \mathrm{m}$ white mica & 32 & 34 & 2.304 & 0.703881 & 0.000040 \\
\hline & $355-500 \mu \mathrm{m}$ white mica & 88 & 110 & 2.041 & 0.703871 & 0.000040 \\
\hline & $>500 \mu \mathrm{m}$ white mica & 26 & 42 & 1.591 & 0.703853 & 0.000040 \\
\hline & whole rock & 19 & 110 & 0.442 & 0.703797 & 0.000041 \\
\hline \multirow[t]{6}{*}{ 08-077a } & \multicolumn{6}{|c|}{$3.90 \pm 0.44 \mathrm{Ma}, \mathrm{Sr}_{\mathrm{i}}=0.7044193 \pm 0.000009, \mathrm{MSWD}=\mathbf{0 . 8 2}$} \\
\hline & plagioclase/quartz & 5 & 102 & 0.121 & 0.704423 & 0.000006 \\
\hline & $250-355 \mu \mathrm{m}$ white mica & 74 & 84 & 2.028 & 0.704537 & 0.000006 \\
\hline & $355-500 \mu \mathrm{m}$ white mica & 69 & 86 & 2.028 & 0.704531 & 0.000006 \\
\hline & $>500 \mu \mathrm{m}$ white mica & 87 & 141 & 1.569 & 0.704514 & 0.000006 \\
\hline & whole rock & 38 & 230 & 0.417 & 0.704444 & 0.000006 \\
\hline \multirow[t]{9}{*}{ 08-037a } & \multicolumn{6}{|c|}{$12.0 \pm 5.0 \mathrm{Ma}, \mathrm{Sr}_{\mathrm{i}}=0.706160 \pm 0.000120, \mathrm{MSWD}=5.5$} \\
\hline & plagioclase/quartz & 5 & 48 & 0.255 & 0.706195 & 0.000019 \\
\hline & 250-355 $\mu \mathrm{m}$ white mica & 89 & 116 & 1.910 & 0.706432 & 0.000016 \\
\hline & $250-355 \mu \mathrm{m}$ white mica UC & 94 & 124 & 1.831 & 0.706463 & 0.000017 \\
\hline & $355-500 \mu \mathrm{m}$ white mica & 151 & 200 & 1.874 & 0.706499 & 0.000017 \\
\hline & $355-500 \mu \mathrm{m}$ white mica UC & 90 & 117 & 1.892 & 0.706523 & 0.000015 \\
\hline & $>500 \mu \mathrm{m}$ white mica* & 116 & 124 & 2.324 & 0.706894 & 0.000022 \\
\hline & $>500 \mu \mathrm{m}$ white mica $\mathrm{UC}^{*}$ & 415 & 450 & 2.283 & 0.706950 & 0.000020 \\
\hline & whole rock & 30 & 62 & 1.193 & 0.706387 & 0.000014 \\
\hline \multirow[t]{6}{*}{$06-018 a$} & \multicolumn{6}{|c|}{$2.38 \pm 0.29 \mathrm{Ma}, \mathrm{Sr}_{\mathrm{i}}=0.704753 \pm 0.000014, \mathrm{MSWD}=2.5$} \\
\hline & plagioclase/quartz & 6 & 517 & 0.028 & 0.704739 & 0.000010 \\
\hline & $250-355 \mu \mathrm{m}$ white mica & 2406 & 149 & 4.838 & 0.704911 & 0.000010 \\
\hline & 355-500 $\mu \mathrm{m}$ white mica & 1208 & 74 & 4.911 & 0.704924 & 0.000010 \\
\hline & $>500 \mu \mathrm{m}$ white mica* & 1384 & 82 & 5.075 & 0.704971 & 0.000010 \\
\hline & whole rock & 563 & 847 & 0.185 & 0.704774 & 0.000010 \\
\hline
\end{tabular}


Table 3.10 Rb-Sr analytical data (cont.)

\begin{tabular}{|c|c|c|c|c|c|c|}
\hline Sample No. & Material & $\mathbf{R b}(\mathbf{p p m})$ & $\operatorname{Sr}(\mathbf{p p m})$ & ${ }^{87} \mathbf{R b} /{ }^{86} \mathrm{Sr}$ & ${ }^{87} \mathrm{Sr} /{ }^{86} \mathrm{Sr}$ & ${ }^{87} \mathrm{Sr} /{ }^{86} \mathrm{Sr} \mathrm{2 \sigma}$ \\
\hline \multirow[t]{6}{*}{ 10-071a } & \multicolumn{6}{|c|}{$3.70 \pm 3.80 \mathrm{Ma}, \mathrm{Sr}_{\mathrm{i}}=0.706202 \pm 0.000095, \mathrm{MSWD}=3.9$} \\
\hline & plagioclase/quartz & 4 & 121 & 0.081 & 0.706213 & 0.000012 \\
\hline & $250-355 \mu \mathrm{m}$ white mica & 3174 & 352 & 1.992 & 0.706294 & 0.000010 \\
\hline & 355-500 $\mu$ m white mica & 2402 & 216 & 2.335 & 0.706347 & 0.000011 \\
\hline & $>500 \mu \mathrm{m}$ white mica & 1768 & 229 & 1.714 & 0.706278 & 0.000011 \\
\hline & whole rock* & 464 & 50 & 1.936 & 0.706375 & 0.000012 \\
\hline \multirow[t]{5}{*}{ 08-032a } & \multicolumn{6}{|c|}{$0.22 \pm 0.06 \mathrm{Ma}, \mathrm{Sr}_{\mathrm{i}}=\mathbf{0 . 7 0 5 2 9 0} \pm \mathbf{0 . 0 0 0 2 7 0}, \mathrm{MSWD}=\mathbf{3 8}$} \\
\hline & plagioclase/quartz & 164 & 32 & 1.084 & 0.705349 & 0.000010 \\
\hline & 250-355 $\mu \mathrm{m}$ white mica & 760 & 9 & 19.142 & 0.706138 & 0.000010 \\
\hline & $355-500 \mu \mathrm{m}$ white mica & 2627 & 1 & 660.627 & 0.707308 & 0.000036 \\
\hline & whole rock & 715 & 91 & 1.686 & 0.705313 & 0.000009 \\
\hline \multirow[t]{5}{*}{ 03-086b } & \multicolumn{6}{|c|}{$0.30 \pm 0.39 \mathrm{Ma}, \mathrm{Sr}_{\mathrm{i}}=0.704650 \pm 0.00031, \mathrm{MSWD}=152$} \\
\hline & plagioclase/quartz & 8 & 60 & 0.030 & 0.704516 & 0.000011 \\
\hline & 250-355 $\mu \mathrm{m}$ white mica & 950 & 35 & 5.937 & 0.704783 & 0.000009 \\
\hline & 355-500 $\mu$ m white mica & 1017 & 2 & 113.280 & 0.705122 & 0.000016 \\
\hline & $>500 \mu \mathrm{m}$ white mica & 714 & 45 & 3.410 & 0.704684 & 0.000010 \\
\hline
\end{tabular}

Error of $1 \%$ assigned to the ${ }^{87} \mathrm{Rb} /{ }^{86} \mathrm{Sr}$ ratio. Typical sample weights are $\sim 100 \mathrm{mg}$ for all plagioclase, omphacite, and whole rock; $\sim 50 \mathrm{mg}$ for white mica.

*, not included in isochron age; UC, uncleaned white mica split.

Note: Italics denotes ${ }^{87} \mathrm{Rb} /{ }^{86} \mathrm{Sr}$ ratio was calculated using the correction method detailed in Appendix E.3).

Figure 3.9a presents a $\mathrm{Rb}-\mathrm{Sr}$ internal mineral isochron for a sample of the unretrogressed core of the coesite-bearing eclogite boudin from the UHP locality in the core zone of the Mailolo dome (08-010a; Baldwin et al., 2008). The retrogressed amphibolite-facies rind of this boudin was excluded, and the core was free of veining and hydrous phases (Monteleone et al., 2007). This boudin is $\sim 1 \mathrm{~m}$ in length with a $\sim 20 \mathrm{~cm}$ rind, and occurs within a strongly foliated and folded host orthogneiss (08010c; Baldwin et al., 2008). This sample contains garnet, omphacite, white mica, quartz, hornblende, and minor rutile (Fig. 3.6d; after Brownlee et al., in prep.). Mineral splits of whole rock, $250-355 \mu \mathrm{m}$ white mica, $355-500 \mu \mathrm{m}$ white mica, and $>500 \mu \mathrm{m}$ white mica were analyzed. No mineral splits were excluded from this isochron $(\mathrm{n}=4)$. This sample yielded a Rb-Sr age of $5.7 \pm 2.0 \mathrm{Ma}(2 \sigma ; \mathrm{MSWD}=$ 2.0; probability of fit $>0.05$ ) and an initial ${ }^{87} \mathrm{Sr} /{ }^{86} \mathrm{Sr}$ ratio of 0.7040 .

Figure $3.9 \mathrm{~b}$ presents a $\mathrm{Rb}-\mathrm{Sr}$ internal mineral isochron for a sample of the unretrogressed core of an eclogite cobble from the core zone of the Mailolo dome, collected $\sim 3 \mathrm{~km}$ downstream of the main divide (09-039biii). The retrogressed amphibolite-facies rind of this cobble was excluded, and the core was free of veining 

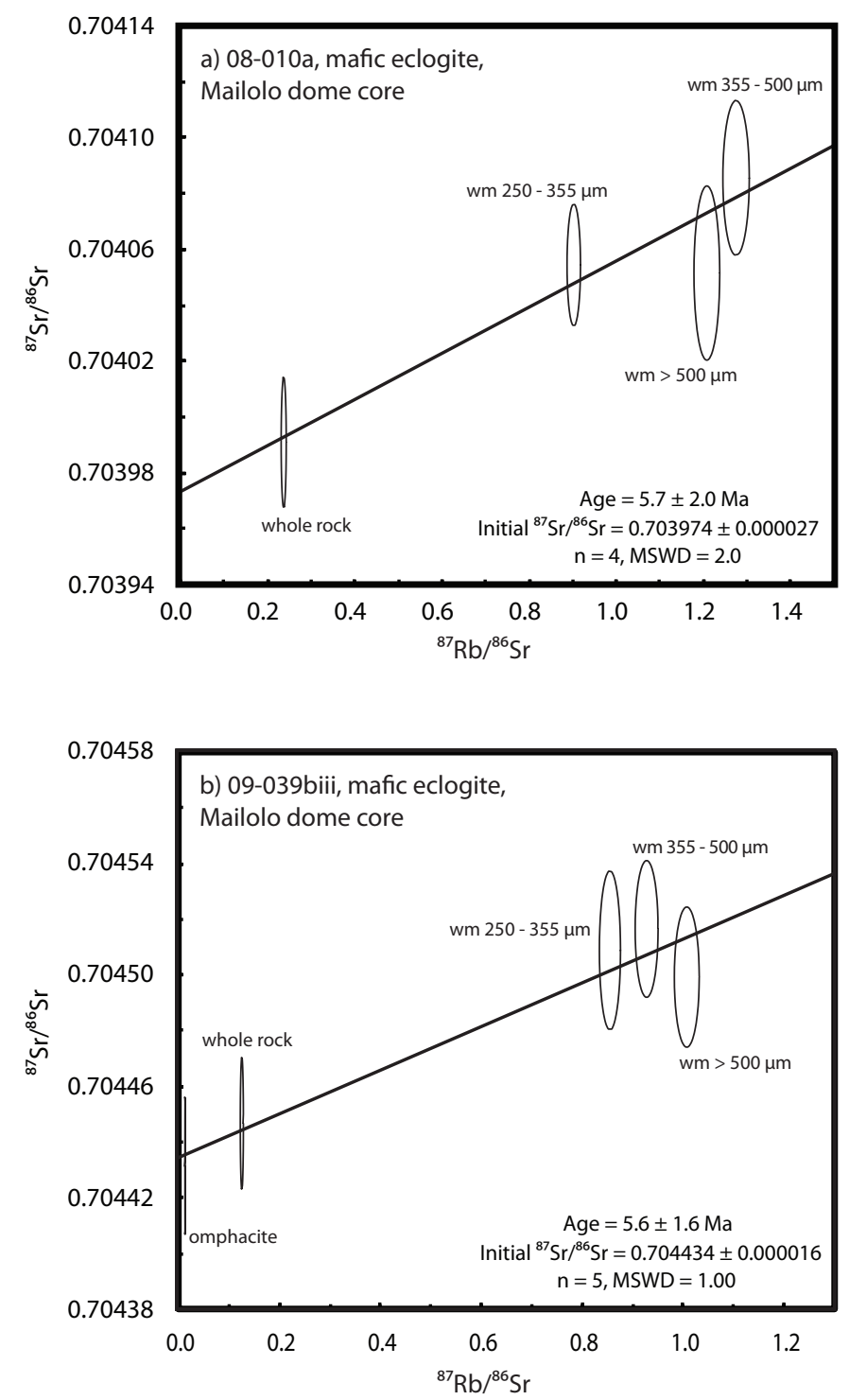

Figure 3.9 Rb-Sr internal mineral isochrons for two mafic eclogites from the core of the Mailolo dome, Fergusson Island: wm, white mica. Data-point error ellipses and errors in the age calculation are two standard deviations. Note that sample 08-010a is the only known coesite-bearing sample in the D'Entrecasteaux Islands, and that sample 09-039biii contains radial fractures around quartz inclusions in garnet (Fig. 3.6h; Baldwin et al., 2008). See Table 3.10 for analytical data and Fig. 3.4 for sample location. 
and hydrous phases (Monteleone et al., 2007). This sample contains garnet, white mica, plagioclase, quartz, hornblende, rutile, and minor biotite (Fig. 3.6h). Garnets in this sample exhibit radial fractures around quartz inclusions in garnet, which implies that this sample once contained coesite (Fig. 3.6h). Mineral splits of whole rock, omphacite, 250 - $355 \mu \mathrm{m}$ white mica, 355 - $500 \mu \mathrm{m}$ white mica, and $>500 \mu \mathrm{m}$ white mica were analyzed. No mineral splits were excluded from this isochron $(n=5)$. This sample yielded a $\mathrm{Rb}-\mathrm{Sr}$ age of $5.6 \pm 1.6 \mathrm{Ma}(2 \sigma ; \mathrm{MSWD}=2.0$; probability of fit $>0.05)$ and an initial ${ }^{87} \mathrm{Sr} /{ }^{86} \mathrm{Sr}$ ratio of 0.7044 . This $\mathrm{Rb}-\mathrm{Sr}$ age is within error $(2 \sigma)$ of the previously discussed $\mathrm{Rb}-\mathrm{Sr}$ age for the coesite-bearing eclogite (08-010a).

Figure 3.10a presents a $\mathrm{Rb}$-Sr internal mineral isochron for a sample of granodioritic orthogneiss from the UHP locality in the core zone of the Mailolo dome (08-010c), which hosts the coesite-bearing eclogite (08-010a). This granodioritic orthogneiss is mappable at a kilometer-scale and is ductilely deformed. It includes foliation-parallel leucosomes ( $\sim 10 \mathrm{~cm}$ in width) and is crosscut by foliated granitic dikes. This sample contains quartz, plagioclase, K-feldspar, white mica, and minor biotite and oxides (Fig. 3.6c). Mineral splits of whole rock, plagioclase and quartz, $250-355 \mu \mathrm{m}$ white mica, $355-500 \mu \mathrm{m}$ white mica, and $>500 \mu \mathrm{m}$ white mica were analyzed. No mineral splits were excluded from this isochron $(\mathrm{n}=5)$. This sample yielded a $\mathrm{Rb}$-Sr age of $2.41 \pm 1.40 \mathrm{Ma}(2 \sigma ; \mathrm{MSWD}=0.50$; probability of fit $>0.05)$ and an initial ${ }^{87} \mathrm{Sr} /{ }^{86} \mathrm{Sr}$ ratio of 0.7038 .

Figure $3.10 \mathrm{~b}$ presents a $\mathrm{Rb}-\mathrm{Sr}$ internal mineral isochron for a sample of granodioritic orthogneiss from the core of the northwest Normanby dome (08-077a). This granodioritic orthogneiss is a ductilely deformed granitic sheet $(\sim 20 \mathrm{~cm}$ thick), which crosscuts the main foliation in the host quartzofeldspathic gneiss. This sample contains quartz, plagioclase, K-feldspar, white mica, and minor biotite and oxides (Fig. 3.6g). Mineral splits of whole rock, plagioclase and quartz, $250-355 \mu \mathrm{m}$ white mica, $355-500 \mu \mathrm{m}$ white mica, and $>500 \mu \mathrm{m}$ white mica were analyzed. No mineral splits were excluded from this isochron $(\mathrm{n}=5)$. This sample yielded a $\mathrm{Rb}-\mathrm{Sr}$ age of $3.90 \pm 0.44 \mathrm{Ma}(2 \sigma ; \mathrm{MSWD}=0.82$; probability of fit $>0.05)$ and an initial ${ }^{87} \mathrm{Sr} /{ }^{86} \mathrm{Sr}$ ratio of 0.7044 . 

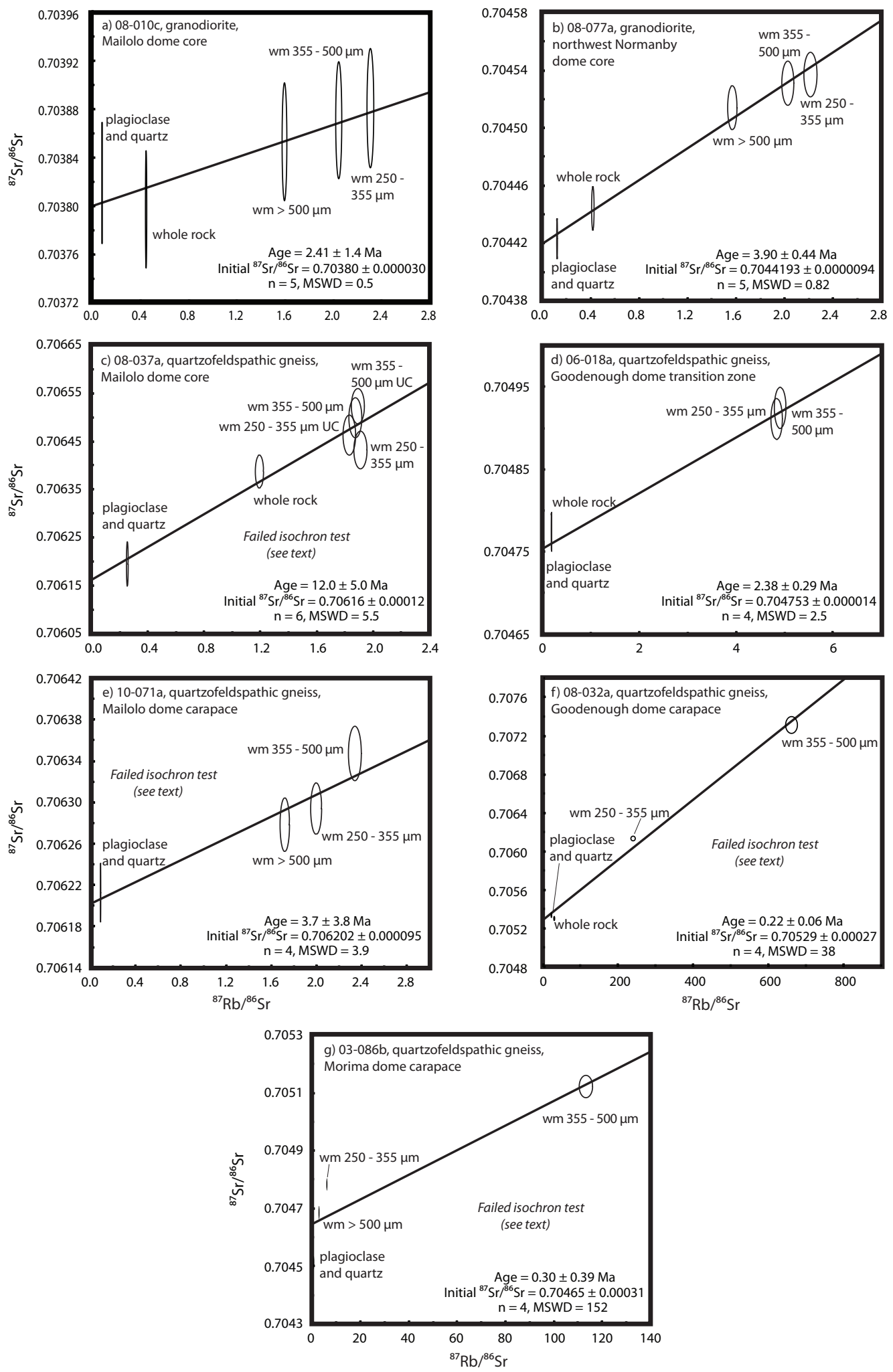

Figure 3.10 Rb-Sr internal mineral isochrons for seven amphibolite-facies samples of quartzofeldspathic gneiss and granitic rock from the northwest D'Entrecasteaux Islands: wm, white mica; UC, uncleaned. Data-point error ellipses and errors in the age calculation are two standard deviations. See Table 3.10 for analytical data and Fig. 3.4 for sample location. 
Figure $3.10 \mathrm{c}$ presents a $\mathrm{Rb}-\mathrm{Sr}$ internal mineral isochron for a sample of quartzofeldspathic gneiss from the core of the Mailolo dome (08-037a). This quartzofeldspathic gneiss is ductilely deformed and finely layered, and hosts retrogressed eclogite boudins. This sample contains quartz, garnet, white mica, plagioclase, K-feldspar, with minor biotite and trace amounts of chlorite (Fig. 3.6f). I analyzed one cleaned and one uncleaned white mica split to test the efficiency of the previously discussed cleaning procedure for mineral separates. There was minimal difference in ${ }^{87} \mathrm{Sr} /{ }^{86} \mathrm{Sr}$ and ${ }^{87} \mathrm{Rb} /{ }^{86} \mathrm{Sr}$ ratios for the cleaned and uncleaned white mica splits. Mineral splits of whole rock, plagioclase and quartz, $250-355 \mu \mathrm{m}$ white mica (cleaned), 250 - $355 \mu \mathrm{m}$ white mica (uncleaned), 355 - $500 \mu \mathrm{m}$ white mica (cleaned), 355 - $500 \mu \mathrm{m}$ white mica (uncleaned), $>500 \mu \mathrm{m}$ white mica (cleaned), and $>500 \mu \mathrm{m}$ white mica (uncleaned) were analyzed. This isochron does not include the $>500 \mu \mathrm{m}$ white mica split $(\mathrm{n}=6)$, the lack of which cannot be explained by a low concentration of $\mathrm{Rb}$ and $\mathrm{Sr}$, or by a small sample size (Table 3.10). The $>500 \mu \mathrm{m}$ white mica rim major element analysis for this sample is much closer to the muscovite end-member than the other two white mica analytical categories $(>500$ $\mu \mathrm{m}$ core, $<500 \mu \mathrm{m}$; Fig. 3.7). This dissimilarity may reflect disequilibrium between the analyzed white mica aliquots. This sample yielded a $\mathrm{Rb}-\mathrm{Sr}$ age of $12.0 \pm 5.0 \mathrm{Ma}$ $(2 \sigma ; \operatorname{MSWD}=5.5$; probability of fit $<0.05)$ and an initial ${ }^{87} \mathrm{Sr} /{ }^{86} \mathrm{Sr}$ ratio of 0.7062 . The probability of fit for this sample is $<0.05$ and the isochron calculation therefore required a Model 3 fit (Ludwig, 2008). Although the Model 3 fit takes into account data-point errors, this fit assumes that excess scatter about the regression line results from uniform error in the Y parameter (Ludwig, 2008). In this case, the Isoplot program solves for the initial-ratio variation as well as for the best-fit line (Ludwig, $2008)$. The $2 \sigma$ errors associated with this age are interpreted as the lower bound of the true errors (Ludwig, 2008). The isochron for this sample is older than any other amphibolite-facies $\mathrm{Rb}-\mathrm{Sr}$ ages calculated by this study and any previous published $\mathrm{U}-\mathrm{Pb}$ zircon ages for the amphibolite-facies metamorphism (Section 3.2.4). Based on the calculated MSWD, I suggest that the three key requirements for successful isotopic dating of deformation were not met for this sample (Section 3.3.2) and I reject this result.

Figure 3.10d presents a $\mathrm{Rb}-\mathrm{Sr}$ internal mineral isochron for a sample of quartzofeldspathic gneiss from Goodenough dome, which is located in a transitional 
zone between the core and the carapace (06-018a). This quartzofeldspathic gneiss contains a folded foliation, which is crosscut by abundant granitic dikes that were also tightly folded during subsequent deformation. Both the folded granitic dikes and the folded amphibolite-facies foliation are crosscut by late-stage and moderately deformed granitic dikes ( $\sim 60 \mathrm{~cm}$ wide) which are at a high angle to the main foliation. This sample contains quartz, plagioclase, K-feldspar, biotite, white mica, with minor garnet, biotite, and chlorite (Fig. 3.6b). Mineral splits of whole rock, plagioclase and quartz, $250-355 \mu \mathrm{m}$ white mica, $355-500 \mu \mathrm{m}$ white mica, and $>500 \mu \mathrm{m}$ white mica were analyzed. This isochron does not include the $>500 \mu \mathrm{m}$ white mica aliquot $(n=4)$, the lack of which cannot be explained by a low concentration of $\mathrm{Rb}$ and $\mathrm{Sr}$ or a small sample size (Table 3.10). White mica compositions for sample 06-018a are similar for all white mica analytical categories (Fig. 3.7), implying that the misfit of the $>500 \mu \mathrm{m}$ white mica aliquot to the rest of the data is not related to preserved zonation. This sample yielded a $\mathrm{Rb}-\mathrm{Sr}$ age of 2.38 $\pm 0.29 \mathrm{Ma}(2 \sigma ; \mathrm{MSWD}=2.5$; probability of fit $>0.05)$ and an initial ${ }^{87} \mathrm{Sr} /{ }^{86} \mathrm{Sr}$ ratio of 0.7048. This Rb-Sr age is within error $(2 \sigma)$ of the age calculated for the granodioritic orthogneiss that hosts the coesite-bearing eclogite from the UHP locality in the core of the Mailolo dome (08-010c).

Figure $3.10 \mathrm{e}$ presents an $\mathrm{Rb}-\mathrm{Sr}$ internal mineral isochron for a sample of quartzofeldspathic gneiss from the carapace of the Mailolo dome (10-071a). This quartzofeldspathic gneiss is ductilely deformed. The gneiss includes pegmatite sheets and deformed granodiorite, sill-like bodies, and is crosscut by a late brittle-ductile shear zone. This sample contains quartz, white mica, biotite, K-feldspar, garnet, and oxides (Fig. 3.6k). Mineral splits of whole rock, plagioclase and quartz, $250-355$ $\mu \mathrm{m}$ white mica, $355-500 \mu \mathrm{m}$ white mica, and $>500 \mu \mathrm{m}$ white mica were analyzed. The whole rock split for this sample was not included in the isochron $(n=4)$ as it includes pervasive biotite $(5-7 \%)$ and minor chlorite $(<2 \%$; Appendix D). This sample yielded a $\mathrm{Rb}-\mathrm{Sr}$ age of $3.7 \pm 3.8 \mathrm{Ma}(2 \sigma$; MSWD $=3.9$; probability of fit $<0.05$ ) and an initial ${ }^{87} \mathrm{Sr} /{ }^{86} \mathrm{Sr}$ ratio of 0.7062 . This sample has a probability of fit of $<0.05$, and the isochron calculation required a Model 3 fit as previously discussed. Although this isochron yielded a geologically acceptable age of 3.7 Ma, the $2 \sigma$ age uncertainty is larger than the calculated age. Based on this large error in the age and the MSWD of 3.9, I reject this result. 
Figure 3.10f presents an $\mathrm{Rb}-\mathrm{Sr}$ internal mineral isochron for a sample of quartzofeldspathic gneiss from the carapace of the Goodenough dome (08-032a). This quartzofeldspathic gneiss is ductilely deformed, and includes foliation-parallel leucosomes $(3-5 \mathrm{~cm}$ in width). This sample contains quartz, plagioclase, $\mathrm{K}-$ feldspar, white mica, and biotite (Fig. 3.6e). Mineral splits of whole rock, plagioclase and quartz, $250-355 \mu \mathrm{m}$ white mica, and $355-500 \mu \mathrm{m}$ white mica were analyzed. No mineral splits were excluded from this isochron $(n=4)$. This sample yielded a $\mathrm{Rb}$-Sr age of $0.22 \pm 0.06 \mathrm{Ma}(2 \sigma ; \mathrm{MSWD}=38$; probability of fit $<0.05)$, which is younger than ${ }^{40} \mathrm{Ar} /{ }^{39} \mathrm{Ar}$ cooling ages for white mica and biotite (Baldwin et al., 1993). Based on the calculated MSWD, I suggest that the three key requirements for successful isotopic dating of deformation were not met for this sample (Section 3.3.2), and I reject this result.

Figure $3.10 \mathrm{~g}$ presents an $\mathrm{Rb}-\mathrm{Sr}$ internal mineral isochron for a sample of quartzofeldspathic gneiss from the carapace of the Mailolo dome (03-086b). This quartzofeldspathic gneiss is intruded by coarse-grained, deformed granodioritic dikes. This sample contains quartz, plagioclase, K-feldspar, white mica, and biotite (Fig. 3.6a). Mineral splits of plagioclase and quartz, 250 - $355 \mu \mathrm{m}$ white mica, $355-$ $500 \mu \mathrm{m}$ white mica, and $>500 \mu \mathrm{m}$ white mica were analyzed. No mineral splits were excluded from this isochron $(\mathrm{n}=4)$. This sample yielded a $\mathrm{Rb}-\mathrm{Sr}$ age of $0.30 \pm 0.39$ Ma $(2 \sigma ; \operatorname{MSWD}=152$; probability of fit $<0.05)$, which is within error of the quartzofeldspathic gneiss from the carapace of the Goodenough dome (08-032a). Based on the calculated MSWD, I suggest that the three key requirements for successful isotopic dating of deformation were not met for this sample (Section 3.3.2), and I reject this result. 


\subsection{Discussion}

\subsubsection{Initial ${ }^{87} \mathrm{Sr} /{ }^{86} \mathrm{Sr}$ ratios}

The $\mathrm{Rb}-\mathrm{Sr}$ internal mineral isochrons presented here yielded an initial ${ }^{87} \mathrm{Sr} /{ }^{86} \mathrm{Sr}$ ratio range of $\sim 0.7038$ to $\sim 0.7048$ (Fig. 3.9, 3.10). I note that these ratios are within the range of initial ${ }^{87} \mathrm{Sr} /{ }^{86} \mathrm{Sr}$ ratio for ocean island basalts $(0.7030-0.7060$; Hofmann, 1997). Initial ${ }^{87} \mathrm{Sr} /{ }^{86} \mathrm{Sr}$ ratios of $0.7100-0.7130$ suggest additional contributions to the granite rock from melting of the pre-existing crustal source and an initial ${ }^{87} \mathrm{Sr} /{ }^{86} \mathrm{Sr}$ ratio of $<0.7100$ in rocks of granitic composition implies derivation of these melts by partial differentiation directly from a mantle source (Singh and Chabria, 2002). Given these initial ${ }^{87} \mathrm{Sr} /{ }^{86} \mathrm{Sr}$ ratios, and that the primitive mantle today has an ${ }^{87} \mathrm{Sr} /{ }^{86} \mathrm{Sr}$ ratio of $\sim 0.7045$, the range of initial ${ }^{87} \mathrm{Sr} /{ }^{86} \mathrm{Sr}$ ratios calculated here indicate that the protolith of the rocks in the D'Entrecasteaux Islands was primitive (Hinchey and Carr, 2006).

The initial ${ }^{87} \mathrm{Sr} /{ }^{86} \mathrm{Sr}$ ratios calculated here supports recent inferences that the protolith of both the eclogites and the quartzofeldspathic gneiss in the D'Entrecasteaux Islands was a segment of the isotopically primitive Whitsunday Volcanic Province of northeastern Australia (Zirakparvar et al., 2010; Zirakparvar et al., 2011). Part of this volcanic terrane, which was active between 120 and $105 \mathrm{Ma}$, was rafted into PNG by the opening of the Coral Sea Basin in $62-56 \mathrm{Ma}$ (Davies and Jacques, 1984; Ewart et al., 1992; Weissel and Watts, 1979). Proterozoic and Siluro-Devonian igneous rocks in the Georgetown inlier of northeast Queensland, which occupies the 100,000 $\mathrm{km}^{2}$ of northeastern Australia that is closest to southeastern PNG, have a range of initial ${ }^{87} \mathrm{Sr} /{ }^{86} \mathrm{Sr}$ of $0.7070-0.7150$ (average of 0.7100; Black and McCulloch, 1990 and ref. therein). This range is dissimilar to that determined here. The Whitsunday Volcanic Province in northeastern Australia has previously been inferred to be the protolith of metamorphic rock along the southern margin of the Woodlark Rift, based on the respective $\mathrm{Nd}$ isotopic compositions of these two areas (Zirakparvar et al., 2010). Initial ${ }^{87} \mathrm{Sr} /{ }^{86} \mathrm{Sr}$ ratios in the volcanic and plutonic rocks through the Whitsunday, Cumberland and Northumberland Island groups along the central Queensland coast, yielded a range of initial ${ }^{87} \mathrm{Sr} /{ }^{86} \mathrm{Sr}$ ratios of $0.7031-0.7045$ (Ewart 
et al., 1992). These results are from an area to the south of the Georgetown inlier, and are a near perfect fit to the initial ${ }^{87} \mathrm{Sr} /{ }^{86} \mathrm{Sr}$ values measured by this study $(0.7037$ $-0.7048)$.

The $\mathrm{Rb}-\mathrm{Sr}$ isochrons derived from the coesite-bearing eclogite (08-010a) and the granodiorite orthogneiss that hosts the UHP eclogite block (08-010c) of the Mailolo dome have initial ${ }^{87} \mathrm{Sr} /{ }^{86} \mathrm{Sr}$ ratios of 0.7040 and 0.7038 respectively (Fig. 3.9a, 3.10a). These ratios are at the lower end of the range observed for the data set as a whole, suggesting a $\sim 5 \%$ more primitive source composition for the meta-basalts and meta-granite rock at the UHP locality. As the lower bound of the range of initial ${ }^{87} \mathrm{Sr} /{ }^{86} \mathrm{Sr}$ ratios for the Whitsunday Volcanic Province is 0.7031 , the initial ${ }^{87} \mathrm{Sr} /{ }^{86} \mathrm{Sr}$ ratios from the UHP locality are within this range. Thus, the common initial ${ }^{87} \mathrm{Sr} /{ }^{86} \mathrm{Sr}$ ratio for samples from the UHP locality is most easily interpreted as reflecting the derivation of these rocks from a section of the Whitsunday Volcanic Province that had a 5\% more primitive $\mathrm{Sr}$ isotopic signature relative to the other samples analyzed here.

\subsubsection{Rb-Sr constraints on the timing of the eclogite-facies metamorphic crystallization}

The eclogites analyzed in this study yielded ages of $5.7 \pm 2.0 \mathrm{Ma}(2 \sigma ; 08-010 \mathrm{a})$ and $5.6 \pm 1.6 \mathrm{Ma}(2 \sigma ; 09-039 \mathrm{biii} ;$ Fig. 3.9). One sample has been proven to be coesitebearing (08-010a) and the other contains radial fractures around quartz inclusions in garnet (09-039biii; Fig. 3.6h), which implies that the latter sample may once have been coesite-bearing (Baldwin et al., 2008; van der Molen and Paterson, 1979). The white mica mineral separates of the eclogite samples analyzed here are phengitic (Fig. 3.7). The unretrogressed interior of the eclogite boudins was used for analysis here, as these appear to have been shielded from the subsequent amphibolite-facies deformation that affected the surrounding quartzofeldspathic gneiss. From these data, I interpret these eclogite isochrons as dating the fluid-present mineral growth and deformation that took place at eclogite-facies UHP conditions $(>90 \mathrm{~km}$; Baldwin et al., 2008). 
The eclogite-facies $\mathrm{Rb}-\mathrm{Sr}$ results presented here agree with a new $\mathrm{U}-\mathrm{Pb}$ chemicalabrasion thermal-ionization mass spectrometry study by Gordon et al. (in review). The single-crystal U-Pb zircon ages determined by Gordon et al. (in review) range from $5.82 \pm 0.20 \mathrm{Ma}$ to $4.78 \pm 0.17 \mathrm{Ma}(2 \sigma$; Section 3.2 .4$)$. The $\mathrm{Rb}-\mathrm{Sr}$ internal mineral isochrons presented here are within this range. Zircon $\mathrm{U}-\mathrm{Pb}$ geochronology has high analytical precision relative to $\mathrm{Rb}-\mathrm{Sr}$ dating and can therefore be used to precisely determine single-grain ages of the zircon crystallization (blocking temperature of $>900^{\circ} \mathrm{C}$; Ireland and Williams, 2003; Reiners et al., 2005). By contrast, the $\mathrm{Rb}$-Sr method is suggested to date fluid-present mineral growth during deformation, and has a lower isotope blocking temperature relative to the $\mathrm{U}-\mathrm{Pb}$ system in zircon (Section 3.3.1). Prior to the study by Gordon et al. (in review), the age of the UHP metamorphism was interpreted to be $7-8 \mathrm{Ma}$. Gordon et al. (in review) argue that the ion microprobe ages for zircons determined by Monteleone et al. (2007) were a simplification of the history of the zircon grains, which may record multiple thermal events. Based on the $\mathrm{Rb}-\mathrm{Sr}$ ages for the amphibolite-facies rock fabric development calculated here, I agree with this interpretation. The similarity between the new $\mathrm{U}-\mathrm{Pb}$ zircon ages and $\mathrm{Rb}-\mathrm{Sr}$ ages presented here strongly supports the recent revision of the timing of the UHP event to $\sim 5$ Ma (Gordon et al., in review).

\subsection{3 $\mathrm{Rb}-\mathrm{Sr}$ constraints on the timing of the amphibolite-facies metamorphic crystallization}

$\mathrm{Rb}-\mathrm{Sr}$ internal mineral isochrons calculated for samples that were retrogressed during the amphibolite-facies metamorphic event yielded an age range of 3.9-2.4 Ma (Fig. 3.10a,b,d). Modally controlled closed system behavior of the Rb-Sr system (Section 3.3.1) implies that the $\mathrm{Rb}-\mathrm{Sr}$ ages for the deformed amphibolite-facies gneiss and granodiorite represent the timing of mineral growth and $\mathrm{Sr}$ equilibration in the presence of fluid at temperatures of $<650{ }^{\circ} \mathrm{C}$. Geothermobarometry for rocks that contain the typical amphibolite-facies mineral assemblage yielded an inferred temperature range of $>640-760{ }^{\circ} \mathrm{C}$ (Section 3.5.2; Table 3.9; Fig. 3.8). As $>640{ }^{\circ} \mathrm{C}$ is the lower bound of the temperature estimate for the amphibolite-facies metamorphism, I interpret these $\mathrm{Rb}-\mathrm{Sr}$ ages as growth ages. The gneiss and granodiorite samples dated here therefore yield $\mathrm{Rb}-\mathrm{Sr}$ isochron ages corresponding to 
the time of mineral growth and fabric development during the final fluid-present stage of pervasive amphibolite-facies overprint that affected the (U)HP terrane upon its departure from the lower crust in the Woodlark Rift. The age of the cessation of the amphibolite overprint was therefore $3.90 \pm 0.44 \mathrm{Ma}(2 \sigma)$ for rocks in the northwest Normanby gneiss dome and $\sim 2.4 \mathrm{Ma}$ for rocks in the Mailolo and Goodenough gneiss domes. These ages do not appear to be dependent on rock type and indicate that the main phase of retrogression and ductile flow in the lower crust took place from $3.90 \pm 0.44 \mathrm{Ma}$ to $2.38 \pm 0.29 \mathrm{Ma}(2 \sigma)$ in the northwestern D’Entrecasteaux Islands.

Pressure estimates presented here indicate that the amphibolite-facies retrogression took place at $10-17 \mathrm{kbar}$ (Table 3.9). This range is higher than the $7-11 \mathrm{kbar}$ range of amphibolite-facies pressure estimates calculated by Hill and Baldwin (1993) study. These maximum pressure estimates have a difference of $6 \pm 2.8 \mathrm{kbar}$ (approximate 95\% confidence interval), implying that the HP body, or "bolus", was thicker when it ponded at the lower crust than previously inferred. The temperature estimates presented here, however, show good agreement with previous estimates for temperature conditions during the amphibolite-facies metamorphism (Table 3.9; Section 3.5.2). Temperature estimates presented here for the later amphibolite-facies metamorphism have a range of $640-720{ }^{\circ} \mathrm{C}$ (Table 3.9). Previous studies estimate that temperatures during the UHP eclogite-facies metamorphism had a range of 612 - $930{ }^{\circ} \mathrm{C}$ (Section 3.2.3). This is a minimal difference relative to the pressure difference between these two metamorphic events, and may reflect the nearly isothermal nature of the rapid exhumation process of the UHP rocks in the D’Entrecasteaux Islands (Baldwin et al., 1993; Baldwin et al., 2004; Baldwin et al., 2008).

The amphibolite-facies $\mathrm{Rb}-\mathrm{Sr}$ isochrons presented here may record an apparent westward decrease in age of retrogression of the (U)HP body in the lower crust. A deformed granodiorite in the northwest Normanby dome (08-077a) yielded a Rb-Sr age of $3.90 \pm 0.44 \mathrm{Ma}(2 \sigma)$, whereas a granodiorite in the Mailolo dome that is located $\sim 45 \mathrm{~km}$ to the west of sample $08-077$ a yielded a $\mathrm{Rb}-\mathrm{Sr}$ age of $2.41 \pm 1.40 \mathrm{Ma}$ (08-010c; 2 $\sigma$ ). Also, a quartzofeldspathic gneiss located an additional $\sim 42 \mathrm{~km}$ to the west of sample $08-077 \mathrm{a}$ in Goodenough dome yielded a Rb-Sr age of $2.38 \pm 0.29 \mathrm{Ma}$ 
(06-018a; 2 $\sigma$; Fig. 3.10a,b,d). Thus, the amphibolite-facies metamorphic retrogression may have affected rocks within the northwest Normanby dome first in the northwest D'Entrecasteaux Islands, followed by rocks in the Mailolo and Goodenough domes. This apparent westward younging may be an indication of the progression of the Woodlark Rift through the crust in southeastern PNG (Fitzgerald et al., 2008; Monteleone et al., 2007). The Rb-Sr ages for samples from the Mailolo and Goodenough gneiss domes imply that the timing of the amphibolite-facies metamorphic event may have been nearly simultaneous for rocks within these domes.

The new $\mathrm{Rb}$-Sr ages presented here that date the timing of deformed in amphibolitefacies conditions compare favorably with previous $\mathrm{U}-\mathrm{Pb}$ zircon ages and ${ }^{40} \mathrm{Ar} /{ }^{39} \mathrm{Ar}$ cooling ages for this metamorphic event (Fig. 3.10; Section 3.2.4). For example, U$\mathrm{Pb}$ zircon ages for weakly deformed granodioritic dikes in the Mailolo dome are $2.418 \pm 0.004 \mathrm{Ma}$ to $2.482 \pm 0.007 \mathrm{Ma}(2 \sigma$; Gordon et al., in review). These U-Pb zircon ages are within error of my amphibolite-facies $\mathrm{Rb}-\mathrm{Sr}$ ages from the Mailolo dome (08-010c; $2.38 \pm 0.29 \mathrm{Ma} ; 2 \sigma)$ and the Goodenough dome (06-018a; $2.41 \pm 1.4$ $\mathrm{Ma} ; 2 \sigma$ ). As the closure temperature of $\mathrm{U}-\mathrm{Pb}$ in zircon is $>900{ }^{\circ} \mathrm{C}$, and the $\mathrm{Rb}-\mathrm{Sr}$ closure is $<650{ }^{\circ} \mathrm{C}$ for rocks analyzed here, $\mathrm{Rb}$ - $\mathrm{Sr}$ closure may have post-dated zircon growth in the dikes and that the $\mathrm{Rb}-\mathrm{Sr}$ ages would therefore be slightly younger than the U-Pb zircon ages (Ireland and Williams, 2003; Reiners et al., 2005). There is, however, good agreement between these two data sets, which is an excellent result as both these ages are inferred to date the timing of the final stages of the retrogressive amphibolite-facies ductile deformation in the Mailolo gneiss domes (Gordon et al., in review). The amphibolite-facies $\mathrm{Rb}-\mathrm{Sr}$ ages presented here are also within error of the Baldwin and Ireland (1995) $\mathrm{U}-\mathrm{Pb}$ zircon age of $2.63 \pm 0.16 \mathrm{Ma}$ $(2 \sigma)$ and $2.72 \pm 0.28 \mathrm{Ma}(2 \sigma)$ for two samples of felsic gneiss from Goodenough Island. These latter ages are interpreted as dating zircon growth subsequent to the eclogite-facies metamorphism. Thus, there is good agreement between the $\mathrm{U}-\mathrm{Pb}$ and the $\mathrm{Rb}-\mathrm{Sr}$ dating technique, similar to the agreement between the $\mathrm{Rb}-\mathrm{Sr}$ ages and the $\mathrm{U}-\mathrm{Pb}$ zircon ages that date the timing of the eclogite-facies metamorphism as discussed above. The available white mica and biotite ${ }^{40} \mathrm{Ar} /{ }^{39} \mathrm{Ar}$ cooling ages for Goodenough dome $(3.0-1.5 \mathrm{Ma})$ are interpreted to date cooling of the rock below $400-300{ }^{\circ} \mathrm{C}$, subsequent to the peak of the amphibolite-facies metamorphism. The 
overlap between the ${ }^{40} \mathrm{Ar} /{ }^{39} \mathrm{Ar}$ cooling ages on mica and the new $\mathrm{Rb}-\mathrm{Sr}$ (growth) ages indicates very rapid exhumation and cooling of the (U)HP terrane $\left(>100{ }^{\circ} \mathrm{C} \mathrm{Ma}^{-}\right.$ ${ }^{1}$ ), similar to that previously suggested by Baldwin et al. (1993, 2004, 2008; Glodny et al., 2002).

\subsubsection{Time scale for decompression of the (U)HP terrane from the mantle to the crust}

The $\mathrm{Rb}$-Sr ages presented in this study indicate that the eclogite-facies crystallization event predated the amphibolite-facies retrogressive event by $2.2 \pm 1.2 \mathrm{Ma}$ (error is the approximate $95 \%$ confidence interval) in the Mailolo dome. $\mathrm{Rb}-\mathrm{Sr}$ ages for the Mailolo dome indicate that the UHP metamorphism took place at $5.62 \pm 1.2 \mathrm{Ma}(\mathrm{n}=$ 2 , error is the approximate $95 \%$ confidence interval for the weighted mean). The 3.4 Ma calculated by Gordon et al. (in review) is interpreted to date the early phases of the amphibolite-facies deformation when the (U)HP terrane reached lower crustal levels (six zircons analyses that yielded a clustering of ages from $3.50 \pm 0.01 \mathrm{Ma}$ to $3.41 \pm 0.02 \mathrm{Ma} ; 2 \sigma$ ). Thus, the Rb-Sr ages for the UHP metamorphism presented here (Fig. 3.9) and the new U-Pb zircon age calculated by Gordon et al. (in review) imply a time lag from the mantle to the crust of $2.2 \pm 1.2 \mathrm{Ma}$ (error is the approximate $95 \%$ confidence interval) for rocks within the Mailolo dome. This time lag indicates that eclogite-facies metamorphism at HP and UHP conditions was followed very quickly by exhumation to lower crustal levels, where the terrane ponded, thinned and flowed laterally parallel to the rift margins (Little et al., 2011).

Based on the time lag between UHP and amphibolite-facies metamorphism, and the new pressure estimates presented here, we calculate a minimum unroofing rate of the UHP terrane of $19 \pm 11 \mathrm{~mm} \mathrm{yr}^{-1}$ (approximate 95\% confidence interval) from the mantle to the lower crust for rocks within the Mailolo dome. I estimate that the pressure during amphibolite-facies metamorphism for a core sample from the Mailolo dome was $\sim 12.5 \pm 2 \mathrm{kbar}$ (assigned $\pm 2 \mathrm{kbar}$ uncertainty). This is a minimum pressure estimate calculated using the garnet- $\mathrm{Al}_{2} \mathrm{SiO}_{5}$-plagioclase-quartz barometer (Fig. 3.8c; Holm et al., 1967). Assuming a rock density of $2.7 \mathrm{~g} \mathrm{~cm}^{-3}$, the pressure estimate at amphibolite-facies compositions corresponds to a depth estimate of $47 \pm$ 7 km (approximate 95\% confidence interval; Harkness, 1891; Hinze, 2003). Based 
on the preservation of coesite in one sample, pressure estimates for the UHP eclogite-facies metamorphism in the D'Entrecasteaux Islands has a minimum bound of 28 kbar (08-010a; Baldwin et al., 2008; Holm et al., 1967). I therefore calculate a minimum of $43 \pm 10 \mathrm{~km}$ of unroofing from UHP conditions $(>90 \mathrm{~km}$ ) to the lower crust between $5.62 \pm 1.2 \mathrm{Ma}$ and $\sim 3.4 \mathrm{Ma}$ for rocks in the Mailolo dome (Gordon et al., in review). This estimate of unroofing rate is similar to previously inferred exhumation rates for the rocks in the D'Entrecasteaux Islands $\left(\mathrm{cm} \mathrm{yr}^{-1}\right.$; Baldwin et al., 1993; Baldwin et al., 2004).

\subsubsection{Ages and P-T estimates for fabric formation in the core and carapace zones}

One of the original aims of this study was to determine if the core and the carapace zones in the D'Entrecasteaux Island gneiss domes were deformed diachronously or contemporaneously. Structural data from the gneiss domes implies that exhumation of the gneiss was diapiric (Little et al., 2011). The carapace of the dome absorbed the greatest amount of pure shear-dominated thinning and solid-state ductile flow as it was structurally the uppermost part of the body of diapir and was highly attenuated (Little et al., 2011). I note that all carapace samples analyzed for Rb-Sr ages here (03-086b, 08-032a, 10-071a) are statistically invalid based on previously stated criteria (Section 3.3.2). The lack of evidence for isotopic homogeneity in the carapace samples suggests that the carapace rocks were affected by fluid-present deformation during the final phases of crustal emplacement. Thus, late-stage isotopic exchange occurred between low $\mathrm{Rb}-\mathrm{Sr}$ ratio minerals (plagioclase) and high $\mathrm{Rb}-\mathrm{Sr}$ ratio mineral (white mica) in the carapace rocks. Little et al. (2011) observe talc-and biotite-bearing phyllonite in shear zones near the southeast coast of Fergusson Island and the northwest tip of Normanby Island. These authors therefore interpret these locations to expose the D'Entrecasteaux Island Fault Zone (a boundary at the base of the upper plate of the dome-bounding normal faults; Fig. 3.2, 3.4), which was altered with extensive fluid flow during the final juxtaposition of the carapace gneiss against the ophiolitic cover rocks. If this extensive fluid flow was pervasive throughout the majority of the carapace rocks in the D'Entrecasteaux Islands, it may have caused the $\mathrm{Sr}$ isotopic disequilibrium between constituent minerals in the carapace observed here. 
The new geothermobarometry data implies that the carapace rocks crystallized at lower pressure and temperature conditions relative to the subadjacent core rocks during the lower crustal amphibolite-facies metamorphism (Table 3.9; Fig. 3.8). Temperatures estimates presented here for the core and carapace rocks of the Mailolo gneiss dome are $720-760{ }^{\circ} \mathrm{C}$ (sample 08-037a) and $640-670{ }^{\circ} \mathrm{C}$ (sample 10-070a), respectively (estimates were derived using the Green and Hellman, 1982 thermometer). Pressure estimates presented here show a corresponding apparent decrease from the core zone relative to the carapace zone. The garnet-plagioclase$\mathrm{Al}_{2} \mathrm{SiO}_{5}$-quartz barometer yielded a pressure estimate of $13-17 \mathrm{kbar}$ for the core of the Mailolo dome (08-037a) and 12 - 15 kbar for the carapace of the Mailolo dome (10-070a; Fig. 3.8c,e). This apparent difference in pressure between the core and the carapace zones is also present in the Goodenough dome (Fig 3.8a,b; Table 3.9), where the rocks yielded pressure estimates of $16-17 \mathrm{kbar}$ for the core zone and $12-$ $14 \mathrm{kbar}$ for carapace zone. Estimates for the pressure of fabric formation in the carapace of the northwest Normanby dome are $10-12$ kbar (10-008a), which is $\sim 2$ kbar less than the pressure estimate for carapace rocks from the Mailolo dome and the Goodenough dome (Fig. 3.8d). This pressure estimates supports previous inferences that the northwest section of the northwest Normanby dome represents a structural level of the gneiss dome that is not observed elsewhere in the D’Entrecasteaux Islands (Little et al., 2011).

\subsubsection{Post-metamorphic ductile thinning estimates}

The original foliation-orthogonal separation between core and carapace samples within the Mailolo dome is uncertain, as there has been post-metamorphic thinning during deformation of the regionally flat lying amphibolite-facies foliation in the lower crust (Little et al., 2011). The intersection of the Green and Hellman (1982) thermometer and the garnet-plagioclase- $\mathrm{Al}_{2} \mathrm{SiO}_{5}$-quartz barometry allows us to determine an apparent difference in pressure between a core sample (08-037a; $16 \pm 2$ kbar) and a carapace sample $(10-070 \mathrm{a} ; 13 \pm 2 \mathrm{kbar})$ in the Mailolo dome (Fig. $3.8 \mathrm{c}, \mathrm{e})$. A similar relative difference in pressure is also shown by the intersection of the Krogh and Raheim (1978) thermometer and the garnet-plagioclase- $\mathrm{Al}_{2} \mathrm{SiO}_{5^{-}}$ quartz barometer (Fig. 3.8c,e). Thus, this apparent difference in pressure between the 
Mailolo dome core and carapace samples is reproducible between gneiss domes and barometers. I therefore suggest that the original difference in pressure that separated the core sample (08-037a) and the carapace sample (10-070a) in the Mailolo dome, prior to the amphibolite-facies ductile thinning, was $3 \pm 2.8 \mathrm{kbar}$ (approximate $95 \%$ confidence interval). This pressure difference equates to $10 \pm 9.3 \mathrm{~km}$ (approximate $95 \%$ confidence interval) of foliation-orthogonal distance (assuming a rock density of $2.7 \mathrm{~g} \mathrm{~cm}^{-3}$ as previously discussed; Harkness, 1891; Hinze, 2003). The current foliation-orthogonal distance separating these samples is $1.1 \pm 0.25 \mathrm{~km}$ (assigned $2 \sigma$ uncertainty; Chapter 2 this thesis). These apparent differences in foliation-orthogonal distance imply $9 \pm 9.3 \mathrm{~km}$ (approximate 95\% confidence interval) of exhumation as the result of ductile thinning between the crust and the carapace in the (U)HP terrane during doming in the upper crust.

This estimate is poorly constrained to the point of being meaningless because of the large errors associated with the original difference in pressure between the core and carapace samples ( $\pm 2.8 \mathrm{kbar}$ ). These errors would decrease if the \pm 2 kbar error I have assigned to pressure estimates calculated here were correlated, possibly through the assumptions related to the thermobarometric calculation. Although the estimates I have presented here are not constrained by meaningful errors, I suggest that a detailed geobarometric study on the core and carapace zones in the D'Entrecasteaux Islands may refine our understanding of the final phases of dome development and emplacement in the mid to upper crust in the D'Entrecasteaux Islands. Structural evidence in the gneiss domes suggests significant contribution of ductile thinning to the exhumation of the gneiss domes through the crust, and constraining the pressure conditions of the formation of the core and carapace zones would help to constrain the magnitude of this ductile thinning (Little et al., 2011).

\subsection{Conclusions}

The $\mathrm{Rb}-\mathrm{Sr}$ internal mineral isochrons presented here are the first attempt to directly date deformation related to the eclogite- and amphibolite-facies metamorphic events in the D'Entrecasteaux Islands, using a radiometric technique that has never been 
applied to these rocks. Initial ${ }^{87} \mathrm{Sr} /{ }^{86} \mathrm{Sr}$ ratios calculated here $(0.7037-0.7047)$ are primitive and support previous inferences that the protolith of the UHP and HP metamorphic rock was the igneous Whitsunday Volcanic Arc Province in northeastern Australia. This province is currently separated from PNG by the Coral Sea Basin ocean floor (Paleocene to early Eocene).

Two samples of eclogite, five samples of quartzofeldspathic gneiss, and two samples of granitic rock were analyzed for $\mathrm{Rb}-\mathrm{Sr}$ isotopic composition. Five of these samples yielded statistically valid isochrons. A coesite-bearing sample of eclogite yielded a $\mathrm{Rb}-\mathrm{Sr}$ age of $5.7 \pm 2.0 \mathrm{Ma}(2 \sigma)$. The other sample of eclogite, which may have once contained coesite based on radial fracturing around quartz inclusions in garnets, yielded an age of $5.6 \pm 1.6 \mathrm{Ma}(2 \sigma)$. These two samples of boudins cores retain their eclogite-facies rock fabric and mineral assemblage, and have remained a closed system since the crystallization of eclogite-facies minerals. These new $\mathrm{Rb}-\mathrm{Sr}$ ages support recent U-Pb zircon ages by Gordon et al. (in review) that indicate the UHP metamorphism took place at $\sim 5 \mathrm{Ma}, \sim 2 \mathrm{Ma}$ younger than previously suggested (Baldwin et al., 2004; Monteleone et al., 2007; Zirakparvar et al., 2011). Based on $\mathrm{Rb}-\mathrm{Sr}$ ages presented here, and previous $\mathrm{U}-\mathrm{Pb}$ zircon ages on granitic dikes by Gordon et al. (in review), I calculate a time lag of $2.2 \pm 1.5 \mathrm{Ma}$ (approximate 95\% confidence interval) between UHP metamorphism in the mantle and amphibolitefacies metamorphism and ductile thinning in the lower crustal for rocks within the Mailolo dome. The $\mathrm{Rb}-\mathrm{Sr}$ ages of three samples of amphibolite-facies quartzofeldspathic gneiss and granodiorite range from $3.90 \pm 0.44 \mathrm{Ma}(2 \sigma)$ in the northwest Normanby dome, to $2.41 \pm 1.40 \mathrm{Ma}(2 \sigma)$ and $2.38 \pm 0.29 \mathrm{Ma}(2 \sigma)$ in the Mailolo dome and Goodenough dome respectively. I interpret these three Rb-Sr ages as recording the timing of the final stage of fluid-rock interaction during the amphibolite-facies retrogression. The latter two ages are remarkably similar to $\mathrm{U}-\mathrm{Pb}$ zircon ages calculated by Gordon et al. (in review), which are similarly interpreted.

I conclude that the estimate of temperature during the amphibolite-facies metamorphism determined by this study $\left(>640-760{ }^{\circ} \mathrm{C}\right)$ is in agreement with previous studies that suggest that the exhumation from the mantle to the surface was nearly isothermal (Baldwin et al., 1993; Baldwin et al., 2004; Baldwin et al., 2008; Little et al., 2011; Monteleone et al., 2007). The pressure estimates for the 
amphibolite-facies metamorphism presented here $(10-17 \mathrm{kbar})$ are $3-6 \mathrm{kbar}$ higher then previous estimates, an apparent increase in pressure that implies the body of gneisses was thicker during ponding at the lower crust. Based on the $2.2 \pm 1.5 \mathrm{Ma}$ (approximate 95\% confidence interval) time lag and the pressure estimates for the amphibolite-facies metamorphism calculated here, I estimate a minimum unroofing rate for the (U)HP gneisses of $19 \pm 11 \mathrm{~mm} \mathrm{yr}^{-1}$ (approximate 95\% confidence interval) from UHP depths to the lower crust. 


\section{Thesis conclusions}

This thesis utilizes geochronology and geothermobarometry to refine the current understanding of the kinematics of exhumation and the timing of deformation in gneiss domes in the D'Entrecasteaux Islands, southeastern Papua New Guinea (PNG). I present two main analytical data sets for this (U)HP terrane, which contains the youngest known eclogite-facies rocks on Earth. First, I undertook a detailed study of the variation of $\mathrm{Ti}$ content in quartz across four gneiss domes in the northwestern D'Entrecasteaux Islands. I conclude that spatial gradients of Ti content in quartz are a valid tectonic tool to discern cooling and exhumation rates in a rapidly exhuming body of rock. Second, nine new Rb-Sr ages are presented here, which are interpreted as constraining the previously undetermined timing of rock fabric development during the ultrahigh-pressure (UHP) metamorphism and the subsequent amphibolitefacies metamorphism in the D'Entrecasteaux Island. Based on these new data sets, and on the cathodoluminescence and thermobarometric analysis undertaken here, I present the following conclusions:

1. $\mathrm{Rb}-\mathrm{Sr}$ isochrons calculated for two samples of the cores of eclogite boudins yield a mean $\mathrm{Rb}-\mathrm{Sr}$ age of $5.6 \pm 1.2 \mathrm{Ma}$ (approximate $95 \%$ confidence interval). As one of these samples has been shown to preserve coesite (08$010 \mathrm{a} ; \mathrm{Rb}-\mathrm{Sr}$ age of $5.7 \pm 2.0 \mathrm{Ma} ; 2 \sigma$ ) and the other contains radial fractures around quartz inclusions in garnet (09-039biii; $\mathrm{Rb}-\mathrm{Sr}$ age of $5.6 \pm 1.6 \mathrm{Ma}$; $2 \sigma$ ), these new $\mathrm{Rb}-\mathrm{Sr}$ ages support recent $\mathrm{U}-\mathrm{Pb}$ zircon ages that revise the age of the UHP metamorphism to $\sim 5 \mathrm{Ma}$ (Gordon et al., in review). This new age is $\sim 2 \mathrm{Ma}$ younger than previous estimates for the timing of this UHP metamorphism (Baldwin et al., 2004; Monteleone et al., 2007; Zirakparvar et al., 2011).

2. I present statistically valid $\mathrm{Rb}-\mathrm{Sr}$ isochrons for three samples of granodiorite and quartzofeldspathic gneiss, which constrain the timing of mineral fabric formation during the amphibolite-facies overprint in the northwestern D'Entrecasteaux Islands to $3.9-2.4 \mathrm{Ma}$. These three ages are $3.90 \pm 0.44 \mathrm{Ma}$ $(2 \sigma)$ for a granodiorite from the northwest Normanby dome, $2.41 \pm 1.40 \mathrm{Ma}$ 
$(2 \sigma)$ for a granodiorite from the Mailolo dome, and $2.38 \pm 0.29 \mathrm{Ma}(2 \sigma)$ for a quartzofeldspathic gneiss from the Goodenough dome. These ages imply a westward younging in age of the amphibolite-facies overprint, which may be related to the propagation of the Woodlark Rift through the crust of eastern PNG.

3. Initial ${ }^{87} \mathrm{Sr} /{ }^{86} \mathrm{Sr}$ ratios calculated here are primitive $(0.7037-0.7047)$, and supports previous inferences that the protolith of the metamorphic rock in the D'Entrecasteaux Islands was the igneous Whitsunday Volcanic Province in northeastern Australia. The Whitsunday Volcanic Province is located on the opposite flank of the oceanic Coral Sea Basin, which was actively spreading from 62 to $56 \mathrm{Ma}$.

4. Based on the Rb-Sr age for the UHP metamorphism presented here and a U$\mathrm{Pb}$ zircon age for the initial phase of the amphibolite-facies metamorphism in the lower crust determined by Gordon et al. (in review), I calculate a time lag of $2.2 \pm 1.2 \mathrm{Ma}$ (approximate 95\% confidence interval) between UHP conditions at mantle depths and metamorphism and ductile thinning at lower crustal depths.

5. Pressure and temperature estimates for the amphibolite-facies metamorphism are $10-17 \mathrm{kbar}$ and $>640-760{ }^{\circ} \mathrm{C}$ respectively. The presence of coesite in one sample of eclogite in the Mailolo dome and a pressure estimate for a core sample from the Mailolo dome of $12.5 \pm 2 \mathrm{kbar}$, implies that this gneiss dome was exhumed from $>90 \mathrm{~km}$ to $\sim 47 \pm 7 \mathrm{~km}$ (approximate $95 \%$ confidence interval). These pressure estimates imply a difference in depth between UHP metamorphism and metamorphism in the lower crust of $43 \pm 10 \mathrm{~km}$ (approximate 95\% confidence interval). Based on this difference in depth, and the time lag between these two metamorphic events calculated here, I estimate an unroofing rate of $19 \pm 11 \mathrm{~mm} \mathrm{yr}^{-1}$ (approximate $95 \%$ confidence interval) during exhumation from the mantle to the lower crust.

6. I present a pressure estimate of $16 \pm 2 \mathrm{kbar}$ for a core sample and $13 \pm 2 \mathrm{kbar}$ for a carapace sample from the Mailolo dome. Based on these estimates, I 
calculate an apparent difference in pressure of $3 \pm 2.8 \mathrm{kbar}$ (approximate $95 \%$ confidence interval) between these samples, which are currently separated by a vertical distance of $\sim 1.1 \pm 0.25 \mathrm{~km}$ (assigned $2 \sigma$ uncertainty). This apparent separation implies post-metamorphic ductile thinning of the gneiss body as it was exhumed through the crust.

7. I analyzed 90 samples by LA-ICP-MS, and determine that the average range of Ti content in quartz in the D'Entrecasteaux Islands is $10-20 \mathrm{ppm}$. In the D'Entrecasteaux Islands, the final Ti equilibration in quartz occurred during dynamic recrystallization by high-temperature grain-boundary migration during the final stage of exhumation of the gneiss domes. Based on this dynamic recrystallization and on temperature constraints from the presence of a partial melt phase in the domes and chessboard microstructures in quartz, I conclude that the sample-averaged $\mathrm{Ti}$ content within the quartz grains in a hot and rapidly exhuming body depends on the relative rates of cooling and recrystallization during final ascent. Assuming that the recrystallization rate across the exhuming body varied less than the cooling rate, the sampleaveraged Ti concentrations may be used as a proxy for cooling rates, and by inference, exhumation rates between samples.

8. I have mapped an increase in Ti content in quartz from $2.5-25 \mathrm{ppm}$ at the margins to $20->100 \mathrm{ppm}$ in the interiors of four gneiss domes in the D'Entrecasteaux Islands. I conclude that this increase is statistically robust based on regression analysis and probabilities determined by a one-sided Student's t test. If the assumption of a constant recrystallization rate is valid for quartz grains within the D'Entrecasteaux Islands, the occurrence of high Ti concentrations in the interior of the gneiss domes implies that this area was subjected to the fastest relative cooling rates. I conclude that the gneiss domes in the D'Entrecasteaux Islands are diapiric in origin, and were exhumed through the crust via pure-shear dominated symmetric doming.

The unroofing rate presented here $\left(19 \pm 11 \mathrm{~mm} \mathrm{yr}^{-1}\right.$; approximate $95 \%$ confidence interval) between UHP conditions at mantle depths and metamorphism and ductile thinning at lower crustal depths implies that exhumation in the D'Entrecasteaux 
Islands occurred at plate tectonic rates $\left(\mathrm{cm} \mathrm{yr}^{-1}\right.$; Baldwin et al., 2008; Monteleone et al., 2007). In addition, the minimal difference between previously published temperature estimates for the UHP metamorphism and the amphibolite-facies temperature estimates presented here support previous inferences that exhumation from mantle depths to the lower crust was nearly isothermal (Baldwin et al., 1993; Baldwin et al., 2004; Baldwin et al., 2008). This rapid and nearly isothermal exhumation strongly supports my conclusion that the crustal exhumation is predominantly affected by pure-shear (diapiric) symmetric doming. I note that this conclusion is in accordance with a previous structural study by Little et al. (2011), who argue that the (U)HP terrane in the D'Entrecasteaux Islands was exhumed from the mantle to the lower crust diapirically. 


\section{References}

Abramoff, M.D., Magalhaes, P.J., and Ram, S.J., 2004, Image processing with ImageJ: Biophotonics International, v. 11, p. 36.

Baldwin, S.L., and Ireland, T.R., 1995, A tale of two eras: Pliocene-Pleistocene unroofing of Cenozoic and late Archean zircons from active metamorphic core complexes, Solomon Sea, Papua New Guinea: Geology, v. 23, p. 10231026.

Baldwin, S.L., Lister, G.S., Hill, E.J., Foster, D.A., and McDougall, I., 1993, Thermochronologic constraints on the tectonic evolution of active metamorphic core complexes, D'Entrecasteaux Islands, Papua New Guinea: Tectonics, v. 12, p. 611-628.

Baldwin, S.L., Monteleone, B.D., Webb, L.E., Fitzgerald, P.G., Grove, M., and Hill, E.J., 2004, Pliocene eclogite exhumation at plate tectonic rates in eastern Papua New Guinea: Nature, v. 431, p. 263-267.

Baldwin, S.L., Webb, L.E., and Monteleone, B.D., 2008, Late Miocene coesiteeclogite exhumed in the Woodlark Rift: Geology, v. 36, p. 735-738.

Beaumont, C., Jamieson, R.A., Butler, J.P., and Warren, C.J., 2009, Crustal structure: A key constraint on the mechanism of ultra-high-pressure rock exhumation: Earth and Planetary Science Letters, v. 287, p. 116-129.

Beltrando, M., Compagnoni, R., and Lombardo, B., 2010, (Ultra-) High-pressure metamorphism and orogenesis: An Alpine perspective: Gondwana Research, v. 18, p. $147-166$.

Black, L.P., and McCulloch, M.T., 1990, Isotopic evidence for the dependence of recurrent felsic magmatism on new crust formation: An example from the Georgetown region of Northeastern Australia: Geochimica et Cosmochimica Acta, v. 54, p. 183-196.

Blanckenburg, F., Villa, I.M., Baur, H., Morteani, G., and Steiger, R.H., 1989, Time calibration of a P-T path from the Western Tauern Window, Eastern Alps: the problem of closure temperatures: Contributions to Mineralogy and Petrology, v. 101, p. 1-11.

Blumenfeld, P., Mainprice, D., and Bouchez, J.L., 1986, C-slip in quartz from subsolidus deformed granite: Tectonophysics, v. 127, p. 97-115. 
Botis, S.M., and Pan, Y., 2009, Theoretical calculations of $\left[\mathrm{AlO}_{4} / \mathrm{M}^{+}\right]^{0}$ defects in quartz and crystal-chemical controls on the uptake of $\mathrm{Al}$ : Mineralogical Magazine, v. 73, p. 537-550.

Brown, M., 2008, Granites, migmatites and residual granulites: Relationships and processes, in Sawyer, E.D., Brown, M., eds., Working with Migmatites: Quebec City, Mineralogical Association of Canada Short Course, v. 38, p. 94-144.

Brownlee, S.J., Hacker, B.R., Sailsbury, M., Seward, G., Little, T.A., Baldwin, S.B., and Abers, G., in prep., Predicted velocity and density structure of the exhuming Papua New Guinea ultra-high pressure terrane.

Burg, J., Kaus, B.J.P., and Podladchikov, Y.Y., 2004, Dome structures in collision orogens: Mechanical investigation of the gravity/compression interplay, in Whitney, D.L., Teyssier, C., and Siddoway, C.S., eds., Gneiss Domes in Orogeny: Boulder, Colorado, Geological Society of America Special Paper, v. 380 , p. $47-66$.

Burton, K.W., Kohn, M.J., Cohen, A.S., and O'Nions, K.R., 1995, The relative diffusion of $\mathrm{Pb}, \mathrm{Nd}, \mathrm{Sr}$ and $\mathrm{O}$ in garnet: Earth and Planetary Science Letters, v. 133, p. 199-211.

Cherniak, D.J., 1998, Pb diffusion in clinopyroxene: Chemical Geology, v. 150, p. 105-117.

Cherniak, D.J., and Ryerson, F.J., 1993, A study of strontium diffusion in apatite using Rutherford backscattering spectroscopy and ion implantation: Geochimica et Cosmochimica Acta, v. 57, p. 4653-4662.

Cherniak, D.J., and Watson, E.B., 1992, A study of strontium diffusion in Kfeldspar, Na-K feldspar and anorthite using Rutherford backscattering spectroscopy: Earth and Planetary Science Letters, v. 113, p. 411-425.

Cherniak, D.J., and Watson, E.B., 1994, A study of strontium diffusion in plagioclase using Rutherford backscattering spectroscopy: Geochimica et Cosmochimica Acta, v. 58, p. 5179-5190.

Chopin, C., 1984, Coesite and pure pyrope in high-grade blueschists of the Western Alps: A first record and some consequences: Contributions to Mineralogy and Petrology, v. 86, p. 107-118.

Chopin, C., 2003, Ultrahigh-pressure metamorphism: Tracing continental crust into the mantle: Earth and Planetary Science Letters, v. 212, p. 1-14. 
Clemens, J.D., and Watkins, J.M, 2001, The fluid regime of high-temperature metamorphism during granitoid magma genesis: Contributions to Mineralogy and Petrology, v. 140, p. 600-606.

Davies, H.L., and Jacques, A.L., 1984, Emplacement of ophiolite in Papua New Guinea: Geological Society of London, Special Publications, v. 13, p. 341349.

Davies, H.L., and Warren, R.G., 1988, Origin of ecolgite-bearing, domed, layered metamorphic complexes ("core complexes") in the D'Entrecasteaux Islands, Papua New Guinea: Tectonics, v. 7, p. 1-21.

Davies, H.L., and Warren, R.G., 1992, Eclogites of the D'Entrecasteaux Islands: Contributions to Mineralogy and Petrology, v. 112, p. 463-474.

Dennen, W.H., Blackburn, W.H., and Quesada, A., 1970, Aluminum in quartz as a geothermometer: Contributions to Mineralogy and Petrology, v. 27, p. 332342.

Dodson, M.H., 1973, Closure temperature in cooling geochronological and petrological systems: Contributions to Mineralogy and Petrology, v. 40, p. 259-274.

England, P.C., and Thomas, A., 1986, Some thermal and tectonic models for crustal melting in continental collision zones: Geology Society of London Special Publications, v. 19, p. 83-94.

Ernst, W.G., 2001, Subduction, ultrahigh-pressure metamorphism, and regurgitation of buoyant crustal slices - Implications for arcs and continental growth: Physics of the Earth and Planetary Interiors, v. 127, p. 253-275.

Ewart, A., Schon, R.W., and Chappell, B.W., 1992, The Cretaceous volcanicplutonic province of the central Queensland (Australia) coast - A rift related 'calc-alkaline' province: Transactions of the Royal Society of Edinburgh: Earth Sciences, v. 83, p. 327-345.

Faydon, A.K., Whitney, D.L., and Teyssier, C., 2004, Exhumation of orogenic crust: Diapiric ascent versus low-angle normal faulting, in Whitney, D.L., Teyssier, C., and Siddoway, C.S., eds., Gneiss Domes in Orogeny: Boulder, Colorado, Geological Society of America Special Paper, v. 380, p. 129-139.

Fitzgerald, P.G., Baldwin, S.L., Miller, S.R., Perry, S.E., Webb, L.E., and Little, T.A., 2008, Low-temperature constraints on the evolution of metamorphic core complexes of the Woodlark Rift system, Southeastern Papua New 
Guinea, Eos Transcripts American Geophysical Union, Fall Meeting Supplement, v. 89, Abstract T11B-1865.

Freeman, S.R., Inger, S., Butler, R.W.H., and Cliff, R.A., 1997, Dating deformation using $\mathrm{Rb}-\mathrm{Sr}$ in white mica: Greenschist facies deformation ages from the Entrelor shear zone, Italian Alps: Tectonics, v. 16, p. 57-76.

Ganguly, J., and Saxena, S.K., 1984, Mixing properties of aluminosilicate garnets: Constraints from natural and experimental data, and applications to geothermobarometry: American Mineralogist, v. 69, p. 88-97.

Ghent, E.G., and Stout, M.Z., 1984, $\mathrm{TiO}_{2}$ activity in metamorphosed pelitic and basic rocks: Principles and applications to metamorphism in southeastern Canadian Cordillera: Contributions to Mineralogy and Petrology, v. 86, p. 248-255.

Giorgis, D., Cosca, M., and Li, S., 2000, Distribution and significance of extraneous argon in UHP eclogite (Sulu terrain, China): Insight from in situ ${ }^{40} \mathrm{Ar} /{ }^{39} \mathrm{Ar}$ UV-laser ablation analysis: Earth and Planetary Science Letters, v. 181, p. 605-615.

Glodny, J., Bingen, B., Austrheim, H., Molina, J.F., and Rusin, A., 2002, Precise eclogitization ages deduced from $\mathrm{Rb} / \mathrm{Sr}$ mineral systematics: The Maksyutov complex, southern Urals, Russia: Geochimica et Cosmochimica Acta, v. 66, p. 1221-1235.

Glodny, J., Austrheim, H., Molina, J.F., Rusin, A.I., and Seward, D., 2003, Rb/Sr record of fluid-rock interaction in eclogites: The Marun-Keu complex, polar Urals, Russia: Geochimica et Cosmochimica Acta, v. 67, p. 4353-4371.

Glodny, J., Lohrmann, J., Echtler, H., Gräfe, K., Seifert, W., Collao, S., and Figueroa, O., 2005a, Internal dynamics of a paleoaccretionary wedge: insights from combined isotope tectonochronology and sandbox modeling of the south-central Chilean forearc: Earth and Planetary Science Letters, v. 231, p. 23-39.

Glodny, J., Ring, U., Kühn, A., Gleissner, P., and Franz, G., 2005b, Crystallization and very rapid exhumation of the youngest alpine eclogites (Tauern Window, Eastern Alps) from $\mathrm{Rb} / \mathrm{Sr}$ mineral assemblage analysis: Contributions to Mineralogy and Petrology v. 149, p. 699-712.

Glodny, J., Echtler, H., Collao, S., Ardiles, M., Burón, P., and Figueroa, O., 2008a, Differential Late Paleozoic active margin evolution in South-Central Chile 
$\left(37^{\circ} \mathrm{S}-40^{\circ} \mathrm{S}\right)$ - the Lanalhue Fault Zone: Journal of South American Earth Sciences, v. 26, p. 397-411.

Glodny, J., Kühn, A., and Austrheim, H., 2008b, Diffusion versus recrystallization processes in $\mathrm{Rb}-\mathrm{Sr}$ geochronology: Isotopic relics in eclogite facies rocks, Western Gneiss Region, Norway: Geochimica et Cosmochimica Acta, v. 72, p. 506-525.

Glodny, J., Ring, U., and Kühn, A., 2008c, Coeval high-pressure metamorphism, thrusting, strike-slip, and extensional shearing in the Tauern Window, Eastern Alps: Tectonics, v. 27, TC4004.

Gordon, S.M., Little, T., Hacker, B., Bowring, S., Baldwin, S., Korchinski, M., Alban, M.A., in review, Multi-stage exhumation of young UHP-HP rocks: timescales of melt crystallization in the D'Entrecasteaux Islands, southeastern Papua New Guinea.

Grujic, D., Stipp, M., and Wooden, J., 2011, Thermometry of quartz mylonites: Importance of dynamic recrystallization on Ti-in-quartz re-equilibration: Geochemistry Geophysics Geosystems, v. 12. Q06012.

Hacker, B., 2006, Pressures and temperatures of ultrahigh-pressure metamorphism: implications for UHP tectonics and $\mathrm{H}_{2} \mathrm{O}$ in subducting slabs: International Geology Review, v. 48, p. 1053-1066.

Hacker, B., 2007, Ascent of the ultrahigh-pressure Western Gneiss Region, Norway, in Cloos, M., Carlson, W.D., Gilbert, M.C., Liou, J.G, and Sorensen, S.S., eds. Convergent Margin Terranes and Associated Regions: A tribute to W.G. Ernst: Boulder, Colorado, Geological Society of America Special Paper, v. 419, p. 171-184.

Hacker, B.R., and Gans, P.B., 2005, Continental collisions and the creation of ultrahigh-pressure terranes: Petrology and thermochronology of nappes in the central Scandinavian Caledonides: Geological Society of America Bulletin, v. 117, p. 117-134.

Harkness, W., 1891, Solar parallax and its related constants, including the figure and density of the Earth: US Government Printing Office, Washington, D.C.

Hill, E.J., 1994, Geometry and kinematics of shear zones formed during continental extension in eastern Papua New Guinea: Journal of Structural Geology, v. 16, p. 1093-1105. 
Hill, E.J., and Baldwin, S.L., 1993, Exhumation of high-pressure metamorphic rocks during crustal extension in the D'Entrecasteaux region, Papua New Guinea: Journal of Metamorphic Geology, v. 11, p. 261-277.

Hill, E.J., Baldwin, S.L., and Lister, G.S., 1992, Unroofing of active metamorphic core complexes in the D'Entrecasteaux Islands, Papua New Guinea: Geology, v. 20, p. $907-910$.

Hill, E.J., Baldwin, S.L., and Lister, G.S., 1995, Magmatism as an essential driving force for formation of active metamorphic core complexes in eastern Papua New Guinea: Journal of Geophysical Research, v. 100, p. 10441-10451.

Hinchey, A.M., and Carr, S.D., 2006, The S-type Ladybird leucogranite suite of southeastern British Columbia: Geochemical and isotopic evidence for a genetic link with migmatite formation in the North American basement gneisses of the Monashee complex: Lithos, v. 90, p. 223-248.

Hinze, W.J., 2003, Bouguer reduction density, why 2.67?: Geophysics, v. 68, p. 1559-1560.

Hodges, K.V., and Crowley, P.D., 1985, Error estimation and empirical geothermobarometry for pelitic systems: American Mineralogist, v. 70, p. 702-709.

Hodges, K.V., and Spear, F.S., 1982, Geothermometry, geobarometry and the $\mathrm{Al}_{2} \mathrm{SiO}_{5}$ triple point at Mt. Moosilauke, New Hampshire: American Mineralogist, v. 67, p. 1118-1134.

Hofmann, A.W., 1997, Mantle geochemistry: The message from oceanic volcanism: Nature, v. 385, p. 219-229.

Holm, J.L., Kleppa, O.J., and Westrum Jr, E.F., 1967, Thermodynamics of polymorphic transformations in silica: Thermal properties from 5 to $1070 \mathrm{~K}$ and pressure-temperature stability fields for coesite and stishovite: Geochimica et Cosmochimica Acta, v. 31, p. 2289-2307.

Huang, R., and Audétat, A., 2011, A critical look at the titanium-in-quartz (TitaniQ) thermobarometer, Abstracts, Goldschmidt 2011, Mineralogical Magazine, v. 75, p. 1065.

Ingamells, C. O., 1980, Microprobe Column, Geostandard Newsletter, v. 4, p. 139. Ireland, T.R., and Williams, I.S., 2003, Considerations in Zircon Geolchronology by SIMS: Reviews in Mineralogy and Geochemistry, v. 53, p. 215-241. 
Jarosewich, E., Nelen, J. A., and Norburg, J. A., 1980, Reference Samples for Electron Microprobe Analysis, Geostandard Newsletter, v. 4, p. 43-47.

Jolivet, L., Raimbourg, H., Labrousse, L., Avigad, D., Leroy, Y., Austrheim, H., and Andersen, T.B., 2005, Softening triggered by eclogitization, the first step toward exhumation during continental subduction: Earth and Planetary Science Letters, v. 237, p. 532-547.

Kohn, M.J., and Northrup, C.J., 2009, Taking mylonites' temperatures: Geology, v. 37, p. $47-50$.

Koziol, A.M., 1989, Recalibration of the garnet - plagioclase - $\mathrm{Al}_{2} \mathrm{SiO}_{5}$ - quartz (GASP) geobarometer and applications to natural parageneses: EOS Transactions of the American Geophysical Union, v. 70, p. 493.

Krogh, E.J., and Raheim, A., 1978, Temperature and pressure dependence of Fe-Mg partitioning between garnet and phengite, with particular reference to eclogites: Contributions to Mineralogy and Petrology, v. 66, p. 75-80.

Kruhl, J.H., 1996, Prism- and basal-plane parallel subgrain boundaries in quartz: A microstructural geothermobarometer: Journal of Metamorphic Geology, v. 14 , p. 581-589.

Kullerud, L., 1991, On the calculation of isochrons: Chemical Geology (Isotope Geoscience section), v. 87, p. 115-124.

Kurz, W., 2005, Constriction during exhumation: Evidence from eclogite microstructures: Geology, v. 33, p. 37-40.

Kylander-Clark, A.R.C., Hacker, B.R., and Mattinson, J.M., 2008, Slow exhumation of UHP terranes: Titanite and rutile ages of the Western Gneiss Region, Norway: Earth and Planetary Science Letters, v. 272, p. 531-540.

Lapen, T.J., Johnson, C.M., Baumgartner, L.P., Mahlen, N.J., Beard, B.L., and Amato, J.M., 2003, Burial rates during prograde metamorphism of an ultrahigh pressure terrane: an example from Lago di Cignana, western Alps, Italy: Earth and Planetary Science Letters, v. 215, p. 57-72.

Leech, M.L., 2001, Arrested orogenic development: eclogitization, delamination, and tectonic collapse: Earth and Planetary Science Letters, v. 185, p. 149-159.

Liou, J.G., Tsujimori, T., Zhang, R.Y., Katayama, I., and Maruyama, S., 2004, Global UHP metamorphism and continental subduction/collision: The Himalayan model: International Geology Review, v. 46, p. 1-27. 
Liou, J.G., Ernst, W.G., Zhang, R.Y., Tsujimori, T., and Jahn, B.M., 2009, Ultrahigh-pressure minerals and metamorphic terranes - The view from China: Journal of Asian Earth Sciences, v. 35, p. 199-231.

Little, T.A., Baldwin, S.L., Fitzgerald, P.G., and Monteleone, B.D., 2007, Continental rifting and metamorphic core complex formation ahead of the Woodlark spreading ridge, D'Entrecasteaux Islands, Papua New Guinea: Tectonics, v. 26, TC1002.

Little, T.A., Hacker, B.R., Gordon, S.M., Baldwin, S., and Fitzgerald, P.G., 2010, Partial melting as a key agent in exhumation of the world's youngest eclogitefacies (and UHP) rocks in the D'Entrecasteaux Islands, Papua New Guinea, Abstract T21H-03 presented at the 2010 Fall Meeting, American Geophysical Union, San Francisco, California, 13-17 December.

Little, T.A., Hacker, B.R., Gordon, S.M., Baldwin, S.L., Fitzgerald, P.G., Ellis, S., and Korchinski, M., 2011, Diapiric exhumation of Earth's youngest (UHP) eclogites in the gneiss domes of the D'Entrecasteaux Islands, Papua New Guinea: Tectonophysics (in press).

Liu, F.L., and Liou, J.G., 2011, Zircon as the best mineral for P-T-time history of UHP metamorphism: A review on mineral inclusions and U-Pb SHRIMP ages of zircons from the Dabie-Sulu UHP rocks: Journal of Asian Earth Sciences, v. 40, p. 1-39.

Ludwig, K.R., 2008, Isoplot 3.70: A geochronological toolkit for Microsoft Excel: Berkeley Geochrology Center Special Publication.

Lus, W.Y., McDougall, I., and Davies, H.L., 2004, Age of the metamorphic sole of the Papuan Ultramafic Belt ophiolite, Papua New Guinea: Tectonophysics, v. 392, p. 85-101.

Martinez, F., Goodliffe, A.M., and Taylor, B., 2001, Metamorphic core complex formation by density inversion and lower-crust extrusion: Nature, v. 411, p. 930-934.

McDougall, I., and Harrison, T.M., 1999, Geochronology and thermochronology by the ${ }^{40} \mathrm{Ar} /{ }^{39} \mathrm{Ar}$ method: New York, Oxford University Press, $269 \mathrm{p}$.

Monteleone, B.D., Baldwin, S.L., Webb, L.E., Fitzgerald, P.G., Grove, M., and Schmitt, A.K., 2007, Late Miocene-Pliocene eclogite facies metamorphism, D'Entrecasteaux Islands, SE Papua New Guinea: Journal of Metamorphic Geology, v. 25, p. 245-265. 
Newton, R.C., and Haselton, H.T., 1981, Thermodynamics of the garnetplagioclase- $\mathrm{Al}_{2} \mathrm{SiO}_{5}$-quartz geobarometer, in Newton, E., ed., Thermodynamics of Minerals and Melts: New York, Springer-Verlag, p. 131147.

Norlander, B.H., Whitney, D.L., Teyssier, C., and Vanderhaeghe, O., 2002, Partial melting and decompression of the Thor-Odin dome, Shuswap metamorphic core complex, Canadian Cordillera: Lithos, v. 61, p. 103-125.

Parrish, R.R., Gough, S.J., Searle, M.P., and Waters, D.J., 2006, Plate velocity exhumation of ultrahigh-pressure eclogites in the Pakistan Himalaya: Geology, v. 34, p. 989-992.

Pennacchioni, G., Menegon, L., Leiss, B., Nestola, F., and Bromiley, G., 2010, Development of crystallographic preferred orientation and microstructure during plastic deformation of natural coarse-grained quartz veins: Journal of Geophysical Research, v. 115, B12405.

Reiners, P.W., Ehlers, T.A., and Zeitler, P.K., 2005, Past, present, and future of thermochronology: Reviews in Mineralogy and Geochemistry, v. 58, p. 1-18.

Rey, P.F., Teyssier, C., and Whitney, D.L., 2009, Extension rates, crustal melting, and core complex dynamics: Geology, v. 37, p. 391-394.

Rubatto, D., and Hermann, J., 2001, Exhumation as fast as subduction?: Geology, v. 29, p. 3-6.

Scotfeld, D.M., 1975, A test of aluminium in quartz as a geothermometer: American Mineralogist, v. 60, p. 139-142.

Singh, Y., and Chabria, T., 2002, Early Proterozoic ${ }^{87} \mathrm{Rb}-{ }^{86} \mathrm{Sr}$ model ages of pegmatitic muscovite from rare metal-bearing granite-pegmatite system of Kawadgaon, Bastar Craton, central India: Gondwana Research, v. 5, p. 889893.

Smith, D.C., 1984, Coesite in clinopyroxene in the Caledonides and its implications for geodynamics: Nature, v. 310, p. 641-644.

Sneeringer, M., Hart, S.R., and Shimizu, N., 1984, Strontium and samarium diffusion in diopside: Geochimica et Cosmochimica Acta, v. 48, p. 1589-1608.

Solar, G.S., 2008, The interplay between tectonics/structure and migmatite morphology in the field, in Sawyer, E.D., Brown, M., eds., Working with Migmatites: Quebec City, Mineralogical Association of Canada Short Course, v. 38, p. 145-157. 
Spear, F.S., and Kohn, M.J., 1999, Program Thermobarometry: GTB program manual, v. 2.1, http://ees2.geo.rpi.edu/MetaPetaRen/Software/GTB _Prog/GTB.html

Spear, F.S., and Wark, D., 2004, TITANiQ: Potential applications of the Ti-inQuartz (+ Rutile) thermometer in metamorphic rocks: Transcripts of the American Geophysical Union, v. 85, Abstract V33A-05, Fall Meeting Supplement.

Spear, F.S., and Wark, D.A., 2009, Cathodoluminescence imaging and titanium thermometry in metamorphic quartz: Journal of Metamorphic Geology, v. 27, p. $187-205$.

Stipp, M., Stünitz, H., Heilbronner, R., and Schmid, S.M., 2002, The eastern Tonale fault zone: a 'natural laboratory' for crystal plastic deformation of quartz over a temperature range from 250 to $700{ }^{\circ} \mathrm{C}$ : Journal of Structural Geology, v. 24, p. 1861-1884.

Taylor, B., Goodliffe, A.M., and Martinez, F., 1999, How continents break up: Insights from Papua New Guinea: Journal of Geophysical Research, v. 104, p. 7497-7512.

Terry, M.P., Robinson, P., Hamilton, M.A., and Jercinovic, M.J., 2000, Monazite geochronology of UHP and HP metamorphism, deformation, and exhumation, Nordoyane, Western Gneiss Region, Norway: American Mineralogist, v. 85, p. 1651-1664.

Teyssier, C., and Whitney, D.L., 2002, Gneiss domes and orogeny: Geology, v. 30, p. 1139-1142.

Thomas, J., Bruce Watson, E., Spear, F., Shemella, P., Nayak, S., and Lanzirotti, A., 2010, TitaniQ under pressure: the effect of pressure and temperature on the solubility of Ti in quartz: Contributions to Mineralogy and Petrology, v. 160, p. 743-759.

Thomson, S.N., Ring, U., Brichau, S., Glodny, J., and Will, T.M., 2009, Timing and nature of formation of the Ios metamorphic core complex, southern Cyclades, Greece: Geological Society of London, Special Publications, v. 321, p. 139167.

Tirel, C., Brun, J., and Burov, E., 2004, Thermomechanical modeling of extensional gneiss domes, in Whitney, D.L., Teyssier, C., and Siddoway, C.S., eds., 
Gneiss Domes in Orogeny: Boulder, Colorado, Geological Society of America Special Paper, v. 380, p. 67-78.

Tirel, C., Brun, J-P., and Burov, E., 2008, Dynamics and structural development of metamorphic core complexes: Journal of Geophysical Research, v. 113.

van der Molen, I., and Paterson, M.S., 1979, Experimental deformation of partiallymelted granite: Contributions to Mineralogy and Petrology, v. 70, p. 299-318.

Wallace, L.M., Stevens, C., Silver, E., McCaffrey, R., Loratung, W., Hasiata, S., Stanaway, R., Curley, R., Rosa, R., and Taugaloidi, J., 2004, GPS and seismological constraints on active tectonics and arc-continent collision in Papua New Guinea: Implications for mechanics of microplate rotations in a plate boundary zone: Journal of Geophysical Research, v. 109, B05405.

Wark, D.A., and Watson, E.B., 2006, TitaniQ: a titanium-in-quartz geothermometer: Contributions to Mineral Petrology, v. 152, p. 743-754.

Webb, L.E., Baldwin, S.L., Little, T.A., and Fitzgerald, P.G., 2008, Can microplate rotation drive subduction inversion?: Geology, v. 36, p. 823-826.

Weissel, J.K., and Watts, A.B., 1979, Tectonic evolution of the Coral Sea Basin: Journal of Geophysical Research, v. 84, p. 4572 - 4582.

White, R.W., 2008, Insights gained from the petrological modeling of migmatites: Particular reference to mineral assemblages and common replacement textures, in Sawyer, E.D., Brown, M., eds., Working with Migmatites: Quebec City, Mineralogical Association of Canada Short Course, v. 38, p. 77-93.

Whitney, D.L., Teyssier, C., and Vanderhaeghe, O., 2004, Gneiss domes and crustal flow, in Whitney, D.L., Teyssier, C., and Siddoway, C.S., eds., Gneiss Domes in Orogeny: Boulder, Colorado, Geological Society of America Special Paper, v. 380, p. 15-33.

Wilson, C.J.N, Seward, T.M., Allan, A.S.R., Charlier, B.L.A., Bello, L., and Hildreth, W., in review, A comment on: 'TitaniQ under pressure: the effect of pressure and temperature on the solubility of Ti in quartz', by Jay B. Thomas, E. Bruce Watson, Frank S. Spear, Phillip T. Shemella, Saroy K. Nayak, and Antonio Lanzirotti: Contributions to Mineralogy and Petrology.

Yin, A., 2004, Gneiss domes and gneiss dome systems, in Whitney, D.L., Teyssier, C., and Siddoway, C.S., eds., Gneiss Domes in Orogeny: Boulder, Colorado, Geological Society of America Special Paper, v. 380, p. 1-14. 
Young, D.J., Hacker, B.R., Andersen, T.B., and Corfu, F., 2007, Prograde amphibolite facies to ultrahigh-pressure transition along Nordfjord, western Norway: Implications for exhumation tectonics: Tectonics, v. 26, TC1007.

Zirakparvar, N.A., Baldwin, S., Fitzgerald, P.G., and Vervoort, J.D., 2010, Piecing together the eastern Australian margin in Gondwana: Origin of metamorphic rocks in the Woodlark Rift, SE Papua New Guinea, Abstract T13C-2220 presented at the 2010 Fall Meeting, American Geophyscial Union, San Fransisco, California, 13-17 December.

Zirakparvar, N.A., Baldwin, S.L., Vervoort, J.D., 2011, Lu-Hf garnet geochronology applied to plate boundary zones: Insights from the (U)HP terrane exhumed within the Woodlark Rift: Earth and Planetary Science Letters, v. 309, p. 55-56. 


\section{Appendix B Ti-in-quartz methods}

\section{B.1 Methods}

Hand samples were cut into sub-samples $\sim 5 \mathrm{~mm}$ in size and then pressed onto tape with the epoxy mould. EPO-TEK epoxy was used to mount the samples into $25 \mathrm{~mm}$ half-moons briquettes for the laser ablation inductively coupled plasma mass spectrometer (LA-ICP-MS). Once the epoxy was dry, the mounts were ground down on a diamond cup-wheel until a large sample surface area was exposed, and then polished using $6 \mu \mathrm{m}, 3 \mu \mathrm{m}$, and $1 \mu \mathrm{m}$ Kemet International Ltd. liquid diamond polish on an ATM Saphir 560 polishing machine. Before analysis, sample mounts were coated with $\sim 25 \mathrm{~nm}$ of carbon in a JEOL vacuum evaporator.

Two sets of pre-analyses images were obtained to facilitate sample location during LA-ICP-MS. Reflected light microscopy was carried out on an Olympus BX51 microscope with an Olympus DP70 camera (which contains in-built scale bars) at Victoria University of Wellington (VUW), in order to create a background to the map of quartz grains selected for analysis. Back-scattered electron images were captured on the JEOL JXA-733 SuperProbe and the new JEOL JXA-8230 electron probe microanalyzer at VUW. Back-scattered electron images were used to locate quartz for analyses. These two images sets were combined to create the final map for LA-ICP-MS analysis.

The New Wave $193 \mu \mathrm{m}$ solid-state Nd-YAG laser at VUW causes trace elementpoor and Si-rich material to fracture during interaction of the laser with the target. Ideally, this interaction should create a round crater. This fracturing results in the creation of mineral shards in the first few seconds of laser ablation that are subsequently blown away by the gas flow, and may result in unwanted mineral phases being incorporated into the signal and the destruction of the area immediate to the shot. Laser settings (such as optional gas flow, extract voltage, and torch position) were tuned during ablation of the NIST 612 standard to ensure that: (1) the quartz ablated as well as possible, and (2) the ICP-MS was at optimum sensitivity 
and low internal errors (Table B.1). The switch between pulse (P; $<1 \times 10^{6}$ counts per second; $\left.{ }^{43} \mathrm{Ca},{ }^{47} \mathrm{Ti},{ }^{49} \mathrm{Ti},{ }^{27} \mathrm{Al}\right)$ and analog $\left(\mathrm{A} ;>1 \times 10^{6}\right.$ counts per second; $\left.{ }^{29} \mathrm{Si}\right)$ counting modes was carried out by the ICP-MS. The P/A factor was measured on all analyzed elements during tuning to ensure the switch between high and low signal was performed correctly. Elemental oxide production was maintained below $1.5 \%$ by tuning the conditions of the plasma torch, and was monitored by $\mathrm{ThO}^{+} / \mathrm{Th}^{+}$.

Table B.1 Analytical conditions of the LA-ICP-MS

\begin{tabular}{|c|c|}
\hline \multicolumn{2}{|l|}{ ICP-MS } \\
\hline System & Agilent $7500 \mathrm{CS}$ \\
\hline Acquisition mode & Peak-hopping \\
\hline Detection mode & pulse $\left({ }^{43} \mathrm{Ca},{ }^{47} \mathrm{Ti},{ }^{48} \mathrm{Ti},{ }^{27} \mathrm{Al}\right)$ and analogue $\left({ }^{29} \mathrm{Si}\right)$ \\
\hline \multicolumn{2}{|l|}{ Laser ablation } \\
\hline System & New Wave 193 nm (deep UV) solid state laser \\
\hline Laser power & $65 \%$ for NIST $612, \sim 85 \%$ for quartz grains \\
\hline Ablation mode & Static spot analysis \\
\hline Repetition rate & $10 \mathrm{~Hz}$ \\
\hline \multicolumn{2}{|l|}{ Standards } \\
\hline Bracketing/Calibration standards & NIST 612 \\
\hline \multicolumn{2}{|l|}{ Analysis method } \\
\hline Standard/sample acquisition & 60 seconds \\
\hline Wash out/background acquisition & 90 seconds \\
\hline Measured isotopes and integrations times & ${ }^{29} \mathrm{Si},{ }^{43} \mathrm{Ca},{ }^{47} \mathrm{Ti},{ }^{49} \mathrm{Ti},{ }^{27} \mathrm{Al}$; all 0.01 seconds \\
\hline \multicolumn{2}{|l|}{ Tuning } \\
\hline Tuning standards & NIST 612 \\
\hline Monitored isotopes during tuning & ${ }^{29} \mathrm{Si},{ }^{43} \mathrm{Ca},{ }^{47} \mathrm{Ti},{ }^{49} \mathrm{Ti},{ }^{27} \mathrm{Al}$ \\
\hline Ablation mode & $50 \mu \mathrm{m}$ diameter spots \\
\hline Monitored isotopes during ablation & ${ }^{29} \mathrm{Si},{ }^{43} \mathrm{Ca},{ }^{47} \mathrm{Ti},{ }^{49} \mathrm{Ti},{ }^{27} \mathrm{Al}$ \\
\hline Background & ${ }^{47} \mathrm{Ti}<400$ counts per second $*$ \\
\hline Oxides & $<1.5 \%$ (checked during tuning) \\
\hline Carrier gas $(\mathrm{Ni})$ & $0.75-0.85 \mathrm{~L} \mathrm{~min}^{-1}$ \\
\hline Optional gas $(\mathrm{He})$ & $75-85 \%$ \\
\hline RF Power & $1500 \mathrm{~W}$ \\
\hline RF matching & $1.96 \mathrm{~V}$ \\
\hline Sample depth & $3-4 \mathrm{~mm}$ \\
\hline
\end{tabular}

\section{B.2 Errors and uncertainties calculations}

The total uncertainty related to the Ti-in-quartz apparent temperature (Table 2.1) is derived from three sources. First, there is an uncertainty in the slope and intercept of 
the least-squares regression-analysis carried out during calibration of the thermometer $\left(\sim 5^{\circ} \mathrm{C}\right.$ of uncertainty; Thomas et al., 2010; Wark and Watson, 2006). Secondly, there is the analytical uncertainty, which is a $95 \%$ confidence interval of the average Ti concentration. Thirdly, there is an assigned uncertainty of \pm 0.2 in the Ti activity $\left(\alpha_{\mathrm{TiO}_{2}}\right)$. I suggest that the three sources of uncertainty are independent of each other as they arise from different contributions. Wark and Watson (2006) and Thomas et al., (2010) determined the calibration uncertainty. The analytical uncertainty is calculated from the ICP-MS measurement statistics. The $\alpha_{\mathrm{TiO}_{2}}$ uncertainty is an assigned value.

\section{B.2.1 Wark and Watson (2006) uncertainty}

The combination of the three sources of uncertainties into the single value was determined as a $95 \%$ confidence interval of the quotient. The calibration uncertainty $\left(c^{1}= \pm 24\right.$ and $\left.c^{2}=0.02\right)$, the analytical uncertainty $\left(\varepsilon_{\mathrm{j}}\right)$, and the Ti activity uncertainty

$(\alpha)$ were all incorporated into the original Wark and Watson (2006) equation:

$$
T=\frac{-\left(3765+c^{1}\right)}{\left(\log _{10}\left(\frac{T i+\varepsilon_{j}}{\alpha_{0}+\alpha}\right)-\left(5.69-c^{2}\right)\right)}-273
$$

Expanding the logarithm and converting to base e gives the denominator as

$$
0.4343\left(\operatorname{Ln}\left(T i+\varepsilon_{j}\right)-\operatorname{Ln}\left(\alpha_{0}+\alpha\right)\right)-\left(5.69-c^{2}\right),
$$

which can be rearranged to

$$
0.4343\left(\operatorname{LnTi}-\operatorname{Ln} \alpha_{0}+\operatorname{Ln}\left(1+\frac{\varepsilon_{j}}{T i}\right)-\operatorname{Ln}\left(1+\frac{\alpha}{\alpha_{0}}\right)\right)-\left(5.69-c^{2}\right) \text {. }
$$

Approximating $\operatorname{Ln}(1+x)$ by the first term of its power series is valid if $x^{2}<<x$. Thus, the denominator is approximately

$$
0.4343\left(\operatorname{LnTi}-\operatorname{Ln} \alpha_{0}+\frac{\varepsilon_{j}}{T i}-\frac{\alpha}{\alpha_{0}}\right)-\left(5.69-c^{2}\right) \text {. }
$$

The variance of the denominator is

$=0.4343^{2}\left(\frac{\sigma_{\varepsilon}}{T i}\right)+0.4343^{2}\left(\frac{1 / 2 \alpha}{\alpha_{0}}\right)^{2}+\left(\frac{0.02}{2}\right)^{2}$. 
The variance of the numerator is

$=\left(\frac{c^{1}}{2}\right)^{2}$

where I have taken the ranges $\mathrm{c}^{1}, \mathrm{c}^{2}$, and $\alpha$ to be $2 \sigma$. The two variances were then input in the equation for the $95 \%$ confidence interval of a quotient:

$\operatorname{var}\left(\frac{A}{B}\right)=\frac{1}{B^{2}} \operatorname{var} A+\frac{A^{2}}{B^{4}} \operatorname{var} B$

in order to determine the combined uncertainty. This equation is valid provided A and $\mathrm{B}$ are independent and $\operatorname{var} \mathrm{B}$ is small $(<\sim 0.1)$ compared to $\mathrm{B}$.

\section{B.2.2 Thomas et al. (2010) uncertainty}

The combination of the three sources of uncertainties into the single value for the calculated Thomas et al. (2010) TitaniQ apparent temperatures was accomplished with a method similar to that discussed in Section B.2.1. The calibration uncertainty $\left(c^{1}= \pm 3122, c^{2}= \pm 0.04, c^{3}= \pm 63\right)$, the analytical uncertainty $\left(\varepsilon_{\mathrm{j}}\right)$, and the Ti activity uncertainty $(\alpha)$ were all incorporated into the original Thomas et al., (2010) equation: $T\left({ }^{\circ} C\right)=\frac{\left(60952 \pm c^{1}\right)+\left(1741 \pm c^{3}\right) P}{\left(1.520 \pm c^{2}\right)-R\left(\ln X_{T i O_{2}}^{Q t z} \pm \varepsilon_{j}\right)+R\left(\ln \alpha_{T i O_{2}} \pm \alpha\right)}-273.15$

Expanding the denominator gives

$$
\left(1.520 \pm c^{2}\right)-R\left\{\ln \left(\frac{X_{T i O_{2}}^{Q t z}}{\alpha_{T i O_{2}}}\right)+\ln \left(1+\frac{\varepsilon_{j}}{X_{T i O_{2}}^{Q t z}}\right)-\ln \left(1+\frac{\alpha}{\alpha_{T i O_{2}}}\right)\right\} \text {. }
$$

Approximating $\operatorname{Ln}(1+x)$ by the first term of its power series is valid if $x^{2}<<x$. If

$$
\begin{aligned}
& \frac{\sigma_{\varepsilon}}{X_{\mathrm{TiO}_{2}}^{Q t z}} \text { and } \frac{\alpha}{\alpha_{\mathrm{TiO}_{2}}}<<1 \text {, the denominator is approximately } \\
& \left(1.520 \pm c^{2}\right)-R\left\{\ln \left(\frac{X_{\mathrm{TiO}_{2}}^{Q t z}}{\alpha_{\mathrm{TiO}_{2}}}\right)+\frac{\varepsilon_{j}}{X_{\mathrm{TiO}_{2}}^{Q t z}}-\frac{\alpha}{\alpha_{\mathrm{TiO}_{2}}}\right\} .
\end{aligned}
$$

So the variance of the denominator is

$$
=-R^{2}\left\{\operatorname{var}\left(\frac{\varepsilon_{j}}{X_{\mathrm{TiO}_{2}}^{Q_{\mathrm{It}}}}\right)+\operatorname{var}\left(\frac{\alpha}{\alpha_{\mathrm{TiO}_{2}}}\right)\right\}+\left(\frac{c^{2}}{2}\right)^{2},
$$


which expands to

$$
=R^{2}\left\{\frac{1}{\left(X_{\mathrm{TiO}_{2}}^{Q \mathrm{Qtz}}\right)^{2}} \sigma_{\varepsilon}^{2}+\frac{(\alpha / 2)^{2}}{\left(\alpha_{\mathrm{TiO}_{2}}\right)^{2}}\right\}+\left(\frac{c^{2}}{2}\right)^{2} .
$$

The variance of the numerator is

$=\left(\frac{c^{1}}{2}\right)^{2}+\left(\frac{c^{3}}{2}\right)^{2}$

where I have taken the ranges $c^{1}, c^{2}$, and $\alpha$ to be $2 \sigma$, and $c^{3}$ to be $<<c^{1}$. The two variances were then input in the equation for the $95 \%$ confidence interval of a quotient:

$\operatorname{var}\left(\frac{A}{B}\right)=\frac{1}{B^{2}} \operatorname{var} A+\frac{A^{2}}{B^{4}} \operatorname{var} B$

in order to determine the combined uncertainty, with the same requirements as before.

\section{B.3 One-sided t distribution}

A one-sided t distribution was used to determine the probability that the slopes for the linear regressions in Fig. 2.15 were negative or zero (Table B.2). I assume that the uncertainties or scatter in the data, and hence the slope estimates, are Normal/Gaussian random variables (Fig. B.1).

Table B.2 Results of one-sided t distribution

\begin{tabular}{rcccccc}
\hline Fault & Slope (m) & $\begin{array}{c}\text { Standard } \\
\text { Deviation } \mathbf{m} \\
\mathbf{( s d )}\end{array}$ & $\begin{array}{c}\text { No. of } \\
\text { data }^{\mathbf{a}}\end{array}$ & $\mathbf{m} / \mathbf{s d}$ & $\begin{array}{c}\text { p0 (Probability } \\
\text { slope is negative } \\
\text { or zero) }\end{array}$ & p0 \\
\hline Wakonai & 0.00826 & 0.00283 & 21 & 2.92260 & 0.00437 & $<1 \%$ \\
Mwadeia & 0.00109 & 0.00072 & 14 & 1.51883 & 0.07735 & $<8 \%$ \\
Morima & 0.00046 & 0.00005 & 5 & 9.29280 & 0.00132 & $<1 \%$ \\
NW Norm. & 0.00054 & 0.00127 & 5 & 0.42839 & 0.34863 & $<35 \%$ \\
SE Norm. & 0.00321 & 0.00126 & 5 & 2.53610 & 0.04248 & $<5 \%$ \\
\hline
\end{tabular}




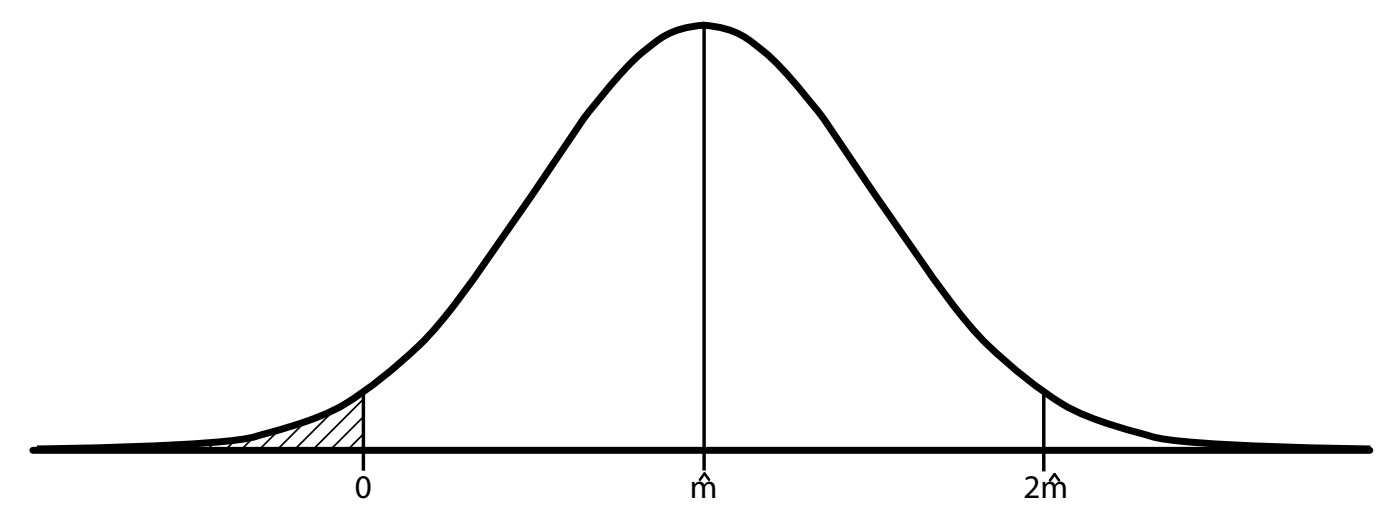

Figure B.1. A Normal or Gaussian distribution. The probability that the slope listed in Table B.3 is zero or negative is the probability that the slope will fall into the shaded area of the graph (onesided test). If it did so, this area gives the corresponding probability that the slope of the linear regressions on Figure 2.15 is zero or negative. 


\section{Appendix C MATLAB ${ }^{\mathrm{TM}}$ script}

\section{C.1 MATLAB ${ }^{\mathrm{TM}}$ input file formatting}

The MATLAB ${ }^{\mathrm{TM}}$ script presented here was used to calculate averages and standard deviations of all the inductively coupled plasma mass spectrometry (ICP-MS) analyses undertaken by this study. This script was written by Euan Smith (Victoria University of Wellington). The MATLAB ${ }^{\mathrm{TM}}$ script requires the user to set the initial wait, which is the length of time before the first analysis of the standard. There was some variation in this value for certain analytical sessions undertaken by this study. If the initial wait is inaccurate, the average and standard deviation of the ICP-MS analyses will be inaccurate as well. This parameter is marked "sampwait $=84 ; \ldots . . . \% \% \% \% \% \% \% \% \% \% \% \% \% \%$ TUNABLE !!" in the MATLABTM script. The input file must be a csv file, and must be formatted as in Fig. C.1.

\section{C.2 MATLAB ${ }^{\text {TM }}$ script}

$\%$

$\%$

\% LAICPMS output averaging

$\%$

\% Euan Smith 110908

$\%$

\% with some code borrowed from an unpublished MatLab script by Brian Anderson (february 2009)

$\%$

$\%$ 


\begin{tabular}{|c|c|c|c|c|c|c|}
\hline$\triangle$ & A & B & C & D & $\mathrm{E}$ & $F$ \\
\hline 1 & Time [Sec] & Al27 & Si29 & $\mathrm{Ca} 43$ & Ti47 & Ti48 \\
\hline \multicolumn{7}{|l|}{2} \\
\hline 3 & 0.259 & 4500.73 & 59729.22 & 833.36 & 120 & 316.67 \\
\hline 4 & 0.508 & 3200.37 & 66459.94 & 766.69 & 60 & 166.67 \\
\hline 5 & 0.757 & 4100.61 & 65153.72 & 666.68 & 80 & 300 \\
\hline 6 & 1.006 & 3900.55 & 67062.86 & 683.35 & 110 & 333.34 \\
\hline 7 & 1.255 & 4900.87 & 63847.63 & 833.36 & 50 & 266.67 \\
\hline 8 & 1.504 & 3100.35 & 64952.78 & 633.35 & 60 & 250 \\
\hline 9 & 1.753 & 3700.5 & 61938.94 & 533.34 & 60 & 333.34 \\
\hline 10 & 2.002 & 2700.26 & 61336.26 & 600.01 & 110 & 450.01 \\
\hline 11 & 2.251 & 3700.5 & 65857.06 & 666.68 & 70 & 233.34 \\
\hline 12 & 2.5 & 3100.35 & 62642.12 & 750.02 & 90 & 216.67 \\
\hline 13 & 2.749 & 2100.16 & 65555.64 & 766.69 & 100 & 383.34 \\
\hline 14 & 2.998 & 3400.42 & 67163.34 & 600.01 & 60 & 350 \\
\hline 15 & 3.247 & 4000.58 & 58524.07 & 566.68 & 110 & 300 \\
\hline 16 & 3.496 & 4100.61 & 64651.37 & 583.35 & 70 & 300 \\
\hline 17 & 3.745 & 4200.64 & 59026.19 & 766.69 & 40 & 266.67 \\
\hline 18 & 3.994 & 4100.61 & 62240.3 & 800.02 & 70 & 350 \\
\hline 19 & 4.243 & 3100.35 & 60130.97 & 983.37 & 60 & 316.67 \\
\hline 20 & 4.492 & 3900.55 & 64249.49 & 516.68 & 70 & 233.34 \\
\hline 21 & 4.741 & 4000.58 & 68369.25 & 666.68 & 90 & 266.67 \\
\hline 22 & 4.99 & 4600.77 & 74500.92 & 850.03 & 20 & 283.34 \\
\hline 23 & 5.239 & 3200.37 & 65254.21 & 716.69 & 80 & 183.33 \\
\hline 24 & 5.488 & 4000.58 & 61436.7 & 716.69 & 70 & 366.67 \\
\hline 25 & 5.737 & 3600.47 & 64048.56 & 583.35 & 60 & 333.34 \\
\hline 26 & 5.986 & 3900.55 & 58724.91 & 466.67 & 100 & 150 \\
\hline 27 & 6.235 & 3800.52 & 59628.78 & 733.35 & 60 & 266.67 \\
\hline 28 & 6.484 & 2600.25 & 68771.25 & 900.03 & 90 & 200 \\
\hline 29 & 6.733 & 3200.37 & 59126.63 & 616.68 & 50 & 233.34 \\
\hline 30 & 6.982 & 3600.47 & 61838.51 & 683.35 & 120 & 200 \\
\hline 31 & 7.231 & 3400.42 & 59227.05 & 550.01 & 40 & 250 \\
\hline
\end{tabular}

Figure C.1 MATLAB ${ }^{\mathrm{TM}}$ program input file formatting. There must be no data or notations after the end of the ICP-MS measurements. 
clear all

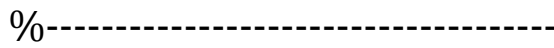

$\%$

$\%$ parameters

$\%$

$\%$

headlines $=2$;

initialwait=80; \%default now overwritten by dialogue prompt

sampwait=84; $\quad \% \% \% \% \% \% \% \% \% \% \% \% \%$ TUNABLE !!

stdwait=90;

backwait=40;

nsample=60;

nstd=60;

nback=30;

$\%$

$\%$

$\%$ Get and read datafile (.csv)

$\%$

$\mathrm{fd}=\operatorname{dir} ;$

fnstr $=\{$ fd.name $\}$;

$[\mathrm{s}, \mathrm{ok}]=\operatorname{listdlg}($ 'PromptString','Select data file (.csv):',,..

'SelectionMode','single',...

'ListString',fnstr); 
if ok error('user pressed cancel'); end

ss=getfield $(f d,\{s\})$;

fdata=ss.name;

$M=$ csvread(fdata,headlines, 0 );

\%now read those headerlines

fid=fopen(fdata);

$\%$ read all text to the end of line, including whitespace

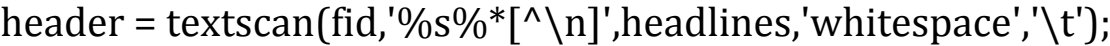

fclose(fid);

$\%$

$\%$ extract field names

fn=textscan(strvcat(header(Blanckenburg et al.)(1)),'\%s','delimiter',',');

field_names=fn(Blanckenburg et al.);

$\%$

$\%$ plot all data and draw legend

$\%$

\% Modification 11/2010 get starting wait

$\%$

prompt $=\{$ 'Enter initial wait' $\}$;

dlg_title = 'wait(s)'; 
num_lines $=1$

initial = inputdlg(prompt,dlg_title,num_lines);

initialwait=str2num(initial(Blanckenburg et al.));

$\operatorname{clf}$

time $=\mathrm{M}(:, 1)$

nelements=length(field_names)-1; \%process each element

nd=length(time);

$\mathrm{dt}=\max ($ time $) /(\mathrm{nd}+1) ;$

\%convert wait times to indices

nextstd=ceil(nstd/dt);

nextsamp=ceil(nsample/dt);

nextback=ceil $($ nback $/ \mathrm{dt})$;

nsampwait=ceil(sampwait/dt);

nstdwait=ceil(stdwait/dt);

nbackwait=ceil(backwait/dt);

for iel=2:nelements +1

clear back 
clear sample

clear stnd

dataleft $=1$

$\mathrm{ip}=$ ceil(initialwait/dt);

$\mathrm{h}=0 ; \%$ processed samples and standards

jstd=0;

jsample=0;

jback $=0$

\%method: rtecord background before each std or sample

while dataleft

$\mathrm{h}=\mathrm{h}+1$;

if $\bmod (h, 5)==1 \%$ standard

jstd $=\mathrm{jstd}+1$

jback=jback+1;

$\% 1$ st background

if ip+nextback-1 <= nd

samplemask=zeros(nd,1);

samplemask(ip:ip+nextback-1,1)=ones(nextback,1);

sett=samplemask'*(M(:,iel).^2); \%squares 
back(jback,1)=(1/nextback)*samplemask'*M(:,iel);

$\operatorname{varr}=(1 /$ nextback $) *$ sett-back(jback, 1$)^{\wedge} 2$;

back(jback,1)=(1/nextback)*samplemask'*M(:,iel);

$\operatorname{back}(j b a c k, 4)=\operatorname{sqrt}(\operatorname{varr} /$ nextback $)$;

$\operatorname{back}(j b a c k, 2)=i p ;$

back(jback,3)=ip+nextback-1;

ip=ip+nextback+nbackwait;

end

\%now std

if ip+nextstd- $1<=$ nd

samplemask=zeros(nd,1);

samplemask(ip:ip+nextstd-1,1)=ones(nextstd,1);

sett=samplemask'*(M(:,iel).^2); \%squares

stnd(jstd,1)=(1/nextstd)*samplemask'*M(:,iel);

$\operatorname{varr}=(1 / \text { nextstd })^{*}$ sett-stnd(jstd, 1$)^{\wedge} 2$;

stnd(jstd,1)=(1/nextstd)*samplemask'*M(:,iel);

stnd(jstd,4)=sqrt(varr/nextstd $)$;

stnd(jstd,2)=ip;

stnd(jstd,3)=ip+nextstd-1;

ip=ip+nextstd+nstdwait;

end

else

jsample=jsample+1; 
jback=jback+1;

$\% 1$ st background

if ip+nextback-1 $<=$ nd

samplemask=zeros(nd,1);

samplemask(ip:ip+nextback-1,1)=ones(nextback,1);

sett=samplemask'*(M(:,iel).^2); \%squares

back(jback,1)=(1/nextback)*samplemask'*M(:,iel);

$\operatorname{varr}=(1 / \text { nextback })^{*}$ sett-back $(j \text { back, } 1)^{\wedge} 2$;

back(jback,1)=(1/nextback)* samplemask'*M(:,iel);

back $(j b a c k, 4)=\operatorname{sqrt}($ varr $/$ nextback $)$;

$\operatorname{back}(j b a c k, 2)=i p ;$

back(jback,3)=ip+nextback-1;

ip=ip+nextback+nbackwait;

end

\%now sample

if ip+nextsamp-1 $<=$ nd

samplemask=zeros(nd,1);

samplemask(ip:ip+nextsamp-1,1)=ones(nextsamp,1);

sett=samplemask'*(M(:,iel).^2); \%squares

sample(jsample,1)=(1/nextsamp)*samplemask ${ }^{*} \mathrm{M}(:, \mathrm{iel})$;

$\operatorname{varr}=(1 / \text { nextsamp })^{*}$ sett-sample(jsample, 1$)^{\wedge} 2$; 


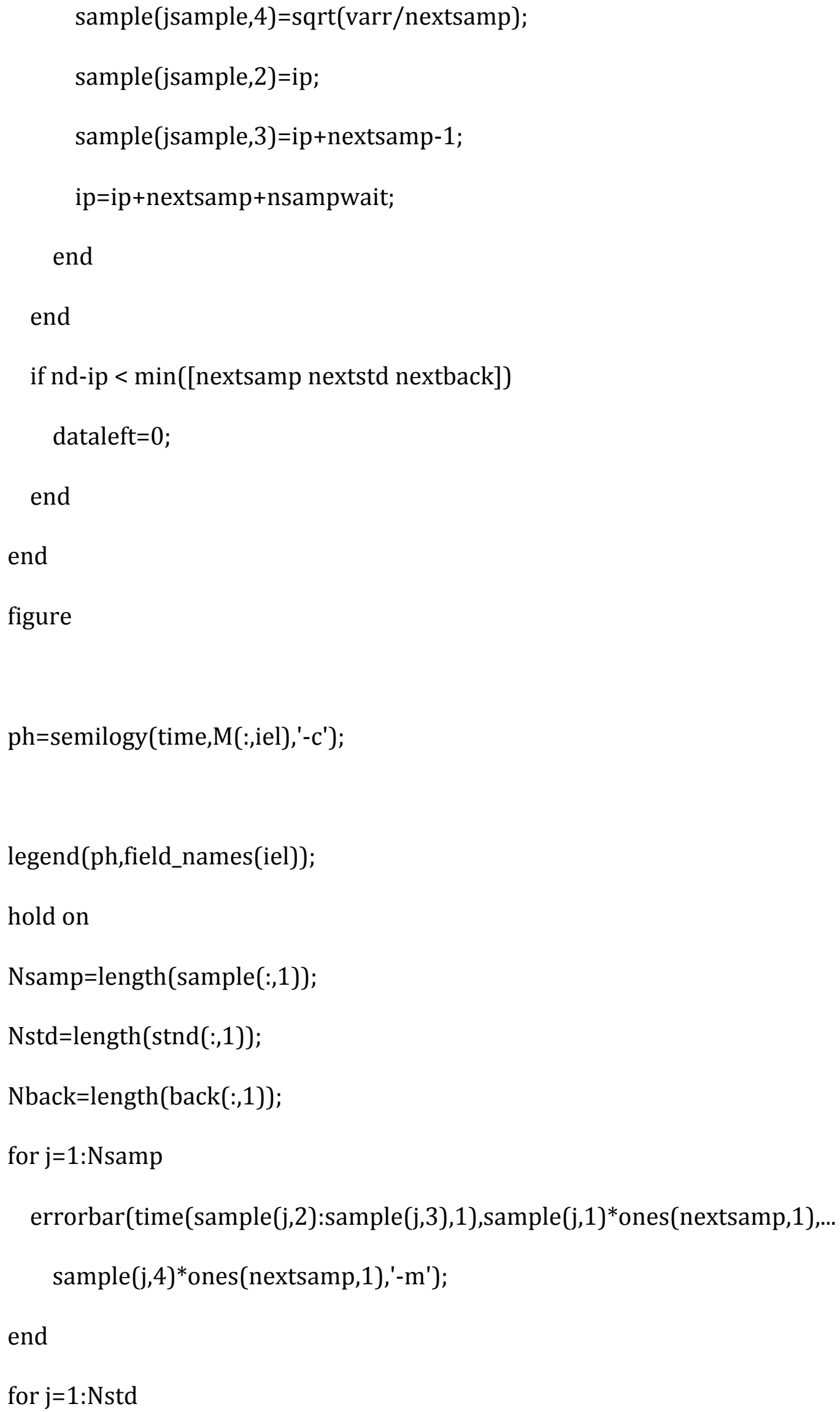


errorbar(time(stnd(j,2):stnd(j,3),1),stnd(j,1)*ones(nextstd,1),stnd(j,4)*ones(ne xtstd,1),'-r');

end

for $\mathrm{j}=1$ :Nback

errorbar(time(back(j,2):back(j,3),1),back(j,1)*ones(nextback,1),back(j,4)*ones( nextback,1),'-k');

end

$\%$

$\%$

$\%$ write data to .xls

$\%$

$\%$

lf=length(fdata);

fout=[fdata(1:lf-4) 'out.xls'];

datout=[stnd;zeros(1,4);sample;zeros(1,4);back];

xlswrite(fout,datout,field_names\{iel\},'A2');

end \%of file 


\section{C.3 MATLAB ${ }^{\mathrm{TM}}$ output}

The output of the MATLAB ${ }^{\mathrm{TM}}$ script is shown in Fig. C.2. The user must check the position of each ICP-MS measurement on the graphs output by the program, in order to determine if the average and standard deviation of the ICP-MS analysis and the background is accurate. If they are not accurate, the initial wait time must be adjusted. 
a)

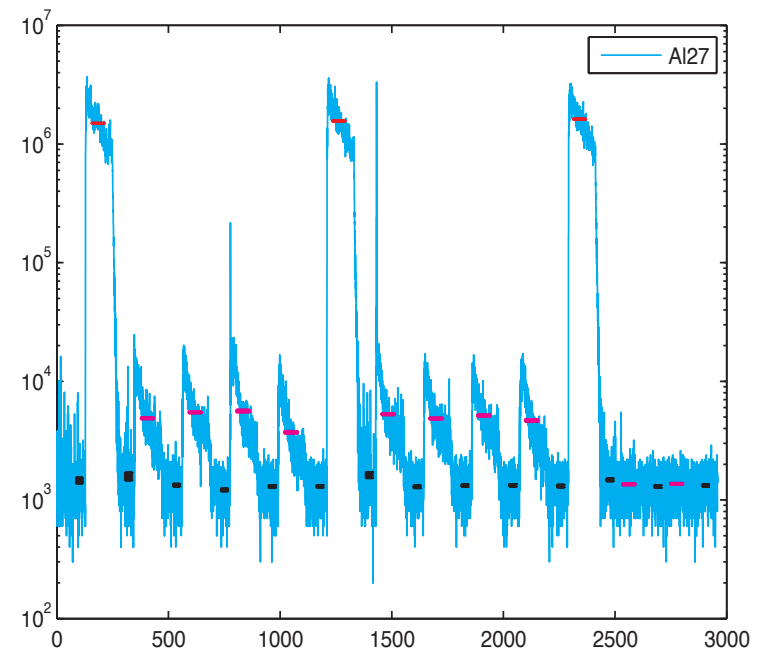

b)

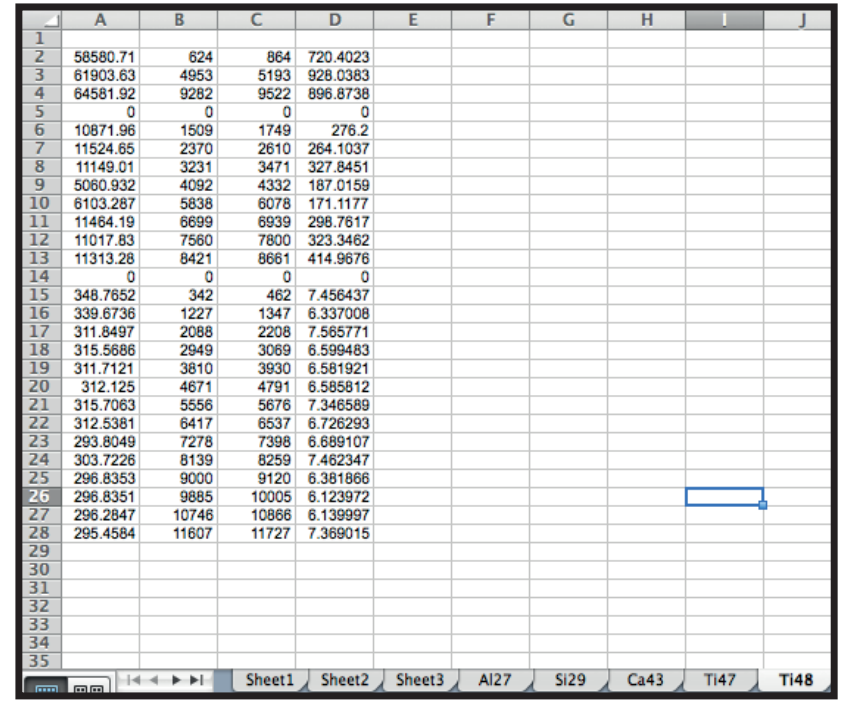

Figure C.2 MATLAB ${ }^{\mathrm{TM}}$ program results. (a) Example of one of the five graphs for each mass measured by ICP-MS (Al27, Si29, Ca43, Ti47, Ti48) that is output by the MATLAB ${ }^{\text {TM }}$ script presented here. These can be saved as Adobe Illustrator (Adobe Systems Incorporated. San Jose, CA, USA) files. The position and length of the red bars is the average and standard deviation respectively of each ICP-MS analysis. The position and length of the black bars is the average and standard deviation respectively of each background measurement. If the position of these markers is inaccurate, they can be adjusted by changing the initial sample wait (see text). (b) A screen shot of the Microsoft Excell (Microsoft. Redmond, WA, USA) file that is output by the MATLAB ${ }^{\mathrm{TM}}$ script, labeled as MKiout. The last five tabs shown at the bottom left of the image are for each mass analysed by the ICP-MS. The columns contain the following data: A, average counts per second or signal of the ICP-MS; B, start of the indicies on the input csv file; $C$, end of the indicies on the input csv file; $D$, standard deviation the ICP-MS measurements for that analysis. The first set of data (row 2 - 4 here) are the standard measurements, the second set of data (row 6 - 13 here) are the unknown measurements, and the third set of data (row $15-28$ here) are the background measurements. 


\section{Appendix D \\ $\mathrm{Rb}-\mathrm{Sr}$ and thermobarometry sample petrology}

\section{D.1 Mailolo dome, Fergusson Island}

08-010c, coarse-grained granodioritic host orthogneiss, core zone, $2.41 \pm 1.40$ Ma

Assemblage: quartz, plagioclase, K-feldspar, and white mica with minor orthopyroxene, biotite, oxides, and clinozoisite.

Quartz $(300-1000 \mu \mathrm{m})$ exhibits a well-developed subgrain structure with deformation bands and rounded interlobated grain boundaries. Plagioclase grains $(200-600 \mu \mathrm{m})$ are inequigranular and exhibit lamellar twinning with minor white mica inclusions $(<1 \%)$. White mica is fresh, coarse-grained $(300-900 \mu \mathrm{m})$, and has been affected by minor regression to biotite at the grain boundaries $(<2 \%)$.

\section{8-010a, ultra-high pressure eclogite, core zone, $5.7 \pm 2.0 \mathrm{Ma}$}

Assemblage: garnet, omphacite, white mica, quartz, and hornblende with minor rutile, orthopyroxene, zoisite, and apatite.

Petrology after Brownlee et al. (in prep.). Garnets $(200-400 \mu \mathrm{m})$ are rounded and equigranular. Omphacite is coarse-grained $(>500 \mu \mathrm{m})$ and retrogressed to a fine symplectite of plagioclase and hornblende at grain boundaries. Phengite is coarsegrained $(500-1000 \mu \mathrm{m})$ and retrogressed to biotite and plagioclase at the grain boundaries. Phengite and has been affected by retrogression to biotite between the mica sheets $(<1 \%)$. Hornblende grains are present $(200-500 \mu \mathrm{m} ; 5 \%$ volume $)$ Rutile grains $(200-300 \mu \mathrm{m})$ exhibit minor retrogression to ilmenite at the grain boundaries. This rock contains coesite (Baldwin et al., 2008).

08-037a, quartzofeldspathic gneiss, core zone, $12.4 \pm 5.0 \mathrm{Ma}$ Assemblage: quartz, garnet, white mica, plagioclase, and K-feldspar with minor biotite, chlorite, rutile, ilmenite, and kyanite.

Quartz is coarse-grained $(\sim 1000 \mu \mathrm{m})$ with rounded polygonal grain boundaries and sweeping deformational bands. Garnets are rounded and equigranular, and vary from 
coarse- (1000 $\mu \mathrm{m}$; fractured with biotite and quartz inclusions) to fine-grained $(<400$ $\mu \mathrm{m})$. White mica is coarse-grained $(500-1000 \mu \mathrm{m})$ and has been affected by retrogression to biotite at grain boundaries $(20 \%)$ and between mica sheets $(1 \%)$. Plagioclase and K-feldspar are fine-grained $(200-300 \mu \mathrm{m})$, relative to the elongate quartz grains. Biotite grains $(<5 \%$ volume $)$ have been affected by minor retrogression to chlorite at grain boundaries $(<<1 \%)$.

\section{9-039biii, eclogite float, core zone, $5.6 \pm 1.6 \mathrm{Ma}$}

Assemblage: garnet, white mica, plagioclase, quartz, hornblende, and rutile with minor biotite, ilmenite, apatite and oxides.

Garnets $(700-1200 \mu \mathrm{m})$ are rounded and fractured, with some radial fracturing around quartz inclusions. Garnets exhibit fine rutile exsolution needles and white mica inclusions, and are retrogressed to hornblende at grain boundaries. At the grain boundaries of hornblende there is a symplectite of plagioclase, quartz, biotite, albite, and pyroxene. Phengite $(300-500 \mu \mathrm{m})$ has been retrogressed to muscovite and biotite at the grain boundaries $(\sim 15 \%)$. Plagioclase (where not included in a symplectite) is coarse-grained $(400-600 \mu \mathrm{m})$ with lamellar twinning. Quartz is coarse-grained $(500-1000 \mu \mathrm{m})$ with interlobate boundaries. Rutile $(100-200 \mu \mathrm{m})$ is retrogressed to ilmenite at grain boundaries $(\sim 1 \%)$. Albite is fine-grained $(<100$ $\mu \mathrm{m})$ with dentate margins.

\section{0-070a, mica-bearing quartz sheet, carapace zone, thermobarometry sample}

Assemblage: quartz, K-feldspar, plagioclase, white mica, garnet, kyanite, biotite, and chlorite with minor rutile and ilmenite.

Quartz $(500-700 \mu \mathrm{m})$ exhibits undulose sweeping extinction and has rounded to dentate grain boundaries. Plagioclase $(600-700 \mu \mathrm{m})$ exhibits lamellar twinning. Garnets $(2000-2500 \mu \mathrm{m})$ are fractured and euhedral, and in some cases completely replaced by chlorite and biotite. Coarse-grained white mica $(\sim 1000 \mu \mathrm{m})$ exhibits minor $(<<1 \%)$ retrogression to biotite on the grain boundaries. Kyanite grains are fractured. 


\section{0-071a, quartzofeldspathic gneiss, carapace zone, $3.7 \pm 3.8 \mathrm{Ma}$}

Assemblage: quartz, white mica, biotite, K-feldspar, garnet, and hornblende with minor oxides.

White mica is coarse-grained $(800-1200 \mu \mathrm{m})$ with retrogression to biotite and chlorite at the grain boundaries $(<2 \%)$. Coarse-grained white mica grains form large aggregates $(>2000 \mu \mathrm{m})$. Quartz grains $(400-600 \mu \mathrm{m})$ occur in aggregates and have polygonal grain boundaries with sweeping deformational bands. Plagioclase $(<10 \%$ volume) exhibits lamellar twinning. Biotite grains ( $400-500 \mu \mathrm{m} ; \sim 5-7 \%$ volume) show retrogression to chlorite at grain boundaries $(<2 \%)$. Garnets $(1000-2000 \mu \mathrm{m})$ are fractured with quartz and rutile inclusions.

\section{D.2 Morima dome, Fergusson Island}

\section{3-086b, leucocratic orthogneiss, carapace zone, $0.30 \pm 0.39$ Ma}

Assemblage: quartz, plagioclase, K-feldspar, and white mica with minor epidote.

Quartz is coarse-grained $(600-1000 \mathrm{~m})$ with round to dentate margins and undulose extinction. Plagioclase porphyroclasts $(400-700 \mu \mathrm{m})$ show lamellar twinned and contains quartz and epidote inclusions. K-feldspar porphyroclasts are coarse-grained $(2000-4000 \mu \mathrm{m})$, and contains quartz, white mica, and epidote inclusions. White mica occurs as coarse-grained mica fish $(\sim 1000 \mu \mathrm{m})$ and finer-grained matrix grains $(400-600 \mu \mathrm{m})$, and is retrogressed to biotite near grain boundaries $(<5 \%)$ and between mica sheets $(<1 \%)$. White mica occurs as large $(>4000 \mu \mathrm{m})$ aggregates. Fine-grained white mica occurs on the margins of plagioclase and $\mathrm{K}$-feldspar and is in some cases completely retrogressed to biotite. Epidote occurs as two habits: (1) a coarse-grained $(500-600 \mu \mathrm{m})$ and fractured matrix phase, and (2) fine-grained inclusions. 


\title{
D.3 Goodenough dome, Goodenough Island
}

\author{
06-018a, quartzofeldspathic gneiss, transition zone between the core and \\ carapace, $2.38 \pm 0.29 \mathrm{Ma}$
}

Assemblage: quartz, plagioclase, K-feldspar, biotite, and white mica with minor garnet, sphene, chlorite, and oxides.

This sample contains mica-rich and quartz-rich domains. Quartz $(300-600 \mu \mathrm{m})$ grain boundaries are interlobate, and the grains exhibit a well-developed subgrain texture. Plagioclase occurs in two habits: (1) a coarse-grained $(1000-1200 \mu \mathrm{m})$ with lamellar twinning and irregular grain boundaries; or (2) a fine-grained matrix grains $(400-600 \mu \mathrm{m})$ that can exhibit lamellar twinning. K-feldspar $(500-800 \mu \mathrm{m})$ exhibits deformational crosshatched twinning. Garnets $(400-600 \mu \mathrm{m})$ are rounded and fractured, with biotite and quartz inclusions. Garnets occur only in the mica-rich domains. White mica is coarse-grained $(600-1200 \mu \mathrm{m})$ and has been affected by retrogression to biotite between mica sheets $(<<1 \%)$. White mica is slightly zoned under transmitted light. Biotite grains $(500-700 \mu \mathrm{m})$ are retrogressed to chlorite at grain boundaries ( $10 \%$ of biotite grains by volume).

\section{8-032a, leucocratic gneiss, carapace zone, $0.22 \pm 0.06 \mathrm{Ma}$}

Assemblage: quartz, plagioclase, K-feldspar, white mica, and biotite with minor apatite, orthopyroxene, clinozoisite, epidote, and garnet.

Quartz is fine-grained $(300-500 \mu \mathrm{m})$ and exhibits a well-developed subgrain texture with deformation bands. Plagioclase is coarse-grained $(800-1000 \mu \mathrm{m})$ and exhibits lamellar twinned and anti-perthite (exsolution texture). Plagioclase grains are intergrown with adjacent quartz grains. K-feldspar ( $<2 \%$ volume) contains quartz inclusions and is perthitic (exsolution texture). White mica is coarse-grained (600$1200 \mu \mathrm{m})$ and retrogressed to biotite at the grain boundaries $(<2 \%)$. Garnets $(300-$ $500 \mu \mathrm{m} ;<4 \%$ volume) are fractured and intergrown with biotite. 


\section{D.4 Northwest Normanby dome, Normanby Island}

$\bullet 08-077 \mathrm{a}$, foliated $20 \mathrm{~cm}$ granitic sheet hosted by quartzofeldspathic gneiss, core zone, $3.90 \pm 0.44$ Ma

Assemblage: quartz, plagioclase, K-feldspar, and white mica with minor biotite and oxides.

Quartz $(200-500 \mu \mathrm{m})$ has polygonal to interlobate grain boundaries, and can form ribbons aggregates. Quartz exhibits inclusions of fine-grained biotite needles. Plagioclase is coarse-grained $(400-600 \mu \mathrm{m})$ with irregular grain boundaries and lamellar twinning. White mica occurs as coarse-grained fish $(700-1300 \mu \mathrm{m})$ with retrogression to biotite between mica sheets $(<3 \%)$. Fine-grained biotite $(100-200$ $\mu \mathrm{m})$ is present at white mica grain boundaries. White mica grains $(500-1300 \mu \mathrm{m})$ occur in large $(>4000 \mu \mathrm{m})$ aggregates.

-10-008a, pelitic gneiss, carapace zone, thermobarometry sample

Assemblage: plagioclase, K-feldspar, garnet, quartz, white mica, and biotite with minor kyanite, rutile, ilmenite, and oxides.

Extremely coarse-grained garnets $(>1 \mathrm{~cm})$ were once euhedral and are now fractured with rutile, ilmenite, quartz, and oxides inclusions. Quartz occurs as fine-grained matrix grains $(75-200 \mu \mathrm{m})$ and coarse-grained $(800-1300 \mu \mathrm{m})$ ribbon aggregates with a well-developed subgrain texture. Quartz grain boundaries are primarily polygonal and interlobate. White mica is coarse-grained $(700-1000 \mu \mathrm{m})$ and wraps the coarse-grained garnets. Mica-rich domains contain biotite, white mica, and oxides. White mica is retrogressed to biotite at the grain boundaries and between mica sheets. Fine-grained biotite $(200-300 \mu \mathrm{m})$ occurs in the mica-rich domains. 


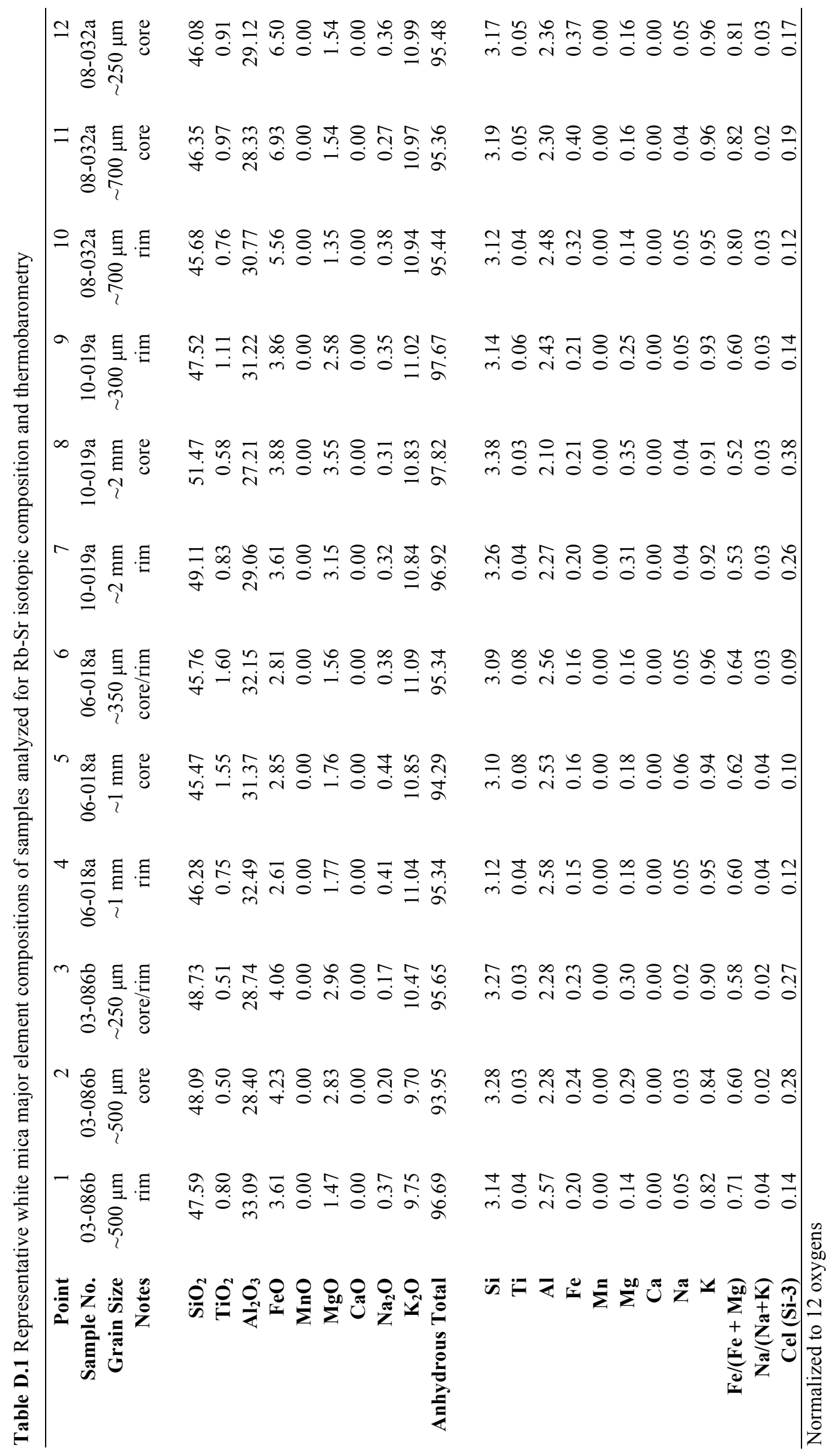




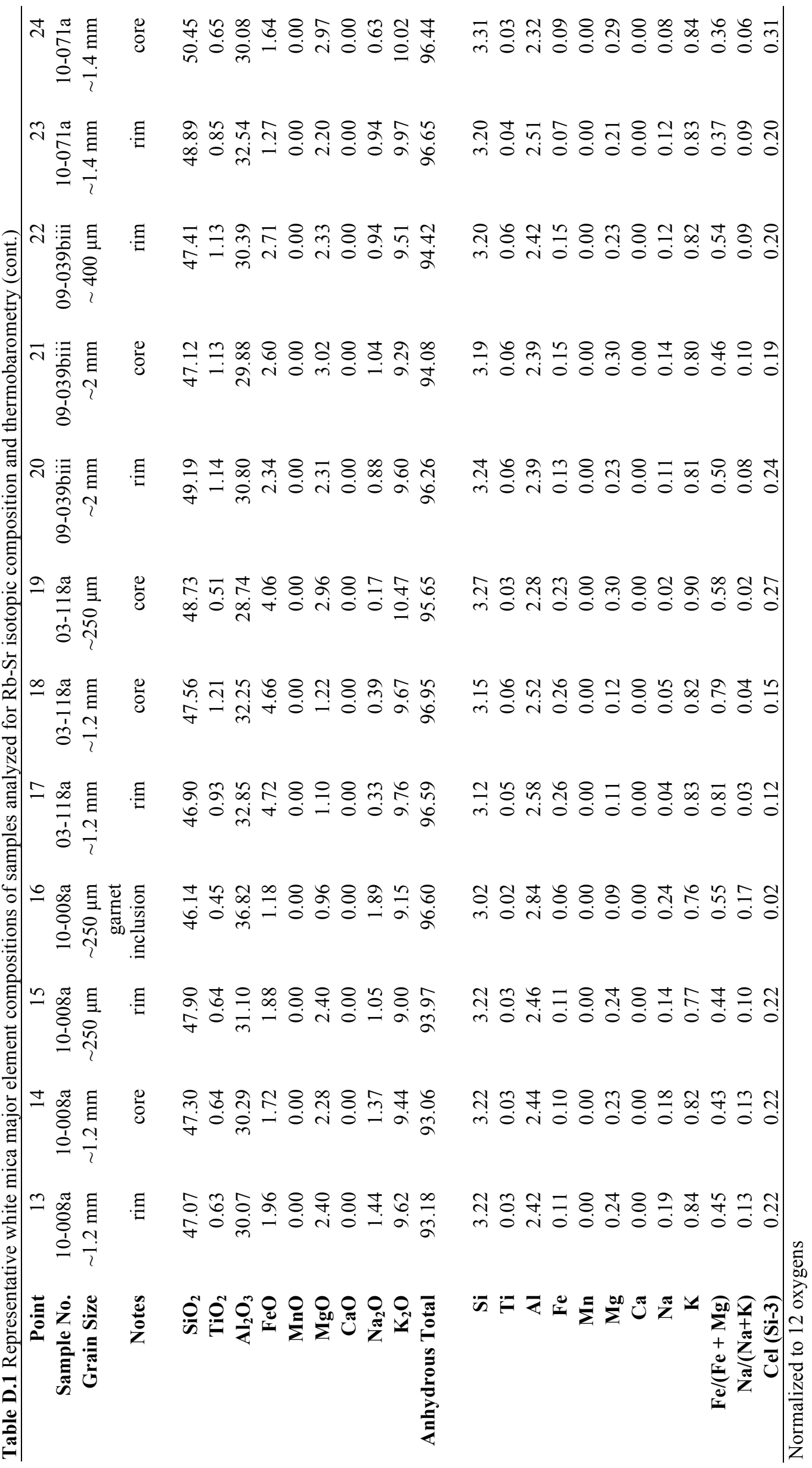




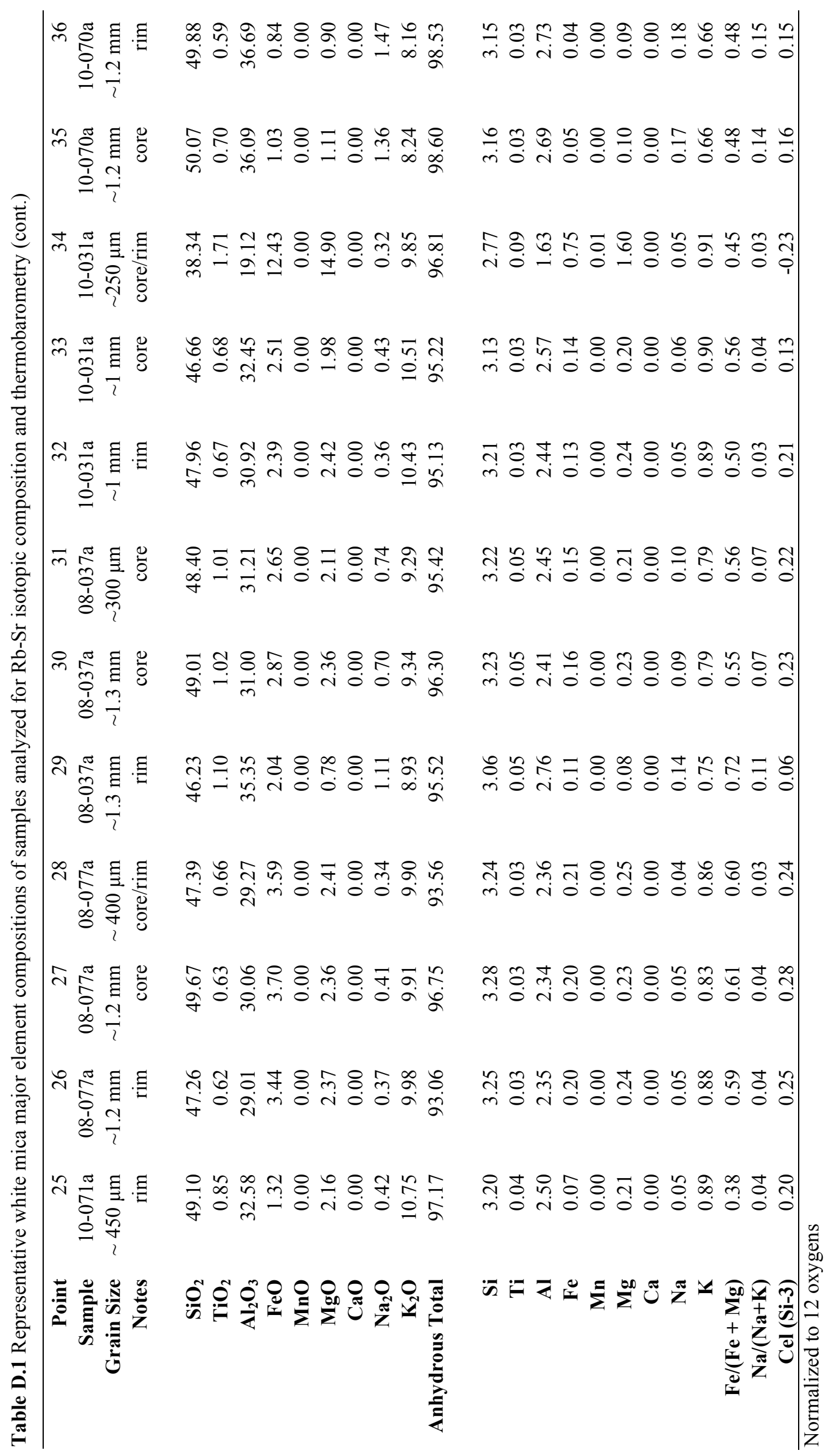




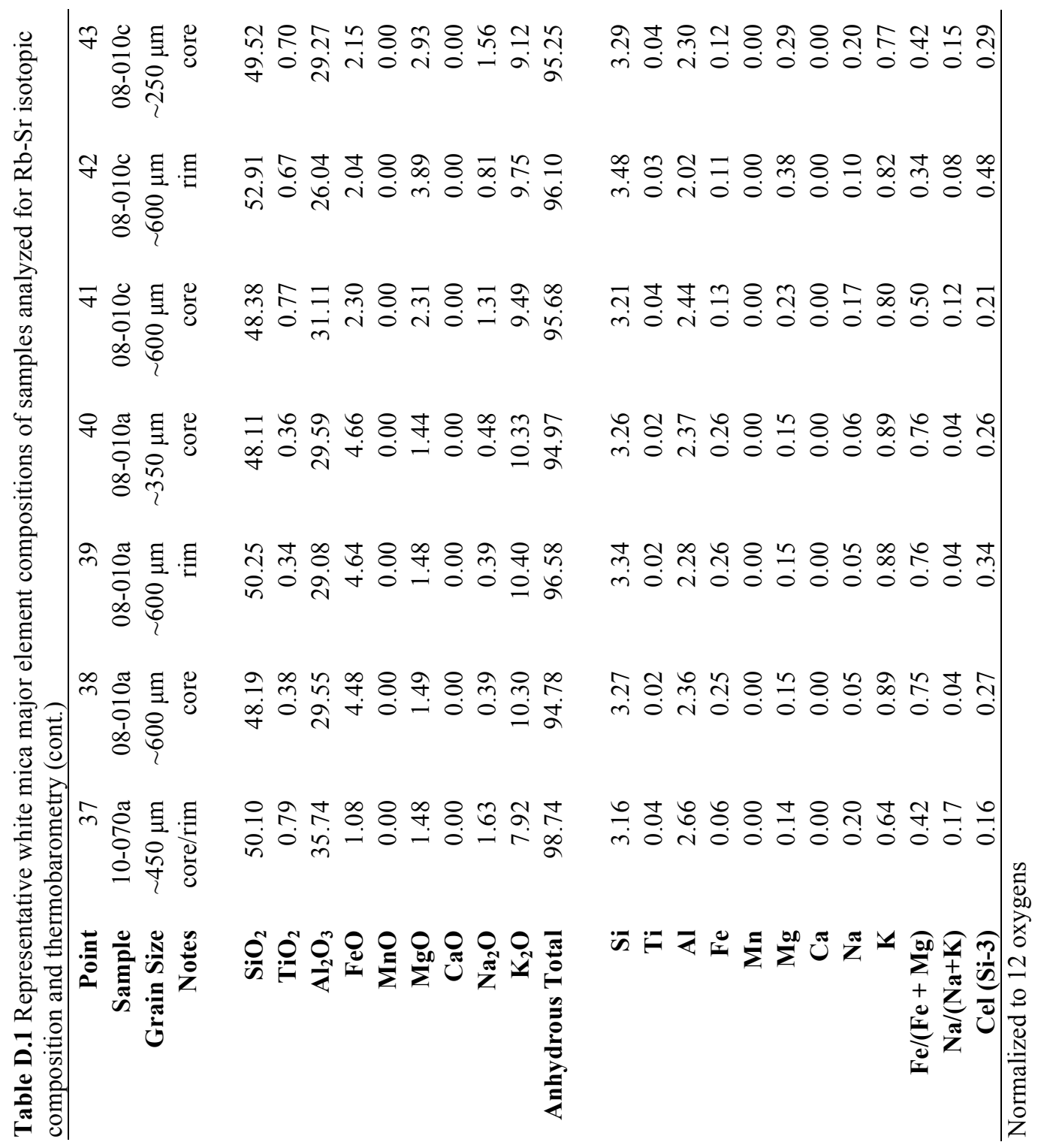




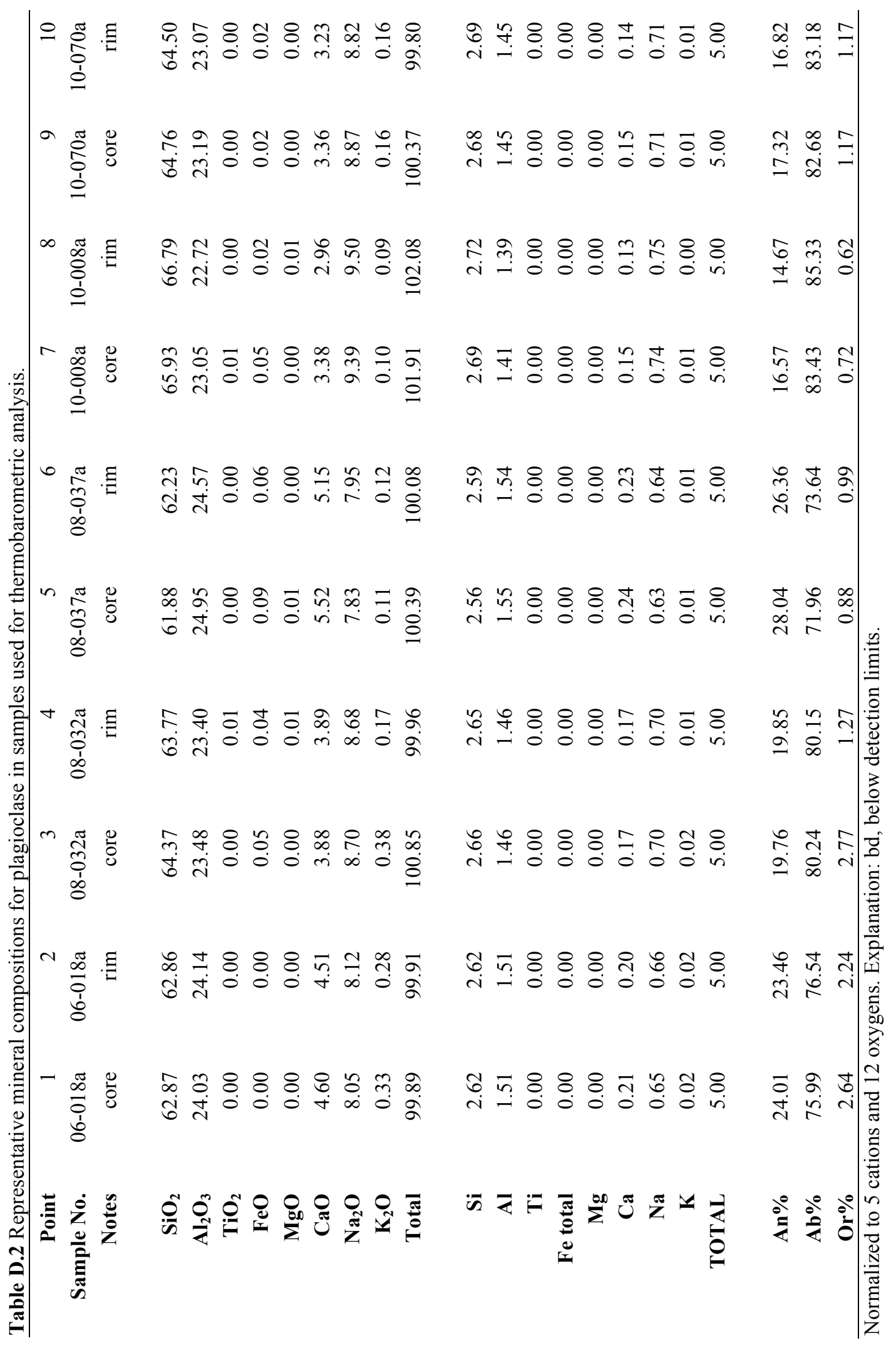




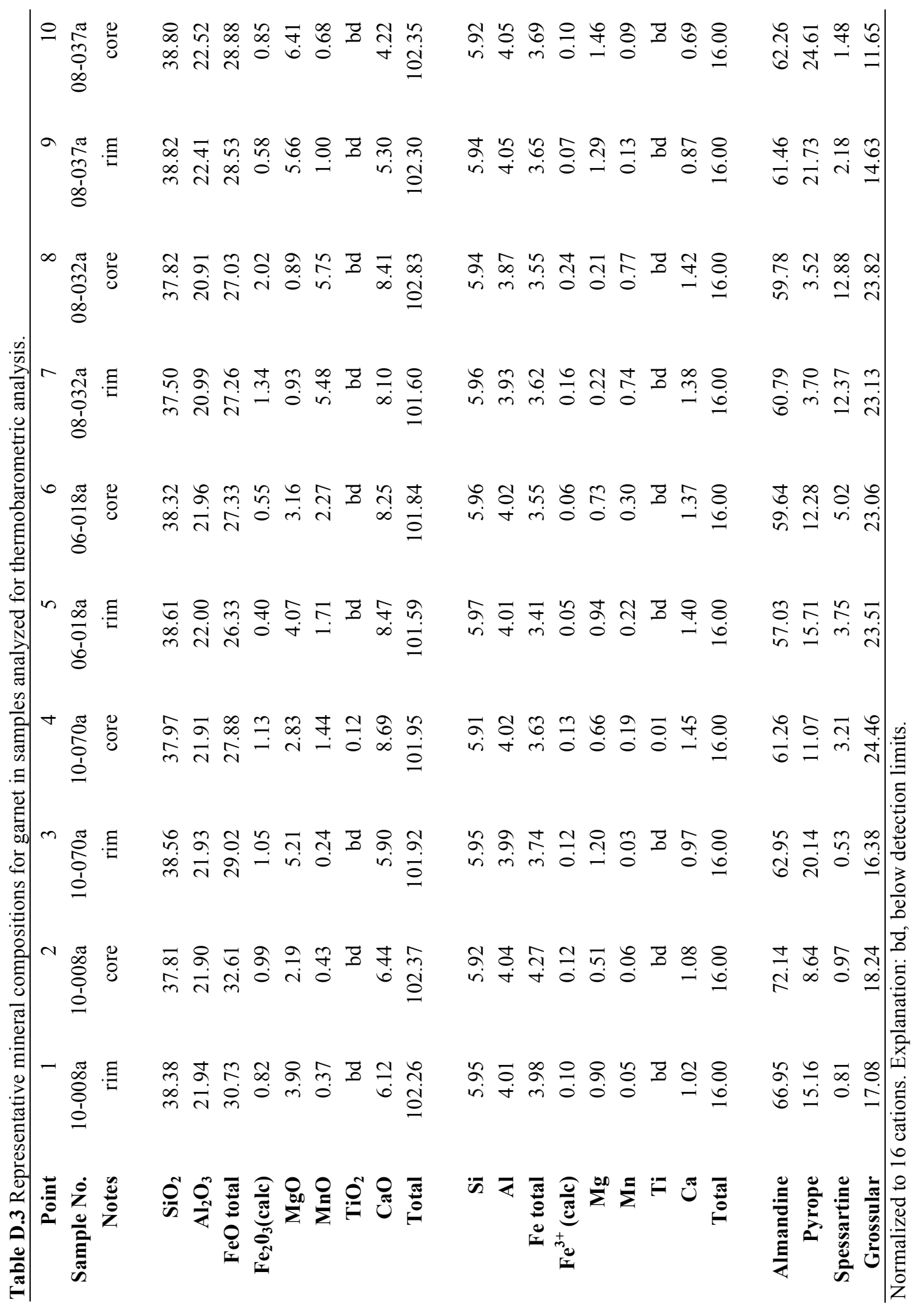




\section{Appendix E $\mathrm{Rb}-\mathrm{Sr}$ dating and thermobarometry methods}

The chemical purification of mineral separates is complex and involves several steps. The method used in this study was adapted from the method of Dr. Johannes Glodny (Glodny et al., 2003; Glodny et al., 2002), with consultation from Dr. Marc AlbanMillet (VUW, pers. comm.), Dr. Julie Vry (VUW, pers. comm.), and Dr. Joel Baker (VUW, pers. comm.).

\section{E.1 Sample selection and preparation}

Rock samples of $<100 \mathrm{~g}$ were used to obtain material for mineral separates. In addition, a small amount of rock sample ( $<30 \mathrm{~g})$ was crushed using a tungsten carbide lined Tema mill in order to obtain a whole rock split. The Tema mill was cleaned with two washes of acetone and processing a load of quartz sand between samples. The $<100 \mathrm{~g}$ rock sample was crushed with a steel percussion mortar, which was cleaned with two washes of acetone between samples. This study used white mica separates that differ in size $(250-355 \mu \mathrm{m}, 355-500 \mu \mathrm{m},>500 \mu \mathrm{m})$, and the crushed material was sieved in order to separate the bulk rock sample into $\geq 500 \mu \mathrm{m}$, $250-500 \mu \mathrm{m}, \leq 250 \mu \mathrm{m}$ size splits. Sieves were cleaned by two acetone washes between samples. This crushed and sieved material was then separated using standard magnetic separation techniques on a Franz isodynamic separator in order to obtain mineral separates that were purified by hand picking on an Olympus SZX7 binocular microscope. The 250-500 $\mu \mathrm{m}$ mica separate was then split into 250-355 $\mu \mathrm{m}$ and 355-500 $\mu \mathrm{m}$ using nylon mesh sieves that were discarded after use.

Mineral separates were cleaned before being weighted into clean beakers (Section E.2). White mica mineral separates were ground by hand in an agate mortar with Argrade methanol and dried, sieved with nylon mesh sieves to remove impurities. Before acid was introduced into the beakers, all mineral separates were washed three times in > 18.2 M $\Omega$ ultra-clean water (Millipore: $\mathrm{MQ} \mathrm{H}_{2} \mathrm{O}$ ). 


\section{E.2 Chemical purification}

All chemical purification of mineral separates was performed in a Picotrace $($ C Class 10 laminar flow hood in an ultra-clean laboratory (positively pressured with air continuously filtered to Class 100). All HF used by this study was Seastar ${ }^{\mathrm{TM}}$ grade ultra-pure (29M; all key metals $<10 \mathrm{ppt}$ ). All acids used in this study (unless otherwise stated) were sub-boil distilled in Teflon $(12 \mathrm{M} \mathrm{HCl})$ and quartz $(16 \mathrm{M}$ $\mathrm{HNO}_{3}$ ) stills. Dilute acids were prepared by dilution of concentrated acids (both subboiled and Seastar(C) with $\mathrm{MQ} \mathrm{H}_{2} \mathrm{O}$. An electronic density meter was used to calibrate dilute acid molarities (assume density of $\mathrm{MQ} \mathrm{H}_{2} \mathrm{O}$ as 0.9998 at $18^{\circ} \mathrm{C}$ ). Eppendorf pipette tips were used during chemical purification and were rinsed three times with $\mathrm{MQ} \mathrm{H}_{2} \mathrm{O}$ before use.

The beakers used were $23 \mathrm{ml}, 7 \mathrm{ml}$, and $3 \mathrm{ml}$ Teflon Savillex $\subseteq$ beakers and were first pre-cleaned by wiping the outside with Ar-grade methanol and then rinsing both the beaker and the lid in tap water. The beakers were then rinsed with $\mathrm{MQ} \mathrm{H}_{2} \mathrm{O}$ and each beaker and lid was individually dipped into a glass beaker of $6-8 \mathrm{M} \mathrm{HCl}$ and left for $>24$ hours at $90^{\circ} \mathrm{C}$. The beakers and lids were then rinsed three times in MQ $\mathrm{H}_{2} \mathrm{O}$ and each beaker and lid was individually dipped into a glass beaker full of $6-8$ $\mathrm{M} \mathrm{HNO}_{3}$ and left for $>24$ hours at $90^{\circ} \mathrm{C}$. The beakers were rinsed out 3 times in MQ $\mathrm{H}_{2} \mathrm{O}$ and filled with enough $7 \mathrm{M} \mathrm{HNO}_{3}$ to cover the bottom of the beaker. The filled beakers were left at $120^{\circ} \mathrm{C}$ for $\geq 24$ hours to reflux. The beakers were then rinsed out three times with $\mathrm{MQ} \mathrm{H}_{2} \mathrm{O}$, and left open to dry on a hot plate $\left(120^{\circ} \mathrm{C}\right)$.

Mineral separates are measured into cleaned beakers using a high precision balance ( $\pm 0.00001 \mathrm{~g}$ ), which was tarred to the weight of the beaker before introduction of the mineral separate. As a rule of thumb, $40 \mathrm{mg}$ of mica separates and $\sim 100 \mathrm{mg}$ of all other mineral separates and standards was used. All sample material were then refluxed with $\sim 1 \mathrm{ml}$ concentrated $\mathrm{HF}$ and $\sim 0.25 \mathrm{ml}$ concentrated $\mathrm{HNO}_{3}$ in sealed beakers at $120^{\circ} \mathrm{C}$ for $\sim 72$ hours. In the case of mineral separates of garnet and omphacite with garnet inclusions, concentrated $\mathrm{HF}$ and $\mathrm{HNO}_{3}$ was evaporated and 3 
$\mathrm{ml}$ concentrated HCL was added to beakers. These were sealed and refluxed at $120^{\circ} \mathrm{C}$ for $>12$ hours and then evaporated. The garnet and omphacite separates were then once more refluxed in $1 \mathrm{ml}$ concentrated $\mathrm{HF}$ and $0.25 \mathrm{ml}$ concentrated $\mathrm{HNO}_{3}$ in sealed beakers at $120^{\circ} \mathrm{C}$ for $\sim 72$ hours.

The resultant solution was evaporated to incipient dryness to avoid sample loss, followed by two more evaporations with concentrated $\mathrm{HNO}_{3}$ and one of $2 \mathrm{ml} 3 \mathrm{M}$ $\mathrm{HNO}_{3}$. Once the samples were dry $2 \mathrm{ml}$ of $3 \mathrm{M} \mathrm{HNO}_{3}$ was added to the beakers and they were refluxed at $120^{\circ} \mathrm{C}$ for 24 hours. It is essential that the samples were completely dissolved, as an incomplete dissolution would result in fractionation of $\mathrm{Rb}$ and $\mathrm{Sr}$ between the solutions and the solid residues. The solution was therefore visually checked for any remnant solute and if needed additional $3 \mathrm{M} \mathrm{HNO}_{3}$ is added in $2 \mathrm{ml}$ steps. Once the solution was free of solids to the naked eye, it was spun on a Heraeus@ Millifuge 1s at 5000 revolutions per minute for five minutes and once more carefully examined for any remaining solute. In some cases, the samples were not solute-free even when $>20 \mathrm{ml}$ of $3 \mathrm{M} \mathrm{HNO}_{3}$ was introduced; these samples were evaporated and re-dissolved with concentrated $\mathrm{HF}$ and $\mathrm{HNO}_{3}$. If a sample contained oxides that could not be dissolved, it was re-centrifuged at 5000 revolutions per minute for five minutes and care was taken in extracting the solution for the ${ }^{87} \mathrm{Rb} /{ }^{86} \mathrm{Sr}$ and ${ }^{88} \mathrm{Sr} /{ }^{86} \mathrm{Sr}$ aliquots in order to avoid the oxides.

The completely dissolved mineral separate was split into an ${ }^{87} \mathrm{Rb} /{ }^{86} \mathrm{Sr}$ aliquot, which was set aside for analysis, and an aliquot used to obtain a purified $\mathrm{Sr}$ cut through column chemistry. In the case of samples which required $>10 \mathrm{ml}$ of $3 \mathrm{M} \mathrm{HNO}_{3}$ to completely dissolve, three steps were taken to split the sample: (1) $25 \%$ of the completely dissolved sample was extracted for the ${ }^{87} \mathrm{Rb} /{ }^{86} \mathrm{Sr}$ aliquot, (2) the remainder of the sample was evaporated down and brought back into solution in $3 \mathrm{ml}$ of $3 \mathrm{M} \mathrm{HNO}_{3}$, (3) $2 \mathrm{ml}$ of the partially dissolved sample was extracted with a pipette, and was used for column chemistry. Before analysis, the ${ }^{87} \mathrm{Rb} /{ }^{86} \mathrm{Sr}$ aliquot was evaporated in a $3 \mathrm{ml}$ Teflon beaker at $120^{\circ} \mathrm{C}$. The evaporate was then brought into solution with $1 \mathrm{ml} 1 \mathrm{M} \mathrm{HNO}_{3}\left(\right.$ Seastar $\left.^{\mathrm{TM}}\right)$ for analysis on the inductively coupled plasma mass spectrometer (ICP-MS). 
The remaining $75 \%$ of the completely dissolved mineral separate was used to separate $\mathrm{Sr}$ with a double pass through Eichrom $^{\mathrm{TM}} \mathrm{Sr}$-specific resin. Sample solutions were left at $120^{\circ} \mathrm{C}$ for $\sim 1$ hour. Columns were constructed from Eppendorf $1 \mathrm{ml}$ pipette tip columns with polypropylene frits fitted at the bottom of the pipettes. The columns were pre-cleaned by soaking in $1 \mathrm{M} \mathrm{HCl}$, and were then individually rinsed six times with $\mathrm{MQ} \mathrm{H}_{2} \mathrm{O}$. The columns were loaded with Eichrom $\subset$ strontium resin $(50-100 \mu \mathrm{m})$ to create $\mathrm{a}>5 \mathrm{~mm}$ bed of resin. The resin was cleaned with 1.5 $\mathrm{ml} \mathrm{MQ} \mathrm{H}_{2} \mathrm{O}$ followed by $1.5 \mathrm{ml} 3 \mathrm{M} \mathrm{HNO}_{3}$ three times, followed by equilibration with $3 \mathrm{ml} 3 \mathrm{M} \mathrm{HNO}_{3}$. The sample was loaded with a disposable $10 \mathrm{ml}$ pipette and matrix elements were eluted with $4.5 \mathrm{ml} 3 \mathrm{M} \mathrm{HNO}_{3}$. The beakers (which were free of solution at this point) were cleaned by: (1) rinsing three times with $\mathrm{MQ} \mathrm{H}_{2} \mathrm{O},(2)$ adding $\sim 1 \mathrm{ml} 6 \mathrm{M} \mathrm{HCl}$ and refluxing the beaker for 20 minutes at $120^{\circ} \mathrm{C}$, and (3) rinsing out three times with MQ $\mathrm{H}_{2} \mathrm{O}$. The cleaned beakers were used to collect the Sr cut in $4.5 \mathrm{ml} \mathrm{MQ} \mathrm{H}_{2} \mathrm{O}$. The $\mathrm{Sr}$ cut was evaporated at $120^{\circ} \mathrm{C}$, and three drops of concentrated $\mathrm{HNO}_{3}$ was evaporated at $120^{\circ} \mathrm{C}$. The $\mathrm{Sr}$ cut was evaporated once more in $1.5 \mathrm{ml} 3 \mathrm{M} \mathrm{HNO}_{3}$ at $120^{\circ} \mathrm{C}$, was then brought into solution with $1.5 \mathrm{ml} 3 \mathrm{M} \mathrm{HNO}_{3}$ at $120^{\circ} \mathrm{C}$ for $>12$ hours for a second column pass with new pipette tip columns. The double-pass technique reduces the amount of matrix elements in the solution, thus minimizing any analytical artifacts. After the second column pass, the Sr cuts were evaporated with three drops of concentrated $\mathrm{HNO}_{3}$ at $120^{\circ} \mathrm{C}$, and brought into solution with $2 \mathrm{ml} 0.5 \% \mathrm{HNO}_{3}\left(\right.$ Seastar $\left.^{\mathrm{TM}}\right)$ at $120{ }^{\circ} \mathrm{C}$ for $\geq 24$ hours.

\section{E.3 Solution ICP-MS analysis}

An Agilent $\subset 7500$ CS inductively coupled plasma mass spectrometer (ICP-MS) at Victoria University of Wellington, New Zealand was used to analyze the ${ }^{87} \mathrm{Rb} /{ }^{86} \mathrm{Sr}$ solution. The ${ }^{87} \mathrm{Rb} /{ }^{86} \mathrm{Sr}$ solution was diluted with $50 \mu$ of sample into $5 \mathrm{ml} 1 \% \mathrm{HNO}_{3}$ $\left(\right.$ Seastar $\left.^{\mathrm{TM}}\right)$. Analytical conditions for the ICP-MS are given in Table E.1. 
Table E.1 ICP-MS analytical and instrumental conditions

\section{ICP-MS}

System

Acquisition mode

Detection mode

Standards and calibration

Bracketing standards

Secondary standards

\section{Analysis method}

Background acquisition

Standard/sample acquisition

Washout times

Measured isotopes and integrations times

\section{Tuning}

Tuning standards

Monitored isotopes during tuning

Calibration standard

Monitored isotopes during calibration

Background

Oxides

Carrier gas

Make up gas

RF Power

RF matching

Sample depth
Agilent 7500CS

Peak-hopping

Pulse and analogue

$1 \mathrm{ppb} \mathrm{Rb} / \mathrm{Sr}$ standard in $1 \% \mathrm{HNO}_{3}\left(\right.$ Seastar ${ }^{\mathrm{TM}}$ ), $50 \mathrm{ppb} 44 \mathrm{Ca}$ standard in $1 \% \mathrm{HNO}_{3}\left(\right.$ Seastar $\left.{ }^{\mathrm{TM}}\right)$ BHVO-2

30 seconds

120 seconds

Water wash out: 30 seconds; $1 \% \mathrm{HNO}_{3}$ (Seastar ${ }^{\mathrm{TM}}$ ): 90 seconds

${ }^{85} \mathrm{Rb},{ }^{86} \mathrm{Sr},{ }^{87} \mathrm{Sr},{ }^{88} \mathrm{Sr},{ }^{44} \mathrm{Ca} ; 0.01$ seconds

$1 \mathrm{ppb} \mathrm{Rb} / \mathrm{Sr}$ standard in $0.5 \% \mathrm{HNO}_{3}\left(\mathrm{Seastar}^{\mathrm{TM}}\right)$

${ }^{85} \mathrm{Rb},{ }^{86} \mathrm{Sr},{ }^{87} \mathrm{Sr},{ }^{88} \mathrm{Sr},{ }^{44} \mathrm{Ca}(\% \mathrm{RSD}<3 \%)$

$1 \mathrm{ppb} \mathrm{Rb} / \mathrm{Sr}$ standard in $0.5 \% \mathrm{HNO}_{3}$ (Seastar ${ }^{\mathrm{TM}}$ )

${ }^{85} \mathrm{Rb},{ }^{86} \mathrm{Sr},{ }^{87} \mathrm{Sr},{ }^{88} \mathrm{Sr},{ }^{44} \mathrm{Ca}(\% \mathrm{RSD}<3 \%)$

${ }^{85} \mathrm{Rb}<800 \mathrm{CPS},{ }^{86} \mathrm{Sr}<1000 \mathrm{CPS},{ }^{87} \mathrm{Sr}<500 \mathrm{CPS}$,

${ }^{88} \mathrm{Sr}<2000 \mathrm{CPS},{ }^{44} \mathrm{Ca}<200000 \mathrm{CPS} *$

$<1.5 \%$ (checked during tuning)

$1.08-1.12 \mathrm{~L} \mathrm{~min}^{-1}$

$0 \mathrm{~L} \mathrm{~min}^{-1}$

$1500 \mathrm{~W}$

$1.68-1.72 \mathrm{~V}$

$7 \mathrm{~mm}$

* "CPS" is the counts per second or signal measure by the ICP-MS

Two washouts were used: (1) $\mathrm{MQ} \mathrm{H}_{2} \mathrm{O}$ for 30 seconds, and (2) $1 \% \mathrm{HNO}_{3}$ (Seastar ${ }^{\mathrm{TM}}$ ) for 90 seconds. Acquisition time for standards/unknowns was 120 seconds. The mean background was subtracted from the counts per second of the ${ }^{85} \mathrm{Rb},{ }^{86} \mathrm{Sr}$, and ${ }^{88} \mathrm{Sr}$ before during raw data processing before calculation of the ratios.

The majority of the ${ }^{87} \mathrm{Rb} /{ }^{86} \mathrm{Sr}$ ratios (see Table 3.10) were calculated using the ${ }^{85} \mathrm{Rb} /{ }^{88} \mathrm{Sr}$ ratios of samples and standards and the relative abundance of ${ }^{87} \mathrm{Rb}$ and ${ }^{86} \mathrm{Sr}$. Interference from ${ }^{44} \mathrm{Ca}$ dimer on ${ }^{88} \mathrm{Sr}$ was monitored using ${ }^{88} \mathrm{Sr} /{ }^{86} \mathrm{Sr}$ ratio during data processing. Measured ${ }^{88} \mathrm{Sr} /{ }^{86} \mathrm{Sr}$ ratios of samples and standards are tightly clustered at $\sim 8.8$ across all analytical sessions, regardless of the sample composition (whole rock, pyroxene, white mica). This measured ${ }^{88} \mathrm{Sr} /{ }^{86} \mathrm{Sr}$ ratio is very close to the natural value of 8.3752 and this interference was considered 
negligible. The ${ }^{87} \mathrm{Rb} /{ }^{86} \mathrm{Sr}$ ratio and its $1 \%$ error is normally calculated by: (1) calculating the standard-corrected ${ }^{85} \mathrm{Rb} /{ }^{88} \mathrm{Sr}$ ratio as measured by the ICP-MS, (2) correcting this value to the natural value of ${ }^{85} \mathrm{Rb} /{ }^{88} \mathrm{Sr}$, and (3) correcting this ${ }^{85} \mathrm{Rb} /{ }^{88} \mathrm{Sr}$ ratio to the abundance of ${ }^{87} \mathrm{Rb}$ and ${ }^{86} \mathrm{Sr}$. There was, however, inaccuracy in the calculated ${ }^{87} \mathrm{Rb} /{ }^{86} \mathrm{Sr}$ ratios because of uneven pulse/analogue $(\mathrm{P} / \mathrm{A})$ switching of the ${ }^{85} \mathrm{Rb},{ }^{86} \mathrm{Sr}$, and ${ }^{87} \mathrm{Sr}$ isotopes measured during a single analysis. The $\mathrm{P} / \mathrm{A}$ factor is an automatic empirical correction that the Agilent $\mathrm{C} 7500 \mathrm{CS}$ ICP-MS instrument performs to ensure that the switch from pulse mode $\left(<1 \times 10^{6}\right.$ counts per second) to analogue mode $\left(>1 \times 10^{6}\right.$ counts per second $)$ is linear. The P/A factor switch, however, was malfunctioning during some analytical sessions, which lead to inaccurate ratios between isotopes that are not counted on the same mode of the detector. Typically, ${ }^{85} \mathrm{Rb},{ }^{86} \mathrm{Sr}$ and ${ }^{87} \mathrm{Sr}$ would be counted on the Pulse mode, while ${ }^{88} \mathrm{Sr}$ would be counted on the analog mode. This difference in modes lead to measured ${ }^{88} \mathrm{Sr} /{ }^{86} \mathrm{Sr}$ ratios of $91-100$ in some samples and standards affected by the uneven $\mathrm{P} / \mathrm{A}$ switch. Thus, for the mineral splits that were affected by this inaccuracy in the $\mathrm{P} / \mathrm{A}$ factor, ${ }^{87} \mathrm{Rb} /{ }^{86} \mathrm{Sr}$ ratios were estimated by calculated a ratio of total mass 87 signal over the ${ }^{86} \mathrm{Sr}$ measured by the ICP-MS. I then subtracted the accurate multi-collector ICP-MS ${ }^{87} \mathrm{Sr} /{ }^{86} \mathrm{Sr}$ ratios that correspond to each inaccurate mineral split analysis to determine an ${ }^{87} \mathrm{Rb} /{ }^{86} \mathrm{Sr}$ ratio. Accuracy of this correction method was assessed with repeated measurements of the BHVO-2 standard. 